NIST Advanced Manufacturing Series 100-13

\title{
Summary Report on a Workshop on Advanced Monitoring, Diagnostics, and Prognostics for Manufacturing Operations
}

\author{
Brian A. Weiss \\ Donnie Alonzo \\ Steve D. Weinman
}

This publication is available free of charge from:

https://doi.org/10.6028/NIST.AMS.100-13

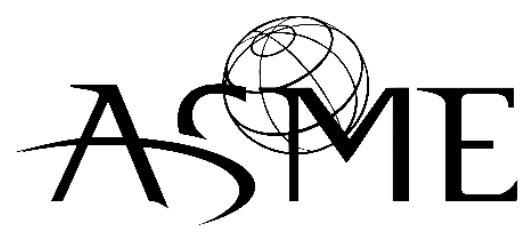

SETTING THE STANDARD

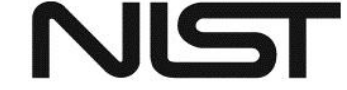

National Institute of Standards and Technology U.S. Department of Commerce 
NIST Advanced Manufacturing Series 100-13

\title{
Summary Report on a Workshop on Advanced Monitoring, Diagnostics, and Prognostics for Manufacturing Operations
}

\author{
Brian A. Weiss \\ Intelligent Systems Division \\ Engineering Laboratory \\ National Institute of Standards and Technology \\ Donnie Alonzo \\ Steve D. Weinman \\ Standardization and Testing \\ American Society of Mechanical Engineers
}

This publication is available free of charge from:

https://doi.org/10.6028/NIST.AMS.100-13

November 2017

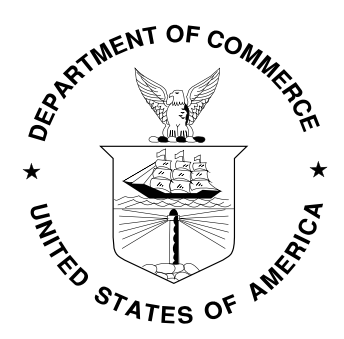

U.S. Department of Commerce

Wilbur L. Ross, Jr., Secretary

National Institute of Standards and Technology

Walter Copan, NIST Director and Under Secretary of Commerce for Standards and Technology 


\title{
Disclaimer
}

This report was prepared as an account of work co-sponsored by National Institute of Standards and Technology (NIST). The views and opinions expressed herein do not necessarily state or reflect those of NIST. Certain commercial entities, equipment, or materials may be identified in this document to illustrate a point or concept adequately. Such identification is not intended to imply recommendation or endorsement by the NIST, nor is it intended to imply that the entities, materials, or equipment are necessarily the best available for the purpose.

\begin{abstract}
The American Society of Mechanical Engineers (ASME), in collaboration with the National Institute of Standards and Technology, hosted a "Workshop on Advanced Monitoring, Diagnostic, and Prognostic Technologies", after the ASME Manufacturing Science and Engineering Conference (MSEC), on June $8^{\text {th }}$ and $9^{\text {th }}, 2017$, on the campus of University of Southern California in Los Angeles, California. The purpose of the workshop was to bring together key subject matter experts to identify manufacturing needs and wants with respect to advanced monitoring, diagnostic, and prognostic technologies (collectively known as Prognostics and Health Management (PHM)), along with ways of verifying and validating their performance to enhance maintenance and control strategies within manufacturing operations at the factory-floor. This report documents this two-day event which summarizes presentations and brainstorming sessions in addition to detailing the key topic area discussions. The findings in this document are expected to provide a foundation for which a future ASME standards effort will be built. Likewise, the next steps in this effort are detailed towards the end of this document including two follow-up events that will further articulate key topic areas of focus.
\end{abstract}

\section{Key words}

ASME; Diagnostics; Manufacturing; Monitoring; Prognostics; Standardization; Workshop. 


\section{Table of Contents}

1. Problem Statement .............................................................................................................. 2

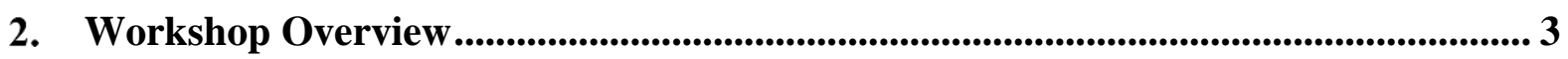

2.1. Workshop Day One Objectives: ......................................................................... 3

2.2. Workshop Day Two Objectives: ....................................................................... 3

3. Summary of Presentations..................................................................................... 4

3.1. Mr. Steve Weinman (ASME), Director of Standardization and Testing .................... 4

3.2. Dr. Brian Weiss (National Institute of Standards and Technology (NIST), Project Leader - Prognostics, Health Management, and Control...................................................... 4

3.3. Dr. Michael Brundage (NIST) - Industrial Engineer ................................................ 5

3.4. Mr. Donnie Alonzo (ASME), Staff Engineer.......................................................... 6

3.5. Mr. Bryan Fischer (Sigmetric), Vice President - Dimensional Engineering .............. 7

3.6. Dr. Xiaoning Jin (Northeastern University) - Assistant Professor ............................. 7

3.7. Mr. Gregg Profozich (California Manufacturing Technology Consulting (CMTC)), Director - Advanced Manufacturing Technologies; Dr. Michael Klopfer (UC Irvine), Technical Director - California Plug Load Research Center................................................ 8

3.8. Dr. Radu Pavel (TechSolve), Vice President - Engineering \& Chief Technology

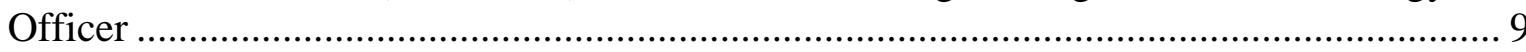

4. $1^{\text {st }}$ Brainstorming Session........................................................................................ 11

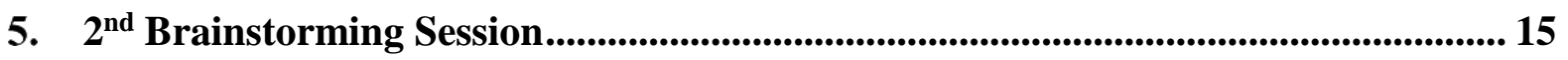

6. Day 2: Results of Priority Topic Discussions .................................................................. 16

6.1. Topic \#1 - Standardized Terminology for PHM....................................................... 16

6.2. Topic \#2 - Guideline to Determine What Health Data to Capture/What Collection

Strategies to Employ ..................................................................................................... 18

6.3. Topic \#3 - Guideline to Determine What Sensors and Where they should be Deployed to Inform on Process/Equipment Health.............................................................. 19

6.4. Topic \#4 - Expand MTConnect/Data Communications ............................................. 21

6.5. Topic \#5 - Guidance for Implementation of Sensor Data Fusion Analysis/Multi-

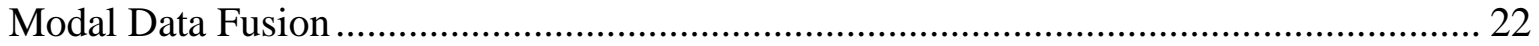

6.6. Topic \#6 - Determination of Where [Health] Analyses Should be Performed......... 22

6.7. Topic \#7 - Determination of Appropriate Visualization/Communication to Enable Human Consumption for Decision Making ………………………………………..... 23

7. Anticipated Next Steps ................................................................................................................ 23

References......................................................................................................................................... 24

Appendix A - Agenda ............................................................................................................ 26

Appendix B - Speaker Bios ................................................................................................................. 28 


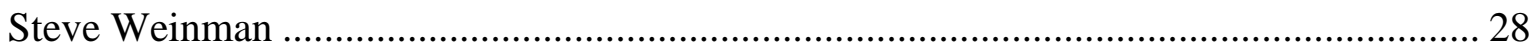

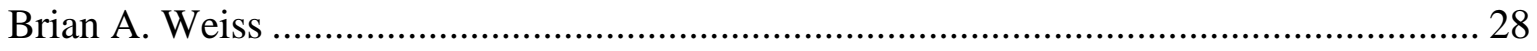

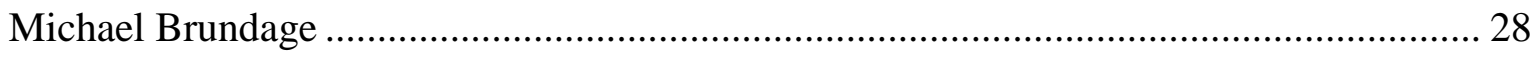

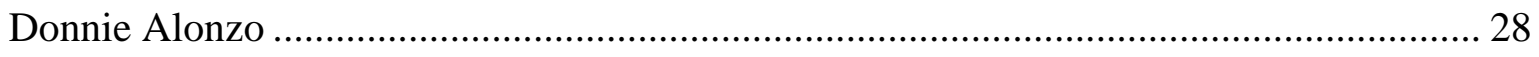

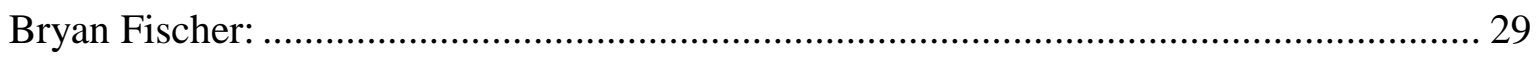

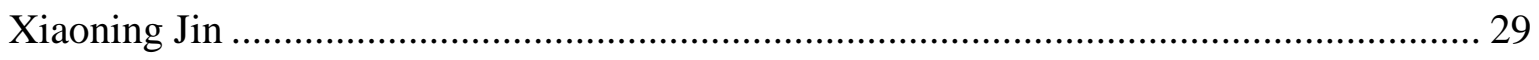

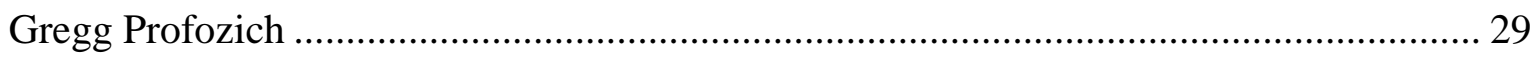

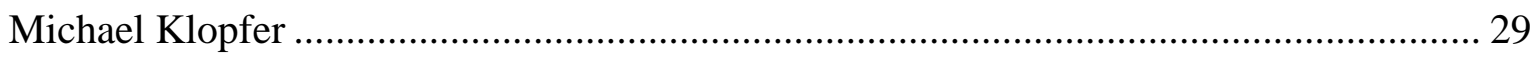

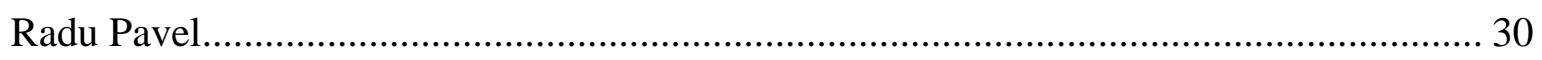

Appendix C - Speaker Presentations ........................................................................ 31

\section{List of Figures}

Fig 1. Dr. Weiss Introducing the Technical Motivation (Photo Credit: Helen Qiao).............. 5

Fig 2. Day 1 Brainstorming Matrix........................................................................... 12

Fig 3. Matrix with Audience Brainstorming Topics (Photo Credit: Helen Qiao) .................. 13 


\section{Acronyms}

AM Additive Manufacturing

ANSI American National Standards Institute

ASME American Society of Mechanical Engineers

CMTC California Manufacturing Technology Consulting

GD\&T Geometric Dimensioning and Tolerancing

HVAC Heating, Ventilation, and Air Conditioning

OEM Original Equipment Manufacturer

NIST National Institute of Standards and Technology

NLP Natural Language Processing

PHM Prognostics and Health Management

S\&C Standards and Certification

SMM Small and Medium-sized Manufacturer 


\section{Problem Statement}

Most manufacturers currently lack the knowledge to effectively design and implement advanced monitoring, diagnostic, and prognostic (collectively known as Prognostics and Health Management (PHM)) technologies across a wide array of factory floor-level processes and systems to optimize their operations and maintenance strategies. This challenge is compounded by the increasing reconfigurability that manufacturers embrace as

- new equipment and processes are integrated (e.g., replacing a subtractive machining process with an additive process),

- existing technology is replaced with newer iterations of increasing performance (e.g., replacing a 20 year-old robot with a brand new one), and

- greater awareness is achieved of operations health and performance (e.g., sensors are becoming more accessible to manufacturers allowing greater knowledge of a process; human-machine interfaces are becoming richer providing more information to the user).

Effectively using PHM can reduce overall downtime, both planned and unplanned, leading to greater asset availability. Likewise, PHM can help maintain process quality and productivity targets, and minimize waste (e.g., excess raw material) all towards reducing cost and increasing profit and efficiency. Presently, manufacturers rely on a combination of maintenance strategies $[1,2]$. The reactive maintenance strategy is when a repair is performed only after a fault or failure has occurred. Reactive maintenance can sometimes be expensive and time-consuming. The preventative maintenance strategy promotes prescribed maintenance routines at certain unit intervals (e.g., xx hours, yy cycles). Over the life of a machine or process, this strategy can be more cost effective than reactive maintenance and typically promotes a safer operating environment.

The predictive maintenance strategy is the most advanced of those mentioned so far and can be considered a 'right-on-time' maintenance strategy. Predictive maintenance occurs when certain monitored metric thresholds are reached, regardless of the number of hours a piece of equipment or process has been in operation or cycles it has run. Since predictive maintenance requires some form of monitoring, either 1) downtime [for maintenance] can be planned to minimally disrupt production without changing process control, 2) process control can be altered to slow the process or equipment degradation to plan maintenance during a minimally disruptive time, or 3 ) maintenance can be more immediately performed to avoid failures and longer periods of downtime.

It is desirable for manufacturers to minimize reactive maintenance and optimize the balance between preventative and predictive maintenance. PHM seeks to advance maintenance such that manufacturers can monitor those metrics they deem critical to operations and process/equipment health, and effectively determine what maintenance will need to be performed, and when, to minimize asset downtime.

To that effect, the development of standards and guidelines that describe and promote advanced monitoring, diagnostic, and prognostic technologies, along with ways of 
verifying and validating their performance, to enhance maintenance and control strategies within manufacturing operations at the factory floor, would highly benefit the manufacturing industry.

\section{Workshop Overview}

The workshop occurred over two days on June 8-9, 2017 at the University of Southern California. A detailed agenda for the two days can be found in Appendix A of this report.

The goal of this workshop was to identify where The American Society of Mechanical Engineers (ASME) might develop guidelines and standards that would make it more efficient, cost-effective, and profitable for every manufacturer, including small and medium-sized manufacturers (SMMs), to monitor the health of their overall factory, and not just individual machines - and predict when, where, and how maintenance will be needed.

This workshop was an open event that did not restrict attendance (approximately 30 people attended the event). The targeted audience included members of the manufacturing and monitoring, diagnostic, and prognostic communities, including technology developers, technology integrators, end-users (including both large manufacturers and SMMs), researchers (from academia and other organizations), and government entities.

There were specific objectives each day of the workshop.

\subsection{Workshop Day One Objectives:}

- Identification of priority topic areas for manufacturing monitoring, diagnostics, and prognostics

- Discussion of which topics present the greatest and/or most frequent challenges making them ripe for standardization

The first day featured a combination of presentations, a panel discussion, and several brainstorming sessions to achieve the stated Day One objectives. To lay the foundation for the brainstorming on Day 1, presentations were selected to give a general overview of the ASME standardization process and information on current PHM use in the industry, as well as other advancements made in this area.

\subsection{Workshop Day Two Objectives:}

- Discussion of priority topic areas in greater detail to lay the foundation for:

- Action plan

- Committee Membership and Charter

- Future Events

- Initiation of a new codes and standards committee

The second day was highlighted by extensive discussion surrounding seven priority topic areas that were identified through the first day's brainstorming sessions. The workshop participants discussed a wide range of elements for each of the priority topic areas. These elements are documented in the Day 2 Priority Topic Discussions Section. 


\section{Summary of Presentations}

\subsection{Mr. Steve Weinman (ASME), Director of Standardization and Testing}

"ASME - Setting the Standard for Safety and Global Relevance"

Mr. Weinman briefly presented ASME's history and the importance of standards.

The ASME Standards and Certification (S\&C) Mission Statement is to develop the best, most applicable codes, standards, conformity assessment programs, and related products and services. Engineering standards were and are developed to improve public safety, allow for uniform consistency of products, and help ensure fair and free commerce and trade. Standards have a wide impact on both the engineering community that uses them and the public, at large.

Mr. Weinman highlighted several key factors to successfully developing and disseminating standards:

- Volunteer participation is the key to committee operation and performance

- ASME Codes \& Standards rely on industry, academia, and government agency participation by knowledgeable experts

- ASME technical staff support is critical,

- Standards development has historically been a very reactive process - waiting until the technology is well-developed before considering standardization or waiting until an industry comes to ASME with a need; more recently, S\&C involvement in new technology areas is much earlier; This requires more interaction with technical divisions within ASME and with the industry to develop guidance early on even as the technology is developing

Mr. Weinman noted that ASME leadership felt the organization [ASME] needs to focus on innovative technologies and to do this they needed to improve their enterprise strategy. To accomplish this, ASME went through several processes to select technology areas in which to focus. These processes included conducting market research, sending out membership questionnaires, and convening panel discussions. These activities yielded five technical areas of focus, which were subsequently selected and approved by the Board of Governors. One area is Advanced Manufacturing, while the other four are Pressure Technology, Robotics, Clean Energy, and Bioengineering. Advanced Monitoring, Diagnostics, and Prognostics for Manufacturing Operations falls under the Advanced Manufacturing technology focus area.

\subsection{Dr. Brian Weiss (National Institute of Standards and Technology (NIST), Project Leader - Prognostics, Health Management, and Control}

"Enhancing Factory-Floor Level Decision-making through Advanced Monitoring, Diagnostics, and Prognostics" 
Dr. Weiss presented the technical motivation for investigating standards and guidelines for monitoring, diagnostics, and prognostics (Fig. 1). He identified the current challenges that the manufacturing community is facing within this specific technical focus:

- Complex interactions and relationships make it challenging to determine the specific influences on the health and degradation of equipment and processes

- Increasing interest and ability to leverage data and analysis to generate actionable intelligence about system interactions and relationships for control

- No uniform process exists that guides sensing, monitoring, and control at all levels from the component to the system to the enterprise

- Opportunities are becoming more apparent at the systems level, especially given the more distributed nature of manufacturing (whether that's at the supply chain level or within a facility)

- Proprietary solutions exist, but they apply to systems from one vendor and are often expensive and inaccessible to many

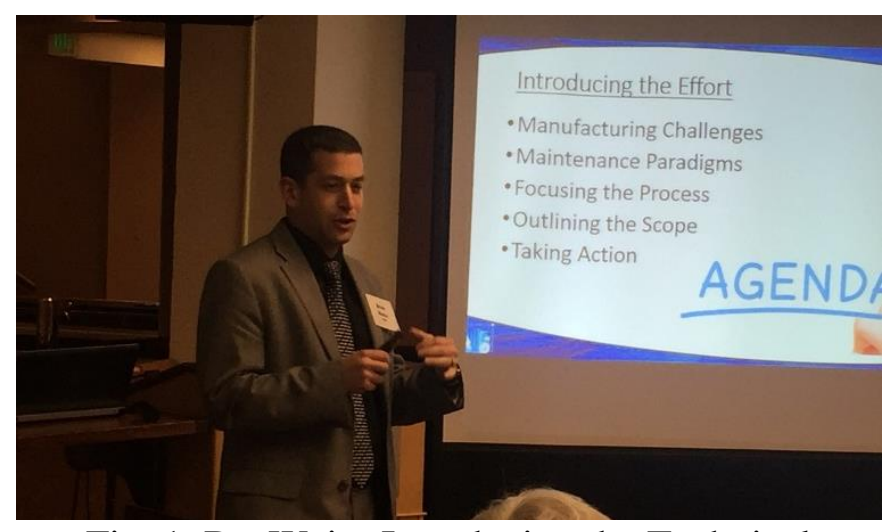

Fig. 1. Dr. Weiss Introducing the Technical Motivation (Photo Credit: Helen Qiao) manufacturers

Dr. Weiss noted the current maintenance paradigms - reactive, preventive, and predictive - and then discussed NIST's research focus in this area.

\subsection{Dr. Michael Brundage (NIST) - Industrial Engineer}

"Framework for an intelligent knowledge-based manufacturing diagnosis system"

Dr. Brundage presented a case study highlighting NIST's research efforts of a Natural Language Processing (NLP) analysis framework. The research goals of this effort are to:

- Create a manufacturing knowledge base for diagnostics

- Learn from previous maintenance issues to make better decisions to improve efficiency

- Formalize root cause analysis procedures for maintenance issues

Dr. Brundage indicated he is actively working with an SMM that provided NIST with two years-worth of manufacturing fault/failure data. While conducting this research, Dr. Brundage identified numerous barriers that he is attempting to overcome, for the benefit of the manufacturing community. These barriers include:

- Lack of standard representation of artifacts for root cause analysis 
- Lack of standardized fault and failure terminology

- Difficulty in sharing information across industries, factories, lines, and employees

- Ad-hoc nature of root cause analysis

Dr. Brundage drew parallels to diagnostic work that is done within the medical community. Symcat (http://www.symcat.com/) is a software tool in the medical field that presents a diagnostic catalog and serves as a symptom checker.

Dr. Brundage's next steps in his research include developing a:

- Standardized data structure for maintenance work orders

- Validating the data cleaning process

- Providing a guide for cleaning data

\subsection{Mr. Donnie Alonzo (ASME), Staff Engineer}

"ASME Standards and Certification Overview"

Mr. Alonzo provided an overview of the ASME standards process and the hierarchy of standards development committees. He discussed how ASME creates standards, including ASME's organizational chart, the work of its many standards committees, ASME's standards proposals, the consensus process, ANSI Accreditation, Conformity Assessment

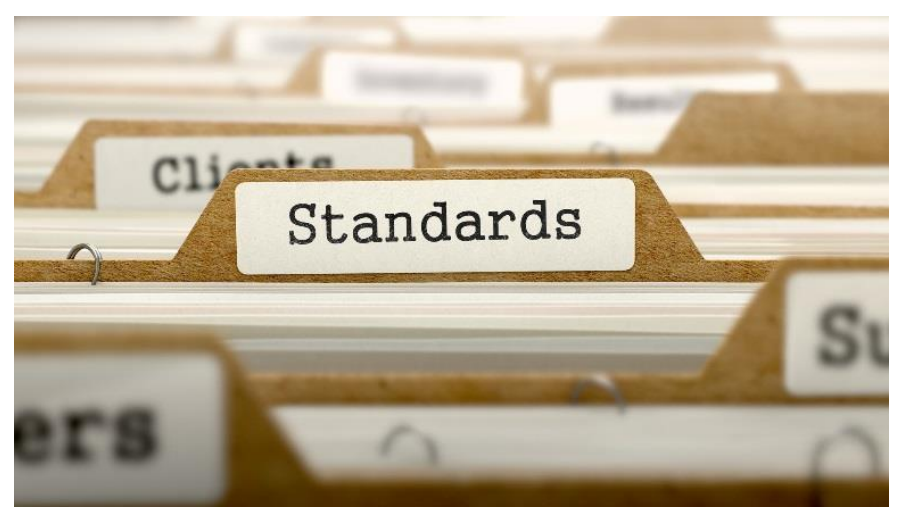

Photo Credit: Fotolia/tashautuvango programs, and how an individual/organization can participate.

The goal of ASME Codes and Standards $(C \& S)$ is to prepare and update consensus standards. There are 600+ standards and 700+ boards, committees, and subgroups. ASME also has 720 student sections. All committees report to ASME Council on Standards and Certifications. Most standards development occurs at lower tier working groups, which develop detailed proposals. Committees have volunteers from all segments of industry (e.g., designers, distributors, producers/ manufacturers, laboratory researchers, academia, consultants, and government). The ASME C\&S Committee meetings are open to the public and anyone can attend; there is no fee for attending. ASME has web-enabled electronic tools (i.e., C\&S Connect) and supports multiple types of membership. ASME standards proposals can be suggested by standards users, individuals or groups, or regulators. Proposals are typically assigned to a working group with a volunteer designated as the project manager of the proposal.

The ASME standards process begins with a submission of a proposal. Following submission, there is consideration/debate by the working group until agreement is reached, 
followed by a technical review and approval by the Consensus Committee whose charter makes it responsible for the document. After Consensus Committee approval, there is a 60day public review period, which is followed by a Supervisory Board procedural approval. Following these steps, the proposal can proceed to the publication process.

The American National Standards Institute (ANSI) essential requirements establish due process for standards development. By following the ASME consensus procedures, which adhere to the essential requirements, ASME retains its accreditation from ANSI. This helps to promote openness and allows for more adaptability.

Other key aspects of ASME standards and the standards process include:

- ASME's standards are reviewed by the respective Consensus Committee at least every five years to ensure continued relevance

- ASME standards are not directly funded by industry or government

- Standards are considered voluntary unless adopted into law by a regulatory authority

- All Consensus Committee members must be voted on by the respective Board

\subsection{Mr. Bryan Fischer (Sigmetric), Vice President - Dimensional Engineering}

"Case Study: Conflict Resolution by Applying GD\&T to Large Weldment"

Mr. Fischer presented a case study that highlights the benefits of the ASME-developed standard, Y14.5 [3]. This standard is actively utilized within manufacturing organizations and is focused on Geometric Dimensioning and Tolerancing (GD\&T). The standard has helped the manufacturing community identify problems and reduce costs.

Applying GD\&T per ASME Y14.5 solves problems for the manufacturer. The benefit of this standard, along with many others, is that it enables manufacturers to solve problems and be creative without having to reinvent the wheel. The GD\&T standard is repeatable and rule-based. Some of the specific benefits seen from application of the GD\&T standard are:

- Eliminated ambiguity

- Eliminated arguments

- Eliminated wasted time

- Saved money

- Allowed schedule to be met

- Techniques used on subsequent designs

\subsection{Dr. Xiaoning Jin (Northeastern University) - Assistant Professor}

"The Present Status, Challenges, and Future Trend of Maintenance in US Manufacturing" 
Dr. Jin presented that there are compelling needs to enable, support, and grow the next generation of manufacturing. She defines "Next Generation Manufacturing" as being 1) self-aware and with a predictive nature of equipment condition, 2) resilient to uncertainties and disruptions, and 3) yielding near-zero defects and downtime factory performance. Supporting next generation manufacturing requires the connection and collection of data. This is a non-trivial challenge given the volume and complexity of data, the lack of perfect and complete data (nearly every data stream is imperfect or is missing some elements), and data is usually gathered from multiple streams and/or sources. Infusing advanced analytics with this wealth of data can lead to greater asset reliability, lower operating costs, increased factory visibility, and worry-free production.

Ultimately the industrial big data analytics capabilities are: connect, monitor, analyze, predict, and optimize. There are both challenges and opportunities to applying/leveraging big data analytics capabilities within next generation manufacturing. They include:

- Rich data/sparse data environment

- Sensor selection and allocation

- Sampling strategy (static, dynamic, event-driven)

- Multi-modal data fusion (image, waveform, discrete)

- Nominal condition (baseline) identification

- Variability and uncertainty quantification and control

- Physics-based or data-driven methods fusion and interface design

- Applications: (1) discrete manufacturing, (2) continuous manufacturing

From a monitoring, diagnostics, and prognostics perspective, effective degradation analysis is critical. Unfortunately, degradation analysis is made difficult by the presence of multiple operating regimes/operating conditions, dynamic environmental conditions, and/or uncertainty in future usage conditions. New methods are needed that can incorporate not only historical (prior) information but also predict what is going to happen in the future.

\subsection{Mr. Gregg Profozich (California Manufacturing Technology Consulting (CMTC)), Director - Advanced Manufacturing Technologies; Dr. Michael Klopfer (UC Irvine), Technical Director - California Plug Load Research Center}

"Energy Monitoring, Diagnostics, Prognostics with the Clean Energy Smart Manufacturing Innovation Institute"

This joint presentation begins with Mr. Profozich defining Smart Manufacturing as the ability to take action, in real time, to optimize assets in the context of business strategies and imperatives. He also notes that Smart Manufacturing is the intersection of business, operations, and technology. Another definition that is referenced for Smart Manufacturing (taken from the Smart Manufacturing Leadership Coalition (SMLC)) is having the right data at the right time with the right people to make the right decision. 
One of CMTC's goals is advancing sensing, controls, platforms and modeling for manufacturing. CMTC is under contract with CESMII - Clean Energy Smart Manufacturing Innovation Institute, a Manufacturing USA public/private partnership, as the California Manufacturing Center. The University of California - Irvine is under contract with CMTC in support of CESMII. CESMII is headquartered in Los Angeles and has five regional centers around the country, including locations in the Northwest, Northeast, California (Headquarters), Gulf Coast, and Southeast. CESMII's goals are to:

- Provide breakthrough capability to drive energy reduction by

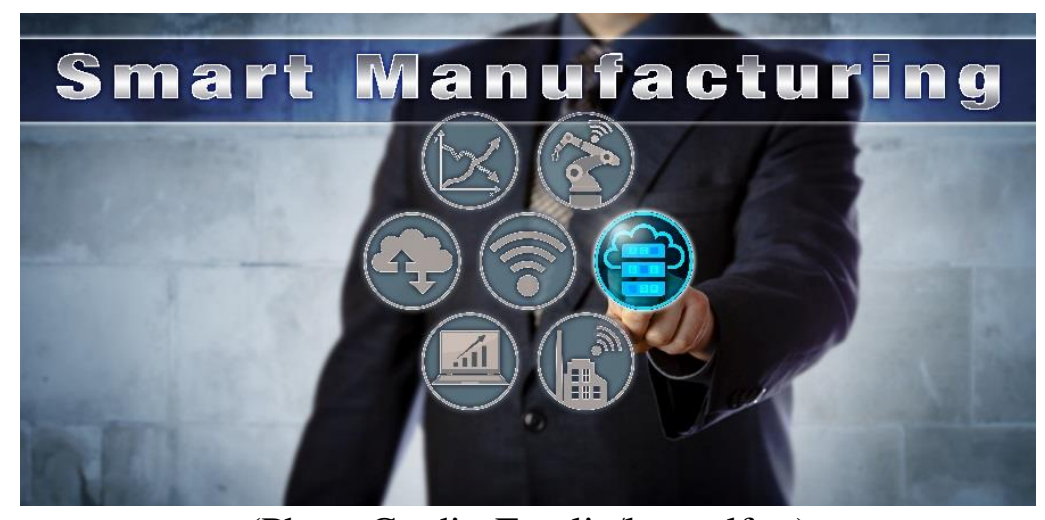

(Photo Credit: Fotolia/leowolfert) \$195B

- Be industry led and driven

- Focus on some of the highest energy consuming industries (e.g., petro-chemicals, metal forming, food production, etc.)

Dr. Klopfer discussed how plug load is relevant to anything that plugs into a wall. Much of the work for heating, ventilation, and air conditioning (HVAC) and lighting has already been done. The question Dr. Klopfer seeks to address is how do you improve efficiency of plugged in devices, especially those within manufacturing? Performing analytics in the cloud has a negative side effect with respect to energy usage. Energy usage, especially within manufacturing, presents a split incentive - someone is using the equipment and another person is paying the bill. There is a big disconnect between an individual's perceptions of energy usage vs. the reality of energy usage. Dr. Klopfer declared that actionability over accuracy is important in addressing energy usage challenges.

Display is another key aspect. Dr. Klopfer's group created an energy television channel and mobile applications so that people could more easily digest and visualize their energy usage. Load monitoring can provide useful information in real-time and advantages including:

- Performance and distribution of discrete running times

- Identification of energy/labor inefficient behaviors

- Fault detection: track nonstandard patterns

- Tailored preventative maintenance

- Integrated security resource management

\subsection{Dr. Radu Pavel (TechSolve), Vice President - Engineering \& Chief Technology Officer}


TechSolve is focused on new research approaches to enhance PHM in manufacturing. TechSolve has a heavily instrumented machining laboratory that provides services and products for manufacturers. Some of their research includes a smart machine platform initiative that has the goal of providing richer PHM information to the machine tool user community. Some of the capabilities they are developing include:

- Machine tool health characterization: $15 \%-40 \%$ of manufacturing costs are typically attributable to maintenance

- Machine tool health dashboard (MTHD)

TechSolve produces a suite of products known as VizProducts. This includes Viz Adapter for MTConnect, ShopViz, and MiniViz.

Dr. Pavel indicated that there is a need for guidelines to help manufacturers

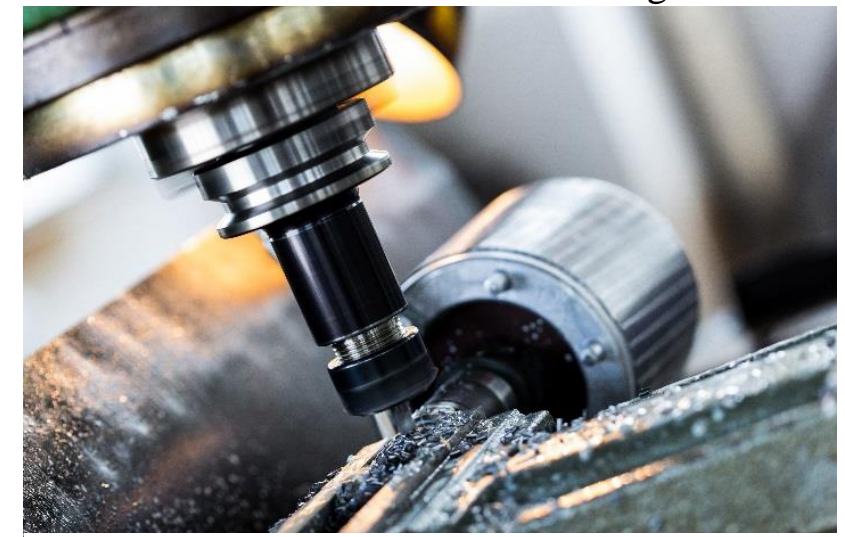

(Photo Credit: Fotolia/Zhu Difeng) determine what to monitor and what type of sensor(s) should be used to capture data to support monitoring activities. More specific to machine tools, two types of sensors are noted as critical to identify machine tool health - vibration and thermal sensors.

TechSolve has an active research effort known as the Smart Machine Platform Initiative. This work is aiming to provide a framework for the identification, development, and transition of technologies that recognize the goal of "First Part Correct" manufacturing. Their research in "Machine Tool Health and Maintenance" aims to identify, evaluate, develop, and demonstrate technologies capable of near-zero downtime and first part correct.

Current machine tool health monitoring solutions are not off the shelf or universal that can be easily implemented. Some of the issues facing manufacturers with respect to identifying and implementing existing solutions include:

- Some degree of customization is required

- Identification or integration may require highly-qualified developers and/or integrators

- Finding the right algorithms and methodologies may be non-trivial

- Selecting what to monitor and how

- Selecting sources of information (sensors, control, other)

- Establishing efficient procedures for data collection

- Lack of standardization 


\section{4. $\mathbf{1}^{\text {st }}$ Brainstorming Session}

The first brainstorming session began with the attendees being presented with the goal of the session along with matrix categories for which they could assign their ideas generated during the brainstorming session. The goal of the brainstorming session was for the attendees to identify and write down the challenges, from their perspectives, at the factory floor level and below, that would benefit from PHM. Specifically, it was noted that this brainstorming activity would be used to identify the topic area(s) that are ripe for standardization whether they are considered 'low-hanging fruit' (something that could be accomplished relatively easily and/or quickly) or something that is critical to advance industry's PHM capabilities. The brainstorming matrix, presented in Fig. 2, identifies three critical PHM topic areas and four manufacturing technology areas to offer a wide-range of options for the workshop attendees to assign their brainstorming topic areas. One axis includes PHM Manufacturing Process Metrics and Techniques, PHM Performance Assessment, and PHM Infrastructure - Hardware, Software, and System Integration. The other axis presents technology domains commonly found in manufacturing: Machining/Subtractive Processes, Robot Systems, 3D Printing/Additive Processes, and Other Technology. Additionally, the last complete row of the matrix is comprised of the 'Parking Lot' that offers the attendees a place to put their ideas if they believe they don't fit into one of the matrix cells above. The three critical PHM topic areas (leveraged from a prior NIST PHM Workshop [4, 5]) are defined as:

- PHM Manufacturing Process Techniques and Metrics - current and projected PHM techniques and methods for application to smart manufacturing systems; metrics used to monitor system health and enable PHM techniques; and the relationships between techniques and metrics.

- PHM Performance Assessment - current and future approaches to assess the performance of PHM systems including (but not limited to) validation and verification of methods and uncertainty quantification.

- PHM Infrastructure: Hardware, Software, and System Integration - current and future hardware and software technologies (including sensors, controllers, models, and simulations) to enable or integrate with PHM techniques.

The four manufacturing technology areas are broken down into common or emerging technologies that are used on the factory floor. They are:

Machining/Subtractive - This area is largely for machine tools including lathes, mills, routers, electrical discharge machines (EDM), and grinders [6-8].

Robot Systems - This area includes industrial robots (typically six degree-of-freedom systems) and mobile autonomous ground vehicles (AGVs) [9, 10].

3D Printing/Additive - This area includes the emerging 3D printing and additive manufacturing technologies [11-13].

Other Technology - This category can be considered a 'catch-all' for technologies that don't cleanly fit into one of the above three categories. Some example technologies would 
be supporting automation or overarching technology such as conveyor systems, linear rails, sensors, human-machine interface, etc.

Each cell is assigned a letter, according to Fig 2, where the results section is organized by cell letter. The largely unfiltered results of this matrix are presented below. With the cells defined, the audience was given the opportunity to write down their brainstorming topics on sticky notes (one idea per note) and place them in the most appropriate cell (Fig 3).

It is worth noting that some minor grammatical corrections are made (so long as the intended meaning is preserved). Likewise, the workshop organizers added some clarifying comments in italics at the end of several topic areas to provide clarity.

\begin{tabular}{|c|c|c|c|}
\hline & $\begin{array}{l}\text { PHM Manufacturing } \\
\text { Process Metrics } \\
\text { and Techniques }\end{array}$ & $\begin{array}{c}\text { PHM Performance } \\
\text { Assessment }\end{array}$ & $\begin{array}{l}\text { PHM Infrastructure - } \\
\text { Hardware, Software, } \\
\text { and System Integration }\end{array}$ \\
\hline $\begin{array}{l}\text { Machining/ } \\
\text { Subtractive }\end{array}$ & $A$ & $B$ & C \\
\hline Robot Systems & $\mathrm{D}$ & $E$ & $F$ \\
\hline $\begin{array}{l}\text { 3D Printing/ } \\
\text { Additive }\end{array}$ & $G$ & $\mathrm{H}$ & I \\
\hline $\begin{array}{c}\text { Other } \\
\text { Technology }\end{array}$ & J & K & $\mathrm{L}$ \\
\hline Parking Lot & & $\mathrm{M}$ & \\
\hline
\end{tabular}

Fig 2. Day 1 Brainstorming Matrix

A: PHM Manufacturing Process Metrics and Techniques - Machining/Subtractive

- Monitoring of sensor signals (What specific signals to track? At what frequency? Resolution?)

- Guidelines to best PHM practices and methods to be standardized (e.g., OEE)

- Tool wear monitoring through acoustic sensors

- Relating machine and process health to part quality (Using part quality measurements to inform on the health of specific manufacturing equipment and the overall manufacturing process)

- Tracking machine health parameters such as bearing wear over time to track precision tolerances

- Machine deformation, temperature effect, loading

B: PHM Performance Assessment - Machining/Subtractive

- Standardized terminology for PHM 
- Guidelines to what sensor types, signals, and features be used for certain equipment/processes

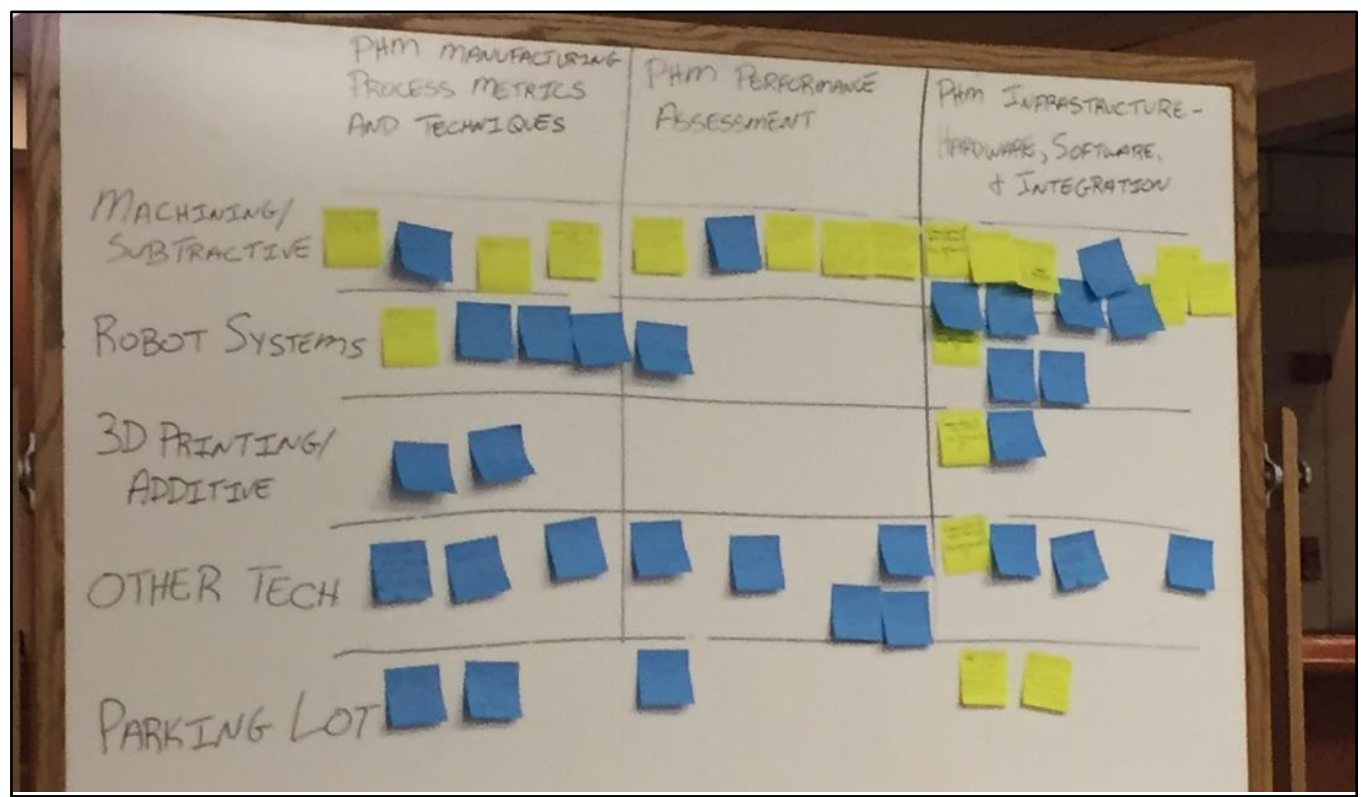

Fig 3. Matrix with Audience Brainstorming Topics (Photo Credit: Helen Qiao)

- Sensor-based online monitoring of process/drift detection (could include trend detection)

- Using sensor data fusion analytics (how to successfully fuse multiple data streams together into meaningful analytics)

- Integrated quality monitoring in manufacturing process

C: PHM Infrastructure - Hardware, Software, and System Integration Machining/Subtractive:

- Chatter excessive vibration, avoidance

- System level integration of hardware and software to enable PHM

- Smart sensors (Effective integration and use for PHM)

- Accuracy measurement - as built, long term effect

- Dynamic characteristic long term effects

- Expand MTConnect schema to address PHM (MTConnect is a communication standard employed within manufacturing operations to provide data in structured XML rather than proprietary formats http://www.mtconnect.org/).

- When and what communication standards to be used (This is a broader topic focus than leveraging MTConnect for PHM)

D: PHM Manufacturing Process Metrics and Techniques - Robot Systems:

A majority of the topics in this category are metrics that workshop attendees believe are critical to monitor and analyze to promote PHM. 
- Minor acceptable work volume

- Motor temperature

- Drive temperature

- Peak currents (statistics)

- Motion data (This would likely include position, velocity, and acceleration information)

- Position error

- Velocity stability

- Vibration data

- Define what robot health means

E: PHM Performance Assessment - Robot Systems:

- $\quad$ Time to required maintenance (e.g., grease bearings)

F: PHM Infrastructure - Hardware, Software, and System Integration - Robot Systems

- Sensors

- Edge computing

- Statistical graphing of data

- Communication of data format (e.g. MTConnect)

G: PHM Manufacturing Process Metrics and Techniques - 3D Printing/Additive

- How to determine that their AM (Additive Manufacturing Equipment or Process is) making bad parts

- 3D Printing / Additive lack of in-process monitoring for process monitoring (e.g., direct metal deposition, melting pool measurement)

$\underline{\text { H: PHM Performance Assessment - 3D Printing/Additive }}$

No topic areas were identified by the audience

I: PHM Infrastructure - Hardware, Software, and System Integration - 3D Printing/Additive

- Understanding a sensor measurement, work that we did in additive $\sim 20$ years ago

- Communication of data format (e.g., MT Connect)

\section{J: PHM Manufacturing Process Metrics and Techniques - Other Technology}

No topic areas were identified that remained in this category. Some topic areas were initially placed in this category, yet were moved to other categories after discussing the intent behind the proposed ideas with the audience. 


\section{K: PHM Performance Assessment - Other Technology}

No topic areas were identified that remained in this category. Some topic areas were initially placed in this category, yet were moved to other categories after discussing the intent behind the proposed ideas with the audience.

L: PHM Infrastructure - Hardware, Software, and System Integration - Other Technology

- Motion stage software to accommodate (monitor health of) travel

\section{$\underline{\text { M: Parking Lot }}$}

- Sensor and user observation correlation with multiple or chained failure - drawing out actionable conclusions from diverse sensor data

- Preservation of data or actions to facilitate repair operations and reduce downtime (e.g., visualization)

- Bearing performance, wear life, preload loss, noise

- Multi-modal data fusion (e.g., images, metrology, waveform signals)

- Decision making guidance

- Metric(s) based on number of degrees-of-freedom or axes to normalize the extent of monitoring

- More standardized metrics for maintenance

\section{$\underline{\text { Panel Discussion }}$}

Following the presentations and the first brainstorming sessions, the audience was given the opportunity to ask questions of some of the presenters (Gregg Profozich, Michael Klopfer, Xiaoning Jin, and Radu Pavel). Questions ranged from broad discussion on manufacturing operations to specific inquiries about a panelist's experience or expertise.

\section{5. $2^{\text {nd }}$ Brainstorming Session}

The second brainstorming session offered each attendee an opportunity to edit the topic areas they declared in the first brainstorming session and add more topics that they believed to be important. The conclusion of the second brainstorming session featured each attendee voting on the topic areas they saw as presenting the biggest challenge to the industry or most beneficial to the industry, which could therefore have the biggest impact if standardized. Each attendee was given four votes to place on any of the four topic areas within the matrix (only a single vote could be cast per topic by each attendee).

Those topic areas receiving the most votes were (in order of votes received, most votes at top):

1. Standardized Terminology for PHM

2. Guidelines to determine what health data to capture / collection strategies 
3. Guidelines to determine what and where sensors should be deployed to inform on process health/equipment health

4. Expand MTConnect/data communications protocol to address PHM

5. Guidance for implementation of sensor data fusion analytics / multi-modal data fusion

6. Determination of where analyses should be performed

7. Determination of appropriate visualization/communication to enable human consumption for decision-making

\section{Day 2: Results of Priority Topic Discussions}

Each of the most voted for topic areas from day 1 were expanded with specific attention paid to addressing the below elements:

- Anticipated product (e.g., Standard, Guideline, training course, etc.)

- Barriers/challenges expected to achieve this objective (e.g., intellectual property issues, immature technologies, scoping)

- Identification of key players (users, providers, technology developers, academia, etc.)

- Expected approach - what research is needed, what information sharing needs to happen?

- Development of initial work-plan:

○ Actions/tasks

- Milestones (with responsible parties)

○ Targets/Capabilities

\subsection{Topic \#1 - Standardized Terminology for PHM}

The anticipated product in developing a standardized terminology for PHM would likely take the form of a standard. Definitions could be in text or from a definition section. ASME could create a list of terms (similar to what has been done for Model-Based Enterprise) and make them freely available to promote greater adoption and usage. Wherever the terminology resides could point back to other efforts to allow for greater industry participation. A relational map could be created to show how terms can be correlated with others so the larger manufacturing community can speak the same language.

There are numerous barriers and challenges standing in the way of successfully developing and disseminating a standardized terminology for PHM. There are different camps that people reside where their access and use vary; there are those who use the technology and those who will be accessing the technology and terminology. A fair number of terms have already been developed independently and therein lies a challenge; research must be done to determine what the current state of this terminology is and what the future state will be so that a middle ground can be determined. Another challenge is that technology in PHM is not well known, where some users think it's high-end research. Because of this, many SMMs do not participate in these research efforts or leverage PHM technology. For the 
standard to be successful, it will be important for the manufacturing community, including the SMMs, to take ownership in this effort [the standard].

Another large obstacle is that there are presently many publications that present PHM terminology. The manufacturing community has varying PHM terms and these would need to be merged into a single, unified standard (e.g., condition-based maintenance versus predictive maintenance - what are the nuances, if any, which make these terms different? Could they be combined into one term that the community can agree on?). Developing a unified terminology could be used in a lexicon or integrated with existing standards.

Cultural acceptance of a standardized terminology would be another hurdle to overcome. PHM has the potential to create new jobs, particularly if PHM increases planned downtime while decreasing unplanned downtime. Language is likely to be another challenge in developing and promoting this terminology as an international standard. When translating terms into other languages there can be issues. It is possible that another country could produce their own competitive documents.

There are challenges to using a standardized terminology. How can you get people to use the terminology in a relatively painless way? How can PHM tools, supported by the terminology, be merged into job functions? One of the focus areas can be to make the terminology broad enough so it can be used in all derivative documents, yet still let it be specific for particular applications.

Many key players were identified during this discussion that should be directly involved or informed (at a minimum) of an effort to develop a standardized terminology for PHM. Above all, the manufacturing community must be represented. This should include personnel from the semi-conductor industry, component original equipment manufacturers (OEMs), aerospace manufacturers, manufacturers who use their own products to build products (e.g., a machine tool manufacturer using their own machine tools to fabricate parts for their machine tools), small and medium-sized manufacturers (they will have different perspectives as compared to their larger counterparts), along with other manufacturing community members. Other key players that should be involved in this effort include organizations already focused on PHM (e.g., the PHM Society http://www.phmsociety.org/, the Center for Intelligent Maintenance Systems http://imscenter.net/), technology developers (including both hardware and software vendors), and technology integrators.

The workshop participants also shared their thoughts on the expected approach to realize a standard terminology for PHM. Discussions included the research and the information sharing that would need to occur. Numerous questions were raised with respect to crafting the expected research approach. These included how, if at all, to expand the various terms and topics that were put on the board during brainstorming? How do we know if we identified the right categories? And to what degree do we need to break down prospective terminology categories into sub-categories and so-on? The terminology can be developed in a hierarchal structure. Basic terms could be initially built to help setup basic concepts; 
wider and/or deeper terms can then be captured and separated out into different categories and sub-categories.

Along this research path, it was agreed that a charter and scope statement would need to be developed. Likewise, a roadmap should be prepared to further focus the effort. As mentioned earlier, key people would need to be identified to support this effort and that should be factored into the approach (since the nature and makeup of the participants will substantially impact the outcome). A group, larger than the number of participants at this workshop, should be involved in this effort, especially more personnel from OEMs.

Bringing in additional OEMs will help the group identify any existing PHM standards that have been successful within manufacturing. Likewise, OEMs can help the group determine what existing standards are not practical or beneficial to implement.

As the standard terminology takes shape, advance implementation could be done to educate small manufacturers. (ASME could host a series of webinars to help educate industry on PHM and why their involvement is important).

\subsection{Topic \#2 - Guideline to Determine What Health Data to Capture/What Collection Strategies to Employ}

This topic area seems to lend well to becoming a suite of guidelines that aid the manufacturing community in determining what health data to capture, including what collection strategies should be employed to obtain this health data. The audience discussed a substantial element that should be used in determining what data to collect - the development and assessment of a cost and risk evaluation matrix.

The audience discussed numerous barriers and challenges to developing this topic area into guidelines. This area may not be immediately ripe for standardization; the participants and industry feedback will set the pace and urgency on what content is developed - adoption will be the main focus during development and after publication to ensure that the guidelines are being embraced by industry.

Challenges are also expected in crafting the scope. Specifically, the scope will want to address the purpose of collecting health data, with some level of specificity. One example that was presented would be Are we collecting data to understand equipment vibration or trying to understand what the vibration sensor does? People want to know the purpose of collecting specific data to help make effective and reliable decisions. In addition, is the data being used mostly for repair, diagnostics, both, or something else altogether? Are there any existing industry standards or guidelines that are driving health data collection?

It was mentioned that there is little need to teach an equipment company about what sensors they need. They are proficient on their products. But for the end user who is using the instrument, there is a need for tools to help users draw a line from normal to abnormal health conditions. Assisting the end user also involves aiding them in determining the life cycle, frequency, resolution, and type of sensor data that should be captured that will offer 
insight on equipment and process health. Given these specific requirements, and the differing challenges between the large manufacturing and SMM communities, dissemination issues could arise. These issues could be mitigated through a 'test pilot' of the guidelines with a small group that would implement [the guidelines] and provide feedback for broader use. Within ASME, there is also the option of a Draft Standard for Trial Use.

Identifying the key players in this topic area included data/information technology personnel, manufacturers, technology solutions providers, technology integrators, hardware/software developers, and the U.S. government.

Addressing this topic area will require several, critical tasks to be incorporated into the expected approach. For example, the determination of data to be captured will be influenced by the tools available to capture, process, and present/visualize the data. If a tool is defined first (what an audience member defined as Tool-Centered Development), this could either constrain or open-up more options to the manufacturer (that they may not have been aware of before or provide them with a more efficient means of capturing additional and beneficial information). In turn, if the data needs are defined first, then this could limit the available tool options or call for the generation of a custom solution. One benefit of defining the data needs first, and achieving a consensus standard, is that software development will be easier since the standard will already define specific parameters that must be adhered (e.g., standardized interface).

Another beneficial step to realize this topic area would be to map out the supply chain. This is relevant to this specific topic area in terms of understanding the propagation and impacts of process health degradation, which can impact part quality. It will be important to map out the process control, both in terms of scalability and understanding impacts between upstream and downstream elements. Mapping out the supply chain should begin with an internal mapping (within a factory) and then extend to other factories within the company (that feed one another) along other feeder/consumer organizations.

Moving forward, the initial work plan should focus on developing the various categories of health data. Then further decompose each category in terms of tasks, energy, performance, and physical integration/connections. This will lay the necessary foundation to identifying the specific data needs and collection strategies based upon determining what information is most critical to know.

\subsection{Topic \#3 - Guideline to Determine What Sensors and Where they should be Deployed to Inform on Process/Equipment Health}

This specific topic area has a strong relationship with the Topic \#2 where these two topic areas could be different 'Parts' within the same suite of documents. Several in the workshop audience expressed differing perspectives as to what would be the output from this effort. The different prospective outputs included producing a general guideline that would determine sensor function and the depth of exploration; a case study that would document living successes; a technical book or document that would explain how people 
could go through the sensor identification and deployment process, and evaluate their operation from risk perspective to guide them if they should implement the PHM technology; and/or a conformity assessment program for companies that would list various sensor tiers to offer some levels of sensor customization (A concept for conformity assessment briefly discussed was that companies would go through a program that allows them to declare they offer varying degrees of sensors to support process/equipment health monitoring). There was large audience agreement that the output should include categories of health data and other relevant information that would map back to specific sensing capabilities.

As with the other topic areas presented, the audience identified numerous barriers and challenges that would have to be surmounted. One of the first challenges identified in realizing this topic area is to draft a clear focal statement, especially in determining what sensors should be considered. Currently, there are a lot of embedded sensors that offer a range of performance and health information on a process or piece of equipment, yet this may not be sufficient for a manufacturer's needs. More external sensing technologies are flooding the market offering greater options for manufacturers to monitor, diagnose, and predict process and equipment health. Some of these emerging sensors are still unproven for PHM application within manufacturing. People are investigating methods to sense various elements where there has been little to no prior technological development, to date. As sensors continue to emerge and evolve, the scope of this topic area has the potential to expand, in either breadth and/or depth. As such, it will be critical to develop a timeline in terms of what should be today's focus and what will need to be addressed later in time.

Another challenge to work through is addressing sensor data accessibility, especially for embedded sensors. Some equipment OEMs restrict user access to the data that is being captured. During typical operations, the user may be privy to a sufficient variety and volume of data that offers them cursory performance and health information. It's possible that additional information is being captured, yet it may only be accessible through 'admin' rights reserved for the OEM or the OEM's certified maintenance representative(s).

Cost is another challenge that will have to be overcome in developing this topic area; specifically, to what extent should cost be addressed. Practically speaking, manufacturers/end-users will select and deploy sensors based upon both the expected value and the cost (i.e., what is the cost/benefit ratio or return on investment of including one sensor over another). It is likely that the manufacturing community will have a hard time accepting and using guidelines on sensor selection and deployment if they don't address the cost of the sensor, its implementation, storage of data, human burden, etc.

As the audience continued discussing this topic area, it became very evident that sensor selection and deployment guidance would be tightly integrated with health data collection and required strategies. For example, sensor selection and deployment will influence data storage strategies and costs. Both of these are influenced by how health data can be, should be, and ultimately, will be collected. Some sensor data could be captured quantitatively, while other data may not. How much customization is available when selecting and deploying a sensor? How does the availability of options, or lack thereof, influence a 
manufacturer's ability to collect health data? These were some the questions that the audience posed as challenges.

The workshop audience discussed that the guidance should allow the manufacturer/enduser to delineate the differences between process health (more functional - one or more physical entities working together) and equipment health (which could be similar across multiple processes). Different sensors will offer different capabilities in terms of the extent of process health data vs. equipment health data that can be captured.

With some similarity to the prior topic area (focused on health data collection), the key players identified by the audience for participation in this activity include: equipment (e.g., sensor) manufacturers, data/information technology engineers, hardware and software integrators, government agencies, and end-users.

The audience then considered the research approach that should be taken to realize this topic area. It was first suggested to conduct a survey of industry to further ensure that the activities surrounding this topic area are aligned with industry needs and wants; and determine if the end-user of the guidelines can improve the efficiency of this effort through trial/pilot deployments. One suggestion was to build a matrix with multiple tiers of companies. First, a user would determine which tier a company belongs. Then identify the minimum requirements of sensor specifications for different tiers.

The research approach then gave way to discussion of the workplan. In addition to addressing the research elements, the work plan should include capturing success stories from the community with respect to sensor selection and deployment strategies. These stories can feed substantially into the guidance documentation, especially if the story contributors can discuss how their strategies led to effective data collection and actionable health intelligence. The workplan could also include a companion publication or technical book to the guidelines. Specifically, this publication could list out different sensors for different processes or equipment along with presenting the pros and cons of each.

As time was limited for the remainder of the workshop, the following topics were discussed in brief detail and were not outlined to the extent as compared to the others above.

\subsection{Topic \#4 - Expand MTConnect/Data Communications}

The audience debated expanding the MTConnect standard to cover PHM and/or generating a PHM-specific data communications standard (separate from MTConnect). There were several audience members who were already familiar with MTConnect who suggested that expanding this existing standard might be the most efficient way to standardize communications of PHM data, especially because MTConnect is becoming more widely used within the manufacturing community. However, for SMMs, MTConnect is likely not in place as most are using legacy machines. Significant effort would be needed to update machines and make them MTConnect compliant. The audience debated whether a guide/program implementation would be a product for the manufacturing community, 
especially the SMMs. More discussion will be required here, especially with the MTConnect community, to ensure that this ASME effort does not 'reinvent the wheel' or do work in an area that is more appropriate for the MTConnect community. The audience further debated that since MTConnect is present, is a new standard really warranted? MTConnect is becoming the de-facto standard; could an alternative task be to prepare communication protocols?

For this topic area to be successful, software vendors would need to make a conscious decision to embrace this effort. This could put the software vendors in direct conflict with their support of MTConnect. As noted earlier, it would be beneficial to interact with the software vendors directly. If it's determined that it's more beneficial to the PHM community to contribute to the MTConnect standard, then the PHM community should clearly communicate any additional data types, etc. that increase the standard's PHM capability. The audience agreed that as a good first step we should reach out to the MTConnect Institute to determine what is already available and what other standards are being developed.

\subsection{Topic \#5 - Guidance for Implementation of Sensor Data Fusion Analysis/Multi-Modal Data Fusion}

This next topic area is also closely related with Topic \#2 - Health Data Collection Strategies and Topic \#3 - Sensor Identification and Deployment Strategies; this topic focuses on offering guidance to the manufacturing community to fuse multiple sensor data streams to generate a meaningful analysis of equipment or process health.

With the limited time the audience had to discuss this topic, the conversation largely focused on the potential barriers and approach to achieve this objective. This effort should begin by appropriately scoping and deconstructing the topic so the community knows what will be in focus and what will be out of focus in this effort. Scoping should include classification of current state and/or estimation of future state (which would likely rely on physical models and other models). This will help people understand how this technology or process can help them.

Moving forward, the output of this effort should offer an understanding of the evolutionary path of multi-model data fusion. This would begin with plotting multiple data streams and looking for any anomalies, notifying others of these anomalies, and continuing the process to estimate, simulate, and diagnose. This effort should also seek to address what are the different types of technologies necessary to enable meaningful sensor data fusion.

\subsection{Topic \#6 - Determination of Where [Health] Analyses Should be Performed}

This topic area aims to help the manufacturing community determine where (e.g., within the organization, external to the organization) PHM analyses should be performed. This topic area was minimally discussed where conversations largely focused on the barriers to development and adoption. 
An important element to this effort will be to present guidance to generate a cost/benefit analysis of the different analysis location options. Another topic of discussion is determining if one really needs to measure the low-level data when doing a health assessment. Some analysis can be done internally (within the manufacturer's organization), otherwise it's the service provider's responsibility to send the data out of house, which would lead to another expense. The analysis technologies are so varied that they should be defined and standardized to some extent.

Some in the audience hypothesized that the consumer of the analysis doesn't care where it is done. If time permitted, this point could have been further debated. Others in the audience postulated that the consumer of the analysis does care where the analysis is performed for several reasons including security (it is easier to avoid accidental sharing by keeping the analysis in-house) and ownership (having the analysis done in-house can make it very straightforward as to who owns the intelligence as compared to the analysis being done outside). Another argument to keeping analysis activities in-house would be if equipment/process health baselines are updated on a frequent basis. These baselines directly impact the PHM analysis making it critical that new prognostic and diagnostic parameters be incorporated in data analysis, which could be challenging if the analysis is done remotely.

The audience noted that there are choices available. It will be important that the output documentation provide the manufacturing community with options to consider.

\subsection{Topic \#7 - Determination of Appropriate Visualization/Communication to Enable Human Consumption for Decision Making}

After data has been collected and analyses performed, it is critical that the resulting intelligence is conveyed in a meaningful way to the human consumer. The audience discussed that there are two primary issues to be conveyed - 1) when something is going to fail, will the failure be on someone's own terms/expectations? People care about the consequence that happens on their terms (by their doing), meaning they may be more controllable; They may also be more productive in terms of their planning and find certain windows for managing issues and, 2) what kind of the guidance should be provided to manufacturers to determine the appropriate time to take actions to not be too late or too early in a response. One recommendation within this effort would be to develop a matrix of the device including overall indicator/ condition of the facility/ component health. If the visualization is complex, it will be too difficult for the user to understand what they are observing.

It was noted that there is currently a lack of standardized visualization of what you should do or not do. Typically, training is required to understand the user interface.

\section{Anticipated Next Steps}

Several next steps were determined from the information gathered at this workshop. These next steps are listed below, in no order of priority. 
1. Numerous industry categories (e.g., manufacturers, technology developers, technology integrators) and members should be in attendance at future events and participate in the development of the priority topic areas.

2. Terminology development is crucial to build up and support other derivative guidelines/products

3. More input is required from industry. To this effort, two sessions/events are being considered:

- October 2017 - Manufacturing Standards Workshop at PHM Society Conference (St. Plersburg, Plorida) (http://www.phmsociety.org/events/conference/phm/17). This conference will feature a workshop on Manufacturing Standards that will be led by ASME personnel. The expected workshop will serve as the next step to this ASME effort in gathering the requirements of what industry is seeking in terms of guidance to design, deploy, verify, and validate monitoring, diagnostic, and prognostic technologies at the factory floor level. The workshop will feature presentations from key industry members along with interactive discussions to further identify the critical needs and wants of the manufacturing community.

○ May 2018 - Industry Forum at NIST (Gaithersburg, Maryland). This event, still in the planning stages, will bring together industry, government, and academia to discuss the current trends, successes, challenges, and needs with respect to advanced monitoring, diagnostic, and prognostic technologies to enhance maintenance and control strategies at the factory floor. The expected multi-day event will feature keynote presentations, panel discussions, and interactive Q\&A sessions with industry leaders focused on monitoring, diagnostic, and prognostic technologies. Part of this event will feature a dedicated discussion on ASME's efforts to build up standards and guidance documentation in PHM.

For anyone interested in participating in this overall standards activity and the above events, please contact Steve D. Weinman (WeinmanS@asme.org), Director Standardization \& Testing, ASME.

\section{References}

[1] Jin, X., Siegel, D., Weiss, B. A., Gamel, E., Wang, W., Lee, J., and Ni, J., 2016, "The present status and future growth of maintenance in US manufacturing: results from a pilot survey," Manufacturing Rev., 3, p. 10.

[2] Jin, X., Weiss, B. A., Siegel, D., and Lee, J., 2016, "Present Status and Future Growth of Advanced Maintenance Technology and Strategy in US Manufacturing," International Journal of Prognostics and Health Management, 7 (Special Issue on Smart Manufacturing PHM)(Sp5), p. 18.

[3] ASME, 2009, "Dimensioning and Tolerancing," American Society of Mechanical Engineers, p. 224. 
[4] Pellegrino, J., Justiniano, M., Raghunathan, A., and Weiss, B. A., 2016, "Measurement Science Roadmap for Prognostics and Health Management for Smart Manufacturing Systems," NIST Advanced Manufacturing Series (AMS).

[5] Weiss, B. A., Vogl, G. W., Helu, M., Qiao, G., Pellegrino, J., Justiniano, M., and Raghunathan, A., 2015, "Measurement Science for Prognostics and Health Management for Smart Manufacturing Systems: Key Findings from a Roadmapping Workshop," Annual Conference of the Prognostics and Health Management Society 2015, PHM Society, ed., PHM Society, Coronado, CA, p. 11.

[6] Xu, X., and Newman, S. T., 2006, "Making CNC machine tools more open, interoperable and intelligent-a review of the technologies," Computers in Industry, 57(2), pp. 141-152.

[7] Boothroyd, G., 1988, Fundamentals of metal machining and machine tools, CRC Press.

[8] Altintas, Y., 2000, Manufacturing automation: metal cutting mechanics, machine tool vibrations, and CNC design, Cambridge University Press.

[9] Engelberger, J. F., 2012, Robotics in practice: management and applications of industrial robots, Springer Science \& Business Media.

[10] Ganesharajah, T., Hall, N. G., and Sriskandarajah, C., 1998, "Design and operational issues in AGV-served manufacturing systems," Annals of Operations Research, 76, pp. 109-154.

[11] Bi, Z. M., Lang, S. Y., Shen, W., and Wang, L., 2008, "Reconfigurable manufacturing systems: the state of the art," International Journal of Production Research, 46(4), pp. 967-992.

[12] Grasso, M., and Colosimo, B. M., 2017, "Process defects and in situ monitoring methods in metal powder bed fusion: a review," Measurement Science and Technology, 28(4), p. 044005.

[13] Mani, M., Feng, S., Lane, B., Donmez, A., Moylan, S., and Fesperman, R., 2015, Measurement science needs for real-time control of additive manufacturing powder bed fusion processes, US Department of Commerce, National Institute of Standards and Technology, NIST Interagency/Internal Report (NISTIR) - 8036. 


\section{Appendix A - Agenda}

ASME Workshop in Prognostics and Health Management Agenda - June 8-9, 2017 - The Radisson at USC

\section{June 8, 2017}

\begin{tabular}{|c|c|c|}
\hline $\begin{array}{l}1: 00-1: 10 \\
\text { PM }\end{array}$ & $\begin{array}{l}\text { Registration / } \\
\text { Welcome }\end{array}$ & \\
\hline $1: 10-1: 15$ & ASME Welcome & Steve Weinman (ASME) \\
\hline $1: 15-1: 30$ & Tech Introduction & $\begin{array}{l}\text { Brian Weiss (NIST) } \\
\text { Present technical focus and projected scope }\end{array}$ \\
\hline $1: 30-1: 45$ & Specific Example & $\begin{array}{l}\text { Michael Brundage (NIST) } \\
\text { Presentation of Case Study showing research } \\
\text { efforts/structure helping a manufacturer }\end{array}$ \\
\hline $1: 45-1: 55$ & $\begin{array}{l}\text { ASME Standards } \\
\text { Process }\end{array}$ & Donnie Alonzo (ASME) \\
\hline $1: 55-2: 10$ & ASME Case Study & $\begin{array}{l}\text { Bryan Fischer (Sigmetrix) } \\
\text { Case study: Conflict Resolution by Applying } \\
\text { GD\&T to Large Weldment }\end{array}$ \\
\hline $2: 10-2: 35$ & Initial Brainstorming & $\begin{array}{l}\text { Audience writes down, on sticky notes, what } \\
\text { they believe are areas of need for standards in } \\
\text { the context of monitoring, diagnostics, and } \\
\text { prognostics. }\end{array}$ \\
\hline $2: 35-2: 50$ & BREAK & \\
\hline $2: 50-3: 15$ & $\begin{array}{l}\text { The present status } \\
\text { and future growth of } \\
\text { maintenance in US } \\
\text { manufacturing }\end{array}$ & $\begin{array}{l}\text { Xiaoning Jin (Northeastern) } \\
\text { Focus on what the overall community is doing } \\
\text { in terms of advancing PHM }\end{array}$ \\
\hline $3: 15-3: 40$ & $\begin{array}{l}\text { Monitoring, } \\
\text { Diagnostics, and } \\
\text { Prognostics with } \\
\text { Clean Energy for } \\
\text { Smart Manufacturing }\end{array}$ & $\begin{array}{l}\text { Gregg Profozich (CMTC) } \\
\text { Dr. Michael Klopfer (UCI) }\end{array}$ \\
\hline $3: 40-4: 05$ & $\begin{array}{l}\text { PHM Research } \\
\text { Advances }\end{array}$ & $\begin{array}{l}\text { Radu Pavel (TechSolve) } \\
\text { Focus on new research approaches to enhance } \\
\text { PHM in manufacturing }\end{array}$ \\
\hline $4: 05-4: 20$ & BREAK & \\
\hline $4: 20-4: 50$ & Panel & Panel Q\&A with previous speakers \\
\hline $4: 50-5: 20$ & $2^{\text {nd }}$ Brainstorming & \\
\hline $5: 20-5: 45$ & Group Discussion & \\
\hline $5: 45-6: 00$ & $\begin{array}{l}\text { Wrap-up / Day } 2 \\
\text { Preview }\end{array}$ & $\begin{array}{l}\text { High Priority Sticky Notes are discussed in } \\
\text { detail }\end{array}$ \\
\hline
\end{tabular}


June 9, 2017

\begin{tabular}{|c|c|c|}
\hline $8: 00-8: 15$ & $\begin{array}{l}\text { Registration / } \\
\text { Breakfast }\end{array}$ & \\
\hline $8: 15-8: 30$ & $\begin{array}{l}\text { Welcome / Day } 1 \\
\text { Recap / Day } 2 \\
\text { Objectives }\end{array}$ & $\begin{array}{l}\text { Present selected topics that were drafted in } \\
\text { Day } 1 \text { as priority for the industry }\end{array}$ \\
\hline $8: 30-8: 45$ & $\begin{array}{l}\text { Overview of ASME } \\
\text { Sectors / Products }\end{array}$ & $\begin{array}{l}\text { Present ASME Offerings and potential } \\
\text { deliverables to the industry as a whole to } \\
\text { participants }\end{array}$ \\
\hline $8: 45-9: 25$ & Topic 1 Discussion & Priority 1 from Day 1 Brainstorming \\
\hline $9: 25-10: 00$ & Topic 2 Discussion & Priority 2 from Day 1 Brainstorming \\
\hline $\begin{array}{l}10: 00- \\
10: 15\end{array}$ & BREAK & \\
\hline $\begin{array}{l}10: 15- \\
10: 50\end{array}$ & Topic 3 Discussion & Priority 3 from Day 1 Brainstorming \\
\hline $\begin{array}{l}10: 50- \\
11: 20\end{array}$ & Topic 4 Discussion & Priority 4 from Day 1 Brainstorming \\
\hline $\begin{array}{l}11: 20- \\
11: 50\end{array}$ & $\begin{array}{l}\text { Summation of Action } \\
\text { Items and Next Steps }\end{array}$ & \\
\hline
\end{tabular}




\section{Appendix B - Speaker Bios}

\section{Steve Weinman}

Mr. Steve Weinman is the Director of ASME Standardization and Testing Department. In this position he is responsible for determining strategic plan and budgetary recommendations for a department that currently has twenty-three Standards Committees. He has been involved with standards activities within ASME for over thirty-six years. Under the department they publish approximately 360 standards.

Mr. Weinman has a Bachelor of Science in Mechanical Engineering from Polytechnic Institute of NYC. He is a member of the American Society of Mechanical Engineers.

\section{Brian A. Weiss}

Dr. Brian A. Weiss is a mechanical engineer and the project leader of the Prognostics, Health Management, and Control (PHMC) project at the National Institute of Standards and Technology (NIST). His current research efforts are focused on developing the necessary measurement science to verify and validate emerging monitoring, diagnostic, and prognostic technologies and strategies for smart manufacturing to enable manufacturers to respond to planned and un-planned performance changes.

\section{Michael Brundage}

Dr. Michael P. Brundage is an Industrial Engineer in the Informational Modeling and Testing Group at NIST. Dr. Brundage's interests include Smart Manufacturing Diagnostics for Intelligent Maintenance, Sustainable Manufacturing Performance Measurement, Smart Manufacturing Capability Assessment, and Manufacturing Knowledge Visualization. His work focuses on data-fication techniques towards intelligent maintenance solutions. Prior to joining NIST, Dr. Brundage was a member of the Intelligent Systems Laboratory at Stony Brook University. His research focused on integrated manufacturing and building automation systems as well as sustainable manufacturing performance indicators.

\section{Donnie Alonzo}

Mr. Donnie Alonzo is a Standards and Certification Engineer at ASME under the Standardization and Testing department. He is responsible for supporting various Committees in their work including several Performance Test Codes, Aerospace and Advanced Engineering Drawings, and most recently the Y14.46 Committee in Product Definition for Additive Manufacturing.

Donnie holds a Bachelor of Science degree in Mechanical Engineering from Columbia University. 


\section{Bryan Fischer:}

Mr. Bryan Fischer has over 30 years' experience in mechanical design and engineering. $\mathrm{He}$ is a subject-matter expert in engineering standards, GD\&T, tolerance analysis, 3D Product and Manufacturing Information (PMI), 3D Model-Based Definition (MBD), Model-Based Enterprise (MBE), and their implementation. Bryan has been active in corporate, national, and international standards development and standards management throughout his career, working with ASME, ISO, AIA, NIST, and industrial clients. He is a leading researcher and developer of standards, processes, tools, and methodologies for GD\&T, 3D PMI, and the implementation of 3D MBD. Bryan is a published author and has written about GD\&T, tolerance analysis, engineering standards, drawing practices, and 3D MBD.

\section{Xiaoning Jin}

Dr. Xiaoning Jin is currently an Assistant Professor in the Department of Mechanical and Industrial Engineering at Northeastern University.

Before she joined Northeastern Univ., she received her $\mathrm{PhD}$ degree in Industrial and Operations Engineering from the University of Michigan. She was a research scientist and project leader at the National Science Foundation (NSF) Intelligent Maintenance Center (IMS) at the University of Michigan. Her research interests are manufacturing system operations and maintenance decision-making, manufacturing process monitoring, diagnostics, and prognostics using model-based and data-driven methods.

\section{Gregg Profozich}

Mr. Gregg Profozich is the Director of Advanced Manufacturing Technologies for CMTC. He also served as the Interim Regional Manufacturing Center Director for CESMII, the Clean Energy Smart Manufacturing Innovation Institute, from October 2016 through April 2017. At CMTC, the Advanced Manufacturing Technologies group identifies practices and develops services to help small manufacturers identify, qualify and adopt technologies that will help them remain globally competitive. Mr. Profozich's responsibilities include executive leadership in program areas including additive manufacturing, flexible hybrid electronics, smart manufacturing, advanced robotics, cyber security, supply chain optimization, exporting, and marketing. He is a skilled leader with over two decades of experience across manufacturing, operations, supply chain, strategy execution and information technology. Drawing on his background across fortune 500 companies, startups and consulting, he is experienced in pioneering new tools, approaches, and services to assist small manufacturers in adopting technologies that will improve their global competitiveness.

\section{Michael Klopfer}

Dr. Michael Klopfer is the technical director of the California Research Center (CalPlug) at the University of California Irvine. He has a background in consumer electronics and 
power system design, and has designed and constructed high-load power supplies and power management systems for medical imaging devices. Dr. Klopfer has also led numerous projects related to the planning, design, and installation of telemetry and data analytic systems for energy monitoring in homes and businesses as well as specialized clean room and semiconductor fabrication process control.

\section{Radu Pavel}

Dr. Radu Pavel is Vice President of Engineering and Chief Technology Officer of TechSolve, Inc.

TechSolve is a process improvement and machining services organization located in Cincinnati, $\mathrm{OH}$.

Dr. Pavel has over 20 years of experience in industry and research laboratories from Europe and United States. He has two PhDs, one in Mechanical Engineering and one in Manufacturing Engineering. Dr. Pavel's core expertise includes machining and grinding processes, monitoring of machining equipment and processes, modeling and simulation, test-bed development and instrumentation, data acquisition and analysis, and teaching and training. 
Appendix C - Speaker Presentations 


\section{The American Society of Mechanical Engineers}

Setting the Standard for Safety and Global Relevance

\section{Steve Weinman}

Director Standardization \& Testing 


\section{ASME Mission Statement:}

To serve diverse global communities by advancing, disseminating and applying engineering knowledge for improving the quality of life; and communicating the excitement of engineering.

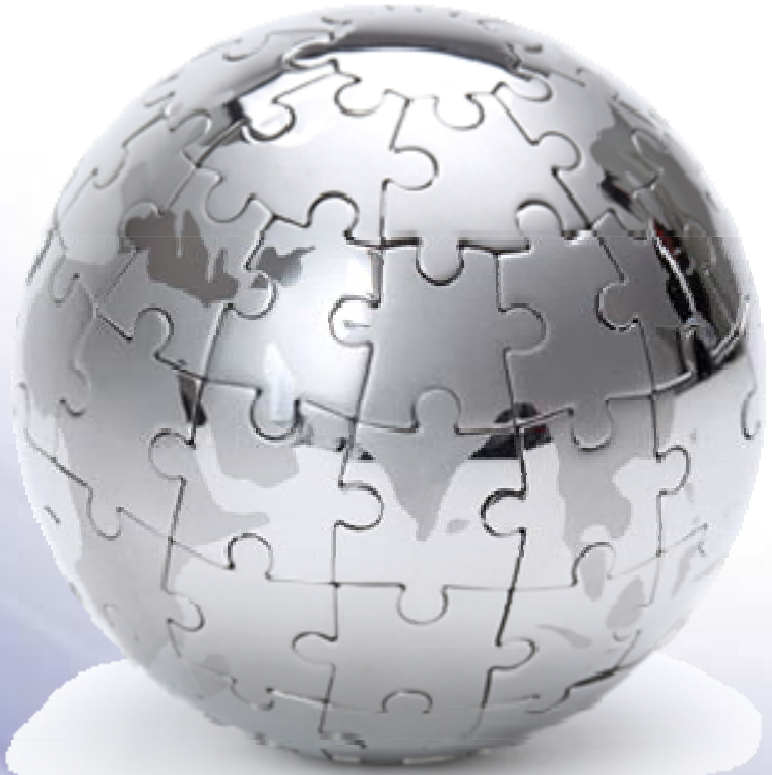

\section{Standards and Certification (S\&C) Mission Statement:}

To develop the best, most applicable codes, standards, conformity assessment programs, and related products and services in the world for the benefit of humanity 


\section{ASME History}

- Between 1898 and 1903 alone, over 1200 people were killed in the U.S. in 1900 separate boiler explosions

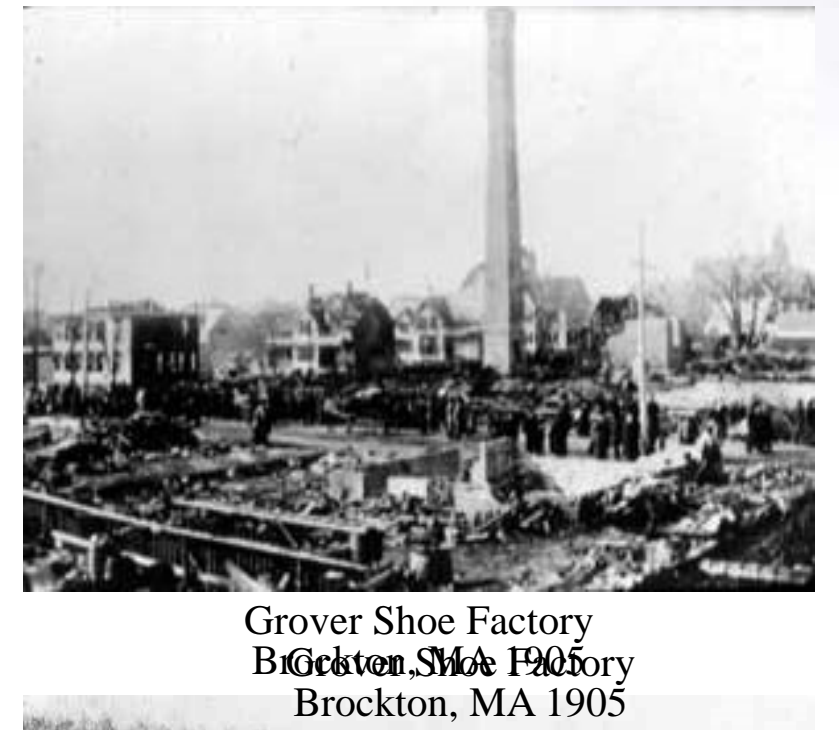

- Key problem: Lack of understanding, consistency, and safety features in boiler design and operation

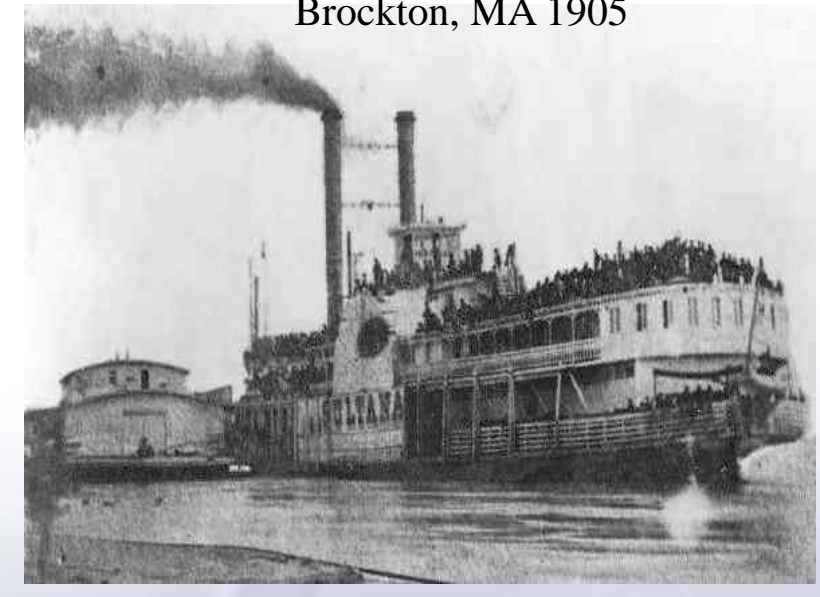

Steamship Sultana, 1865 


\section{ASME History}

\section{Timeline of Early ASME Standardization Milestones}

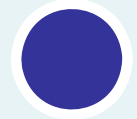

1880

ASME founded to address issues with

industrialization

and mechanization

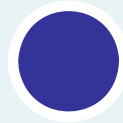

1884

Issues first standard, Code

for the

Conduct of

Trials of Steam

Boilers

\section{NUMBER OF EXPLOSIONS}

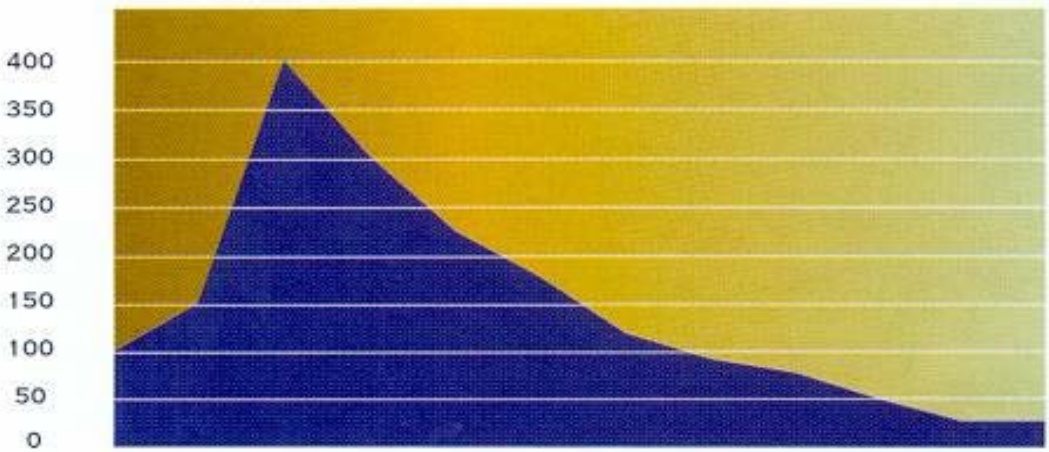

$\begin{array}{lllllllllllll}1880 & 1890 & 1900 & 1910 & 1920 & 1930 & 1940 & 1950 & 1960 & 1970 & 1980 & 1990\end{array}$ YEAR

1905
Standard for
Proportions of
Machine Screw
Sizes

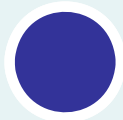

1914

First edition of the Boiler and Pressure Vessel Code hine Screw Sizes

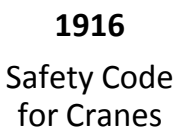

1916

Safety Code for Cranes

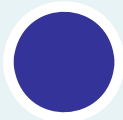

1918

Founding member of American Engineering Standards Committee (later known as ANSI)

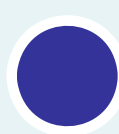

1921

Safety

Code for Elevators
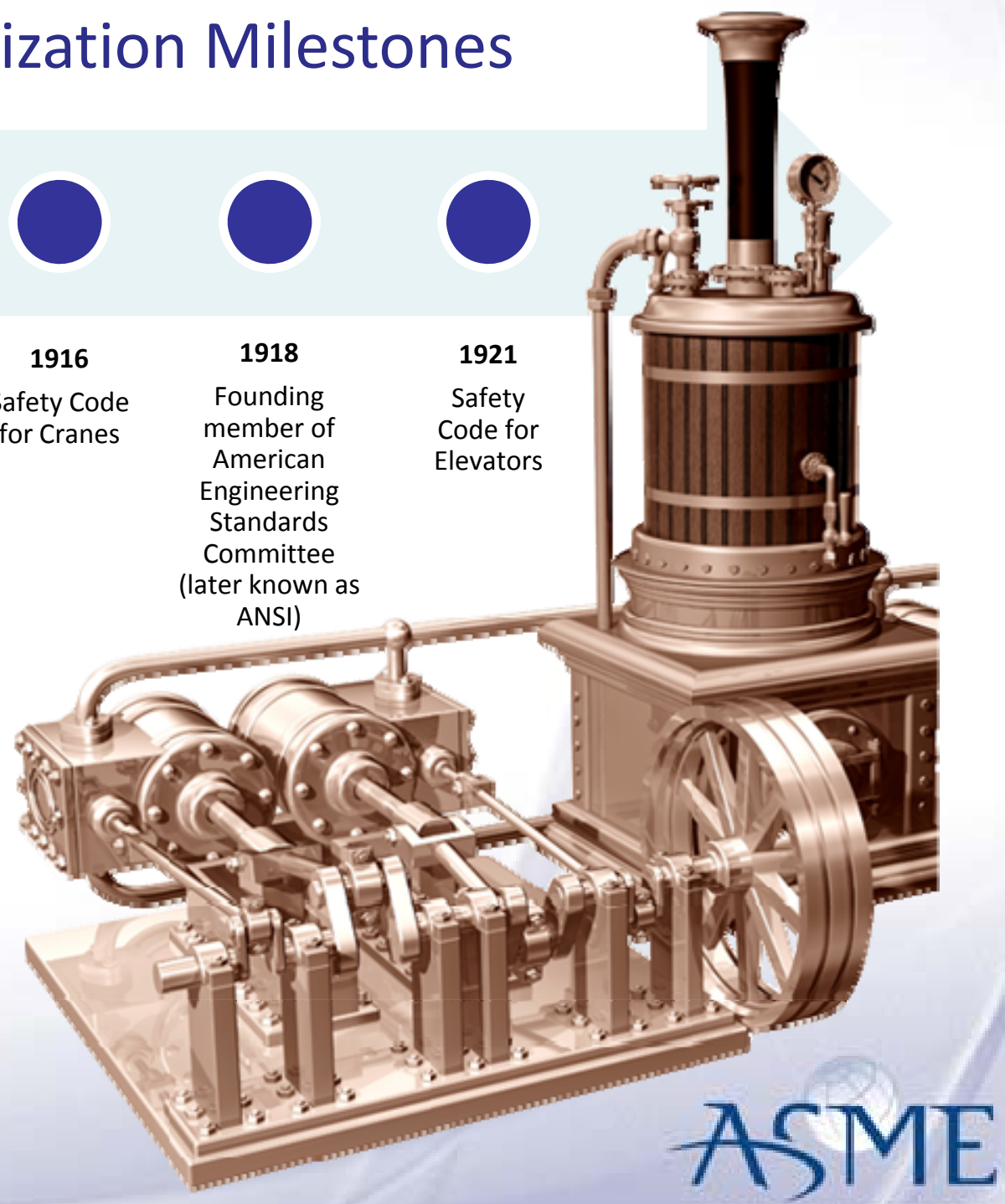


\section{Standards}

- Engineering Standards were and are developed to improve public safety, allow for uniform consistency of products, and help ensure fair and free commerce and trade

- Standards have a wide impact on both engineers and the public, often in unseen and unappreciated ways.

- ASME S\&C has over one hundred years of experience developing standards 


\section{Key Factors}

Volunteer Participation is the key to committee operation and performance

ASME Codes \& Standards relies on industry, academia, and government agency supporting participation by knowledgeable experts

ASME Technical staff support is critical, they are the foundation

S\&C involvement in new technology areas is much early than previously 


\section{Enhancing Factory-Floor Level \\ Decision-making through Advanced Monitoring, Diagnostics, and Prognostics}

Brian A. Weiss, Project Leader

Prognostics, Health Management, and Control

Engineering Laboratory

National Institute of

Standards and Technology

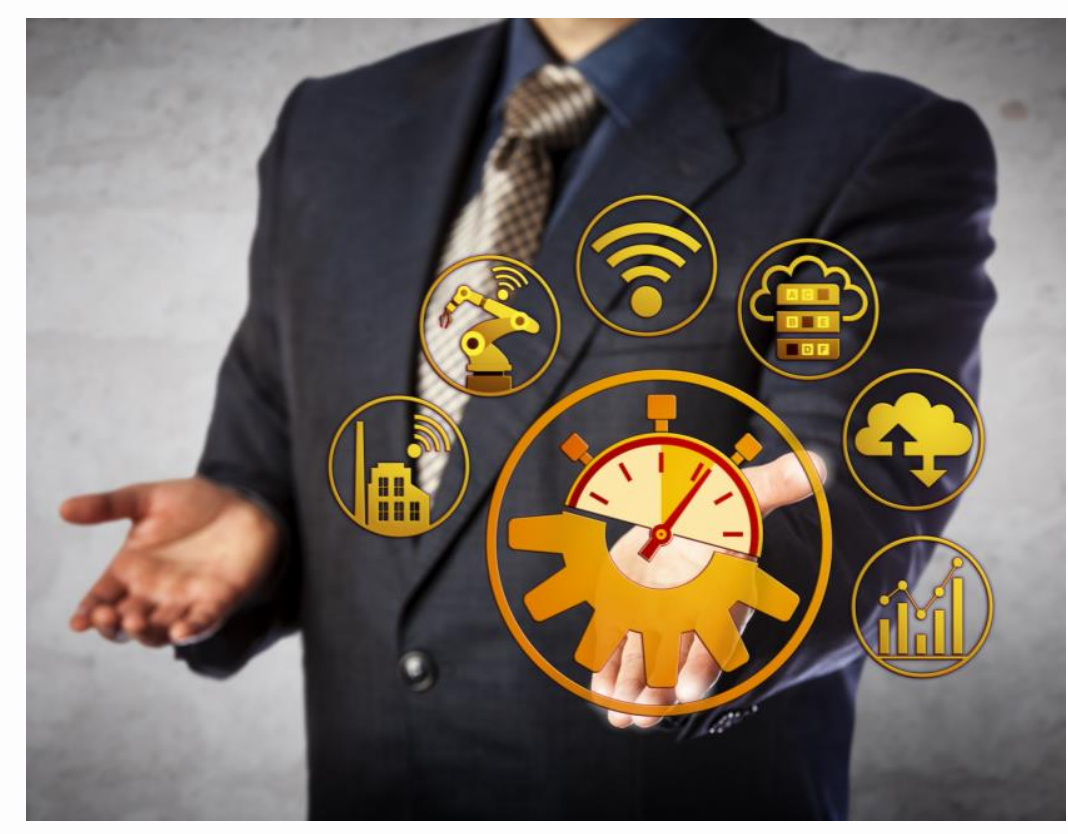




\section{Introducing the Effort}

- Manufacturing Challenges

- Maintenance Paradigms

- Focusing the Process

- Outlining the Scope

- Taking Action 
Complex interactions/relationships make it challenging to determine the specific influences on the health and degradation of equipment and processes

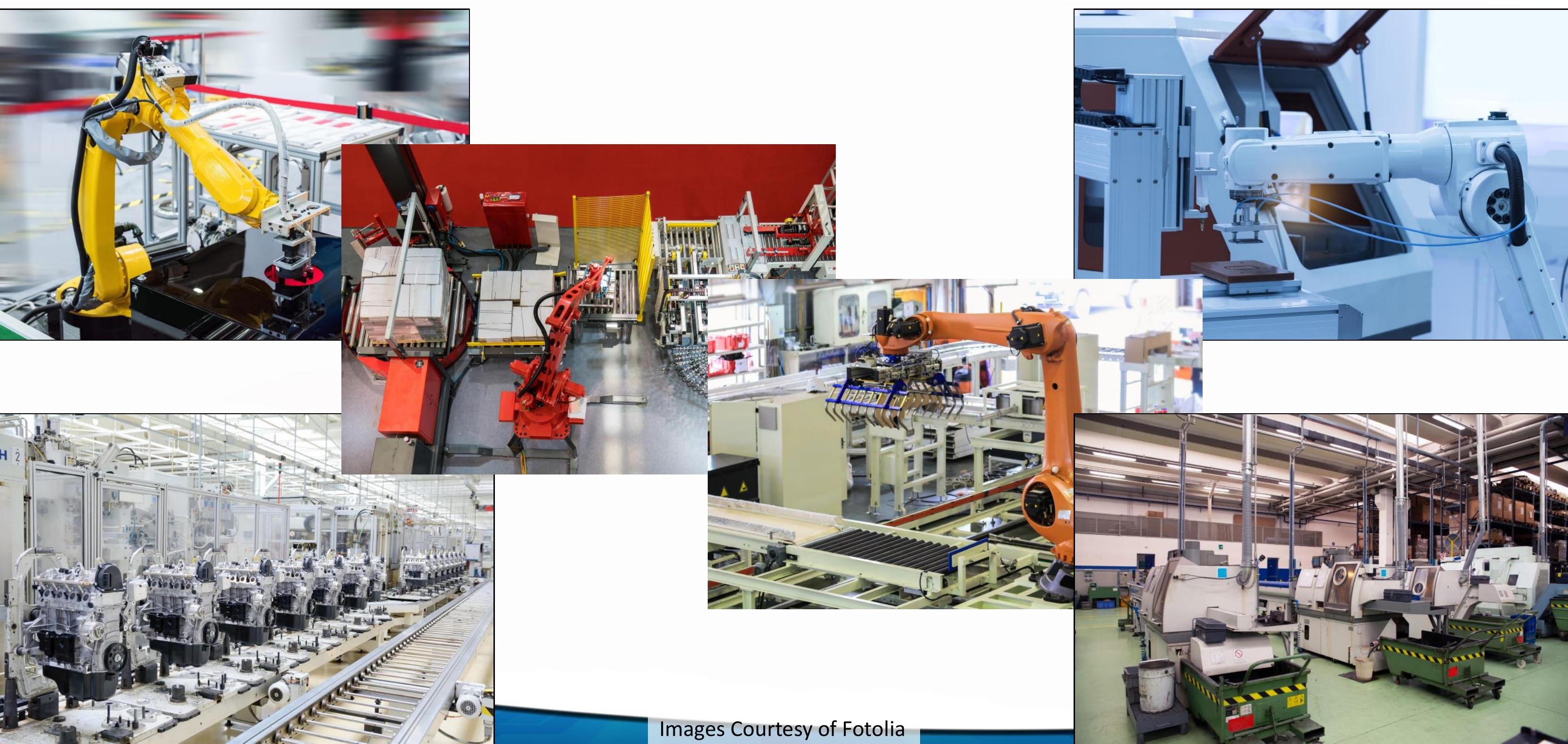


Increasing interest and ability to

leverage data and analysis to generate actionable intelligence about system interactions/ relationships for control

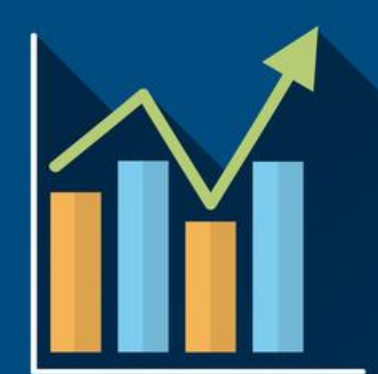

Transforming RAW DATA into useful information
FORECASTING:

predicting future

customer behaviour

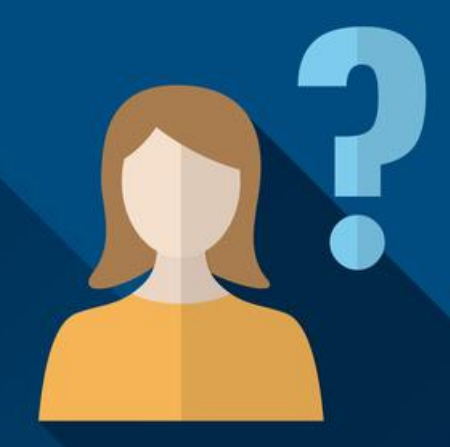

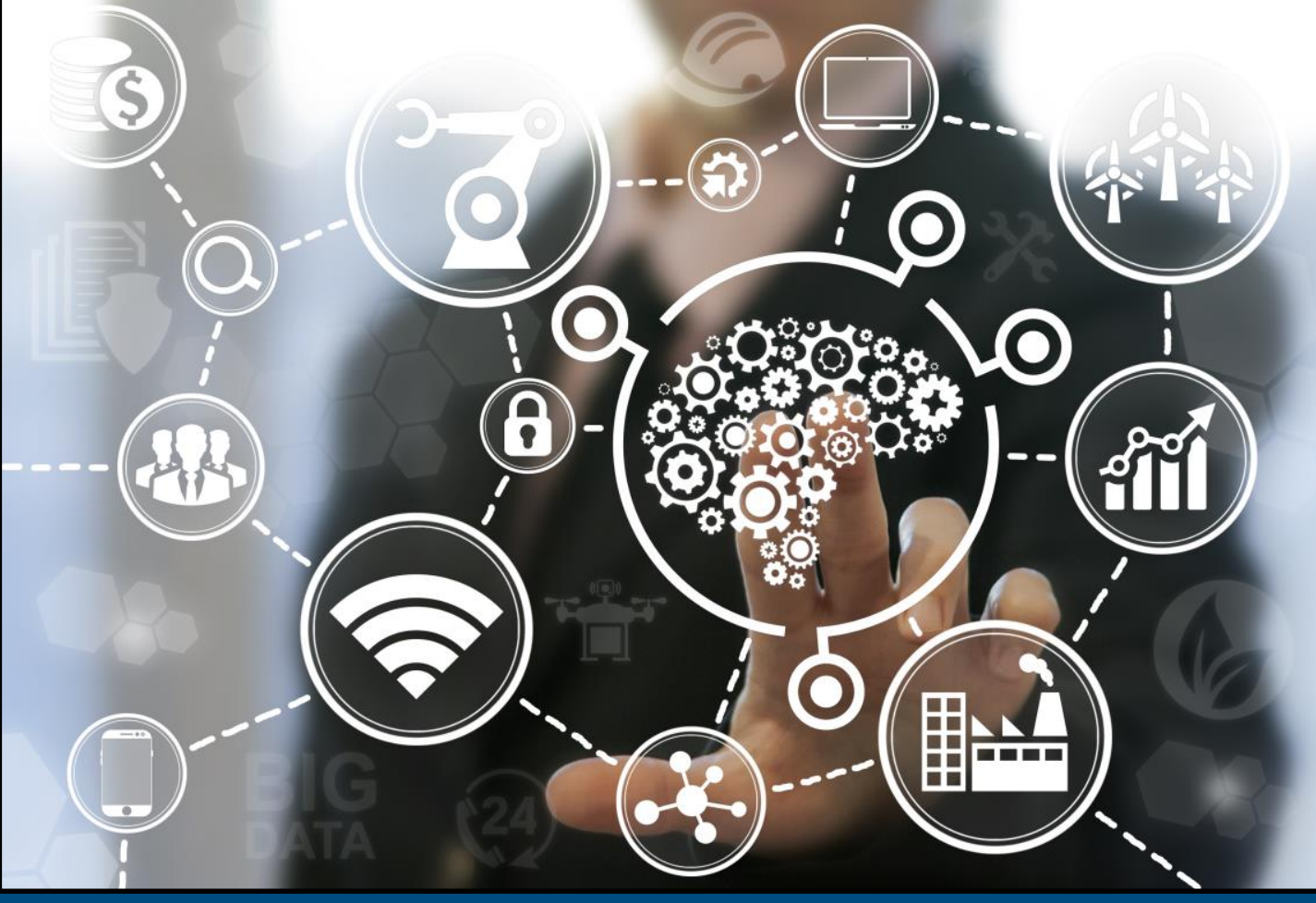

DATA MINING:

searching for hidden patterns

\section{DECISION-MAKING}

support

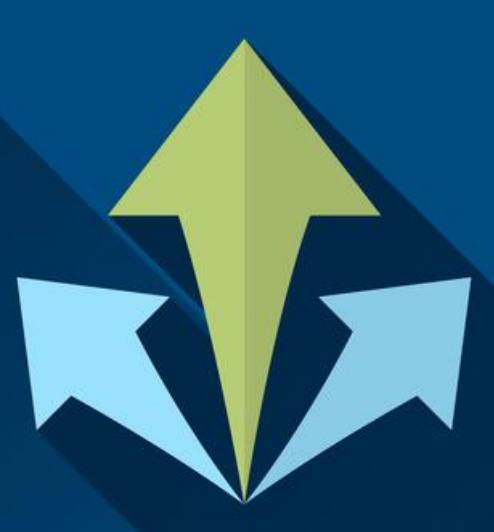

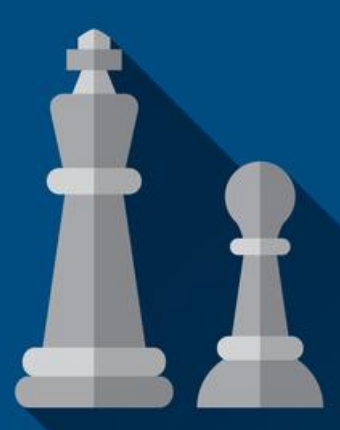

Improving STRATEGY 
No uniform process exists that guides sensing, monitoring, and control at all levels from the component to the system to the enterprise

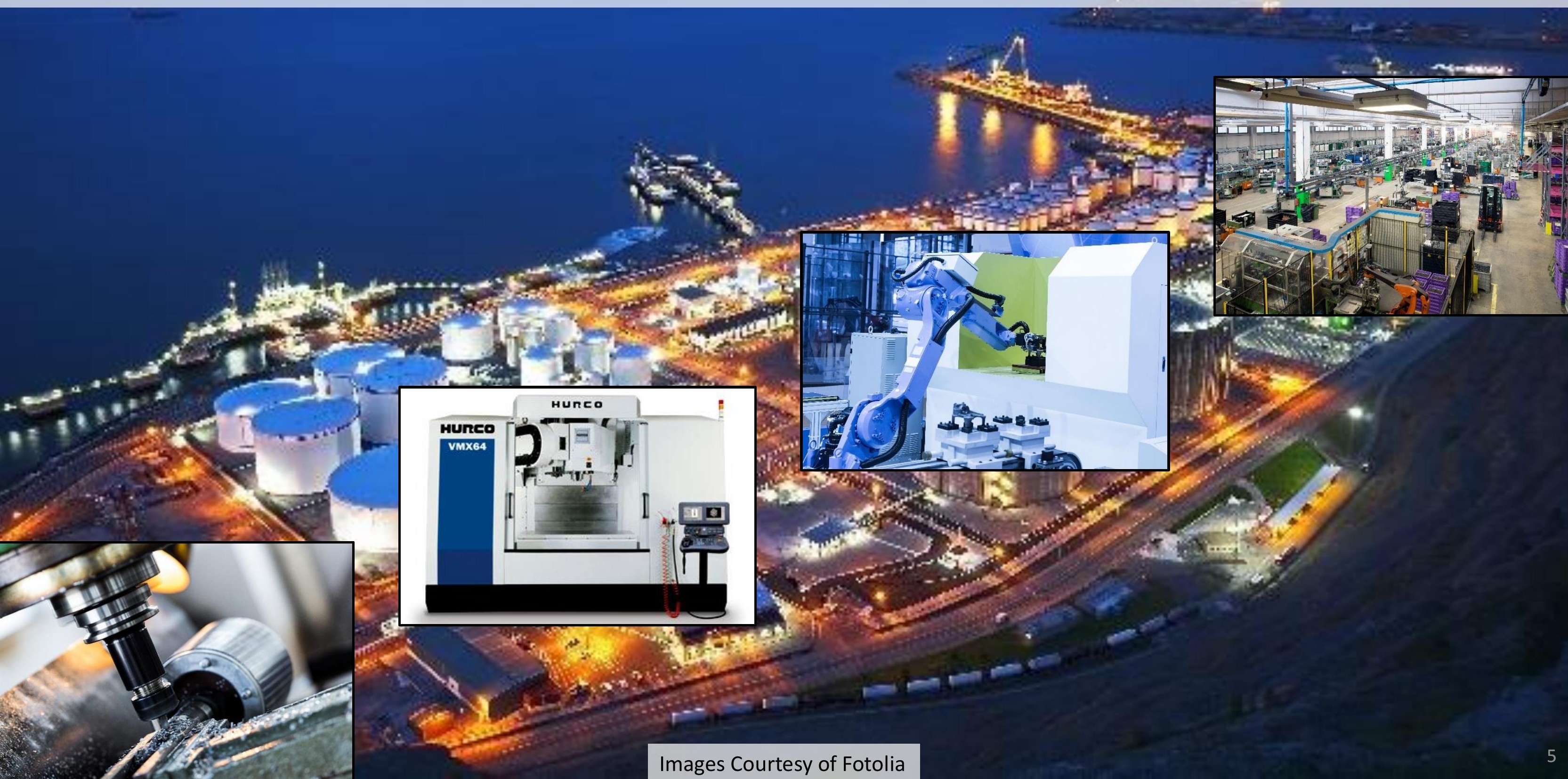




\section{Proprietary solutions exist, but they apply}

to systems from one vendor and are often expensive and inaccessible to many manufacturers.
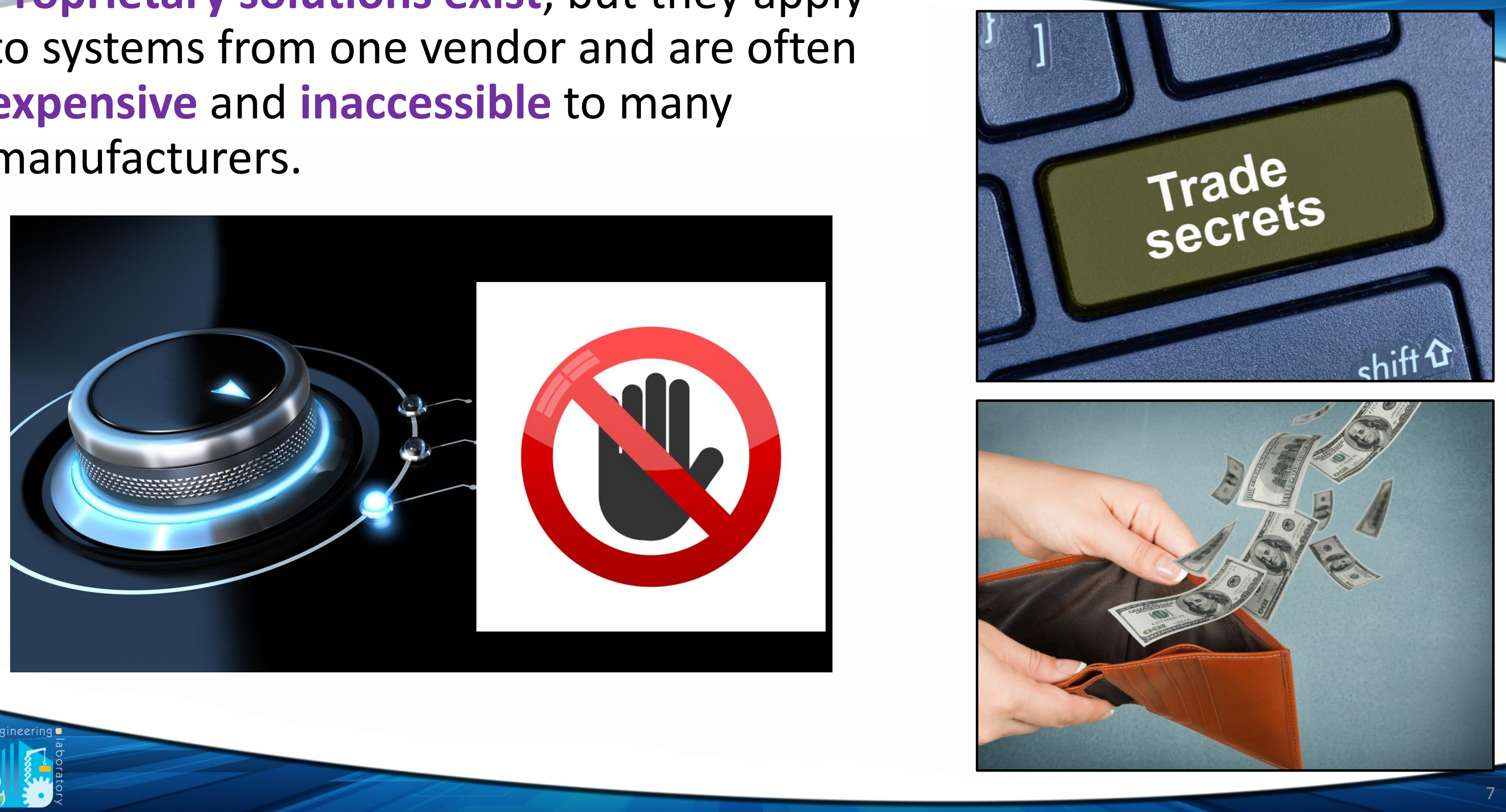


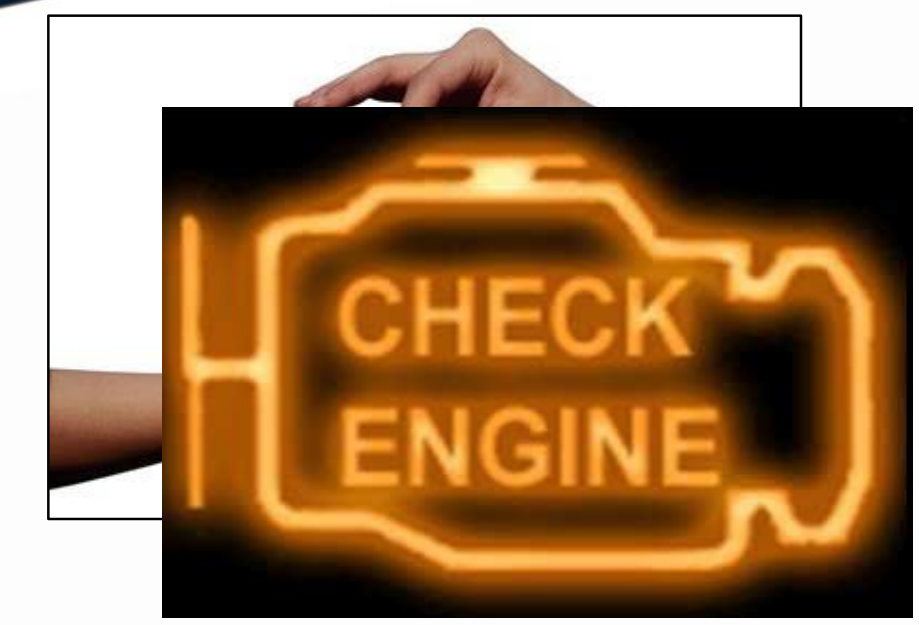

- Human error?, faulty sensing?

- Urgent issue or something to put on the 'to-do' list?
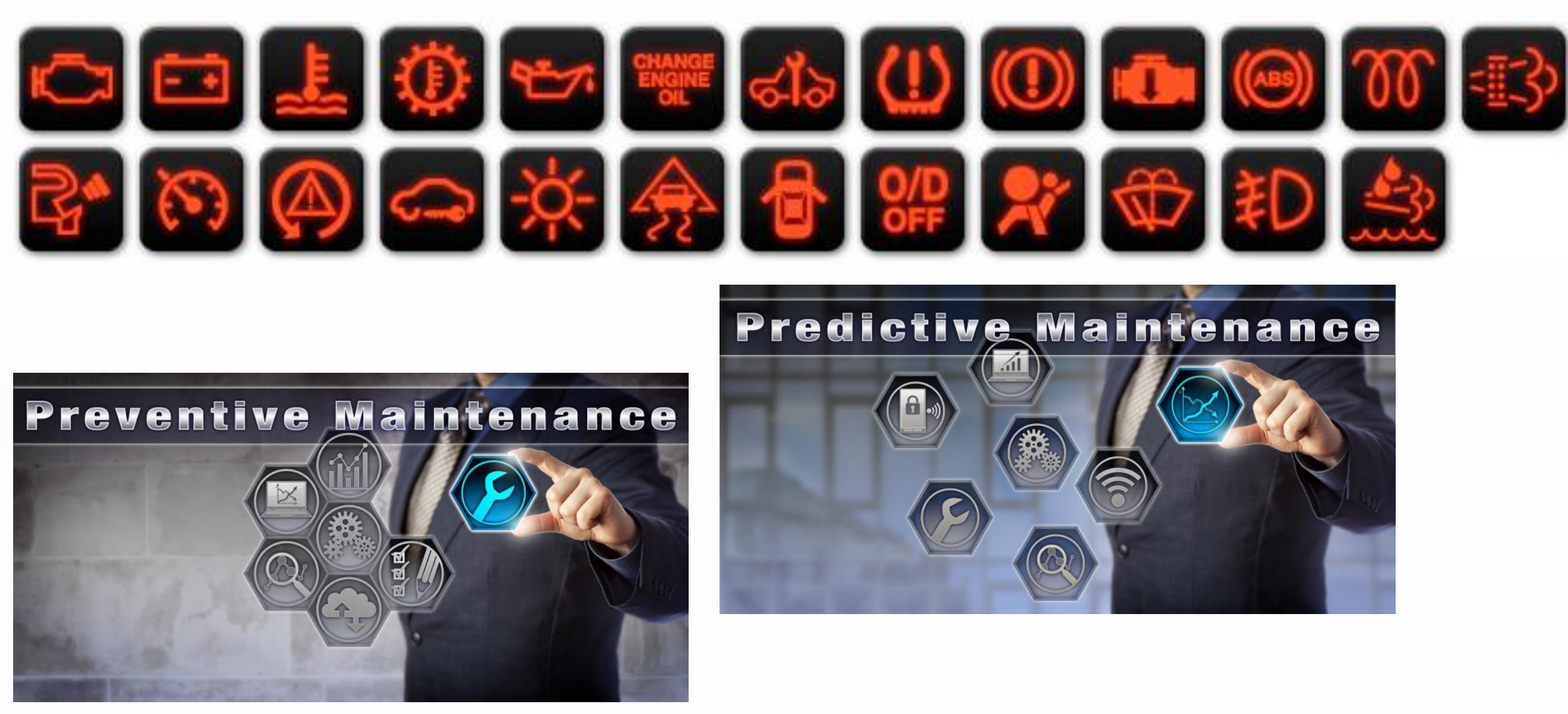


\section{Process v. Product}

- Range from very simple to very complex

- Few to many moving parts

- Few to many relationships among components, sub-processes, etc.

- Both consist of physical components that work together to produce one or more capabilities

- Physical components (and therefore, functional capabilities) will degrade over time

- Maintenance may or may not be required throughout its life






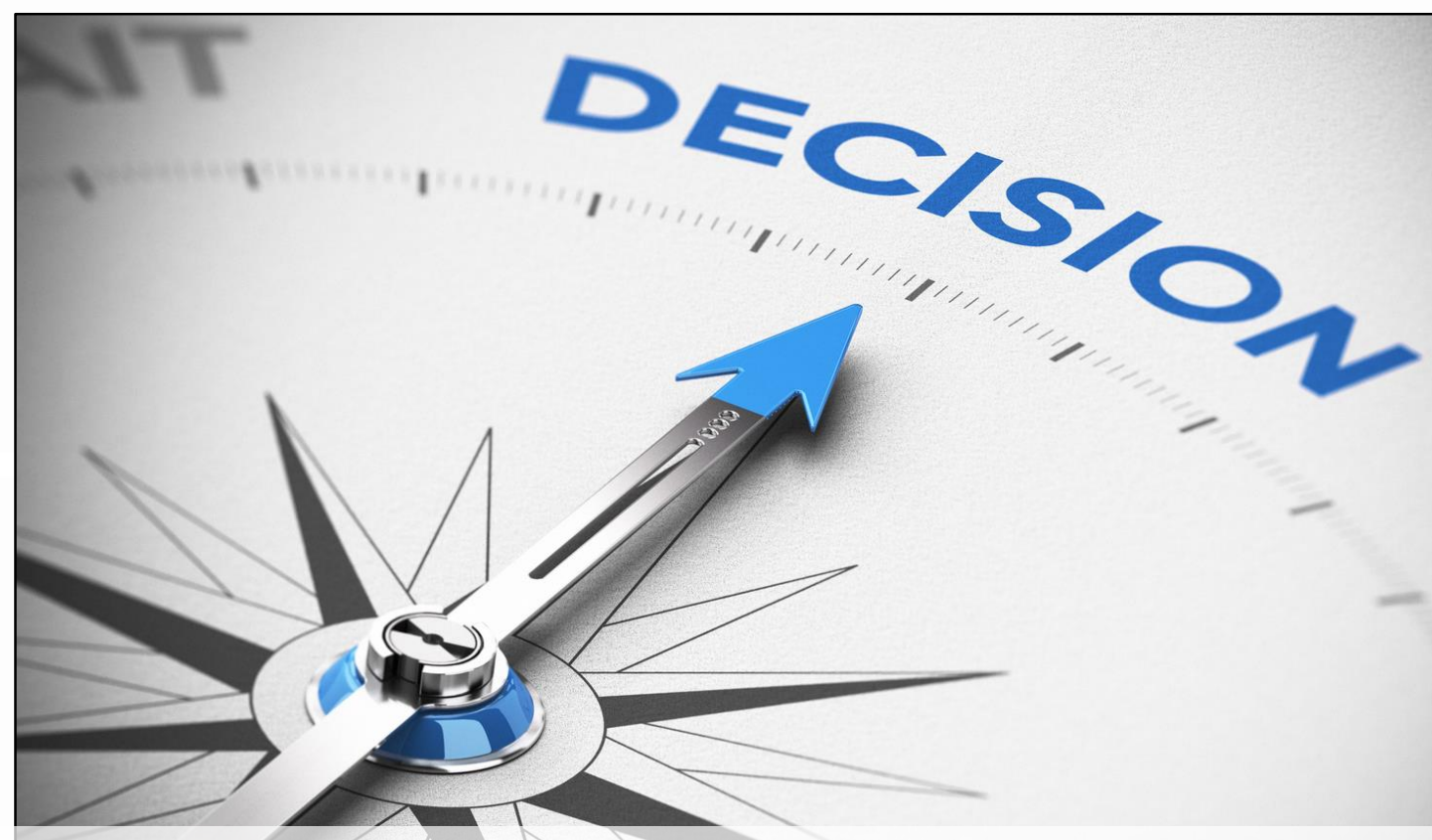

EXPECTED IMPACT: Improved decision-making support and automation with a focus on vendor-neutral approaches and plug-and-play solutions 
PHM Manufacturing Process Metrics and Techniques
PHM Performance

Assessment
PHM Infrastructure Hardware, Software, and System Integration

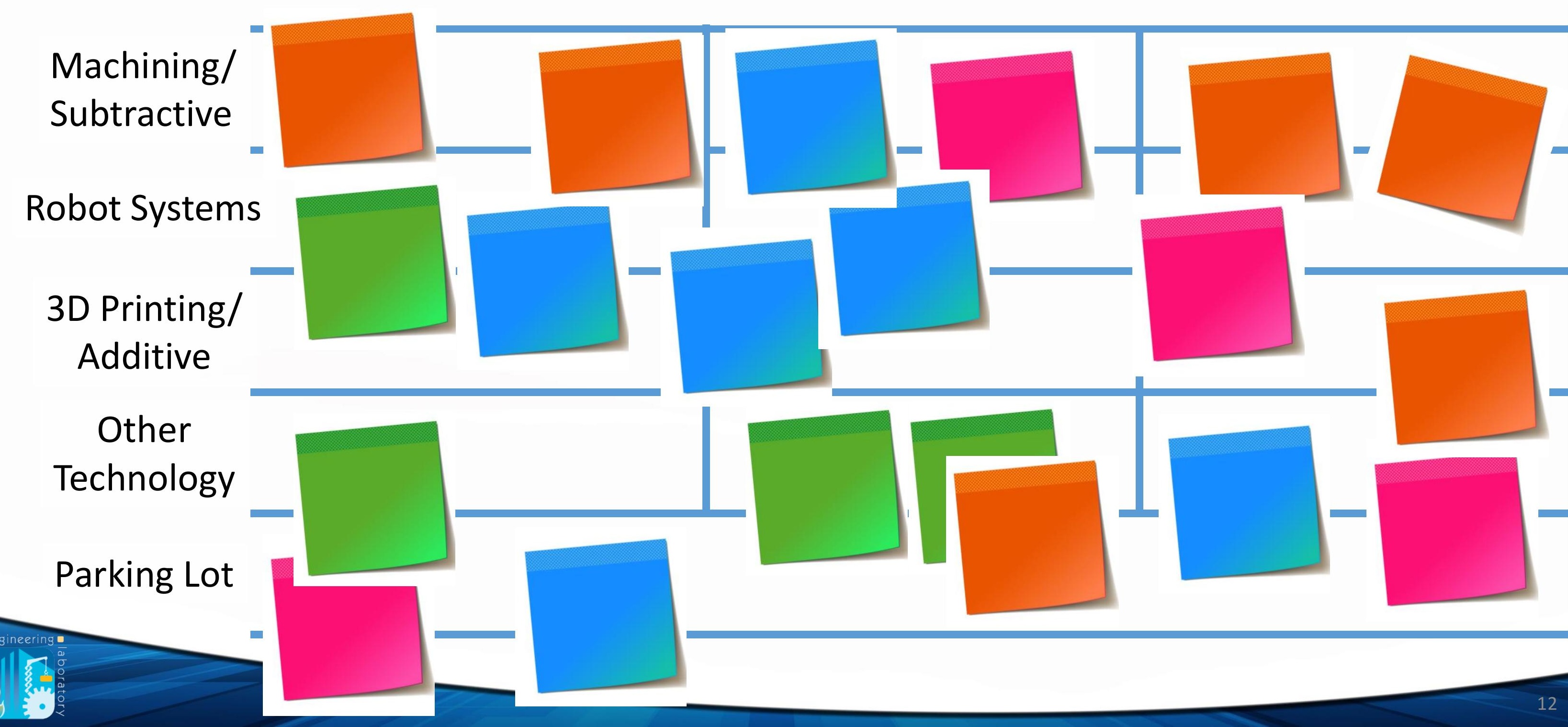




\section{What Now...}

- Listen to the remaining presentations

- Engage and ask questions

- Contribute during brainstorming

- Think critically, challenge constructively

- This workshop is just the beginning...
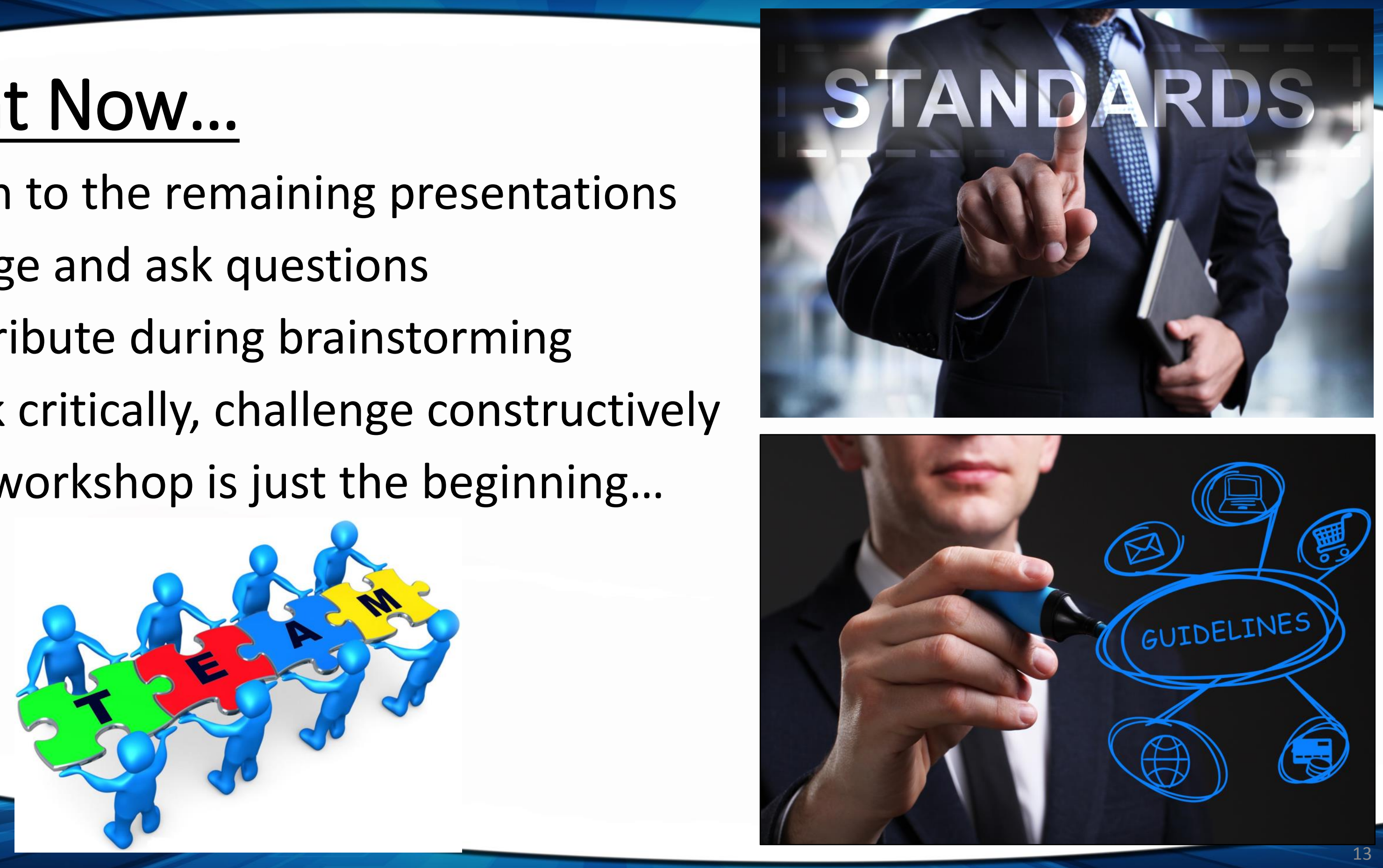
Brian A. Weiss Intelligent Systems Division brian.weiss@nist.gov (301) 975-4373

\section{NIST}

100 Bureau Drive, MS 8230 Gaithersburg, MD 20899

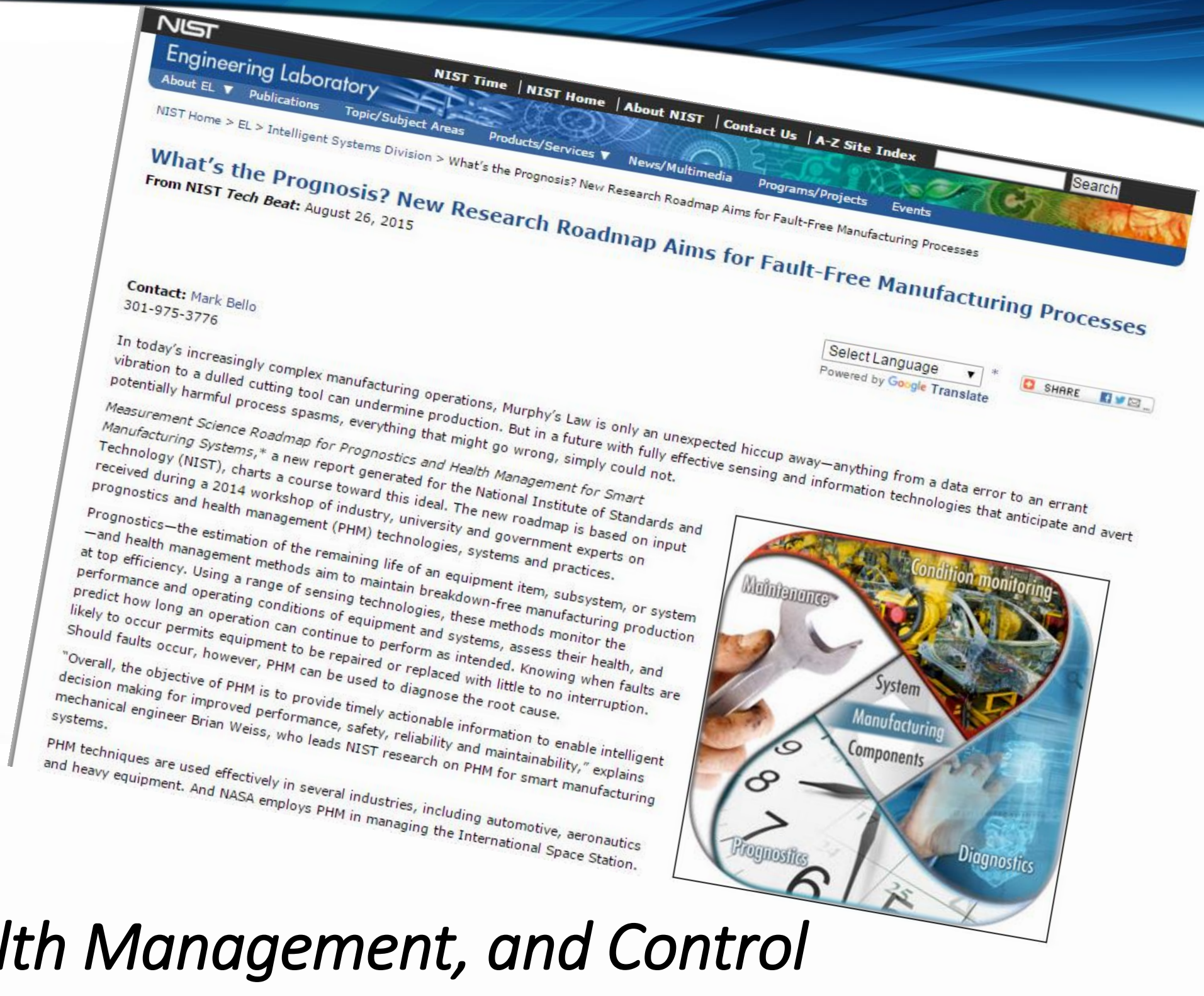

Prognostics, Health Management, and Control

www.nist.gov/el/isd/ks/phmc.cfm 


\title{
Framework for an intelligent knowledge- based manufacturing diagnosis system
}

\author{
Presenter: Michael P. Brundage mpb1@nist.gov
}




\section{Outline}

- Goals/Barriers

- Learning from the Medical Industry

- Framework

- How to Tag the Data

- Demo

- Conclusions

- Future Work 


\section{Maintenance Diagnosis Framework}

Goals

- Create a manufacturing knowledge-based system for diagnostics

- Learn from previous maintenance issues to make better/more efficient decisions

- Formalize root cause analysis procedures for maintenance issues 


\section{Maintenance Diagnosis Framework}

\section{Barriers}

- No standard representation of artifacts for root cause analysis

- Terminology is not standardized

- Difficult to share information across industries, factories, lines, and employees

- Root Cause Analysis is often Ad-hoc

Standard Data Format 


\section{Symptoms + Descriptions}

Your sybhptom list

(add more symptoms to improve the results)

\section{Cough}

$\mathbf{x}$ remove

A quick burst of air from the lungs usually in an attempt by the body to clear out mucus (i.e. "phlegm") or something blocking the airways

Related: Fever? Nasal congestion? Sore throat? Shortness of breath?

+ Enter a symptom Find

Related Symptoms
Occurrence

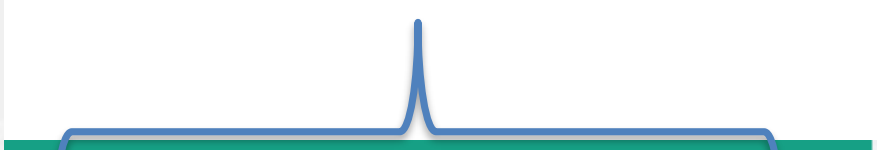

Thinking about...

Common cold $(41 \%)$

Chronic obstructive pulmonary disease (COPD) (14\%)

Asthma (11\%)

Otitis media (8\%)

Pneumonia (6\%)

Chronic sinusitis (6\%)

Review my responses so far 


\section{Symptoms + Descriptions}

\section{Your sybleptom list}

(add more symptoms to improve the results)

\section{Cough}

$\mathbf{x}$ remove

A quick burst of air from the lungs usually in an attempt by the body to clear out mucus (i.e. "phlegm") or something blocking the airways

Related: Fever? Nasal congestion? Sore throat? Shortness of breath?

+ Fevea

Did you mean: Fever

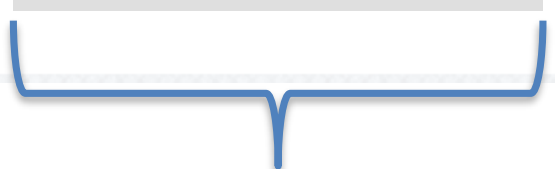

Natural Language Input + Auto Correct

\section{Find}

Nothing else to add?

\section{Continue >}

\section{Thinking about...}

Common cold (41\%)
Chronic obstructive
pulmonary disease
(COPD) (14\%)
Asthma (11\%)
Otitis media ( $8 \%$ )
Pneumonia (6\%)
Chronic sinusitis (6\%)
Review my responses so far


Multiple Symptoms

\section{Your sybintom list}

(add more symptoms to improve the results)

\section{Cough}

\section{Fever}

A high body temperature above $101^{\circ} \mathrm{F}$. Fever is commonly in response to infection, but may also be due to autoimmune diseases, drugs, or cancers

Related: Sore throat? Vomiting? Nasal congestion? Headache?

+ Enter a symptom Find

Nothing else to add?
Continue >

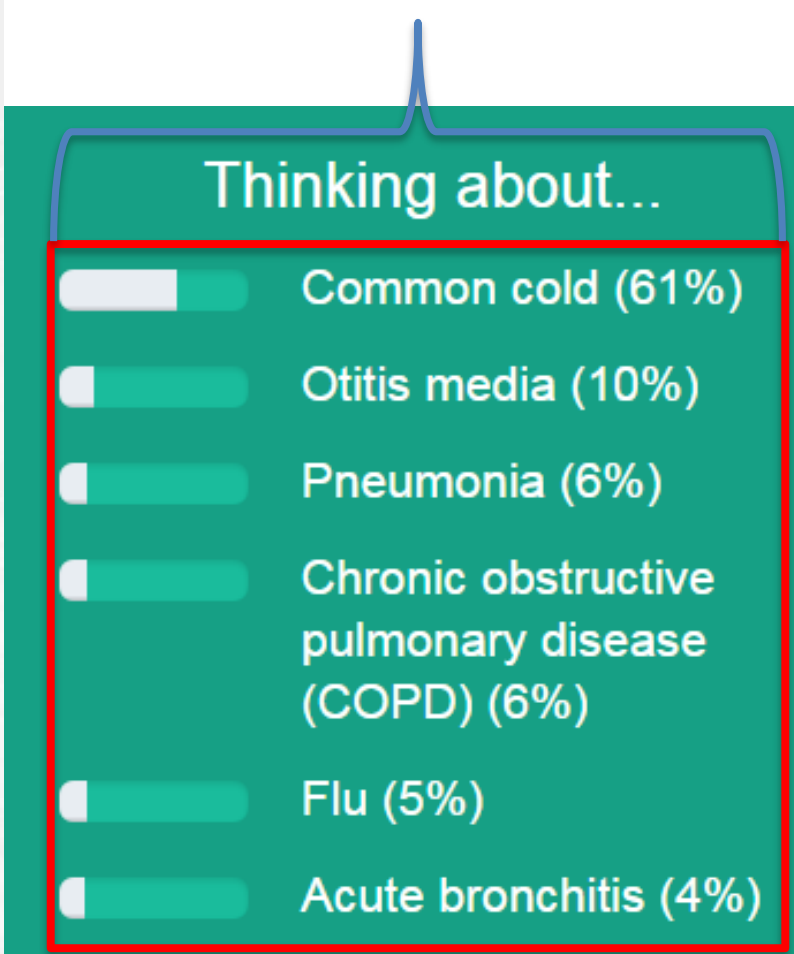

Review my responses so far 


\section{Medical -> Manufacturing}

- Research challenges for leaping from medical ->manufacturing

- Manufacturing Ontologies

- Data inconsistencies

- Finding what is the symptom and what is the resolution

- Not a lot of data

- Propriety information

- Tribal knowledge

- Human illnesses are very similar

- No ground truth to manufacturing

- No standardized terms in manufacturing

- No mandate like Electronic Health Records (EHR) in manufacturing

- Need to be ready for digitalization 


\section{Framework}

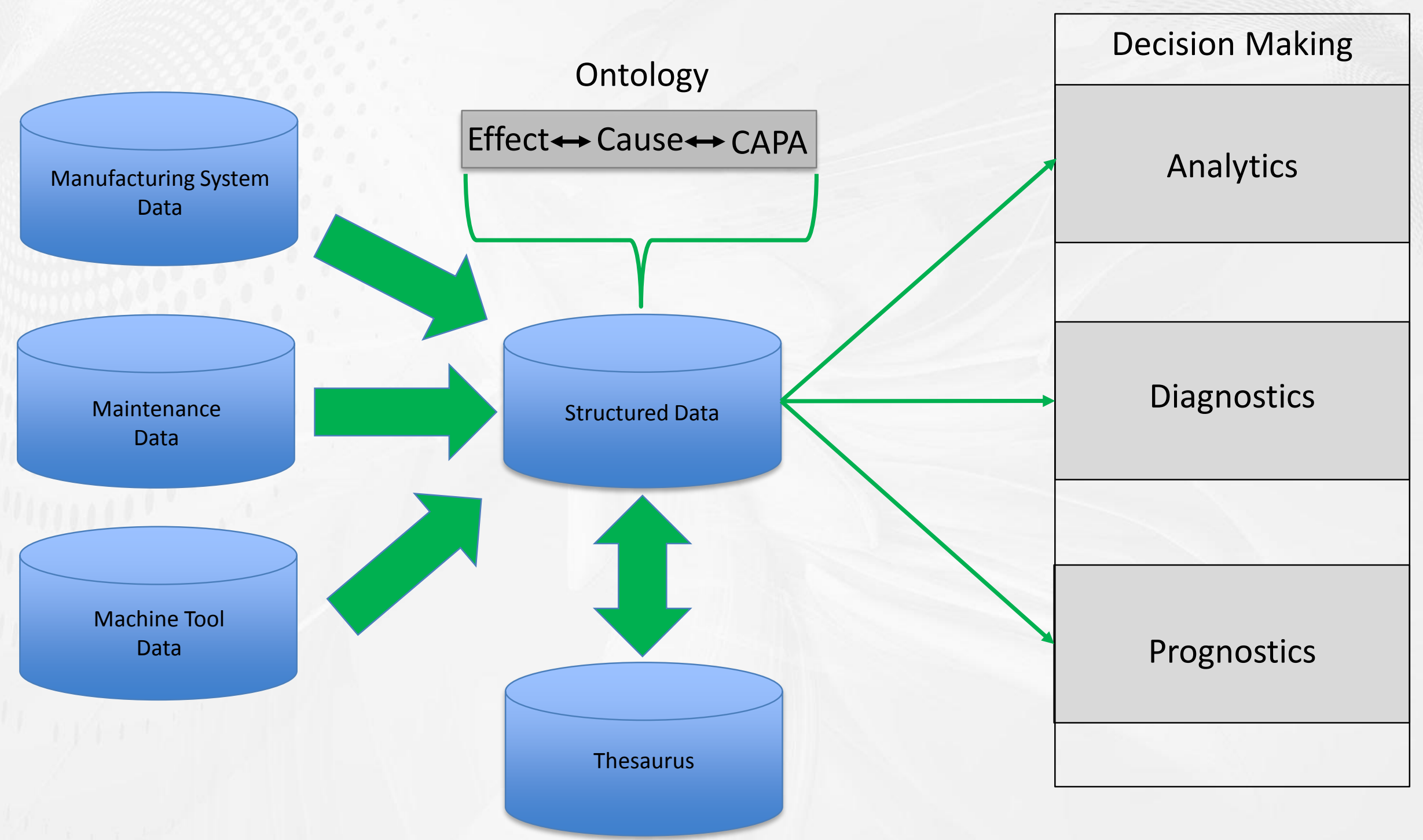




\section{Initial Framework}

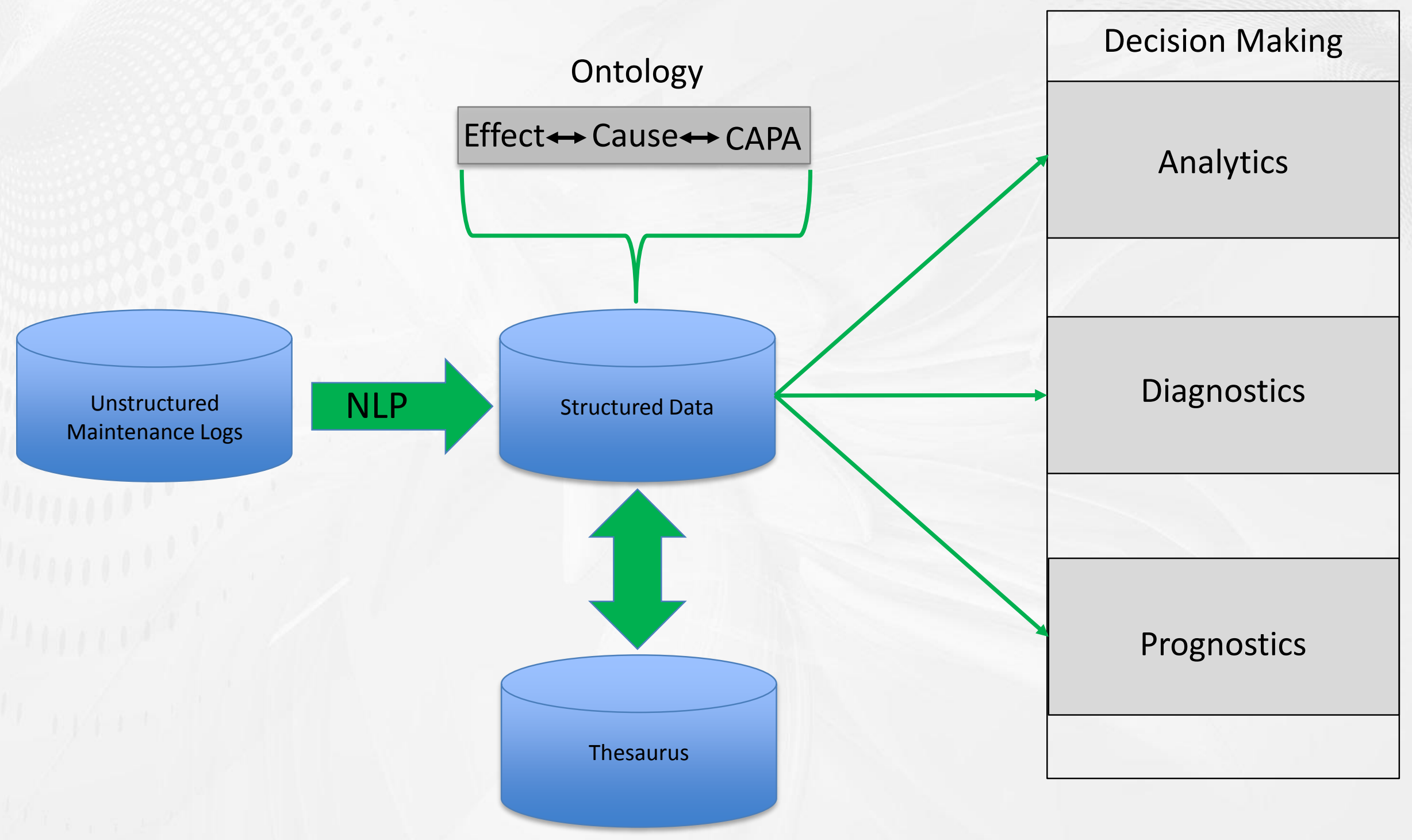




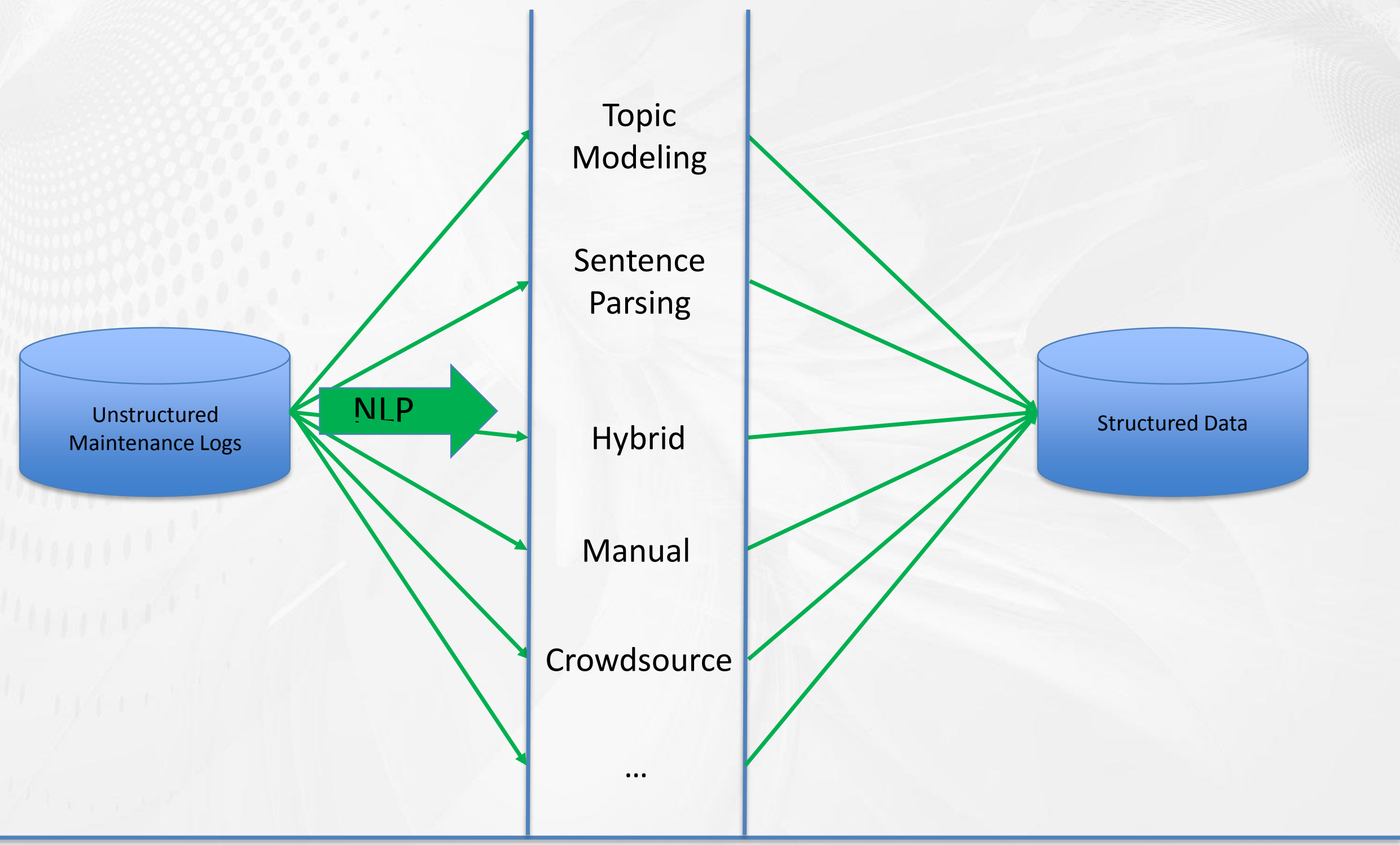




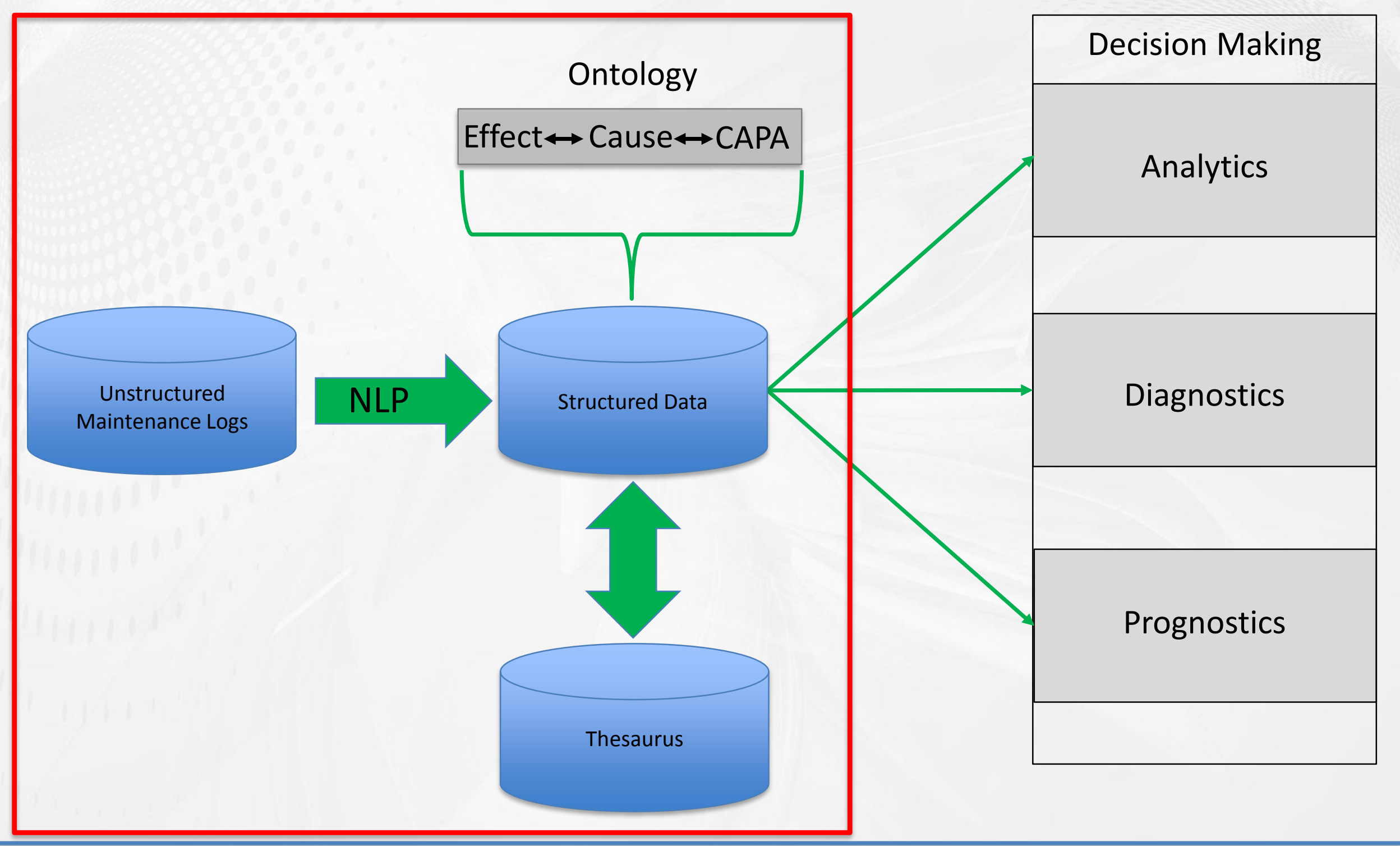




\begin{tabular}{|c|c|}
\hline Description & Resolution \\
\hline Replace Battery Fault & Replaced Battery \\
\hline Power Supply Alarm & $\mathrm{X}$ Axis Over travelled limit switch \\
\hline Chip Conveyor Jam & Cleared by hand crank \\
\hline Chip Conveyor INOP & Cleared large nest of chips \\
\hline Side A Turret Has Chips & Removed and cleaned \\
\hline Hydraulic Leak & Replaced ruptured hydraulic leak side B \\
\hline Exit Conveyor Jam & Replaced broken section of belt \\
\hline Chip Conveyor Jammed & Hand cranked to free minor jam \\
\hline Side B Hydraulic leak & Hydraulic return line replaced \\
\hline Side A Turret Will Not Lock & Fixed \\
\hline Side A Turret Leaking Coolant & Broken Coolant Line Fixed \\
\hline Chips in Side A Turret & Turret removed, cleaned, reinstalled, and aligned \\
\hline Conveyor Jam & Hand cranked to free minor jam \\
\hline Drive Faults & Replaced LT module on Spindle \#3 \\
\hline Hydraulic Leak & Replaced hydraulic hose/base drained with new coolant \\
\hline Hydraulic Faults & P/P Will not build pressure \\
\hline Side B Turret Won't Lock & Spindle Collision with Turret \\
\hline Side B Turret Not Locking & Replaced proximity switch \\
\hline Chip Conveyor Jammed & Cleared by hand crank \\
\hline
\end{tabular}




\begin{tabular}{|c|c|}
\hline Description & Resolution \\
\hline Replace Battery Fault & Replaced Battery \\
\hline Power Supply Alarm & X Axis Over travelled limit switch \\
\hline Chip Conveyor Jam & Cleared by hand crank \\
\hline Chip Conveyor INOP & Cleared large nest of chips \\
\hline Side A Turret Has Chips & Removed and cleaned \\
\hline Hydraulic Leak & Replaced ruptured hydraulic leak side B \\
\hline Exit Conveyor Jam & Replaced broken section of belt \\
\hline Chip Conveyor Jammed & Hand cranked to free minor jam \\
\hline Side B Hydraulic leak & Hydraulic return line replaced \\
\hline Side A Turret Will Not Lock & Fixed \\
\hline Side A Turret Leaking Coolant & Broken Coolant Line Fixed \\
\hline Chips in Side A Turret & Turret removed, cleaned, reinstalled, and aligned \\
\hline Conveyor Jam & Hand cranked to free minor jam \\
\hline Drive Faults & Replaced LT module on Spindle \#3 \\
\hline Hydraulic Leak & Replaced hydraulic hose/base drained with new coolant \\
\hline Hydraulic Faults & P/P Will not build pressure \\
\hline Side B Turret Won't Lock & Spindle Collision with Turret \\
\hline Side B Turret Not Locking & Replaced proximity switch \\
\hline Chip Conveyor Jammed & Cleared by hand crank \\
\hline
\end{tabular}




$\begin{array}{cc}\text { Higher Level Concept } & \begin{array}{c}\text { Conveyor INOP } \\ \text { Preferred Label }\end{array} \\ \text { Alternative Label(s) } & \begin{array}{c}\text { Chip Conveyor } \\ \text { Jammed }\end{array} \\ & \begin{array}{c}\text { Chip Conveyor Jam, } \\ \text { Conveyor Jam, Chip } \\ \text { Conveyor INOP }\end{array} \\ \text { Description } & \begin{array}{c}\text { The chip conveyor has } \\ \text { chips jammed, which } \\ \text { renders the machine } \\ \text { inoperable until the } \\ \text { chips are cleared }\end{array}\end{array}$

\begin{tabular}{|c|c|}
\hline Higher Level Concept & Instance \\
\hline Preferred Label & $\begin{array}{c}\text { Conveyor INOP } \\
\text { Jammed }\end{array}$ \\
\hline
\end{tabular}

Alternative Label(s) Exit Conveyor Jam

Description

The exit conveyor has chips jammed, which renders the machine inoperable until the chips are cleared 


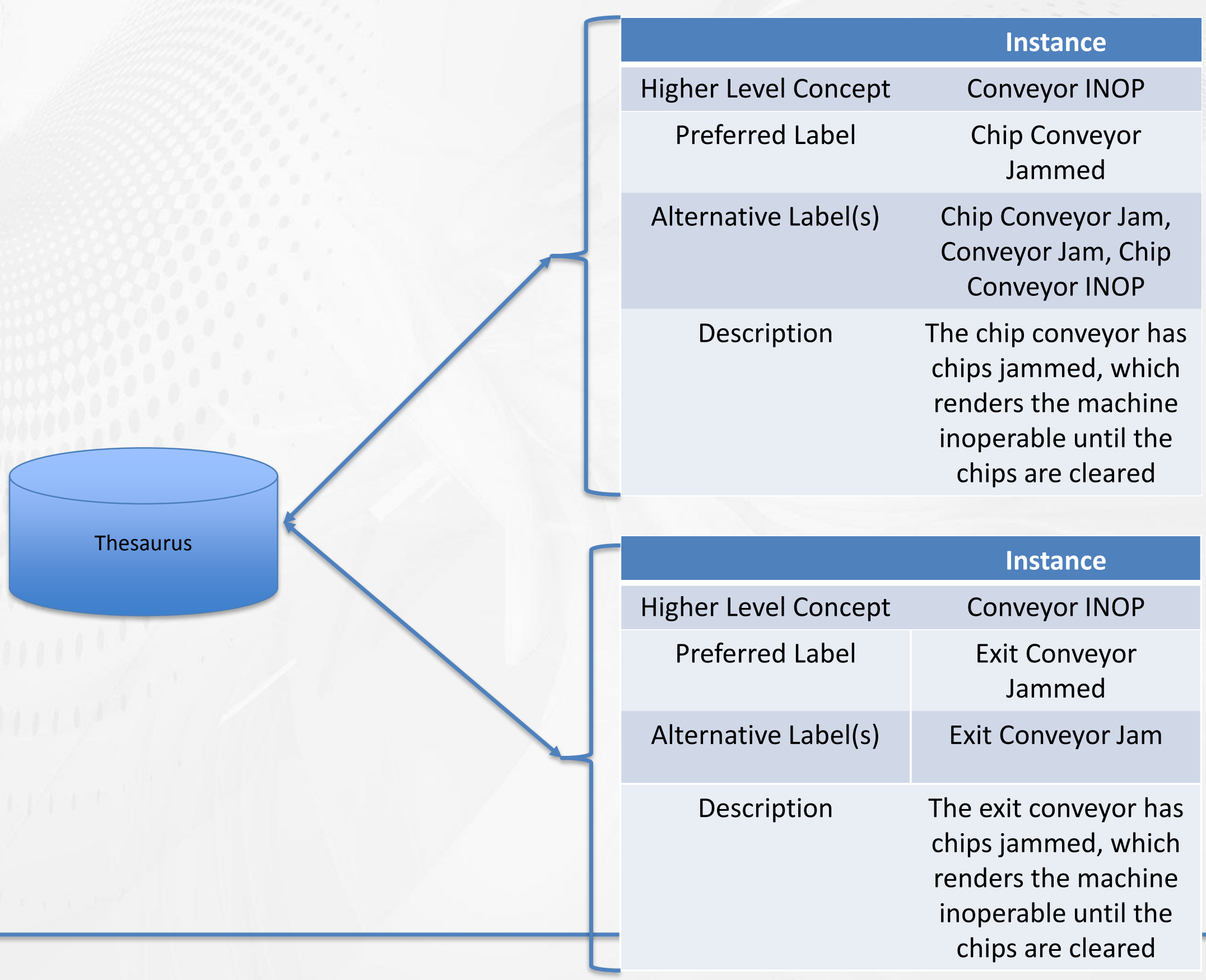




\begin{tabular}{|c|c|}
\hline Description & Resolution \\
\hline Replace Battery Fault & Replaced Battery \\
\hline Power Supply Alarm & X Axis Over travelled limit switch \\
\hline Chip Conveyor Jam & Cleared by hand crank \\
\hline Chip Conveyor INOP & Cleared large nest of chips \\
\hline Exit Conveyor Jam & Replaced broken section of belt \\
\hline Chip Conveyor Jammed & Hand cranked to free minor jam \\
\hline Conveyor Jam & Hand cranked to free minor jam \\
\hline Chip Conveyor Jammed & Cleared by hand crank \\
\hline Side A Turret Has Chips & Removed and cleaned \\
\hline Chips in Side A Turret & Turret removed, cleaned, reinstalled, and aligned \\
\hline Drive Faults & Replaced LT module on Spindle \#3 \\
\hline Hydraulic Leak & Replaced ruptured hydraulic leak side B \\
\hline Side B Hydraulic leak & Hydraulic return line replaced \\
\hline Hydraulic Leak & Replaced hydraulic hose/base drained with new coolant \\
\hline Hydraulic Faults & P/P Will not build pressure \\
\hline Side A Turret Leaking Coolant & Broken Coolant Line Fixed \\
\hline Side A Turret Will Not Lock & Fixed \\
\hline Side B Turret Won't Lock & Spindle Collision with Turret \\
\hline Side B Turret Not Locking & Replaced proximity switch \\
\hline
\end{tabular}




\begin{tabular}{|c|c|}
\hline Description & Resolution \\
\hline Replace Battery Fault & Replaced Battery \\
\hline Power Supply Alarm & X Axis Over travelled limit switch \\
\hline Chip Conveyor Jammed & Cleared by hand crank \\
\hline Chip Conveyor Jammed & Cleared large nest of chips \\
\hline Chip Conveyor Jammed & Replaced broken section of belt \\
\hline Chip Conveyor Jammed & Hand cranked to free minor jam \\
\hline Chip Conveyor Jammed & Hand cranked to free minor jam \\
\hline Exit Conveyor Jammed & Cleared by hand crank \\
\hline Side A Turret Has Chips & Removed and cleaned \\
\hline Chips in Side A Turret & Turret removed, cleaned, reinstalled, and aligned \\
\hline Drive Faults & Replaced LT module on Spindle \#3 \\
\hline Hydraulic Leak & Replaced ruptured hydraulic leak side B \\
\hline Side B Hydraulic leak & Hydraulic return line replaced \\
\hline Hydraulic Leak & Replaced hydraulic hose/base drained with new coolant \\
\hline Hydraulic Faults & P/P Will not build pressure \\
\hline Side A Turret Leaking Coolant & Broken Coolant Line Fixed \\
\hline Side A Turret Will Not Lock & Fixed \\
\hline Side B Turret Won't Lock & Spindle Collision with Turret \\
\hline Side B Turret Not Locking & Replaced proximity switch \\
\hline
\end{tabular}




\section{Analytics Examples: Effects}

\section{Raw Data}

\section{Effect}

Accumulator check requested Vogel lube faults

Base cleaning requested

Table index O/T faults

lemca will not load in Auto

Chip conveyor INOP

Chip conveyor jammed

St\#2 drill detector INOP

Table drifting at $1 / 2$ table setting

Motor thermal overload fault -Hydraulic

Machine will not run in Auto

Part not loading into collet

St\#8 Hyd flange not repeating

Power pack leak

Table index $\mathrm{O} / \mathrm{T}$ at $1 / 2$ table -Turning off Hydraulics

\begin{tabular}{|c|c|c|}
$\begin{array}{c}\text { Average of } \\
\text { Time to } \\
\text { Complete } \\
\text { (hrs) }\end{array}$ & $\begin{array}{c}\text { Number of } \\
\text { Instances }\end{array}$ & $\begin{array}{c}\text { Total Time to } \\
\text { Complete (hrs) }\end{array}$ \\
\hline 1.4590 & 14 & 16.05 \\
\hline 1.5875 & 7 & 6.35 \\
\hline 13.575 & 4 & 27.15 \\
\hline 2.7 & 3 & 2.7 \\
\hline 313.2 & 3 & 939.6 \\
\hline 1.075 & 3 & 2.15 \\
\hline 3.725 & 3 & 7.45 \\
\hline 0.15 & 2 & 0.15 \\
\hline 47 & 2 & 94 \\
\hline 24 & 2 & 24 \\
\hline & 2 & \\
\hline 0.15 & 2 & \\
\hline & 2 & \\
\hline & & \\
\hline & 2 & \\
\hline
\end{tabular}

\begin{tabular}{|c|c|c|c|}
\hline Effect & $\begin{array}{l}\text { Average of } \\
\text { Time to } \\
\text { Complete } \\
\text { (hrs) }\end{array}$ & $\begin{array}{l}\text { Number of } \\
\text { Instances }\end{array}$ & $\begin{array}{l}\text { Total Time to } \\
\text { Complete (hrs) }\end{array}$ \\
\hline Hydraulic Leak & 40.8775 & 39 & 817.55 \\
\hline Accumulator check requested & 1.690 & 26 & 35.5 \\
\hline Coolant Leak & 122.47 & 17 & 1347.2 \\
\hline Bearings check & 16.835 & 16 & 168.35 \\
\hline Chip conveyor INOP & 5.8 & 15 & 63.8 \\
\hline Broken screw & 3.8722 & 14 & 34.85 \\
\hline Table index faults & 24.08 & 13 & 120.4 \\
\hline Brush unit stuck forward & 4.744 & 10 & 42.7 \\
\hline Vogel lube fault & 2.27 & 9 & 11.35 \\
\hline Coolant Pressure Low & 3.26 & 9 & 16.3 \\
\hline Oil leak & 39.2375 & 8 & 156.95 \\
\hline Base cleaning requested & 13.575 & 4 & 27.15 \\
\hline lemca will not load in Auto & 235.9 & 4 & 943,6 \\
\hline Bearings noise & 79 & 4 & 79 \\
\hline Inverter failing to return & 0.3 & 4 & 0.3 \\
\hline \multicolumn{3}{|c|}{ Total Time to Complete (hrs) } & l \\
\hline Raw & \multicolumn{2}{|c|}{ Clean } & I \\
\hline 16.05 & \multicolumn{2}{|c|}{35.5} & \\
\hline
\end{tabular}

\section{Clean Data}

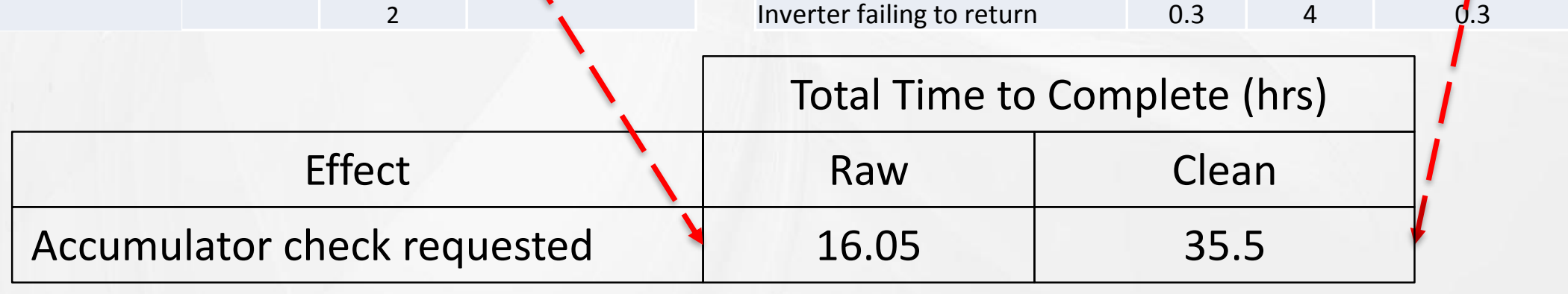




\section{Raw Data}

Hyd leak at Bar stop pre load position

Major Hydraulic leak at Bottom XD head

Hydraulic leak at cutoff unit

Hyd leak at St\#2 chip breaker valve

Hyd leak reported

Hydraulic leak at bar loader -Rubber seal on vacuum

HP Hydraulic line ruptured

Multiple leaks at lemca - 25 Gallons in 48 hours

Hydraulic return line leak

Hyd leak from behind collet \#6

Hydraulic leak turret 2

Hydraulic leak actuator or horseshoe

Hydraulic leak at chip breaker valve (? Valve station)

Hydraulic leaks -from collets??

Leak at High Pressure pump

Hyd leak St\#2 valve

St\#6 valve leaking hydraulic

Hydraulic leak

Hyd leak at locking pin assy

lemca hydraulic pump leaking -Full tank per day

Hydraulic leak on Side A

Hydraulic leak from power pack

St\#8 valve leaking Hyd fluid

Hyd leaks -C/O unit, St\#11 Valve, Collet \#10 (Internal)

Hydr pump? / Power pack leak / CNCs shuddering Hydraulic leak at inverter st\#8

Hyraulic leak at St\#4

Hyd leaks at valve below \#7 / Lid leaks at loader

St\#8 valve spraying hydraulic fluid

Hyd leak at lemca pumps tank

Hyd leak from dressing unit

Hydraulic leak at Cutoff valve

Hydraulic leak at power pack -per PM tix

Hydraulic leak found by Doug -3.1 quill

Hydraulic Leak reported -One tank per day Hydraulics leaking from dressing unit Major hydraulic leak

Major Hydraulic leak at rotator -Rotator rack is broken

Hydraulic oil getting into Vogel waste oil

Clean Data

Hydraulic Leak 


\section{How to Tag Data}

\section{Description}

Hydraulic Leak at cutoff unit

Item

Action

Problem

\section{$\underline{\text { Resolution }}$}

Missing fitting replaced

Action

Item

Solution 


\section{Description}

Hydraulic Leak at cutoff unit

hydraulic,

cutoff_unit, fitting

Item

Action

Problem

\section{$\underline{\text { Resolution }}$}

Missing fitting replaced

Action

$\underline{\text { Item }}$

Solution 


\section{Description}

Hydraulic Leak at cutoff unit

hydraulic,

cutoff_unit, fitting

Item

Action

Problem

\section{$\underline{\text { Resolution }}$}

Missing fitting replaced

Action

$\underline{\text { Item }}$

Solution 


\section{Description}

Hydraulic Leak at cutoff unit

hydraulic,

cutoff_unit, fitting

Item

Action

Problem

\section{$\underline{\text { Resolution }}$}

Missing fitting replaced

replace

Action

$\underline{\text { Item }}$

Solution 


\section{Description}

Hydraulic Leak at cutoff unit

hydraulic,

cutoff_unit, fitting

Item

Action

Problem

\section{$\underline{\text { Resolution }}$}

Missing fitting replaced

replace

fitting

Action

$\underline{\text { Item }}$

Solution 


\section{Original Data}

\section{Description}

\section{Resolution}

Hydraulic Leak at cutoff unit

Missing fitting replaced

\section{$\underline{\text { Tagged Data }}$}

hydraulic, cutoff_unit, fitting

$\underline{\text { Item }}$

Action replace

fitting

Action 


\section{Data Tagging Initial Results}

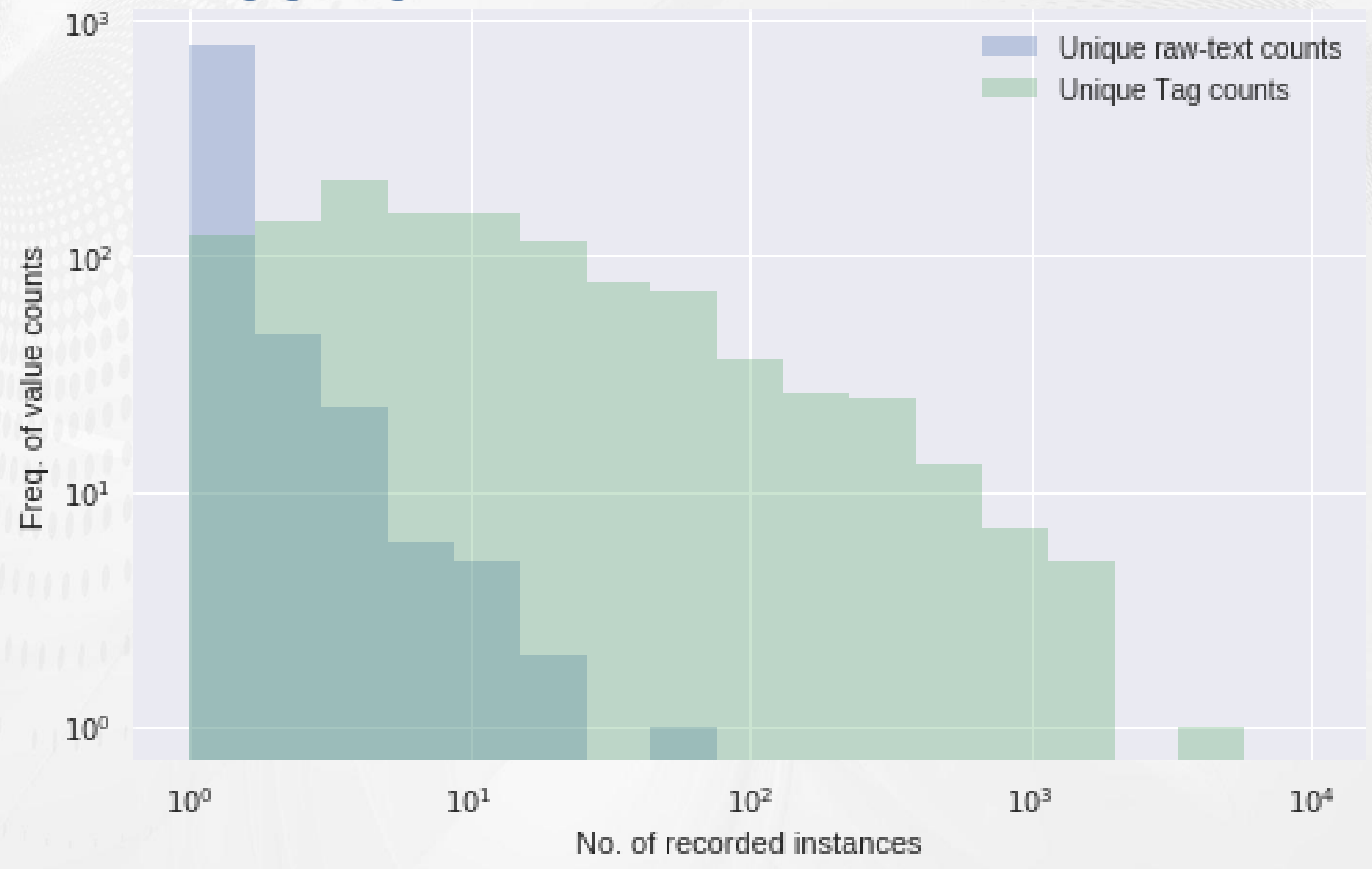




\section{Demo}




\section{Next Steps}

- Standardized Data Structure for Maintenance Work Orders

- Validating data cleaning

- Guide for cleaning data 


\title{
Thanks for your attention...
}

\section{Questions? \\ Objections? Suggestions?}

\author{
Michael P. Brundage, Ph.D. \\ (301) 975-8798 · mpb1@nist.gov \\ Systems Integration Division, NIST
}




\section{The American Society of Mechanical Engineers}

Setting the Standard for Safety and Global Relevance:

An Overview of ASME Standardization and Conformity Assessment Activities 


\section{Why do we need standards?}

- Promote safety, uniformity, consistency, reliability, productivity, efficiency and innovation

- Help communication between producers and users

- Considered a "common language"

- Promote interchangeability

- Allow for more flexibility for designers

- Standards satisfy safety, performance, and economic goals 


\section{ASME Standards Today}

...by the numbers

\section{ASME A17.2-2010}

Guide for Inspection of

Elevators, Escalators,

and Moving Walks

Includes Inspection Procedures for Eectic Trection and Winding Drum

ncined Eleviators, and Escators
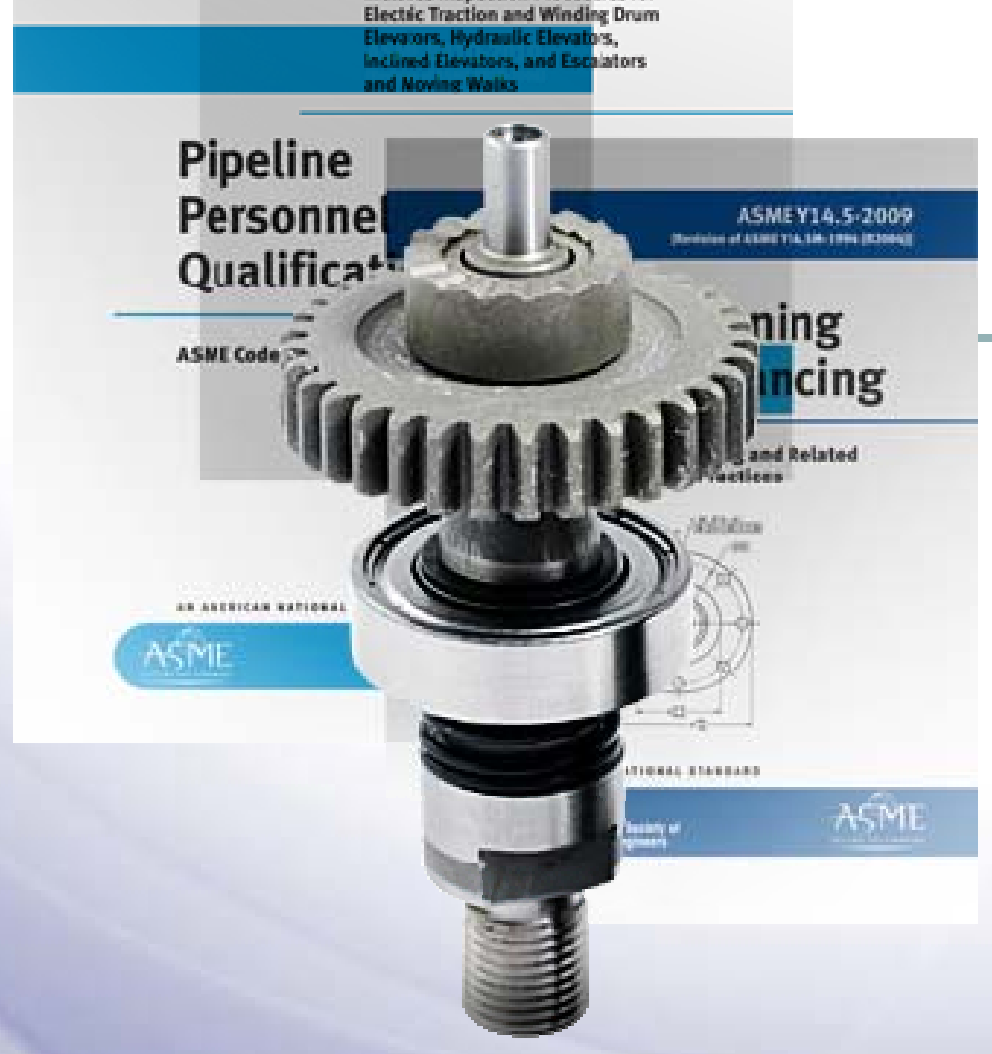

- $600+$ published standards (more recently, over 90 technical related non-standards publications)

- 700 boards, standards developing committees and supporting subgroups

- $130,000+$ members worldwide, including $\mathbf{3 2 , 0 0 0 +}$ student members; 5,555 Standards and Certification Volunteers

- 720 student sections, and 31 local sections outside North America

- 200 professional development courses (many of them standards-based)

- 35 active memorandums of understanding with government, industry and professional organizations around the world 


\section{ASME S\&C Organization Chart}

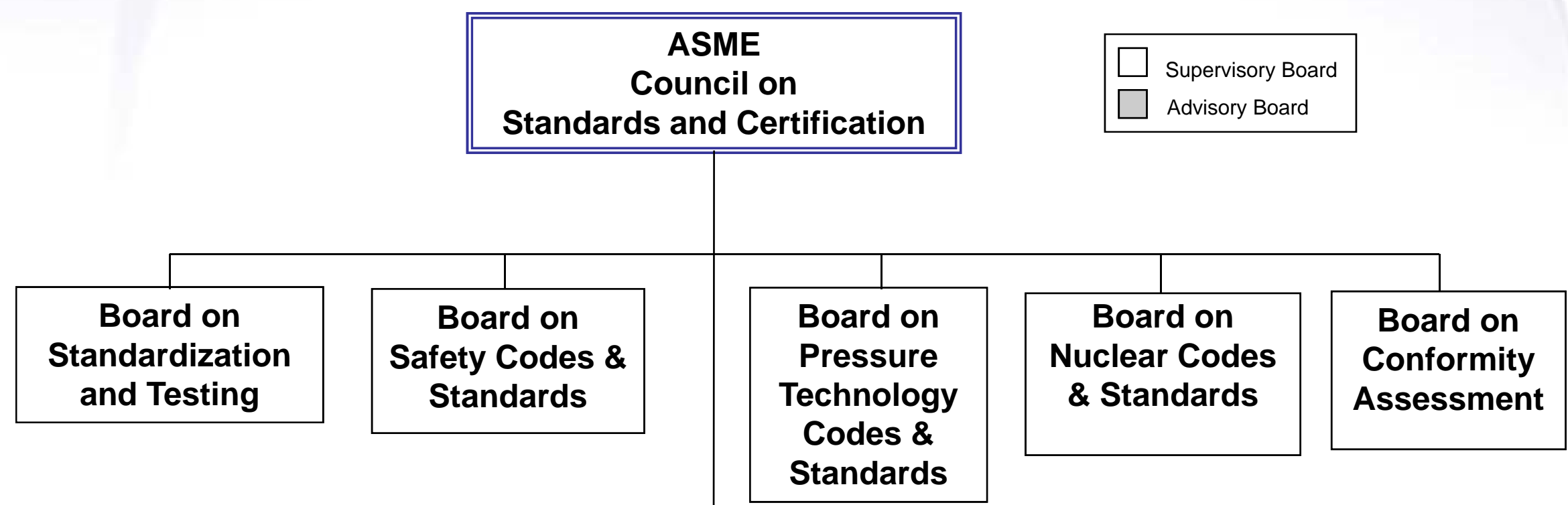

\begin{tabular}{|l|}
\hline Board on \\
Codes \& \\
Standards \\
Operations \\
\hline
\end{tabular}

Board on Hearings and

Appeals

Energy and
Environmental
Standards
Advisory Board

Board on Strategic Initiatives
Board on Level Training Committee 


\section{ASME S\&C Organization Chart}

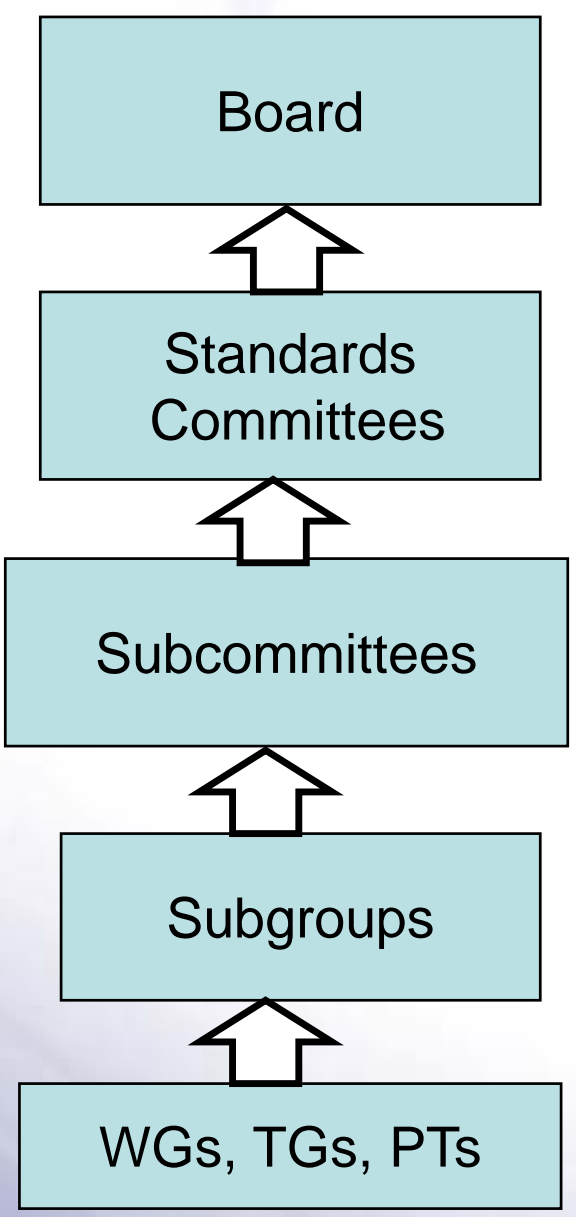

Provides procedural oversight for all activities

Establishes consensus on all technical matters

Provides recommendations on technical matters to the standards committee in a given subject area e.g., nuclear components

Develops proposal in a given specialty - e.g., design

Develops detailed proposals in a specific field - valve design 


\section{Standards Committee Work}

- Any individual having the willingness and ability to participate in the committee's activity may apply for committee membership

- No fees for participation

- Multiple types of membership

- Web-enabled electronic tools

- All meetings free and open to the general public 


\section{ASME Standards Proposals}

Proposals can be suggested by:

- Users of the standards

- Individuals or groups

- Regulators

Typically assigned to a subtier group

- Volunteers are designated as project managers of the proposal 


\section{ASME Consensus Process}

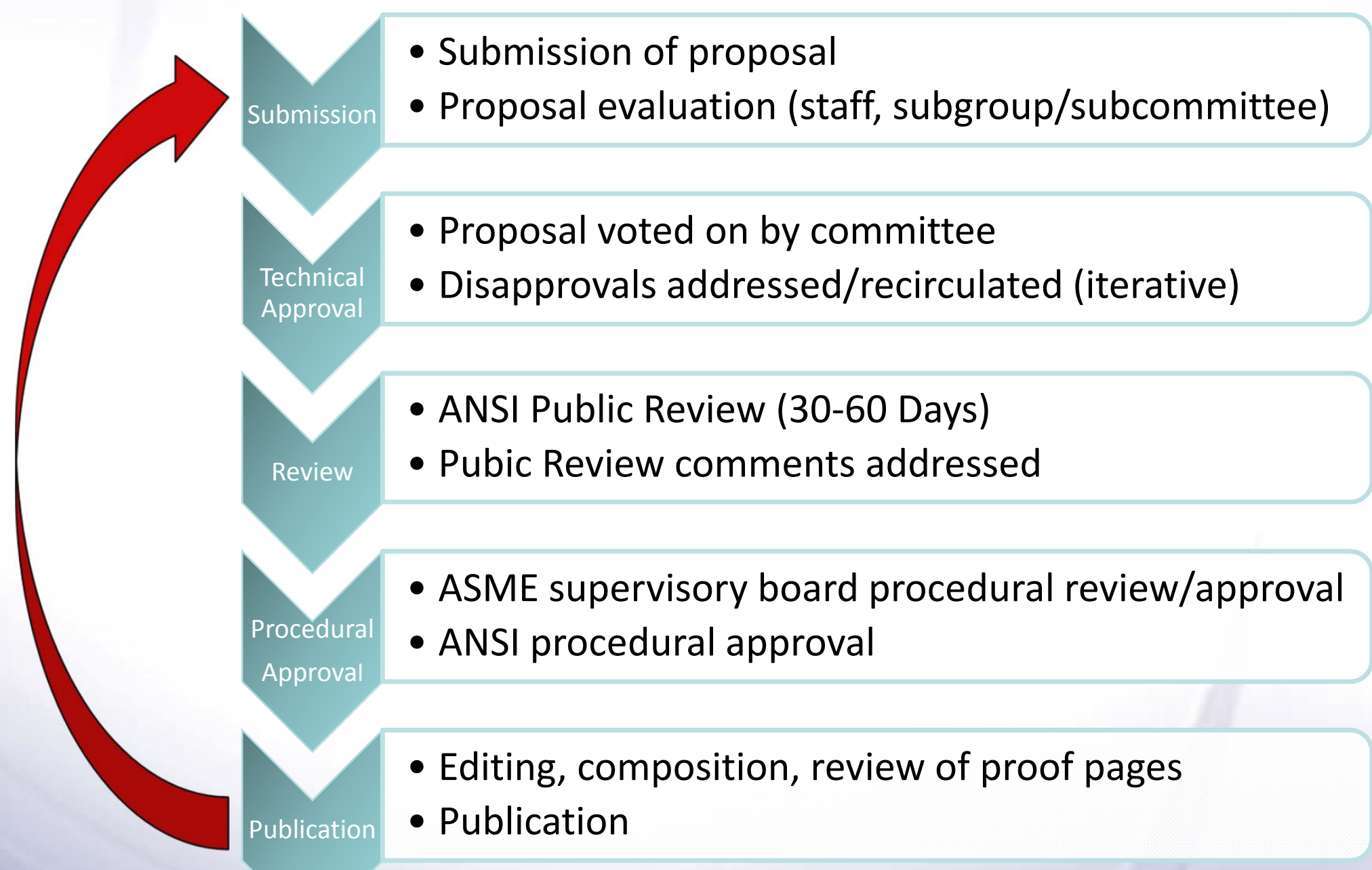




\section{ANSI Accreditation}

\section{ANSI}

American National Standards Institute

ANSI's Essential Requirements establish due process for standards development via:

Openness

Lack of dominance/Balance of interest

Coordination and harmonization

Consensus

Consideration of views and objections

Notification

Written procedures

Appeals 


\section{Other Key Aspects}

- ASME's standards are reviewed by the respective consensus committee at least every 5 years to ensure continued relevance

- Many standards (e.g. BPV codes) are under a continuous state of review

- Interpretations and Code Cases offered for most standards

- Not funded by industry or government

- Note: Standards are considered voluntary unless adopted into law by a regulatory authority 


\section{Scope of Activities}

Pressure Technology
boilers, pressure vessels, piping, materials,
welding, valves, flanges
Standardization/Performance Test Codes
geometric dimensioning and tolerancing,
dimensional metrology, plumbing, turbines and
power plant equipment, fasteners, hand tools,
energy assessment, additive manufacturing
Safety
elevators \& escalators, cranes, automotive
lifts, conveyors, rail transit
Nuclear
component design, containment, quality
assurance, risk assessment, air and gas
treatment, inspection
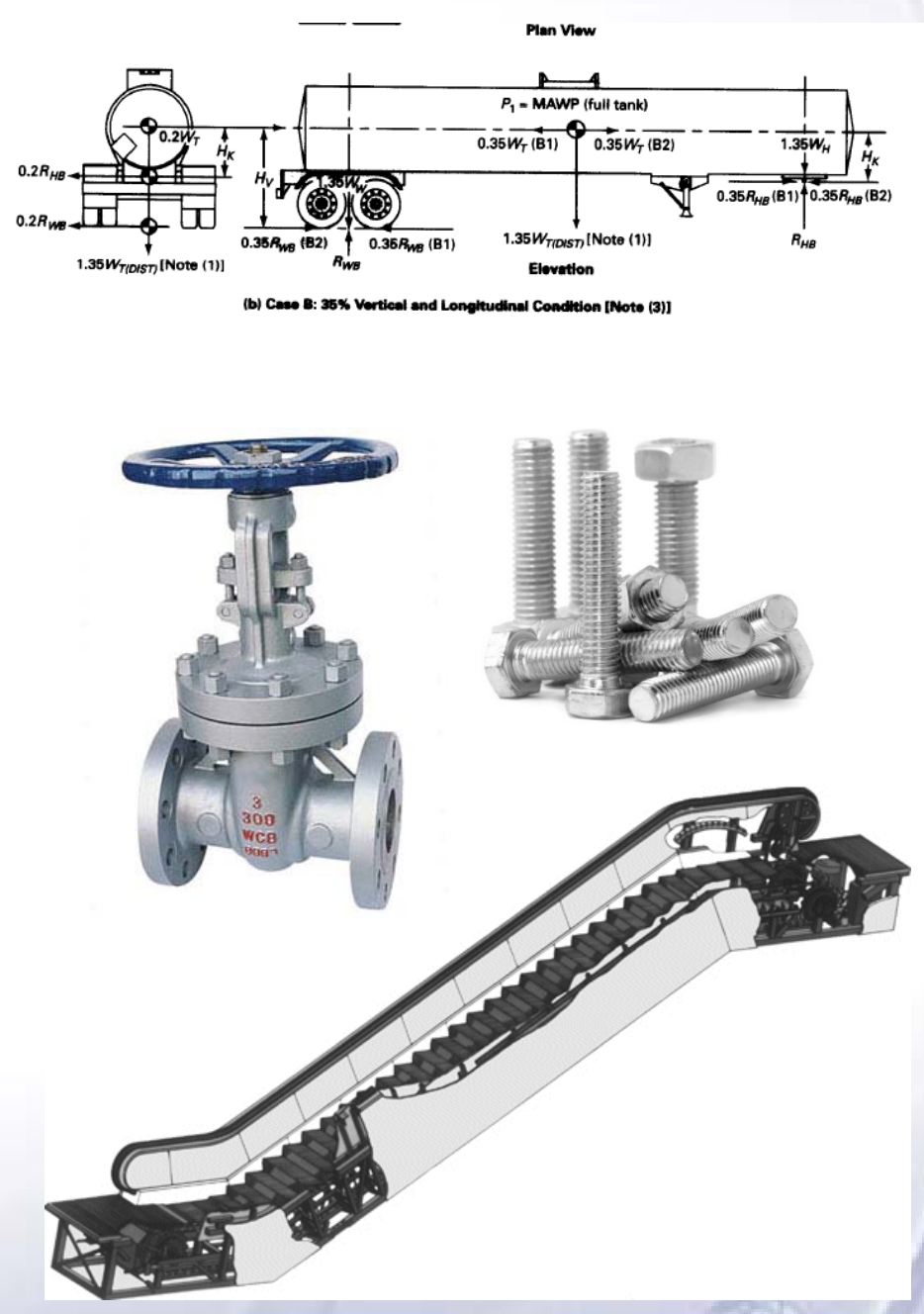

ASME 


\section{The Boiler and Pressure Vessel Code}

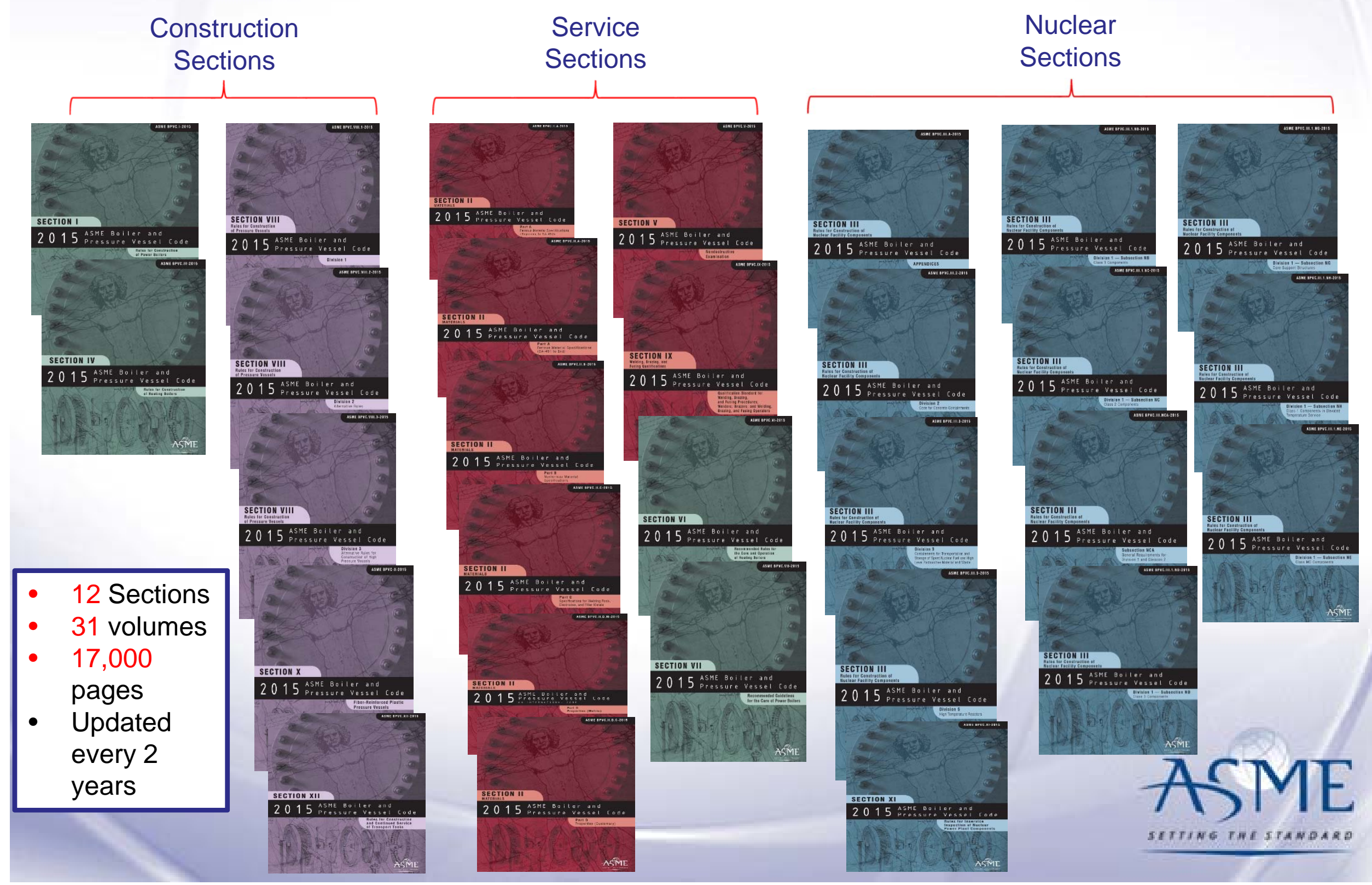




\section{Conformity Assessment}

Conformity Assessment: Activities taken to verify that products and processes conform to particular standards

ASME accredits third party organizations that satisfactorily demonstrate they are capable of implementing activities such as inspection and testing services

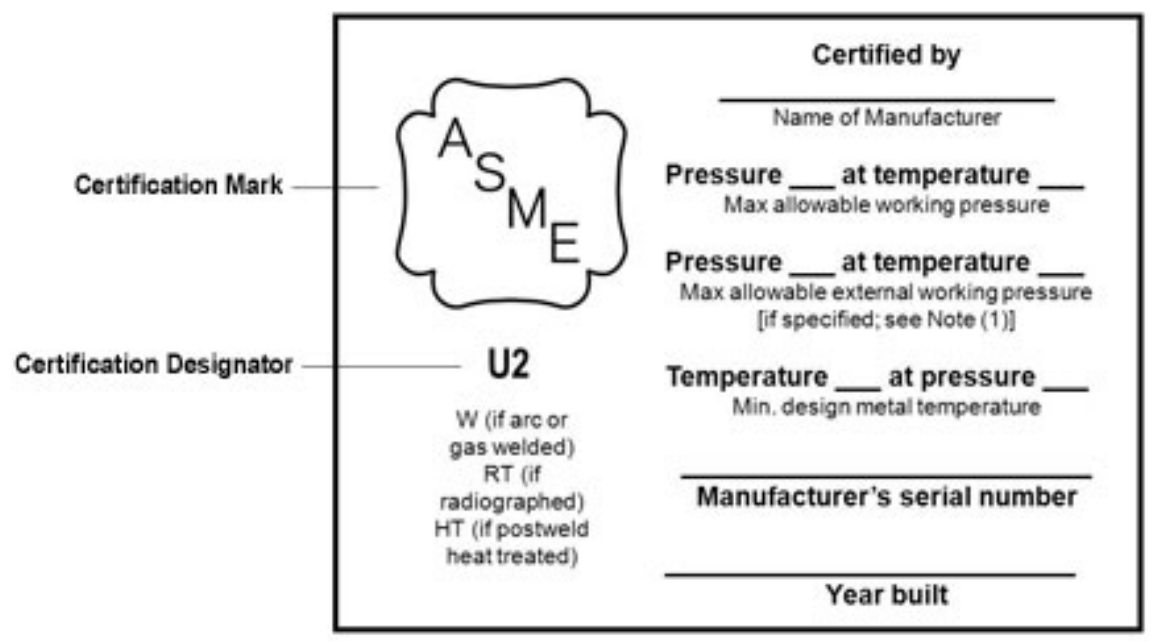

Sample ASME Product Certification Nameplate

ASME certifies individual manufacturers that satisfactorily demonstrate they can build products that meet ASME standards. ASME also certifies personnel to attest that their qualifications conform with its applicable standards

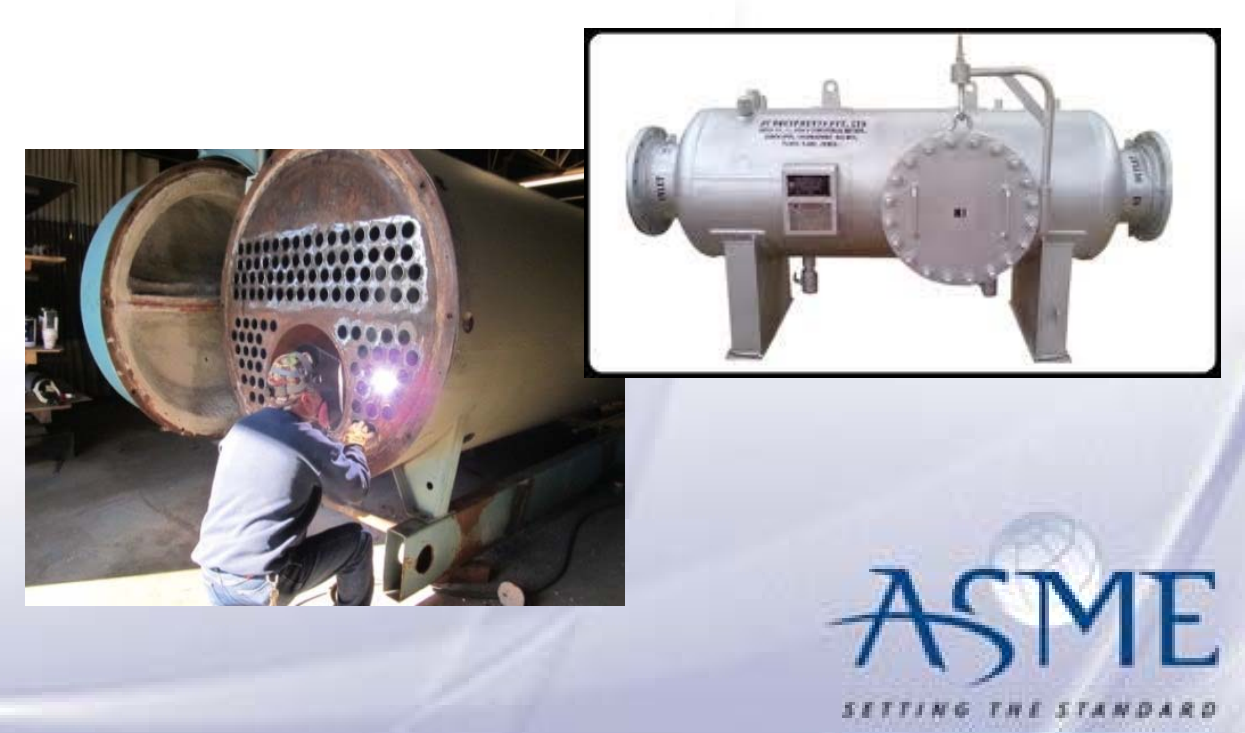




\section{Emerging Areas / New Activities}

Energy

- Concentrating Solar Power Plants

- Energy Assessments for Compressors, Heating Systems, Pumping Systems, and Steam Systems

- Nuclear

- Gas Cooled, Liquid Metal

- Small Modular, Fusion,

- Thermal Energy Storage

- Ultra-Supercritical Boilers

Workforce Development

- Personnel Certifications (ANDE, pipeline engineer, system energy assessment practitioner)
Infrastructure

- Design Basis/Response to Severe Accidents

- Hydrogen Infrastructure

- Water Efficiency (for Power Plants and Other Industrial Facilities)

Technology

- High Temperature Materials

- Overall Plant Performance with Carbon Capture

- Design for Additive Manufacturing

- Verification and Validation (Computational Solid Mechanics, Fluid Dynamics and Heat Transfers) 


\section{Benefits of Volunteering}

- Greater understanding of the requirements in the standard

- Advanced knowledge of new and revised standards

- Opportunity to help shape revisions

- Network with internationally recognized experts 


\section{How to Participate}

- Membership is selected based on:

- Technical experience

- Interest classification

- Ability to actively participate

- No fees or geographical restrictions

- May be requested to attend one or more meetings as a visitor

- New volunteers are encouraged to apply for subtier groups

- To apply, must submit personnel forms (PF-1 and PAF).

- Membership requires committee approval. 


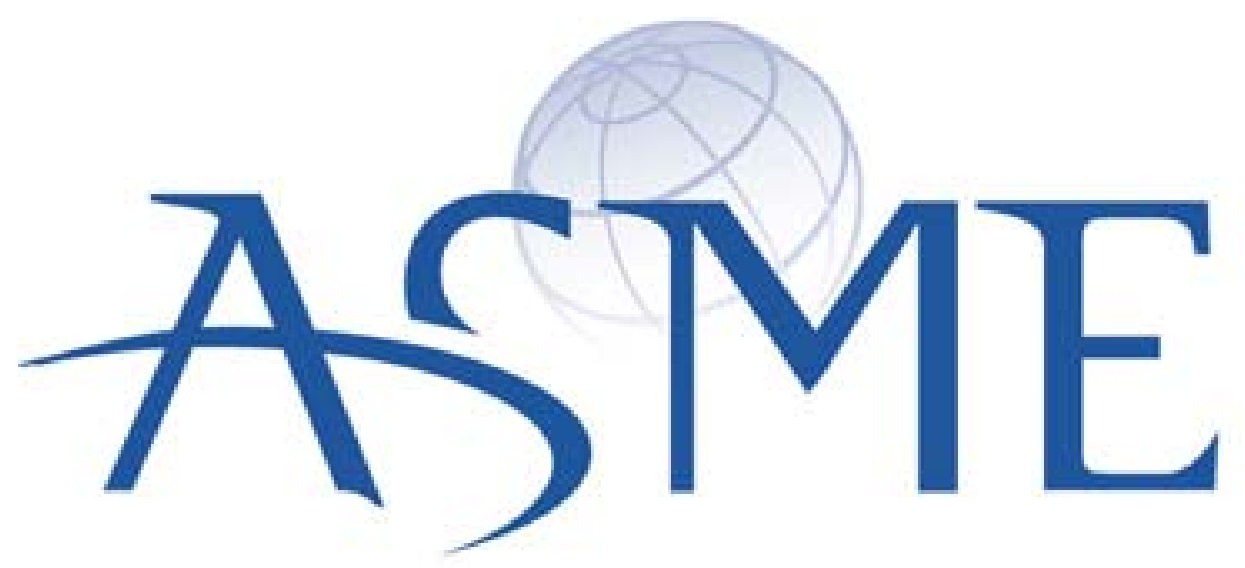

SETTING THE STANDARD

QUESTIONS ?? 


\section{GD\&T and Standardization Presentation Series}

\section{Applying GD\&T per ASME Y14.5 Solves Problems for Manufacturer}




\section{About the presenter}

\section{Bryan R. Fischer Vice-President}

Sigmetrix/Advanced Dimensional Management

Expert, Trainer, Author

GD\&T

Tolerance Analysis 3D MBD, MBE Standards

Training

Consulting

Software

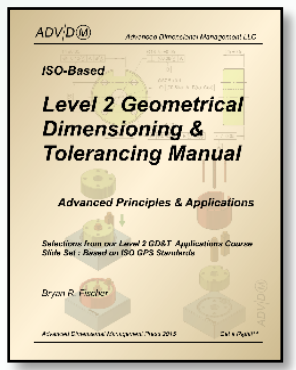

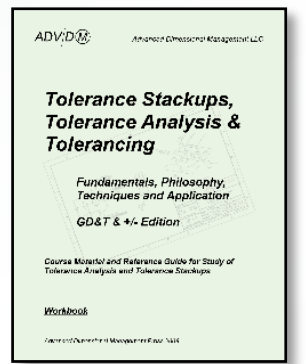

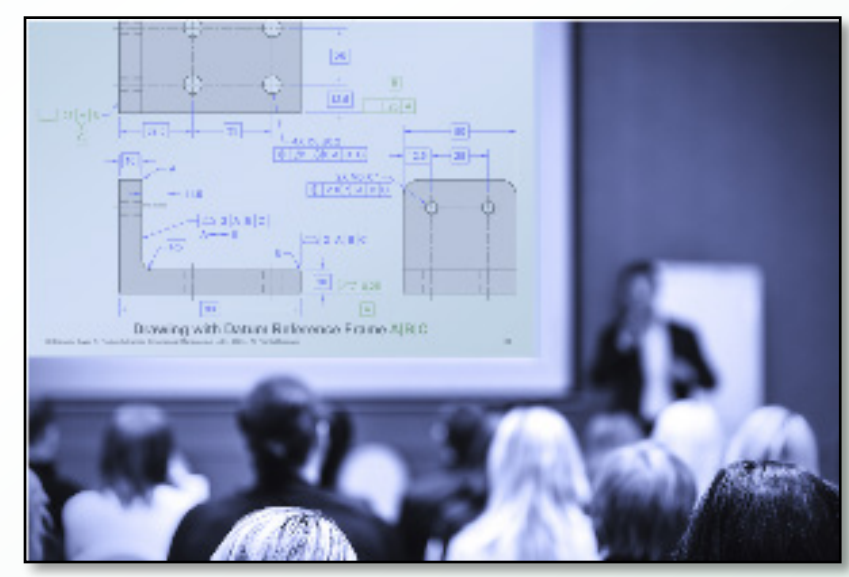

EZTol, CETOL, GD\&T Adviser
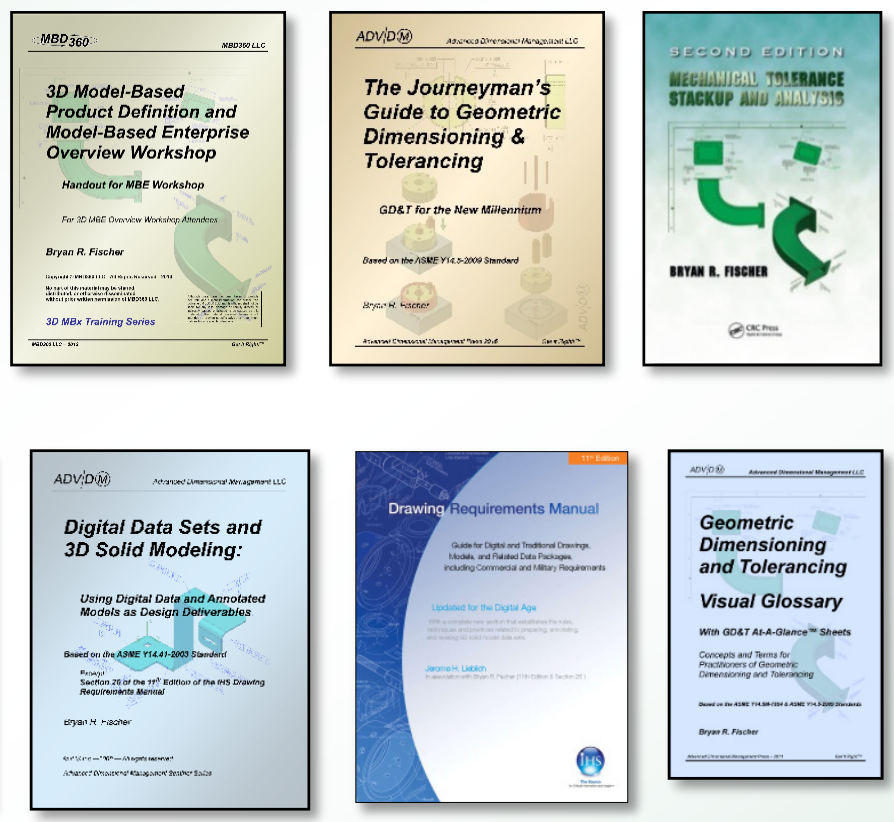

(2)
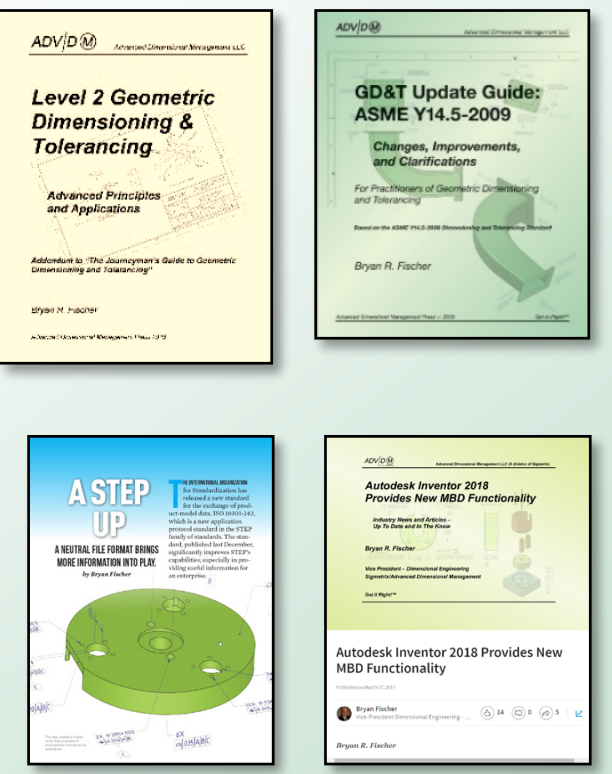


\section{Large Welded Assembly}

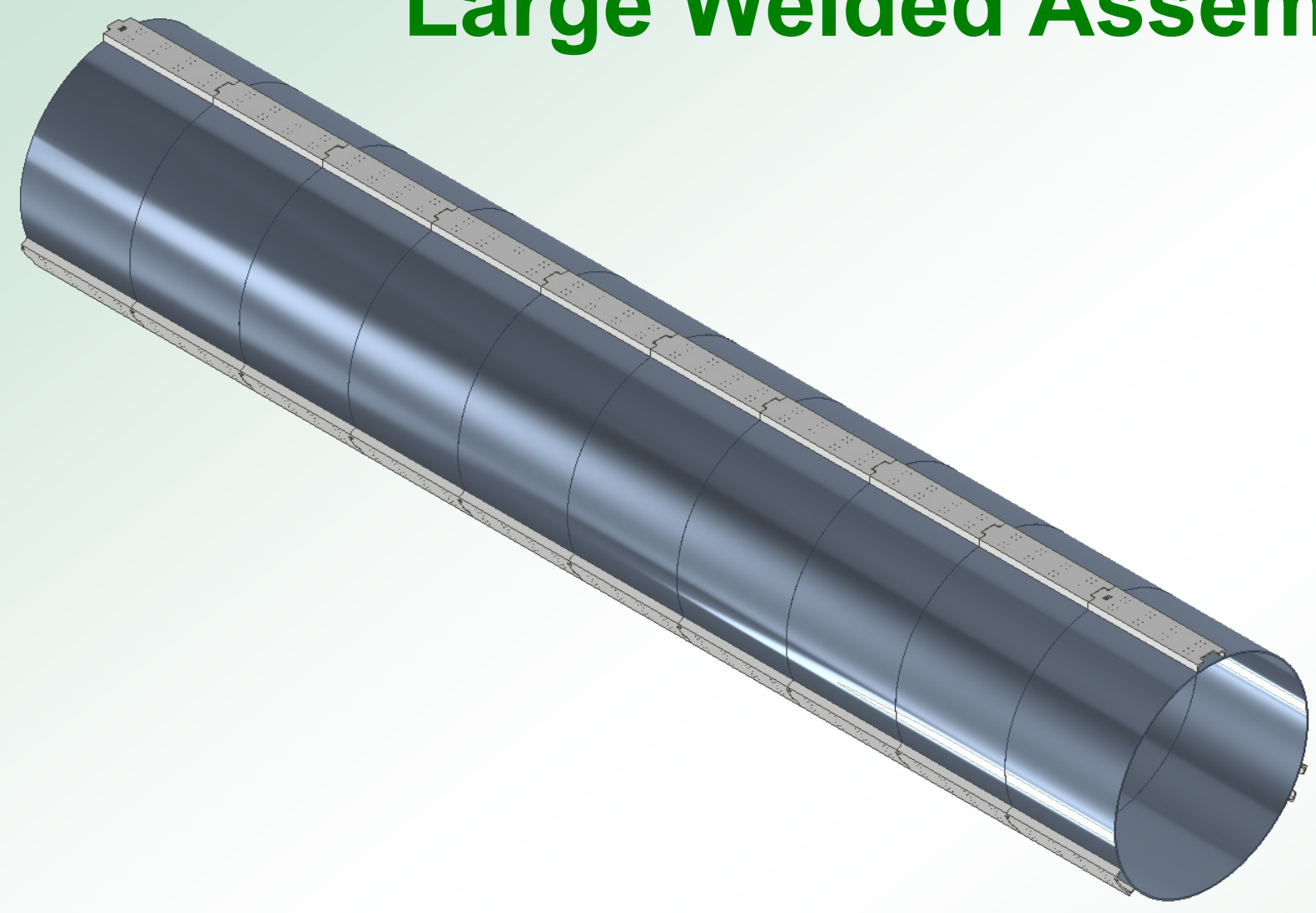

$\longleftarrow 80 \mathrm{ft} \longrightarrow$
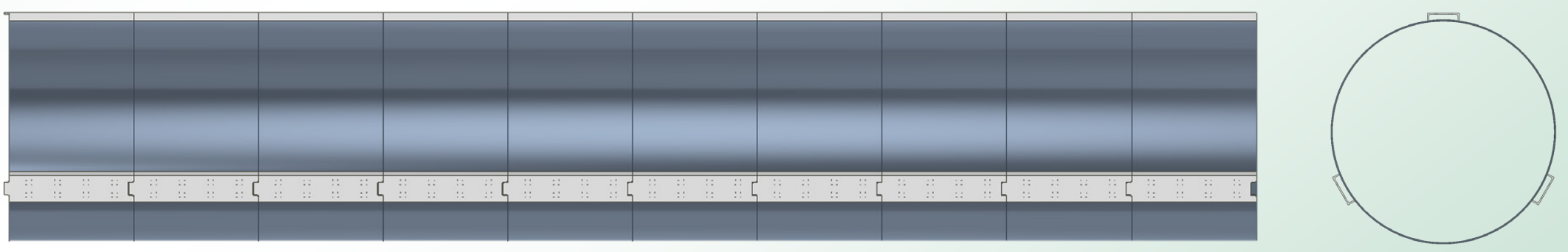


\section{Problem Statement}

Manufacturer and client could not agree how to evaluate conformance to specifications

- No GD\&T on drawing

- Ambiguous specifications

- Continually argued about

- Meaning of specifications

- Requirements imposed

- Acceptance criteria 


\section{Assembly}

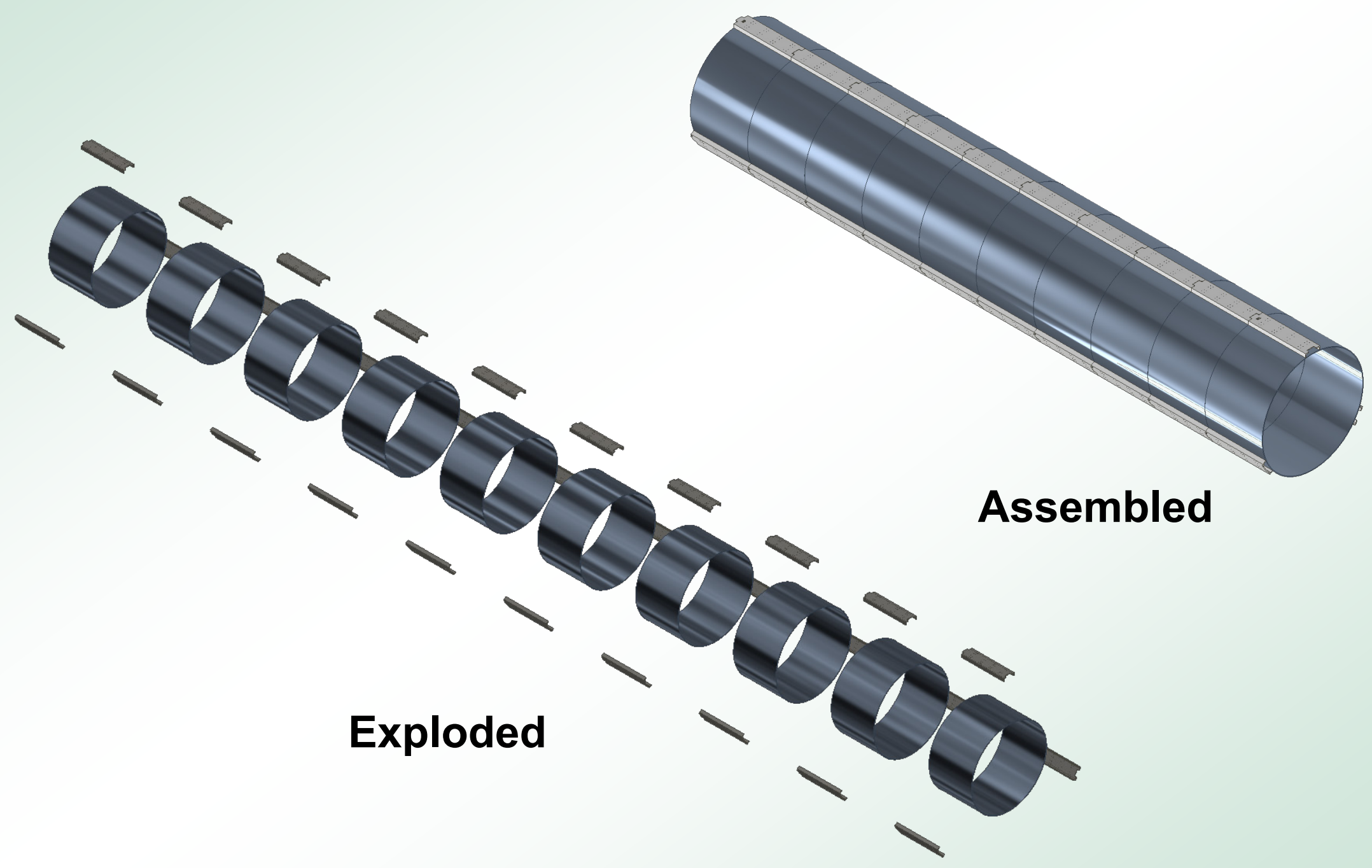




\section{Possible As-Produced Geometry}

Assembly will be manufactured with geometric error, possibly with sections misaligned or bent

Subcomponents may also be mislocated or misaligned

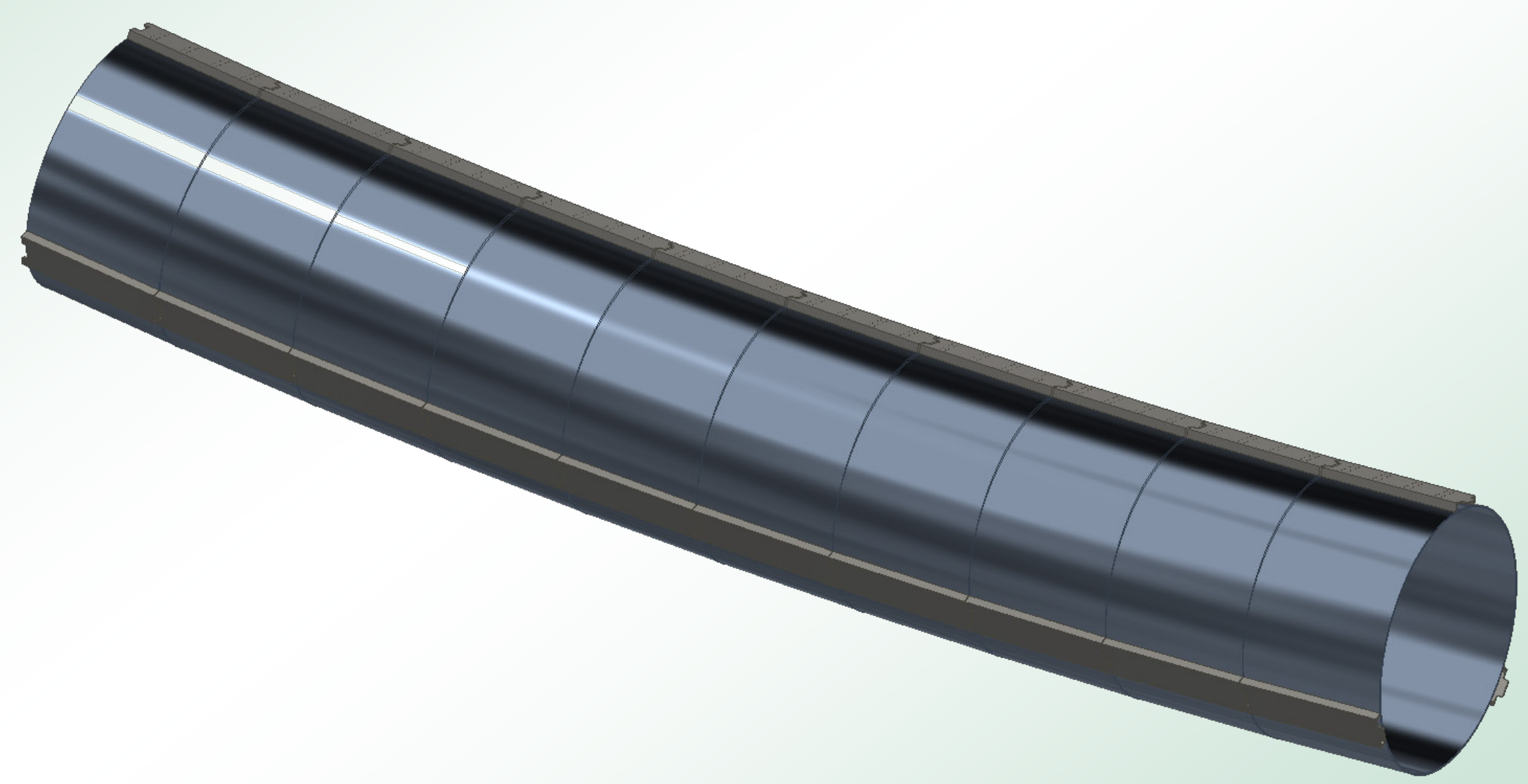




\section{Resolution}

Using GD\&T defined unambiguous requirements Manufacturer and client quickly agreed on conformance

- GD\&T based on ASME Y14.5:

- Eliminated ambiguity

- Eliminated arguments

- Eliminated wasted time

- Saved money

- Allowed schedule to be met

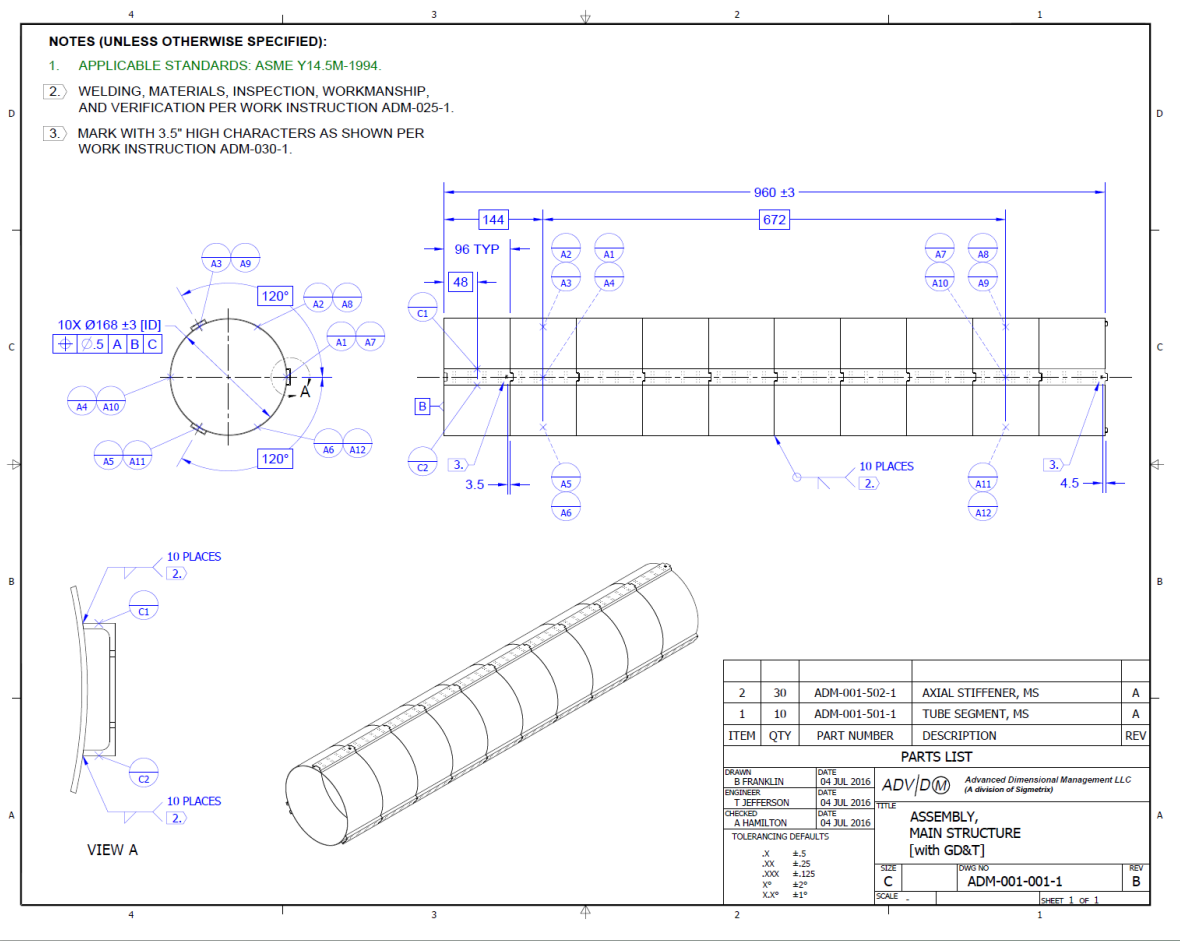

- Techniques used on subsequent designs 


\section{Contact Information}

Bryan R. Fischer

Vice-President - Dimensional Engineering

Sigmetrix/Advanced Dimensional Management

bfischer@sigmetrix.com

503-625-2480 office 503-260-3084 mobile

Industry-leading GD\&T (ASME, ISO), Tolerance Analysis and 3D MBD, MBE Training and Consulting

Industry-leading 1D and 3D Tolerance Analysis and GD\&T Software 


\section{GD\&T and Standardization Presentation Series}

\section{Thank You!}

\section{Contact us for more information and how we can help your company}




\title{
The Present Status, Challenges, and Future Trend of Maintenance in US Manufacturing - Case Studies and Pilot Studies
}

ASME Workshop in Prognostics and Health Management

\author{
Xiaoning Jin \\ Assistant Professor \\ Department of Mechanical and Industrial Engineering \\ Northeastern University
}




\section{Outline}

- PHM Overview

- Industry Cases Studies in PHM

- Pilot Study of PHM in US Manufacturing 


\section{Compelling Needs of Next Generation Manufacturing}

Next Gen. Manufacturing

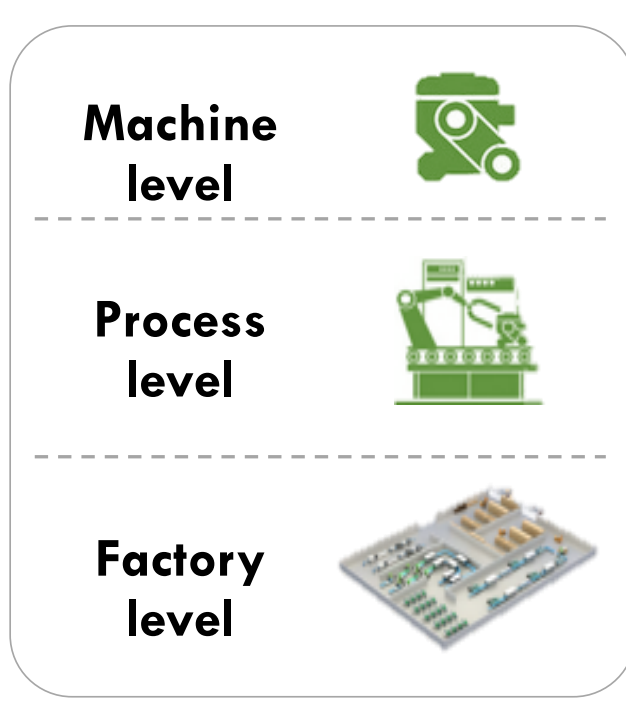

- Self-aware and predictive of equipment condition

- Resilient to uncertainties and disruptions

- Near-zero defect and downtime factory performance

\section{Connect \& Data Collection}

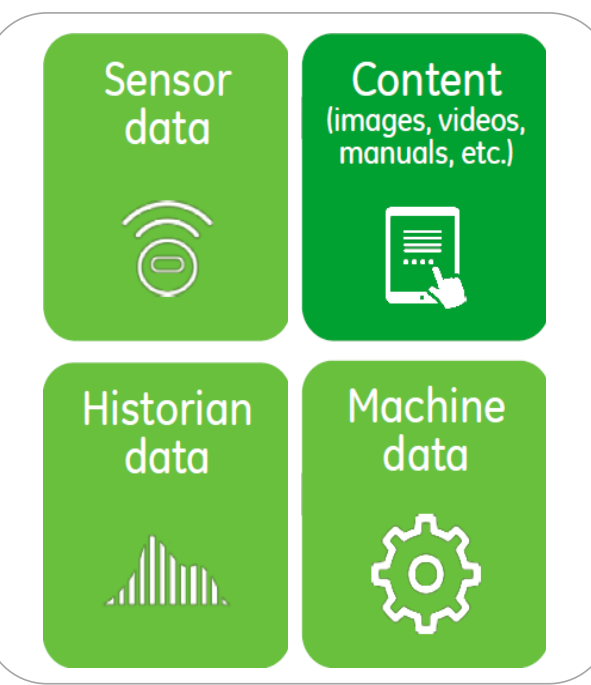

- Massive and complex data

- Imperfect/missing data

- Multi-stream/multi-source data
Advanced Analytics

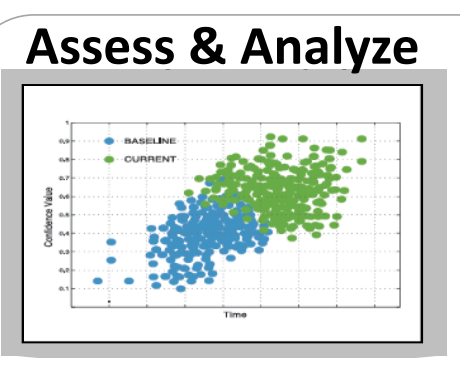

Consolidate

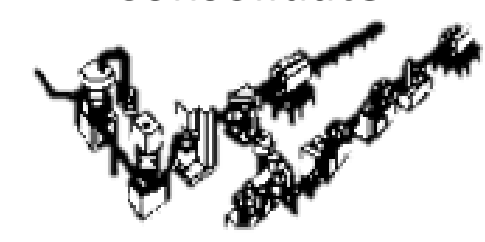

- Greater asset reliability

- Lower operating costs

- Increased factory visibility

- Worry-free production

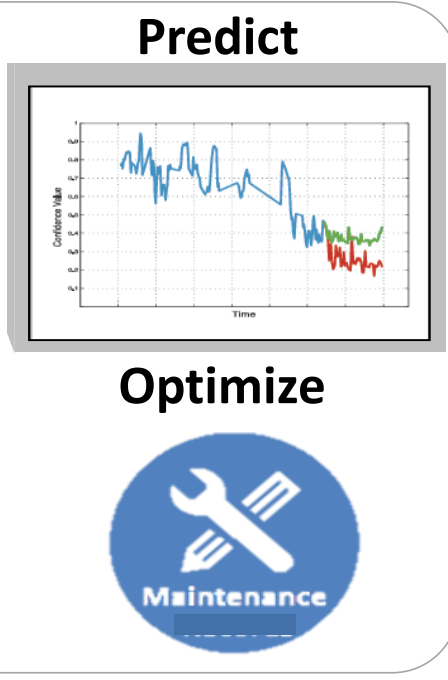

\section{Optimize}




\section{Industrial Big Data Analytics Capabilities}

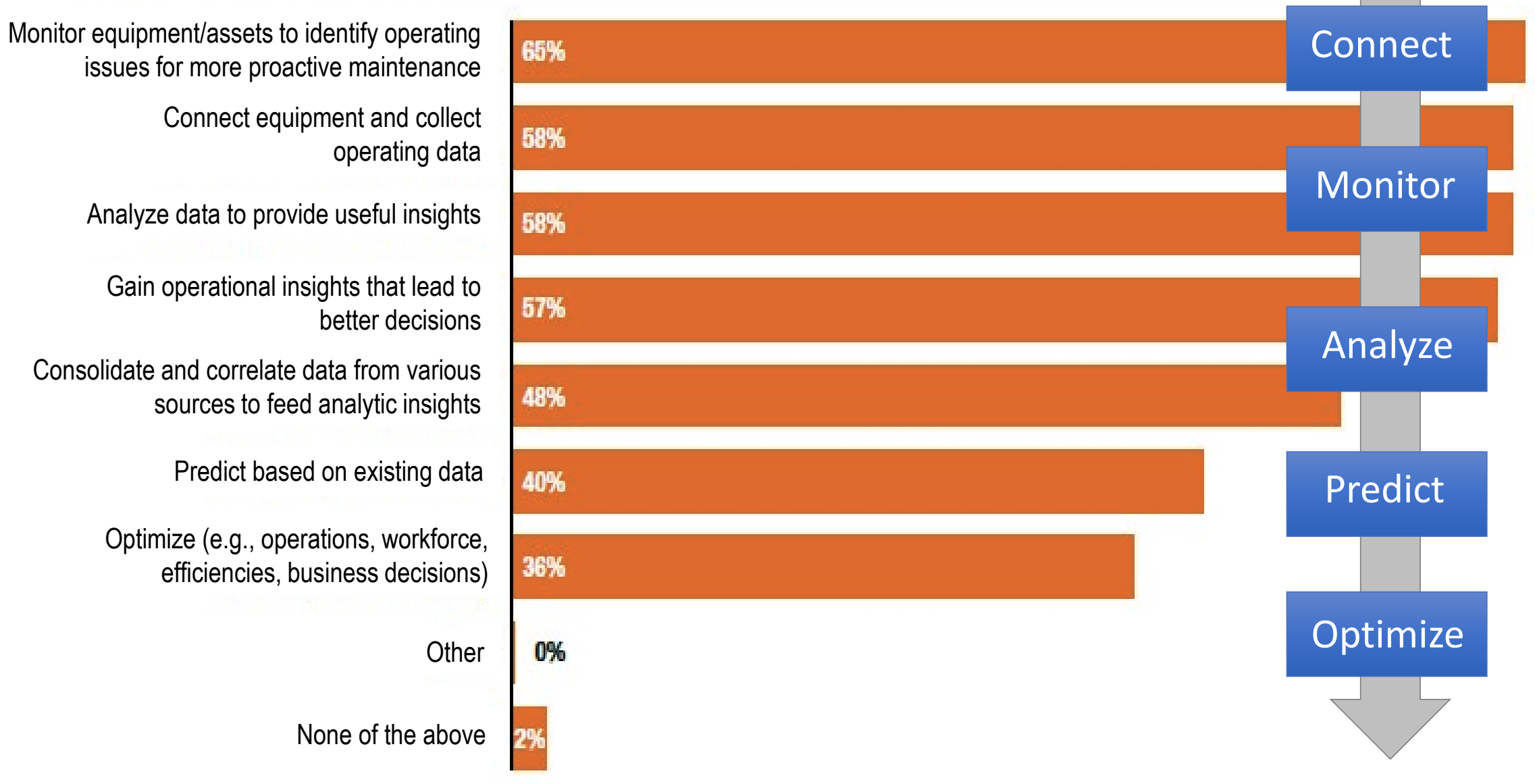

\section{Current Data Analytics capabilities are stronger in the areas of monitoring and}

connecting equipment than in predicting issues and optimizing operations. 


\section{Unobservable Performance Degradation}
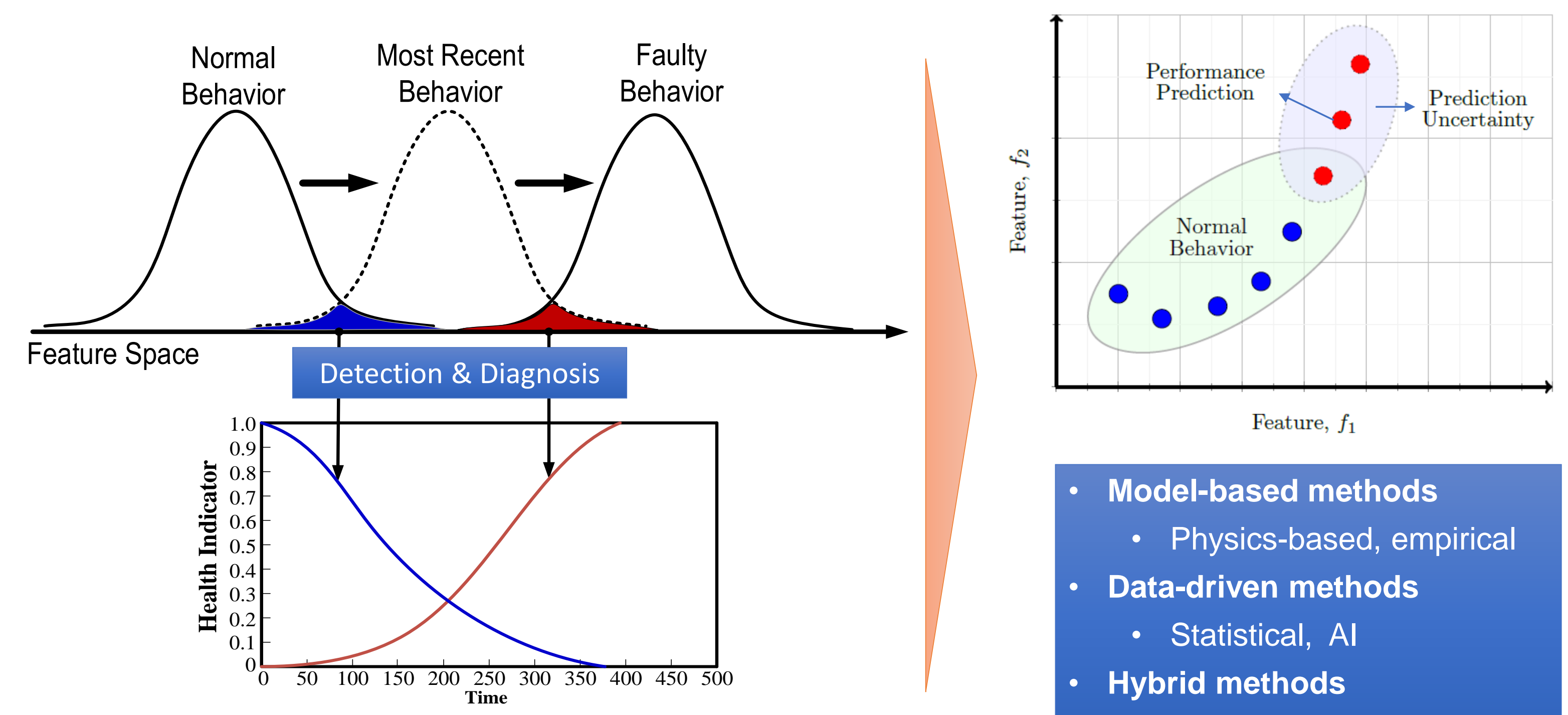

- Model-based methods

- Physics-based, empirical

- Data-driven methods

- Statistical, Al

- Hybrid methods

- Various fusion interface 


\section{Challenges \& Opportunities}

- Rich Data / Sparse Data environment

- Sensor selection \& allocation

- Lack of understanding degradation mechanism

- Sampling Strategy (static, dynamic, event-driven)

- Nominal condition (baseline) identification

- Variability \& uncertainty quantification \& control

- Physics-based or Data-driven methods fusion and interface design

- Applications: (1) discrete manufacturing (2) continuous manufacturing 


\section{Component / Machine-Level Techniques}

$\&$

Case Studies 


\section{Tool Condition Monitoring \& Re-grinding Time Optimization}

Life-cycle of machining tools:

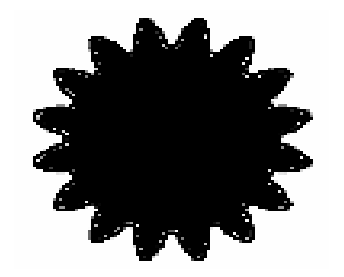

"New" shaving tool
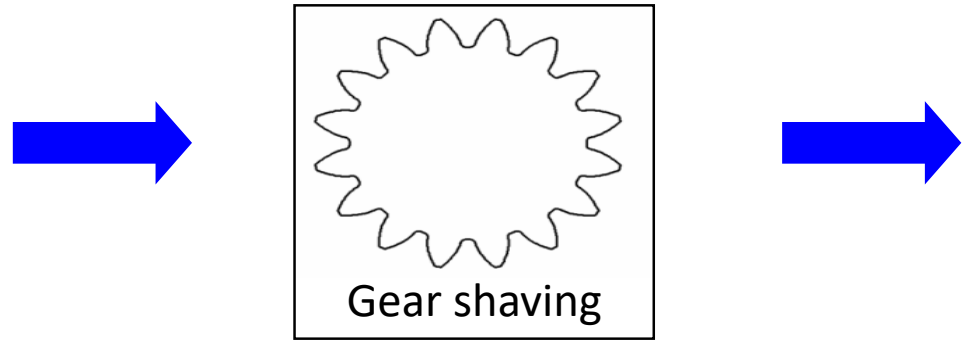

Gear shaving

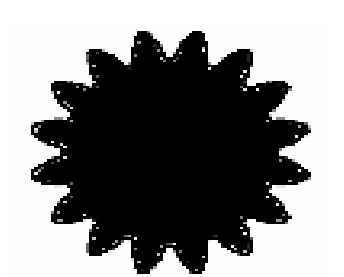

"Worn" shaving tool
Shaving tool regrinding
Illustration of shaving process and broken tool:

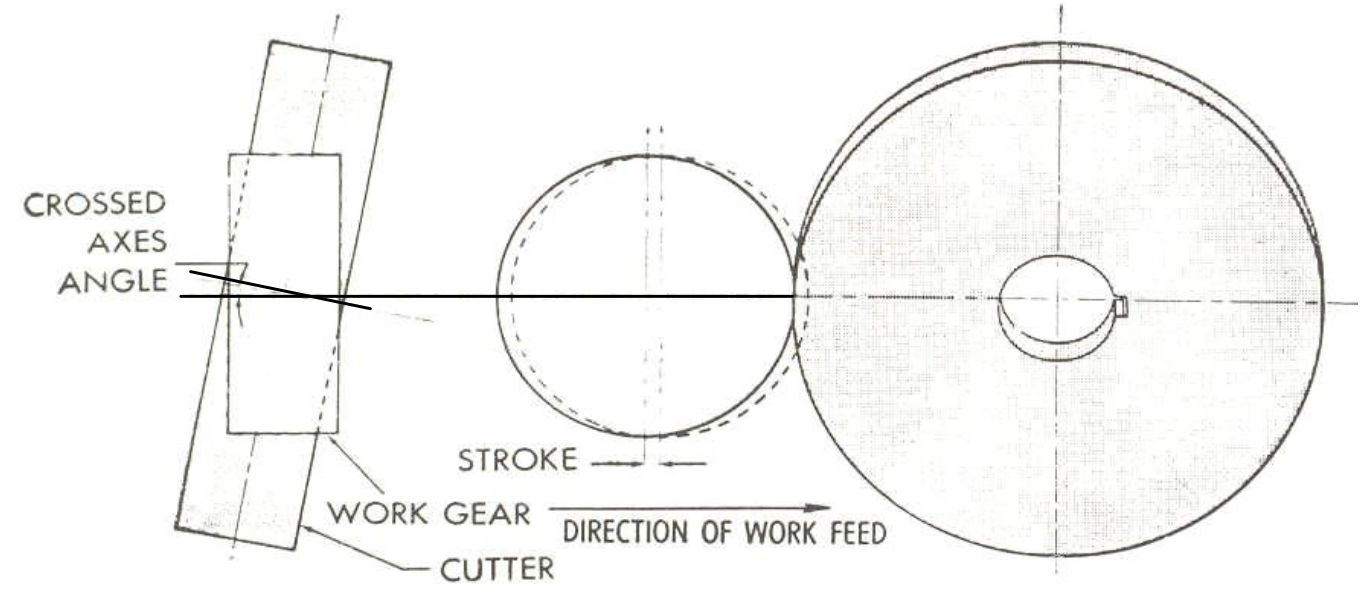

Cost/Tool: $\$ 1800$ (New), \$550 (re-ground)

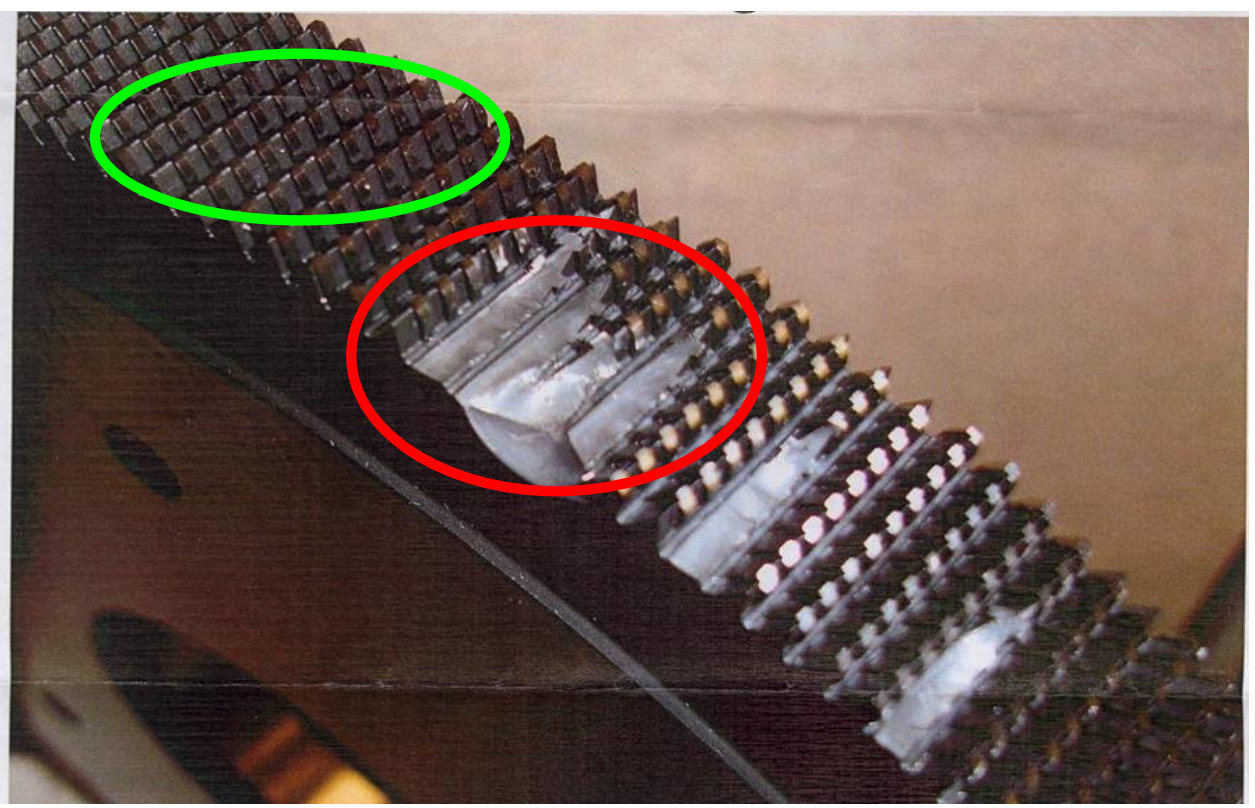




\section{From Rich Data to "Thin Data"}

- Multi-State Classification using heuristic feature selection

- Feature extraction -> Feature reduction -> Classification

- Teeth wear condition estimation

Picture of broken tool
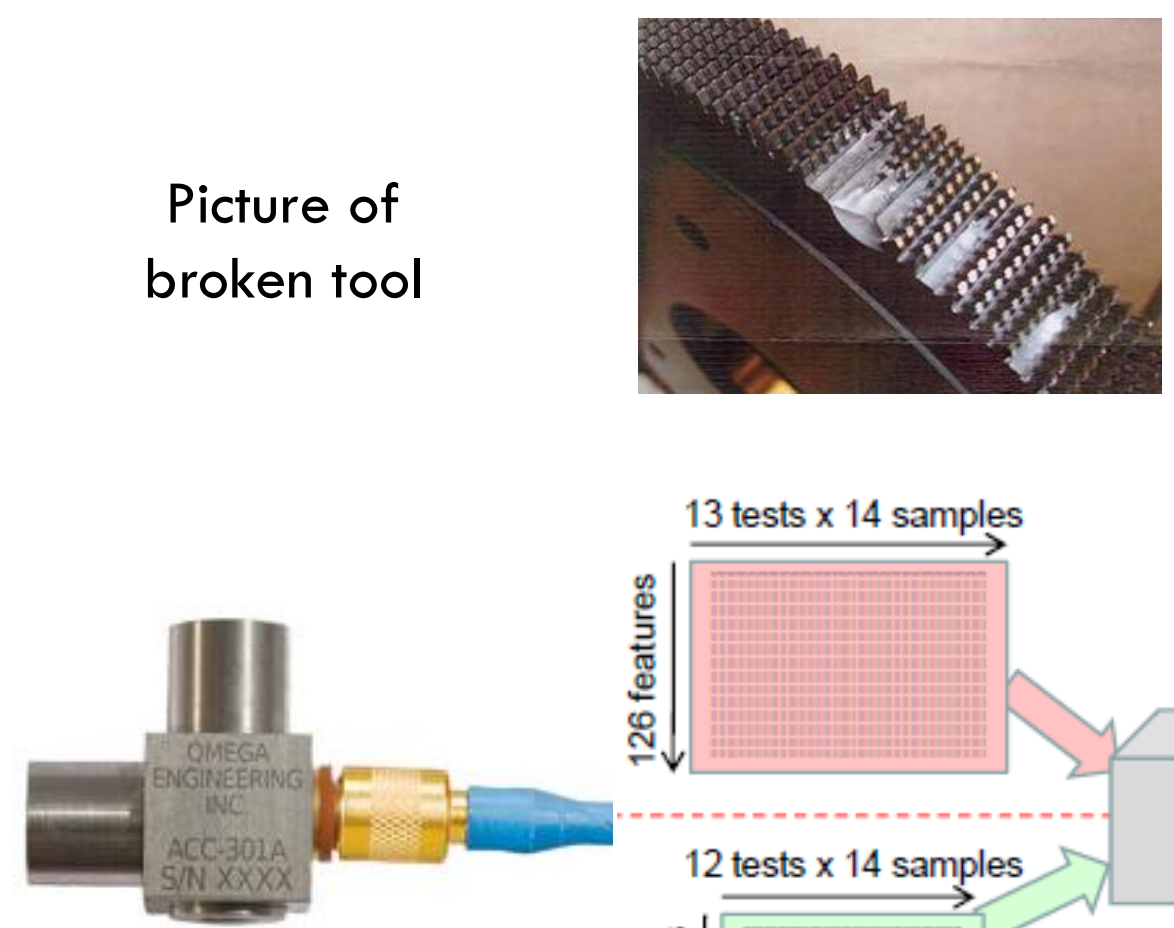

Two 3-axis Accelerometers; 18 metrics for each dimensions $(X, Y, Z)$

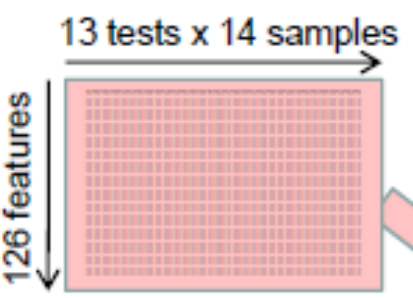

12 tests $\times 14$ samples

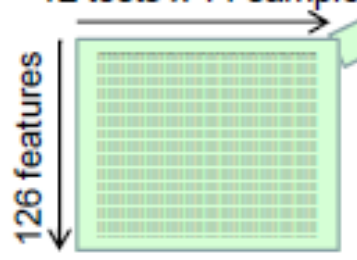

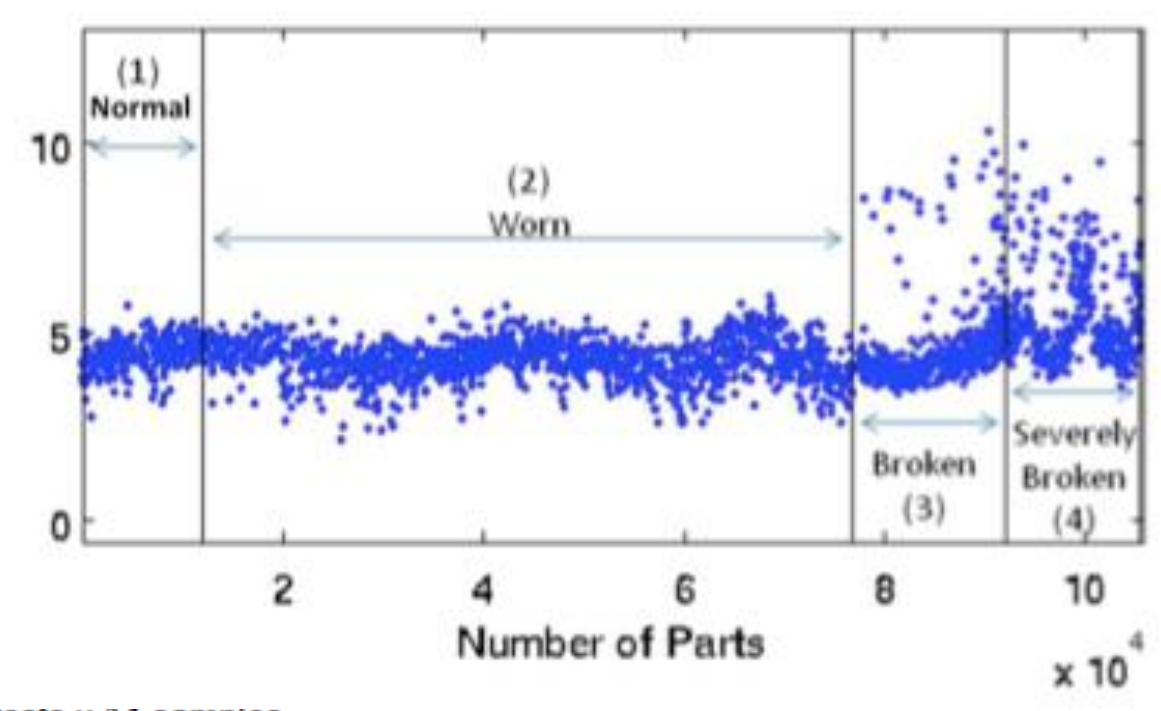

PCA

Evolution of one feature

4 tool conditions

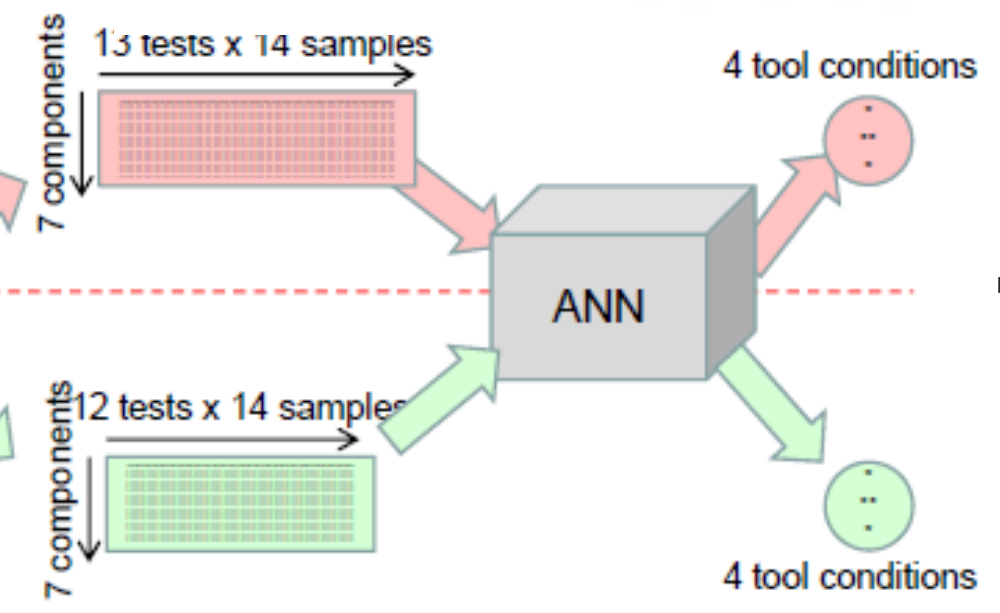

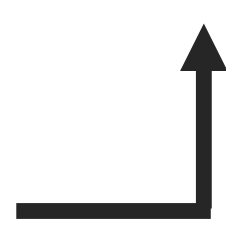




\section{Sparse Failure Data \& Unknown Failure Mode}

» Estimate known condition

» Learn unknown condition

» Unprecedented Failure Mode

" Learning and Updating
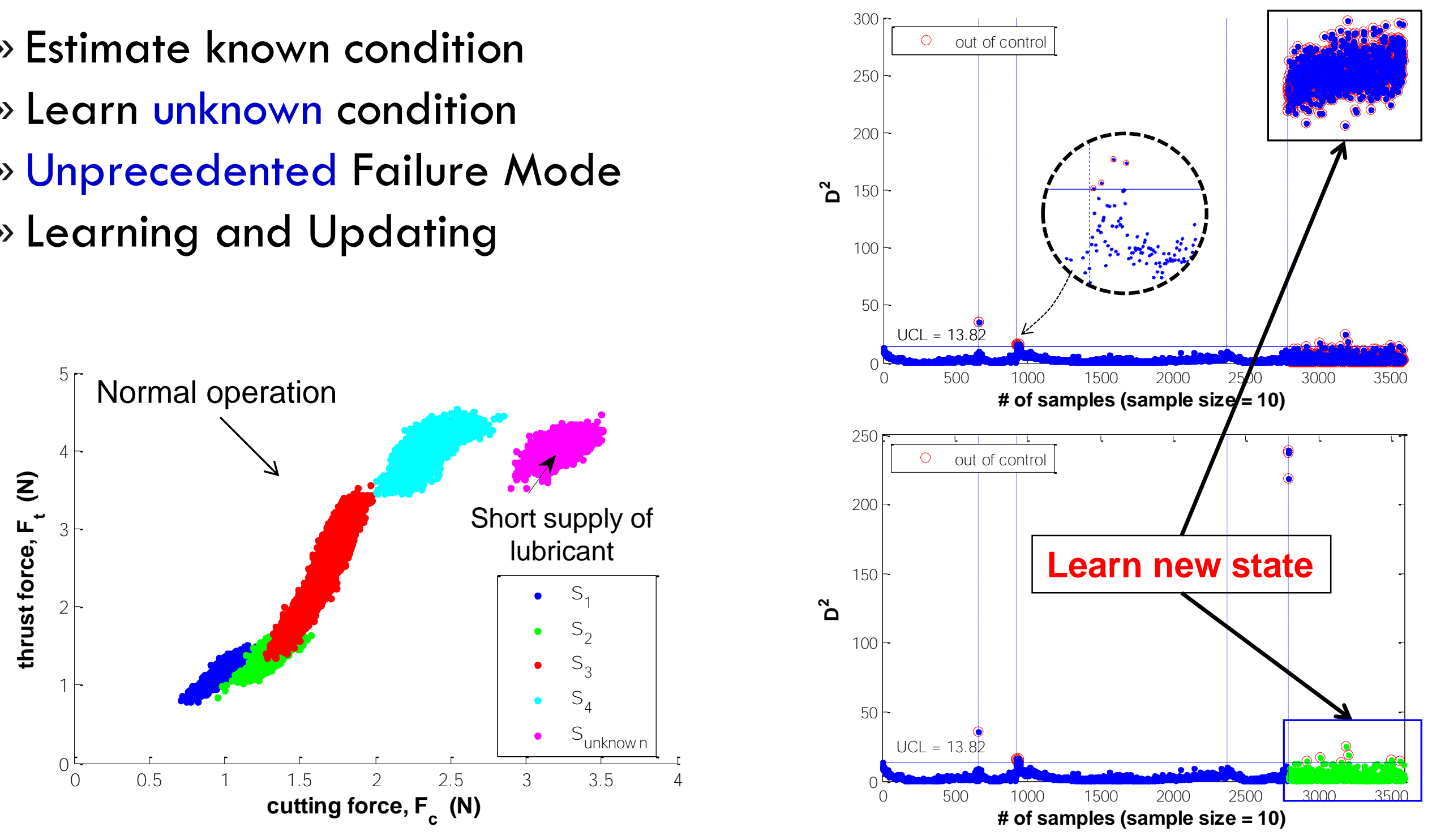


\section{Discrete Multistage Systems Fault Detection (Sensor-Lean)}

Real time monitoring data
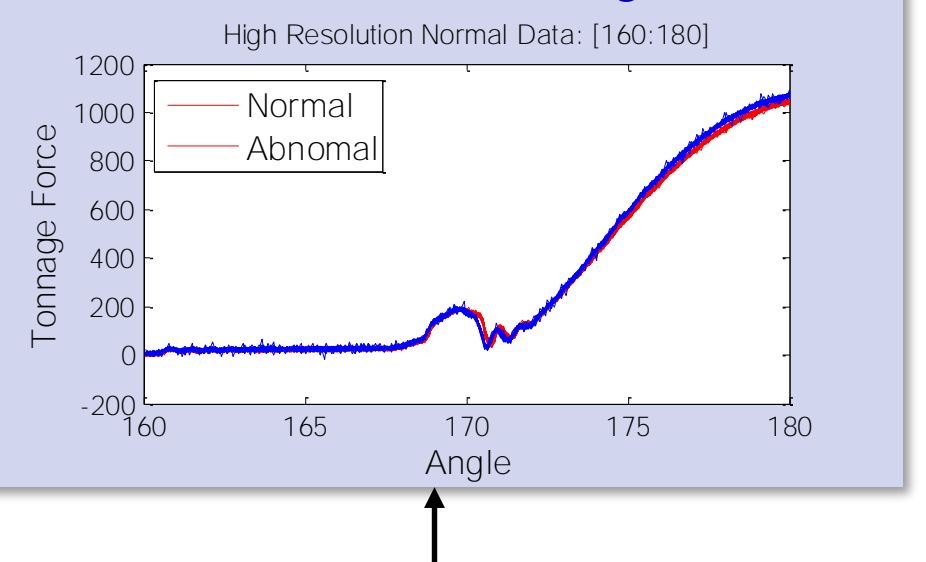

Aggregated Tonnage Force Signal

\section{Challenges}

- Limited Sensor Data

- Multi-component, complex system

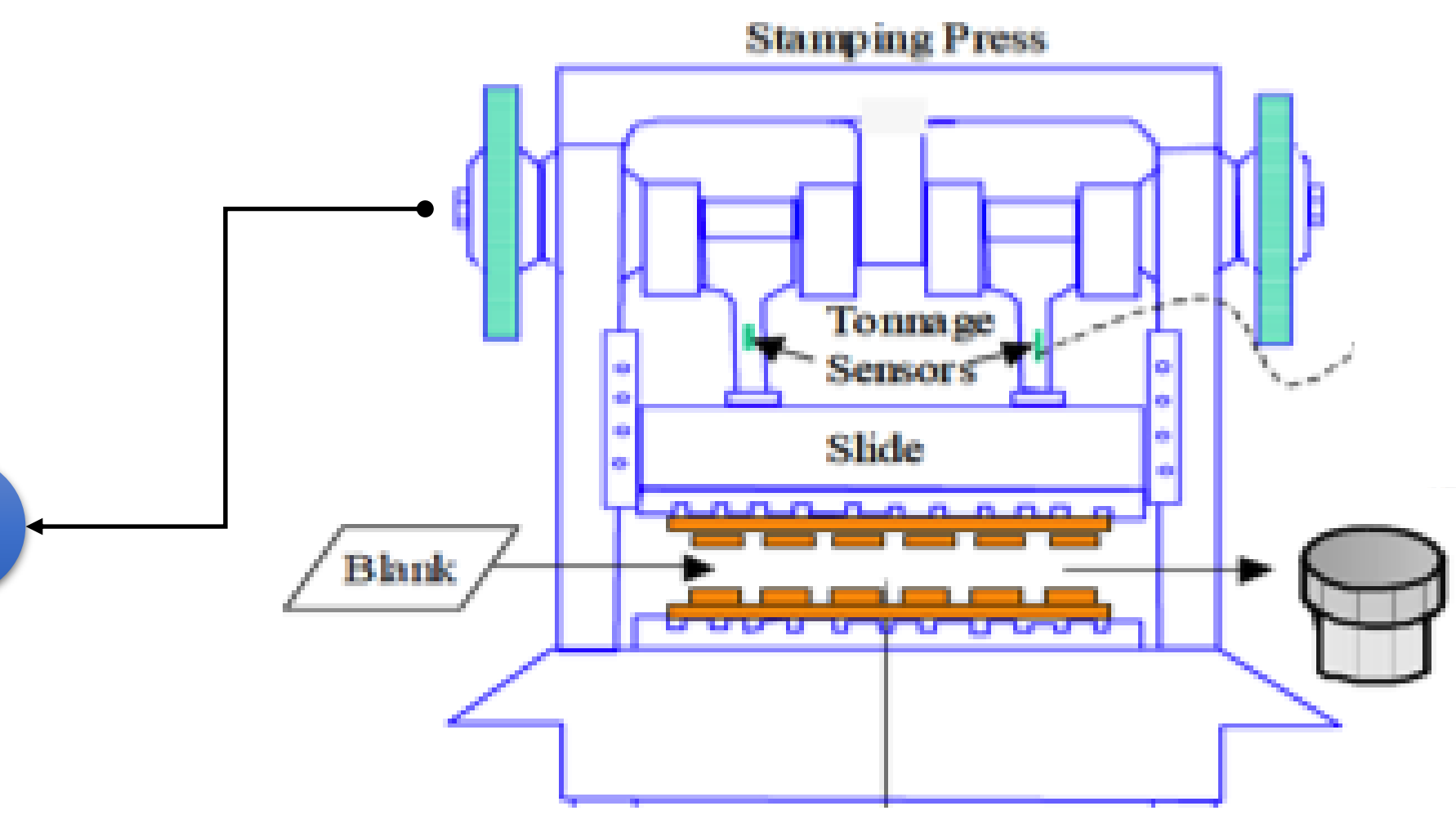

- Signal Decomposition

\section{Progressive stamping process}




\section{Tool Monitoring Using Motor Current}

\section{- Monitor boring process}

- Use time-frequency analysis to characterize process performance

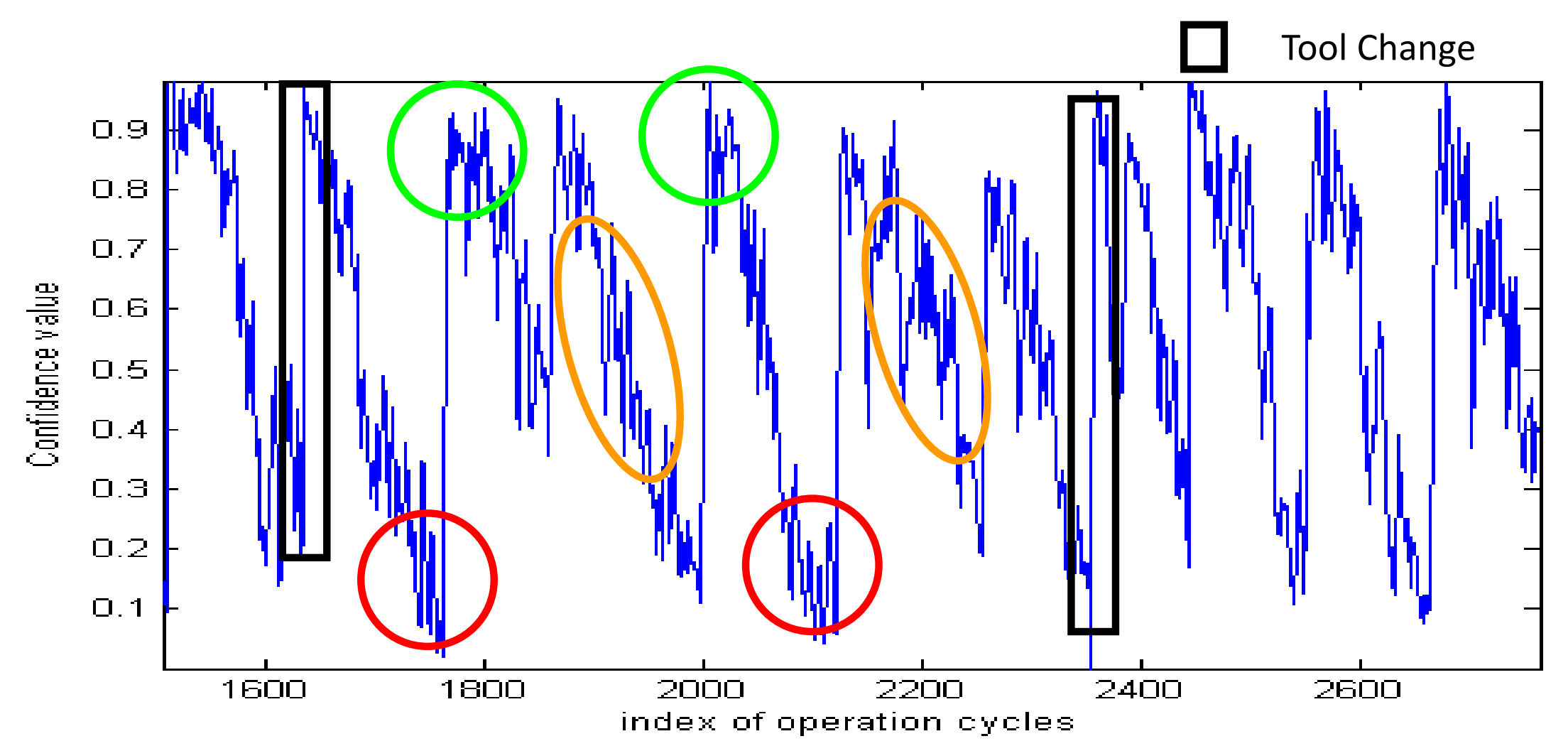

Normal operation

Degradation

Worn Tool

Change 


\section{Challenges in Degradation Analysis}

- Multiple Operating Regimes / Operating Conditions

- Dynamic Environmental Condition

- Uncertainty in future usage condition

New methods are needed that can incorporate not only historical (prior) information but also its unique future operating environmental profile.

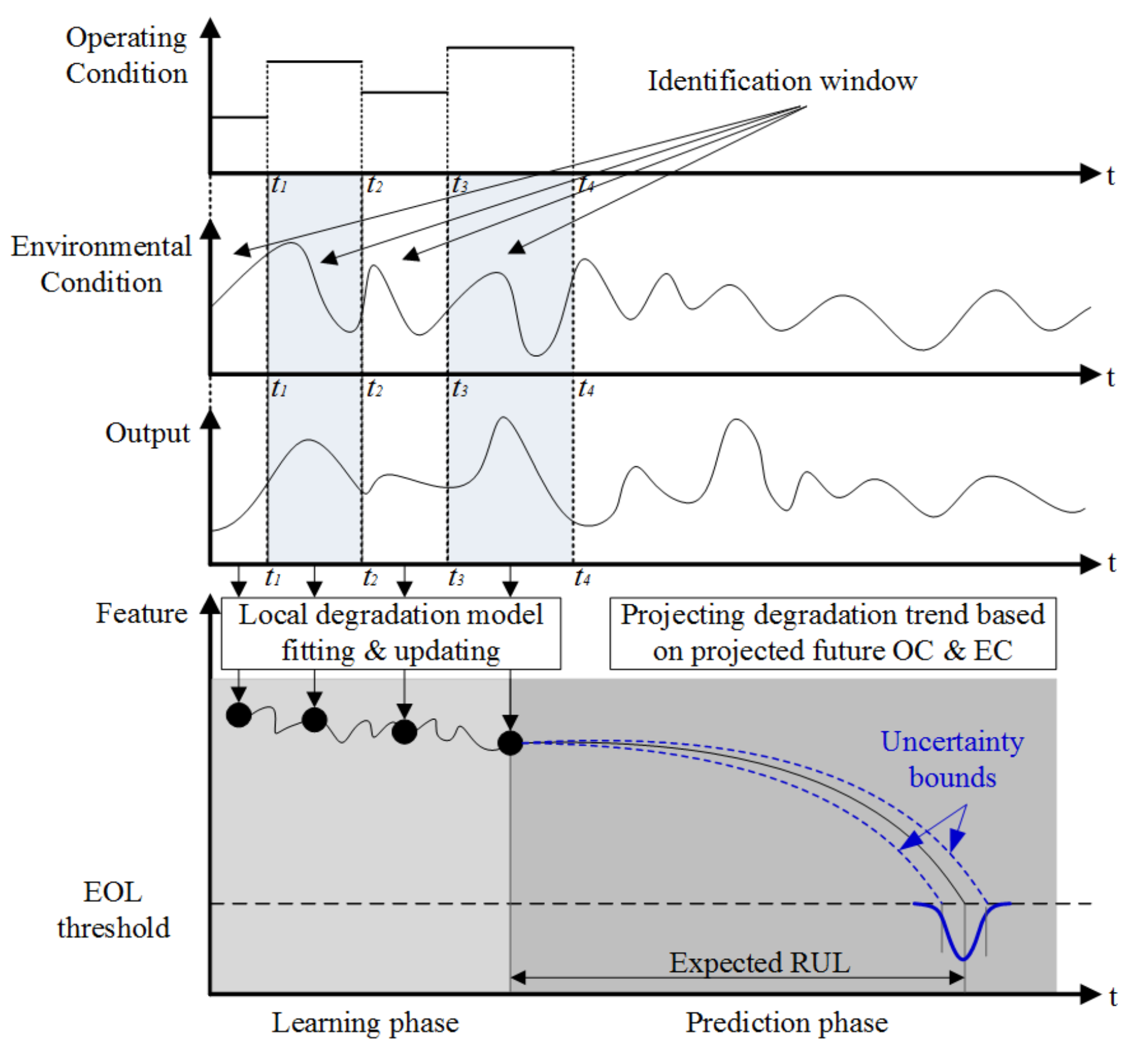




\title{
Process-Level \& System-Level
}

\author{
Case Studies
}




\section{Multistage Discrete Manufacturing Systems (Sensor-Rich)}

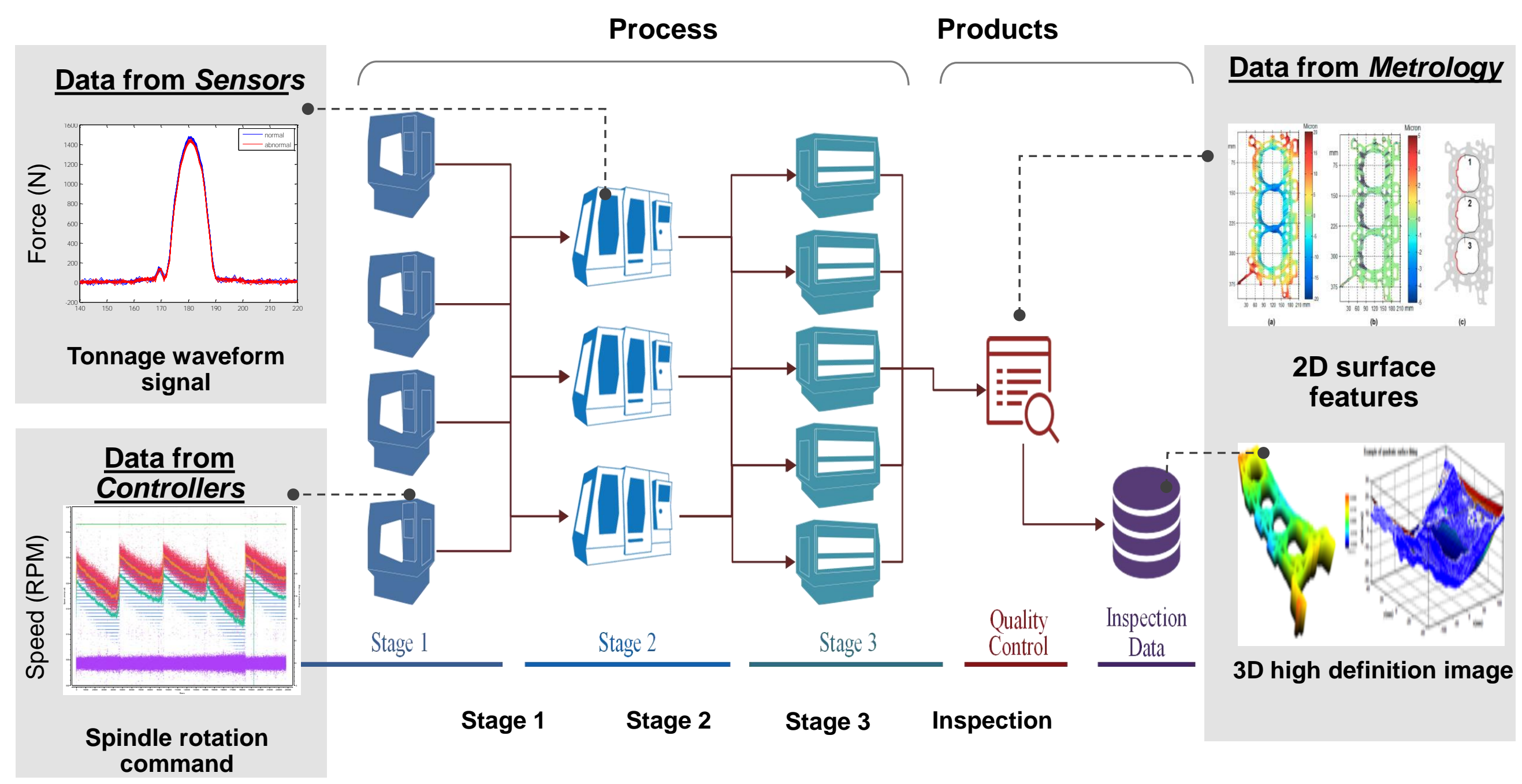




\section{Integrating Data Analytics with Physics-Based Modeling}

\section{Physical World}
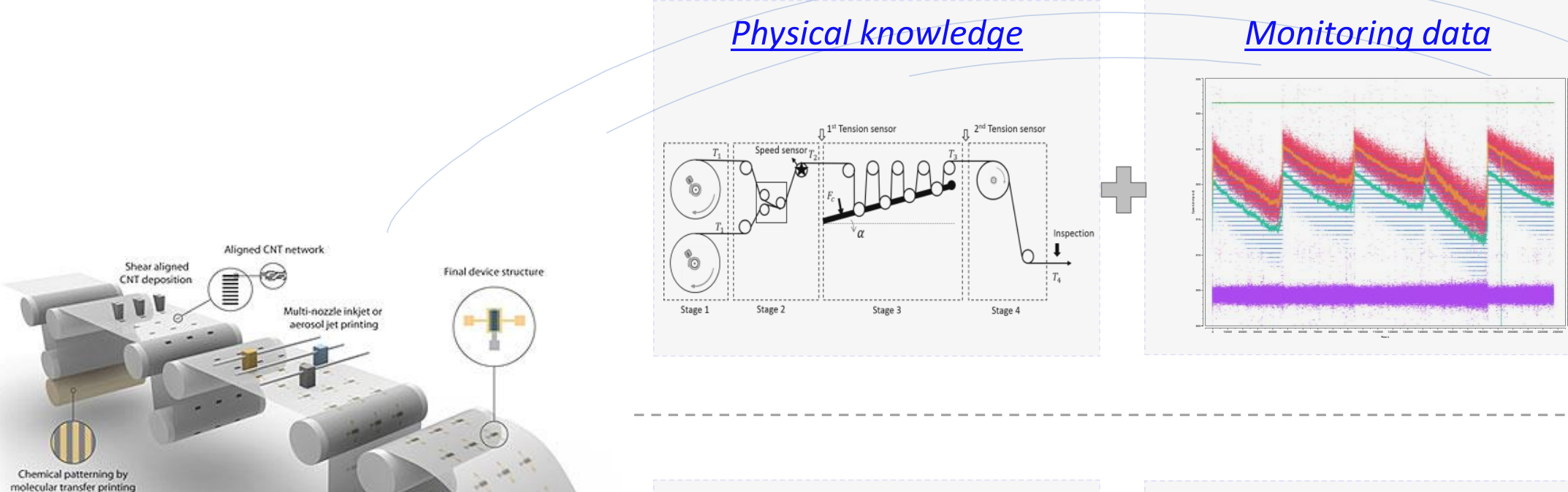

- Real implementation

- Real component

- Real machine

- Real system

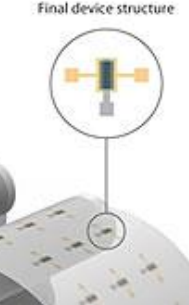

- Real ......

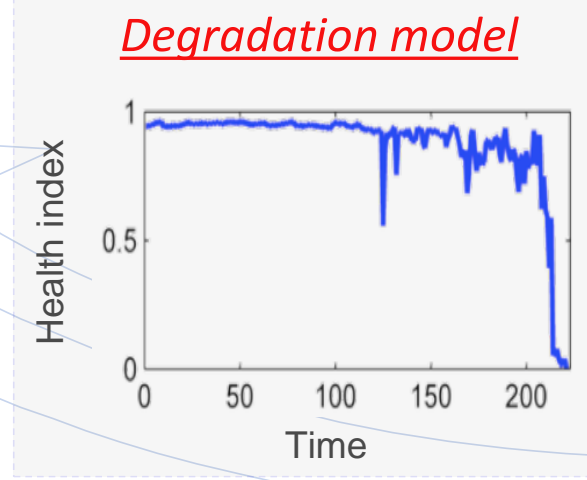

Risk analysis

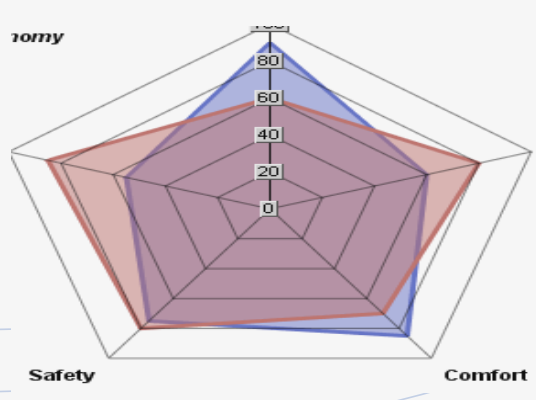

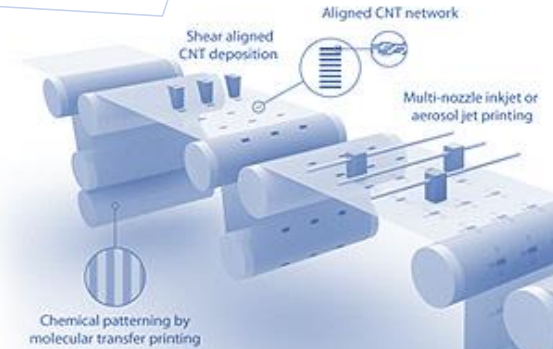

- Virtual synthesis

- Virtual component

- Virtual machine

- Virtual system

- Virtual ...... 


\section{Maintenance Decision-Making: OEE + Predictive Analytics}

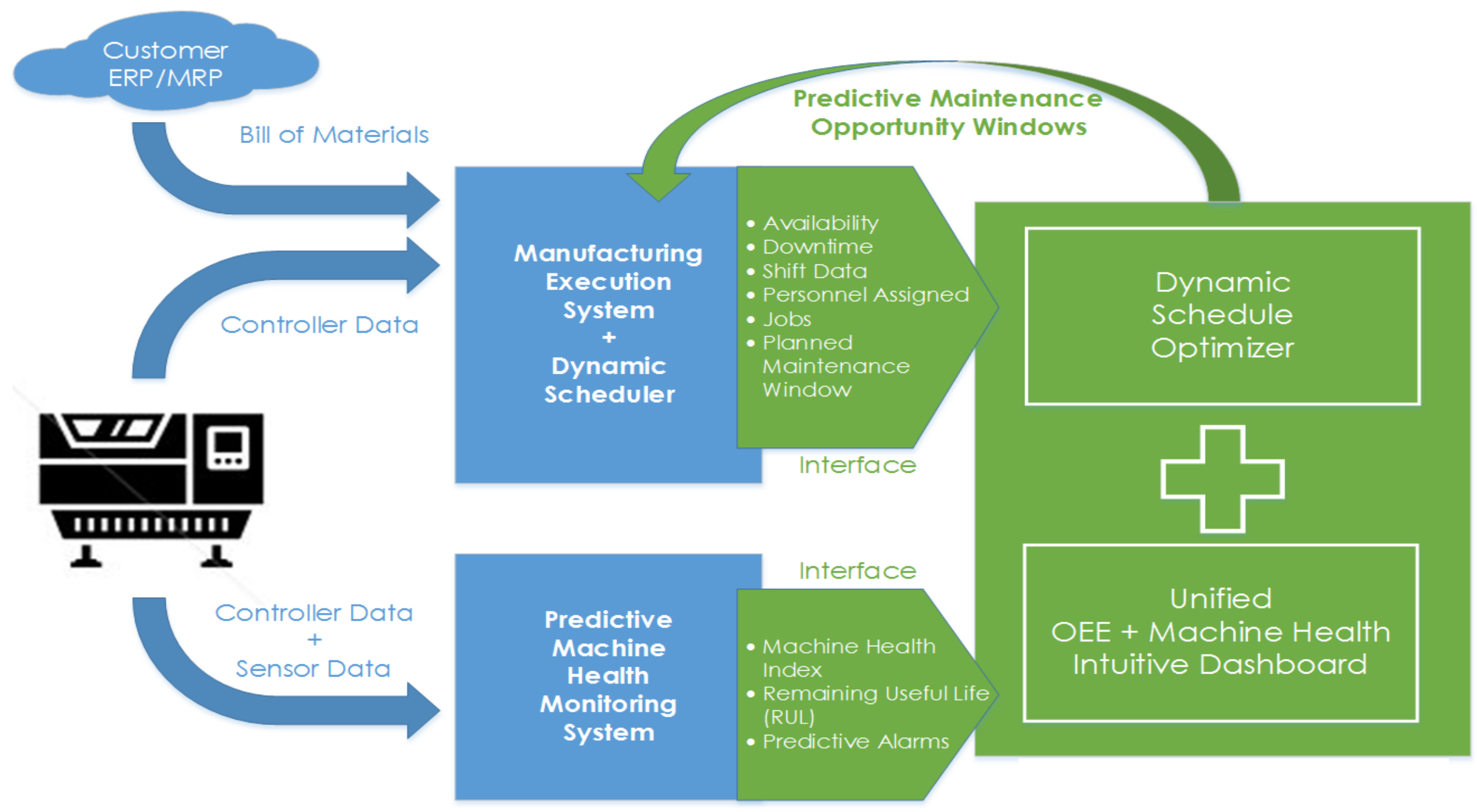

Source: DMDII Project: FORCAM, Predictronics, Northeastern Univ., Lockheed Martin 


\section{Current State and Future Growth of PHM in U.S. Manufacturing - A Pilot Study with NIST}

- Project Motivation - To understand the current state of Prognostics and Health Management in U.S Manufacturing, to understand their current maintenance practices, and what successes and failures the manufacturers had when adding PHM technology to their machines and processes.

- Project Kickoff-September 2014

- Project Data Collection and Case Study Visits - (October 2014 - April 2015) - Data collection and case study visits were performed on a variety of manufactures (from different sectors and sizes). Discussions with technology providers were also added to better understand their perspectives on manufacturing PHM.

- Data Analysis - (May 2015 - September 2015) - The information was organized, summarized, and analyzed in preparation for the journal manuscripts.

- Outcomes - Two journal papers.

- Jin, X., Siegel, D., Weiss, B., Gamel, E., Wang, W., Lee, L. and J. Ni (2016) “The Present Status and Future Growth of Maintenance in US Manufacturing: Results from a Pilot Survey", Manufacturing Review, DOI: 10.1051/mfreview/2016005.

- Jin, X., Weiss, B., Siegel, D. and Lee, J. (2016) “Present Status and Future Growth of Advanced Maintenance Technology and Strategy in US Manufacturing", International Journal of Prognostics and Health Management (Special Issue on Smart Manufacturing PHM). 


\section{Objectives of Pilot Study}

1. Examine the current practices of diagnostics, prognostics and maintenance employed by U.S. manufacturers to achieve productivity \& quality targets, and and review their past successes and failures.

2. Identify the common metrics used by the manufacturing industry to assess their productivity, maintenance and reliability, and product quality.

3. Identify the key factors that affect the effectiveness of maintenance and PHM technology implementation.

4. Research the best practices that manufacturers are using to improve their productivity, lower their maintenance costs, and improve their product quality.

5. The information from this research study provides a strong foundation for developing a set of standards and methodology for deploying intelligent maintenance systems for manufacturing applications. 


\section{Questions We Asked}

What matters to manufacturers?

What maintenance strategy are manufacturers adopting now?

What is the status of manufacturing prognostic and health management?

Are there any maintenance and PHM best practices that can be learned from manufacturer leaders?
Reducing waste, improving equipment up-time, and optimizing product quality are three metrics important to manufacturers

The various maintenance strategies that manufacturers have used are in a constant state of evolution and this study aims to investigate their current practices further

With improvements in computing power, sensors, network communication, and automation, PHM technologies are emerging research topics in manufacturing

This study investigated various manufacturing organizations and help summarize their best practices and success stories 


\section{Evolution of Maintenance Paradigm}

\begin{tabular}{|c|c|c|c|c|}
\hline $\begin{array}{l}\text { Maintenance } \\
\text { Strategy }\end{array}$ & $\begin{array}{c}\text { Reactive Maintenance } \\
\text { (RM) }\end{array}$ & $\begin{array}{c}\text { Preventive Maintenance } \\
\text { (PM) }\end{array}$ & $\begin{array}{c}\text { Predictive Maintenance } \\
\text { (PdM) }\end{array}$ & $\begin{array}{c}\text { Proactive Maintenance } \\
\text { (PaM) }\end{array}$ \\
\hline $\begin{array}{l}\text { Maintenance } \\
\text { Interval }\end{array}$ & Fail and fix & Time based; Usage based & $\begin{array}{c}\text { Reliability based; Condition } \\
\text { based }\end{array}$ & Improve \& sustain \\
\hline Object & $\begin{array}{c}\text { Component; } \\
\text { Sub-system; System }\end{array}$ & $\begin{array}{c}\text { Component; Sub-system; } \\
\text { System }\end{array}$ & $\begin{array}{l}\text { Component; Function; } \\
\text { System }\end{array}$ & $\begin{array}{l}\text { Component; Function; } \\
\text { System }\end{array}$ \\
\hline $\begin{array}{l}\text { Planning \& } \\
\text { Scheduling }\end{array}$ & Planning on the fly & $\begin{array}{c}\text { Planning \& scheduling } \\
\text { based on ideal PM interval }\end{array}$ & $\begin{array}{l}\text { Predictive planning \& } \\
\text { scheduling }\end{array}$ & $\begin{array}{l}\text { Proactive planning \& } \\
\text { scheduling }\end{array}$ \\
\hline $\begin{array}{l}\text { Human Factors } \\
\text { (inspection \& } \\
\text { decision-making) }\end{array}$ & Medium to High & Intermediate & Low & Low (false alarm) \\
\hline Cost Effectiveness & $\begin{array}{l}\text { Labor intensive; Labor } \\
\text { and material }\end{array}$ & $\begin{array}{c}\text { Costly due to over } \\
\text { maintenance or ineffective } \\
\& \text { inefficient PM }\end{array}$ & $\begin{array}{l}\text { Cost-effective; extended life } \\
\& \text { less failure-induced costs }\end{array}$ & $\begin{array}{l}\text { Cost-effective: Substantially } \\
\text { save failures \& extend the } \\
\text { life of equipment }\end{array}$ \\
\hline $\begin{array}{l}\text { Requirement for } \\
\text { Technology } \\
\text { Readiness }\end{array}$ & Low & Low to Medium & High & High \\
\hline
\end{tabular}




\section{Pilot Study - Data Collection}

- The enterprises represent various sectors within manufacturing, including: automotive, aerospace, transportation, machinery and equipment, consumer products, and electronics.

- Participating enterprises segmented by size \& type:

\begin{tabular}{lcccc} 
& SME & Large & Total & Percent \\
$\begin{array}{l}\text { Manufacturing } \\
\begin{array}{l}\text { Enterprise } \\
\text { Technology/Consulting }\end{array}\end{array}$ & 5 & 12 & 15 & $65.2 \%$ \\
$\begin{array}{l}\text { Enterprise } \\
\text { Total }\end{array}$ & 8 & 15 & 23 & $100 \%$ \\
\hline
\end{tabular}

- Five categories of questions:

(1) Manufacturing system performance measurement,

(2) Diagnostics and prognostics technology,

(3) Maintenance strategy and effectiveness,

(4) Key factors that affect maintenance performance,

(5) Future trends for PHM technology for smart manufacturing from an industrial perspective. 


\section{Survey Results and Analysis}

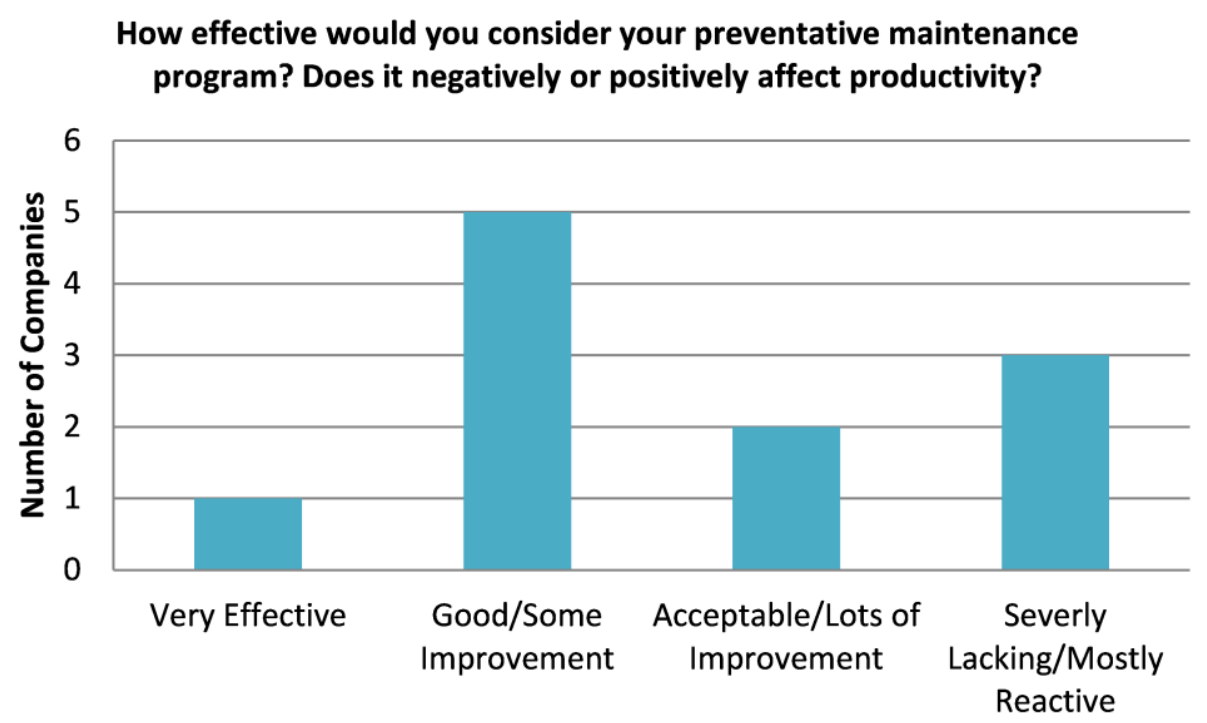

How do you prioritize which failure mode or

asset/machine/component needs a PHM system, what criteria is used? (Companies were allowed to give more than one answer unless they select "other".)

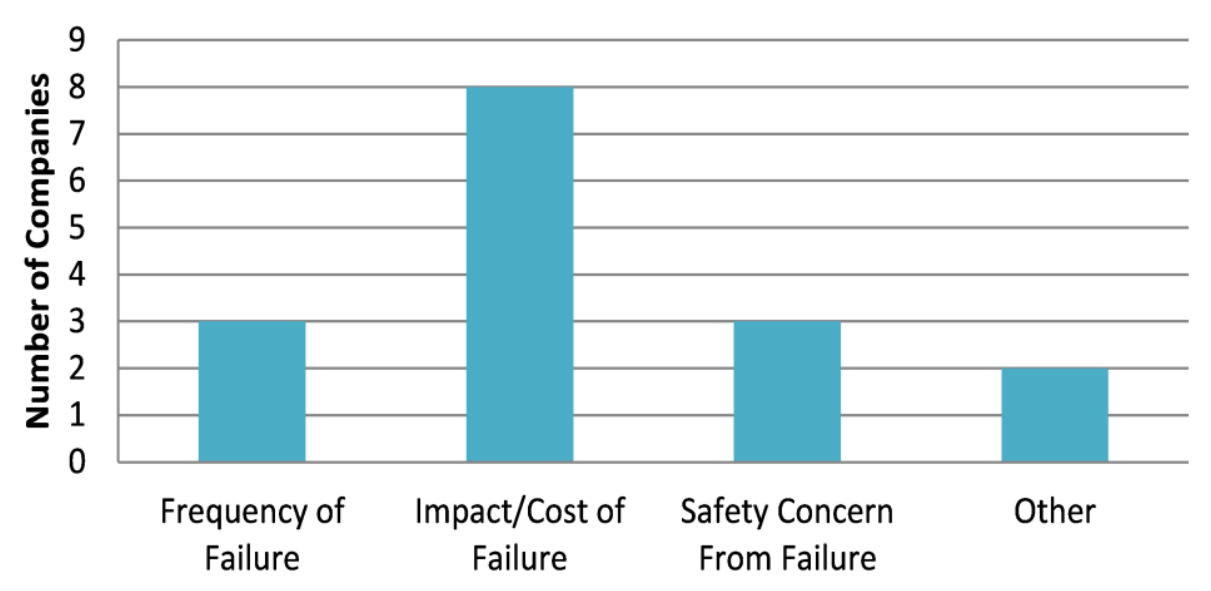

- Larger manufacturing facilities had a more effective preventative maintenance program.

- However, this would also depend on the diversity of assets that they had in their facilities along with the age of the factory and equipment.

- For smaller manufacturing facilities, reactive maintenance was noted as their current strategy.
- The majority of them consider the impact/cost of failure as a key criterion for ranking machines and failure modes. 


\section{Comparison Between SMEs \& Large-sized Manufacturers}

\section{Average Responses from Large Manufacturers}

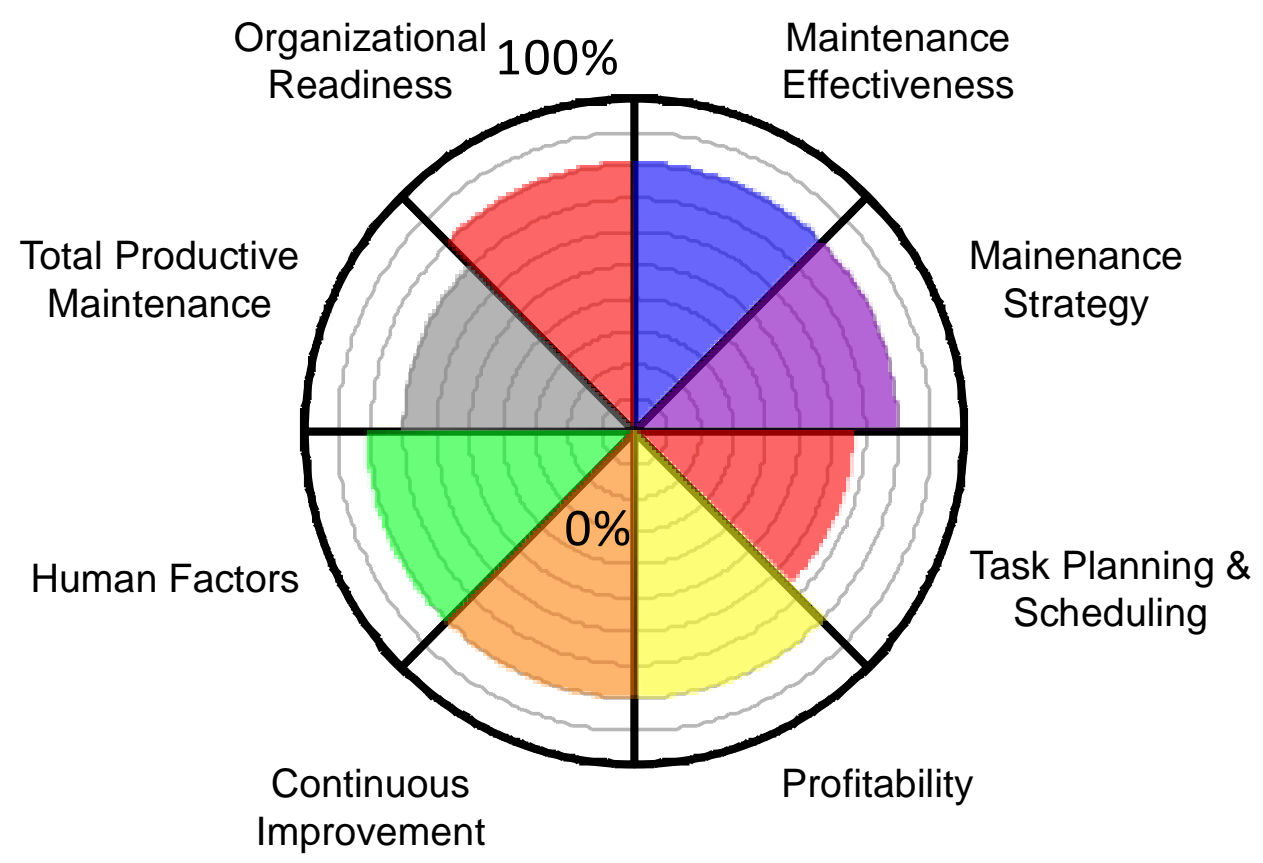

(a)

\section{Average Responses from SMEs}

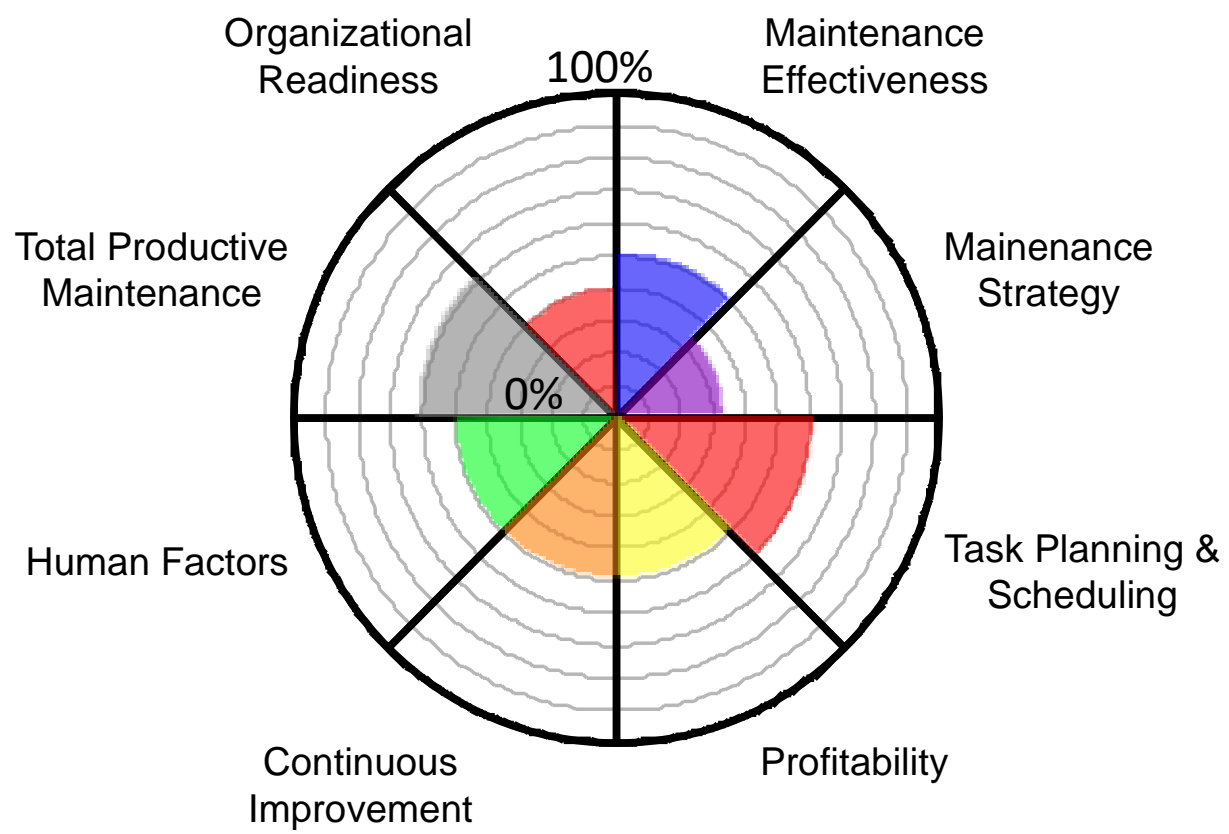

(b)

" Level 1 (Beginning): $0.00 \%-33.3 \%$ corresponds to the beginning level which is least intelligent in maintenance technology and strategy as well as their effectiveness

» Level 2 (Intermediate): $33.3 \%-66.7 \%$ represents the intermediate level

»Level 3 (Advanced) : $66.7 \%$ - $100 \%$ represents the most advanced level in terms of performance and effectiveness

Size-related advantages for large-sized manufacturers: R\&D support, leadership involvement, skilled workforce, etc. 


\section{Correlation analysis}

- Correlation analysis for eight maintenance related factors

\begin{tabular}{|c|c|c|c|c|c|c|c|c|c|c|}
\hline & \multirow{2}{*}{$\begin{array}{l}\text { F1 } \\
\text { Size }\end{array}$} & \multirow{2}{*}{$\begin{array}{l}\text { F2 } \\
\text { Effect. }\end{array}$} & \multirow{2}{*}{$\begin{array}{l}\text { F3 } \\
\text { Strategy }\end{array}$} & \multirow{2}{*}{$\begin{array}{l}\text { F4 } \\
\text { Sched. }\end{array}$} & \multirow{2}{*}{$\begin{array}{l}\text { F5 } \\
\text { Profitability }\end{array}$} & \multirow{2}{*}{$\begin{array}{l}\text { F6 } \\
\text { Impr. }\end{array}$} & \multirow{2}{*}{$\frac{F 7}{H R}$} & \multirow{2}{*}{$\begin{array}{l}\text { F8 } \\
\text { TPM }\end{array}$} & \multirow{3}{*}{$\begin{array}{l}\text { F9 } \\
\text { Readiness }\end{array}$} \\
\hline & & & & & & & & & & \\
\hline F1 & Size & 1.000 & $.608^{*}$ & $.696 *$ & .290 & $.603 *$ & $.613^{*}$ & $.603^{*}$ & .452 & \\
\hline F2 & Effectiveness & $.608^{*}$ & 1.000 & .130 & .204 & $.829 * *$ & $.678^{* *}$ & $.699 * *$ & .453 & .320 \\
\hline F3 & Strategy & $.696 * *$ & .130 & 1.000 & .202 & .258 & .443 & .339 & .225 & $.857 * *$ \\
\hline F4 & Scheduling & .290 & .204 & .202 & 1.000 & .090 & -.046 & -.090 & .031 & .155 \\
\hline F5 & Profitability & $.603^{*}$ & $.829 * *$ & .258 & .090 & 1.000 & $.656^{* *}$ & $.871^{* *}$ & .225 & .413 \\
\hline F6 & Improvement & $.613 *$ & $.678^{* *}$ & .443 & -.046 & $.656^{* *}$ & 1.000 & $.820 * *$ & .365 & $.613^{*}$ \\
\hline F7 & HR & $.603 *$ & $.699 * *$ & .339 & -.090 & $.871^{* *}$ & $.820 * *$ & 1.000 & .225 & $.492 *$ \\
\hline F8 & TPM & .452 & .453 & .225 & .031 & .225 & .365 & .225 & 1.000 & .243 \\
\hline F9 & Readiness & $.685^{* *}$ & .320 & $.857 * *$ & .155 & .413 & $.613 *$ & $.492 *$ & .243 & 1.000 \\
\hline
\end{tabular}

* The correlation is significant at the level of 0.05 (two-sided)

** The correlation is significant at the level of 0.01 (two-sided)

\section{- Key findings:}

- Maintenance effectiveness, maintenance strategy, cost-to-benefits ratio, HR for maintenance and organizational readiness are significantly correlated with the size of manufacturing enterprise

- Maintenance task planning \& scheduling, Total Productive Maintenance (TPM) are NOT significantly correlated with size. 


\section{Case Study 1}

\section{Large-Sized Manufacturing Enterprise}

- Transportation manufacturer - develop a pilot factory implementing new predictive \& preventive maintenance technologies

- 30 different machines in a remanufacturing facility

- Significant efforts on data collection infrastructure and sensor strategies

- Prioritize machine based on cost-to-benefit ratio and level of criticality.

Success: monitoring machine for failure/downtime detection -- statistical control tools and visual inspection of sensor signals

> Pain: (1) Lack of automated process of data analytics and anomaly detection algorithms; (2) False alarms \& miss detection; (2) System barriers in data integration \& fusion prevent collection and correlation of data for maximum impact

$>$ Goal: Automate the diagnostics process, develop predictive capability, have a better baseline fingerprint for each machine. 


\section{Case Study 2}

\section{Small to Mid-Sized Manufacturing Enterprises (SME)}

- A small original equipment manufacturer - manufacturer a component of a varying sizes using a combination of sheet-metal forming, machining, and welding processes.

- $<100$ people on the shop floor

- Work-in-Process (WIP) is between 400 to 600 pieces

- Maintenance strategy is driven by high operation and tooling costs, and spare parts supply issue.

Success: preventive maintenance is dominant, reactive maintenance is effective.

$>$ Pain: poor tool life prediction leads to high investment in spare parts inventory

- Goal: transition to a predictive maintenance strategy -- enhance the ability to plan maintenance around critical machines, reduce WIP, exploring networking equipment systems for data storage, improve job tracking and scheduling. 


\section{Gaps, Future Trends and Research Directions}

\section{- Common issues:}

- False alarm rate

- Lack of failure data, run-to-failure data

- Set up baseline condition for various operating condition

- Lack of system-level methodology

\section{- Barriers:}

- Non-standardized/systematic data collection, integration \& analysis

- Difficulty in interpreting meaning of machine failure/performance change (actionable information)

- Lack of systematic approaches for maintenance planning

\section{» Future Research}

- Development of new technologies and infrastructure to support PHM system implementation for smart manufacturing

- From a fail-and-fix paradigm to a predictive-and-proactive paradigm

- System-level diagnostics and predictive analytics

- Multi-modal data fusion

- Dynamic \& Adaptive decision-making for maintenance scheduling and operations planning. 


\section{Summary}

- Source of Variation identification

- Root cause identification

- Resilient control

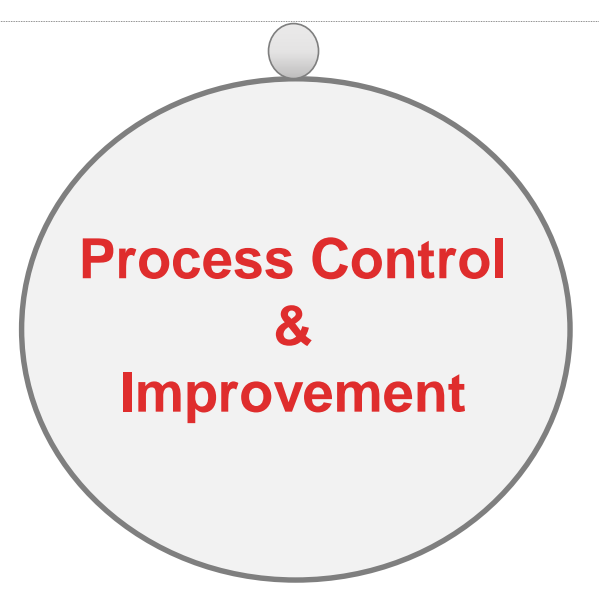

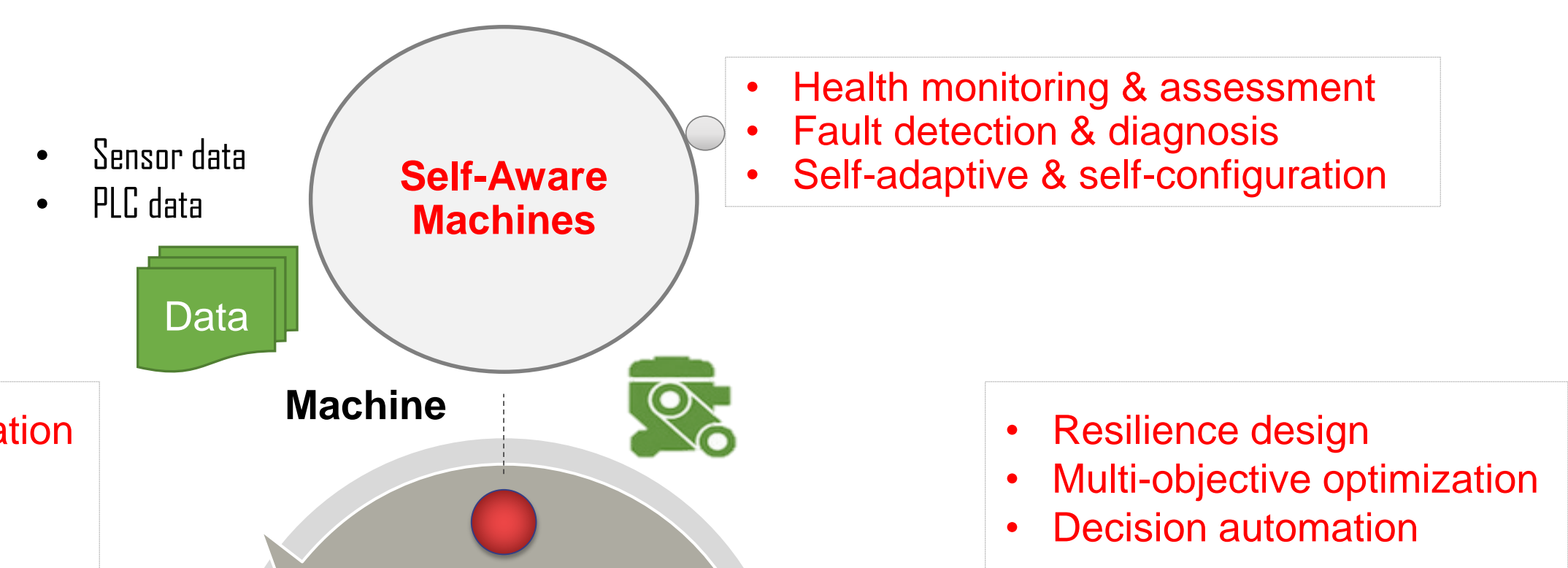

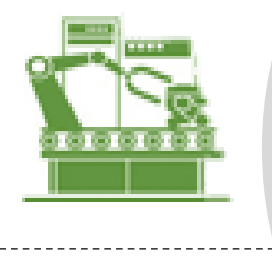

Process

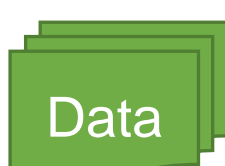

- Controller data

Metrology data
- Multi-objective optimization

- Decision automation

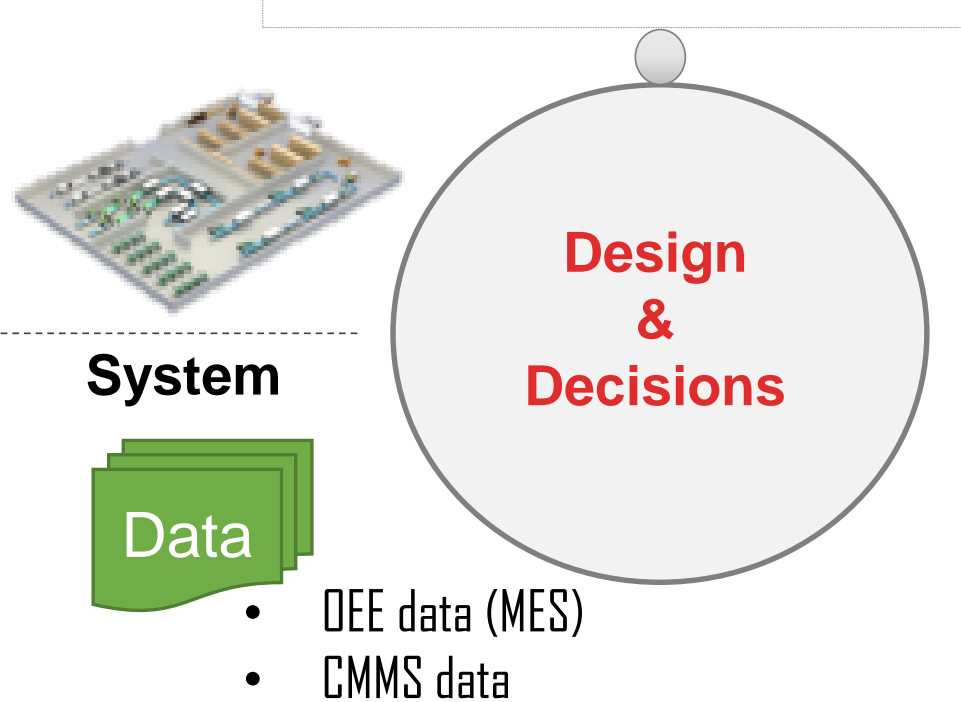




\section{Energy Monitoring, Diagnostics and Prognostics with the Clean Energy Smart Manufacturing Innovation Institute}

Gregg Profozich, CMTC, Former CA RMC Director, CESMII

Dr. Michael Klopfer, California Plug Load Research Center, Calit2, UC Irvine

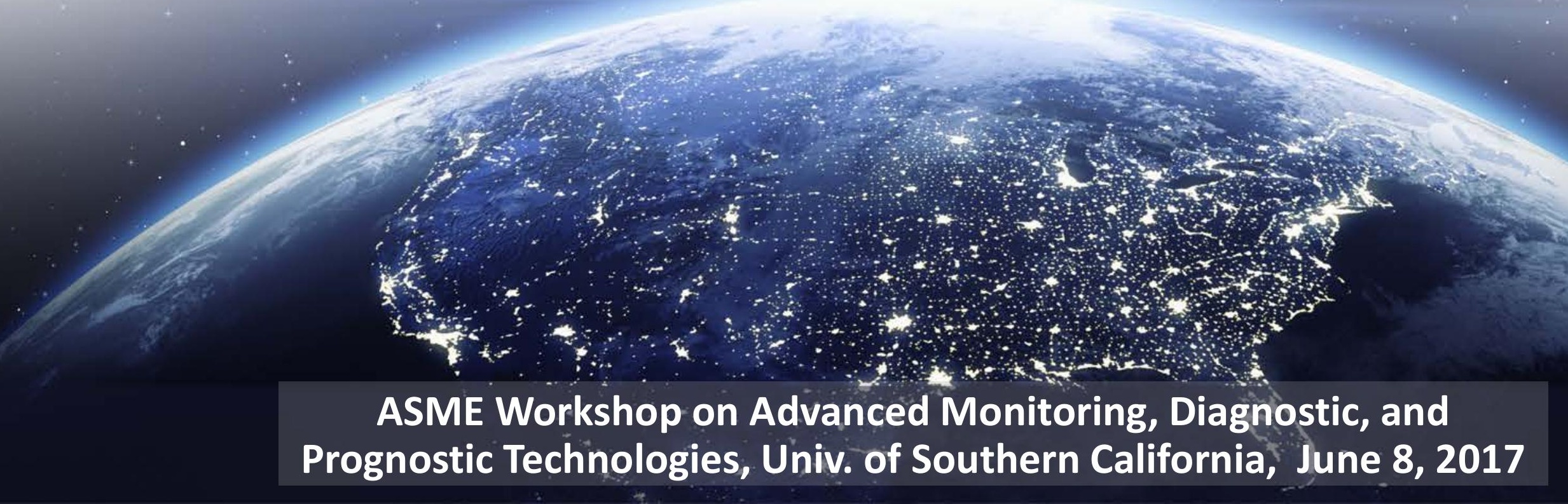




\section{What is Smart Manufacturing?}

The ability to take action, in real time, to OPTIMIZE assets in the context of business strategies and imperatives 


\section{Smart Manufacturing:}

\section{Intersection of Business, Operations, and Technology}

A Comprehensive Approach to Manufacturing to achieve:

$>$ Connected Supply Chain

$>$ Plant-wide Optimization

$>$ Sustainability \& Safety

$>$ Increased Productivity

$>$ Effective Risk Management

$>$ High Quality Products

$>$ Innovation

$>$ Great Customer Service

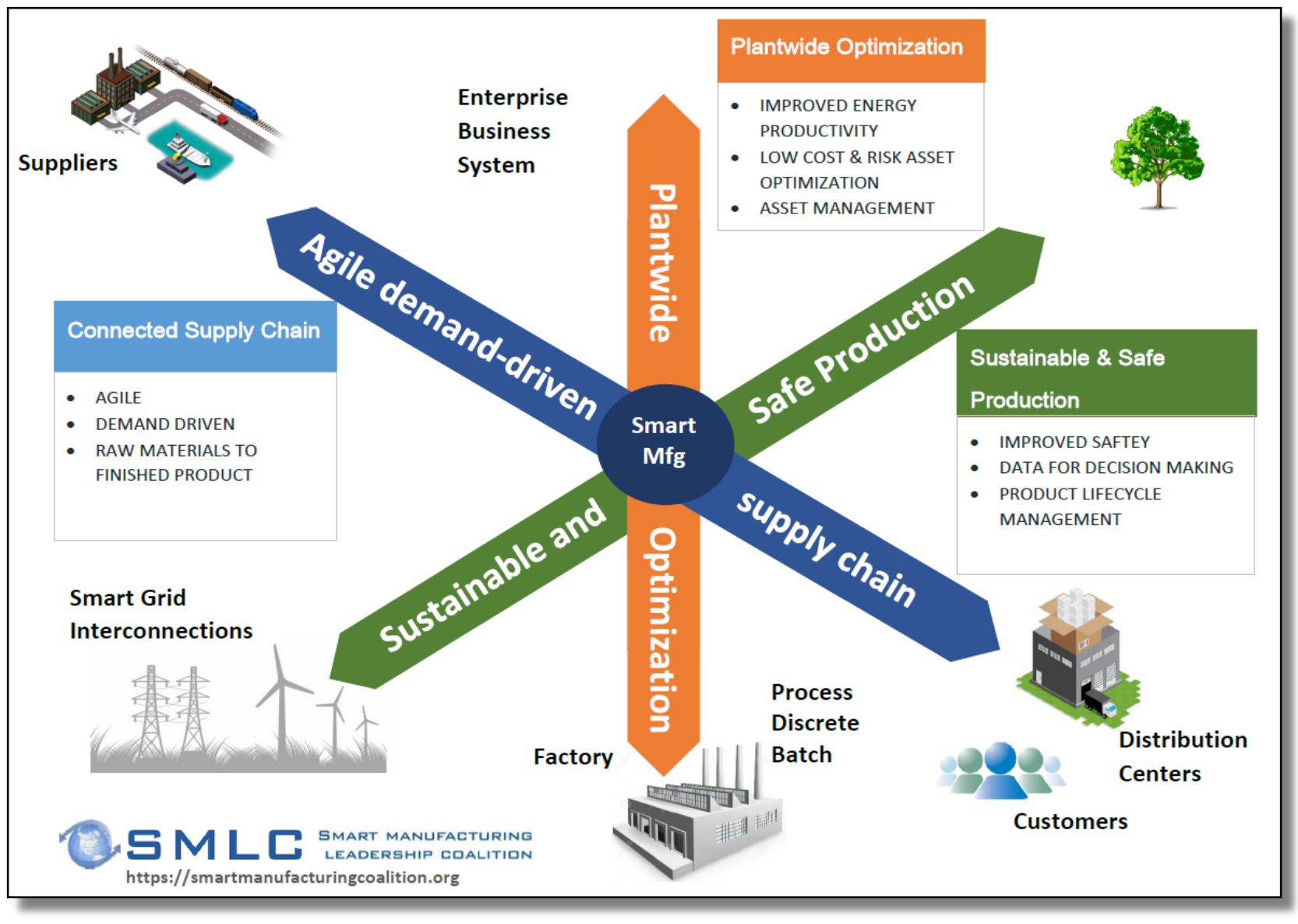

Smart Manufacturing is about: 
Connected Supply Chain

- Agile

- Demand Driven

- Raw Material to Finished Product

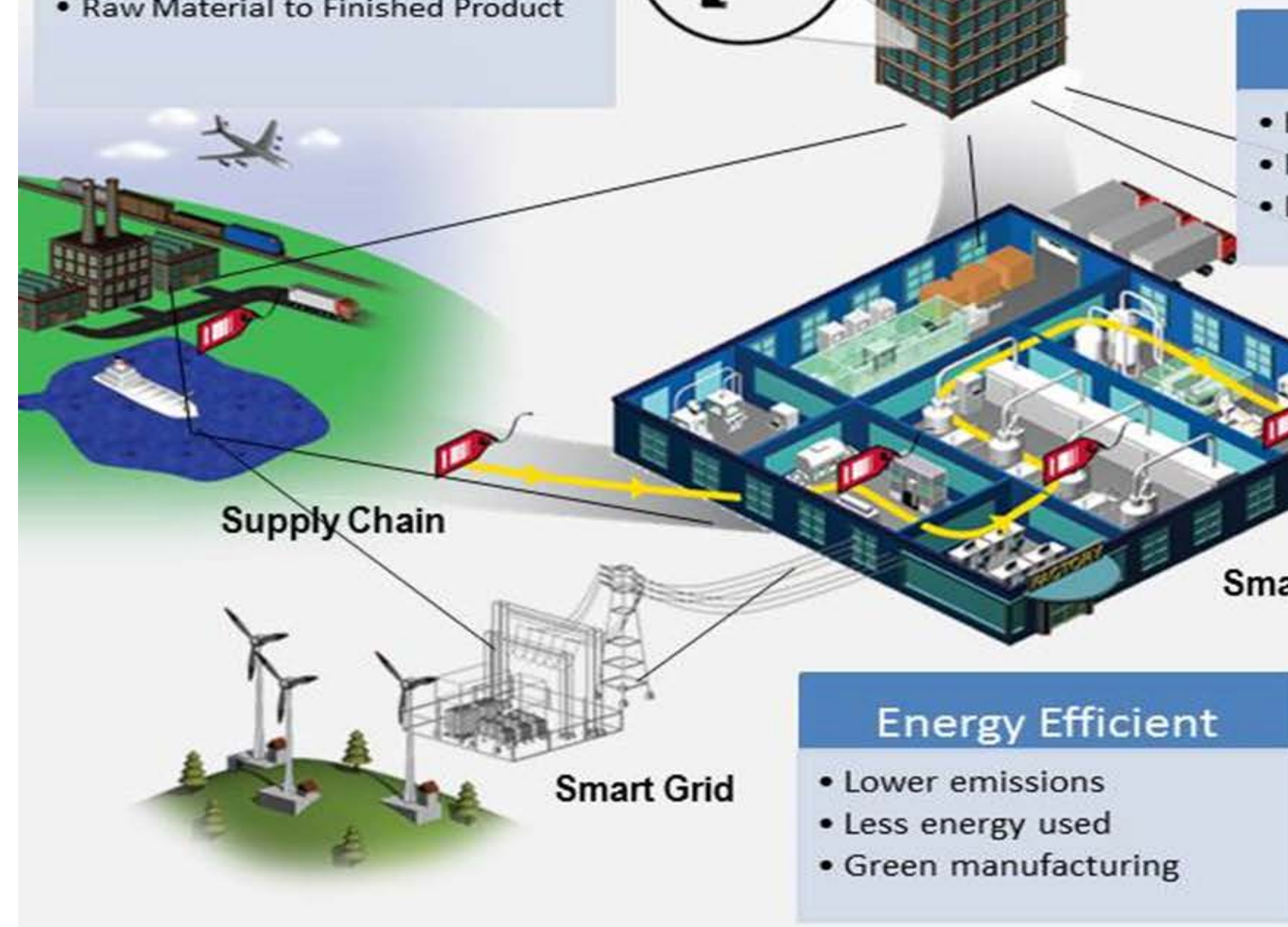
Networked-Based, Smart Manufacturing

\section{Business}

Systems, ERP

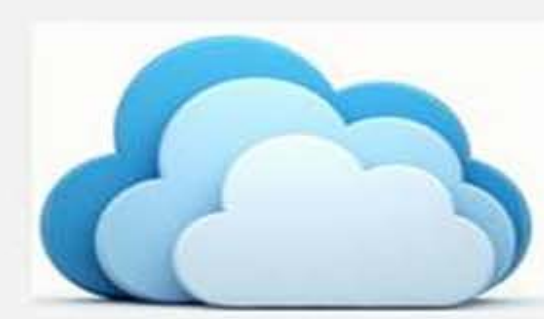

Sustainable Production

\section{Safe Production}

- Improved safety

- Fewer incidents

- More user friendly

- Higher value products

- Data for decision making

- Product Lifecycle

Management

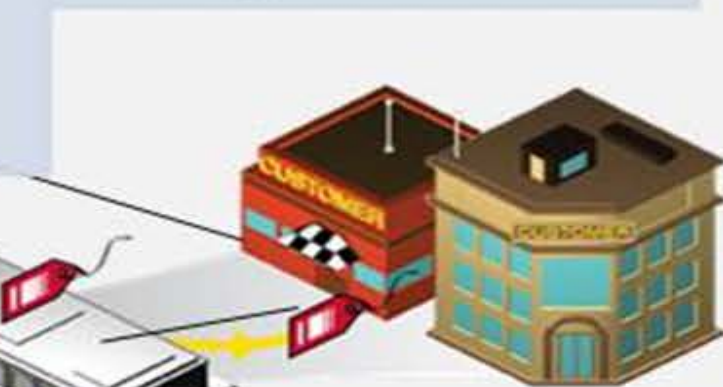

Customer
Smart Factory

\section{Distribution}

Center

\section{Optimization}

- Asset Utility/Zero Downtime

- Quality/Zero Defects

- Reliable results 


\section{Smart Manufacturing:}

Advancing Sensing, Controls, Platforms \& Modeling for Manufacturing

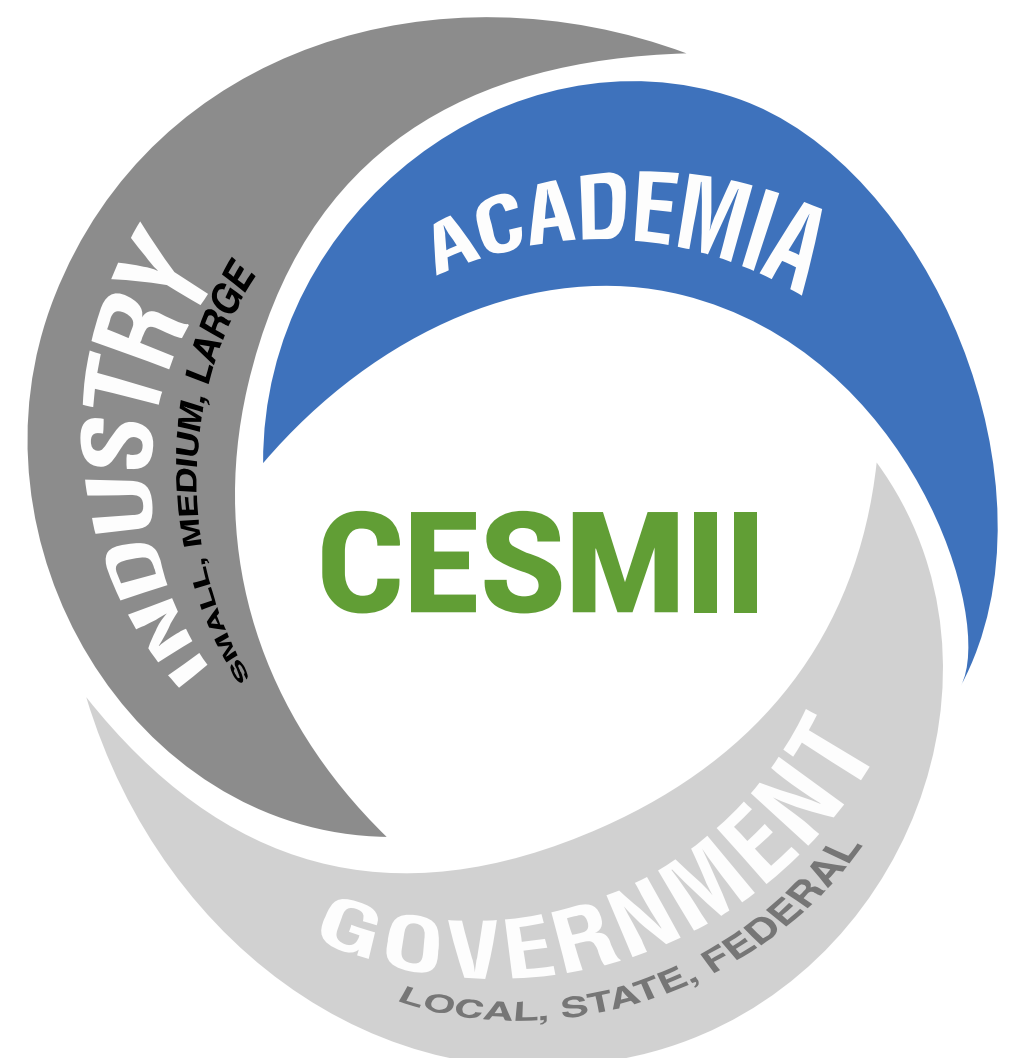

$\$ 140+$ Million in Public-Private

Investment 


\section{CESMII Objectives}

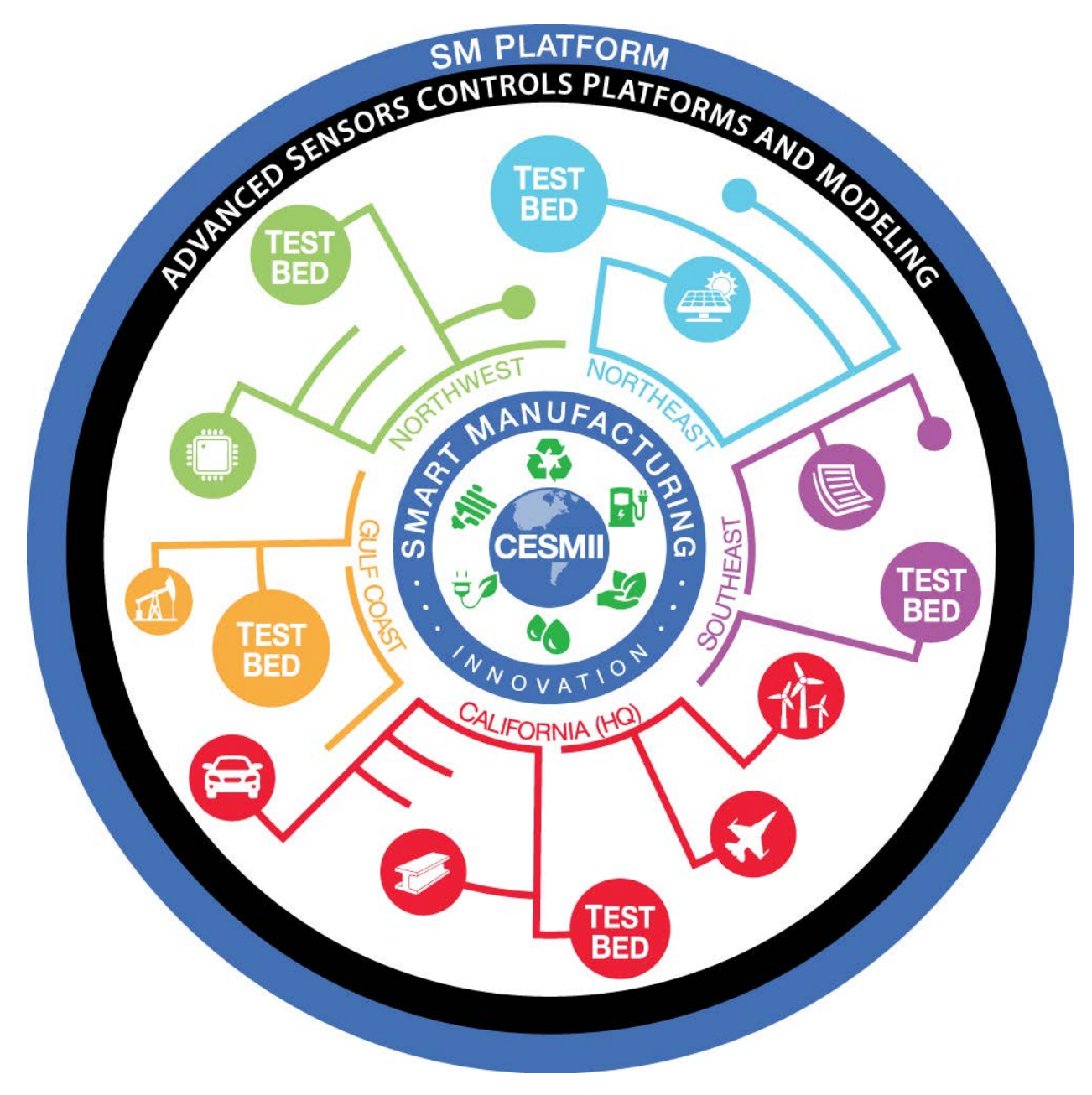

Our Institute will:

- Provide Breakthrough Capability to Drive Energy Reduction by \$195 B

- Be Industry Led and Driven

- Service All Manufacturing Segments

- Develop the Workforce \& Create Jobs

- Be Open to All Size of Enterprises

- Achieve Financial Independence in 5 Years or less 


\section{California Plug Load Research Center (CalPlug)}

\section{Intelligent Management Strategies for Loads}

ASME Workshop on Advanced Monitoring, Diagnostic, and Prognostic Technologies June $8^{\text {th }}, 2017$

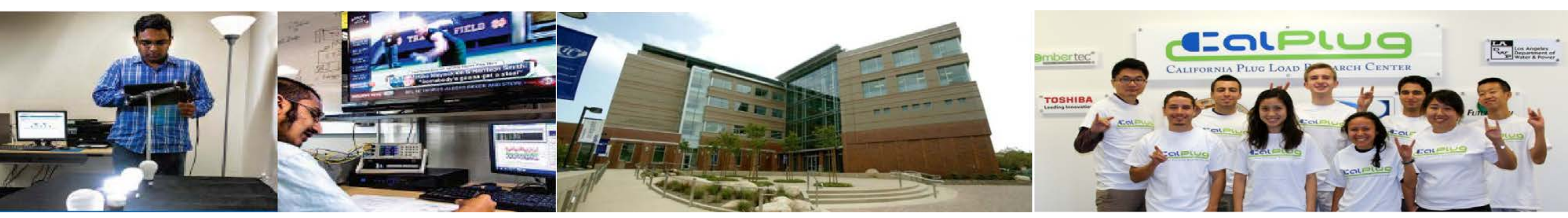

Dr. Michael Klopfer \& Prof. G. P. Li

California Plug Load Research Center

California Institute for Telecommunications and Information Technology 


\section{Residential and Commercial Plug Loads}

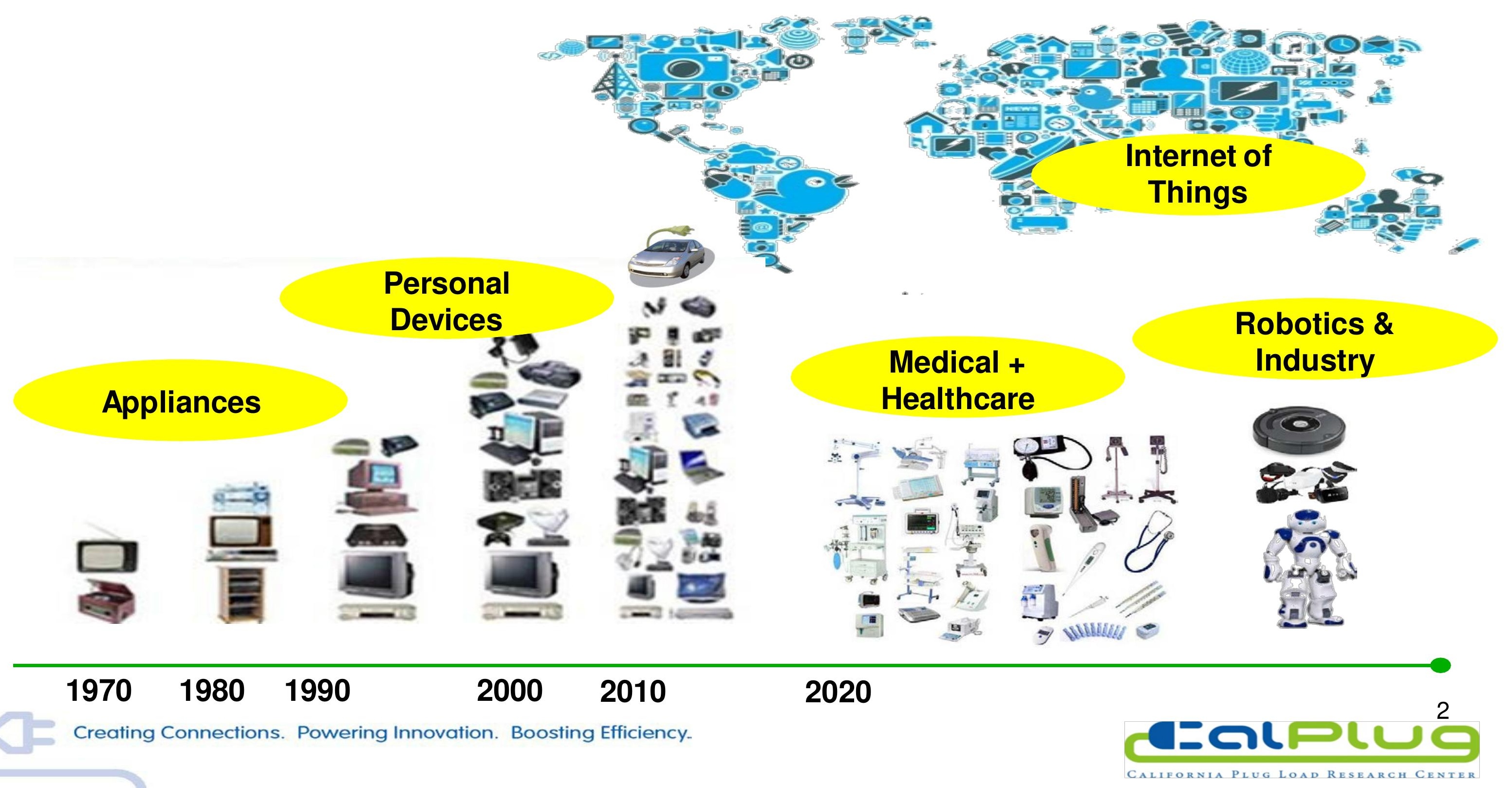




\section{Human/Technology Interaction}

Problem: Users are not effectively using existing sleep settings On Desktop Work PCs. Are Computer Sleep Settings Enabled?

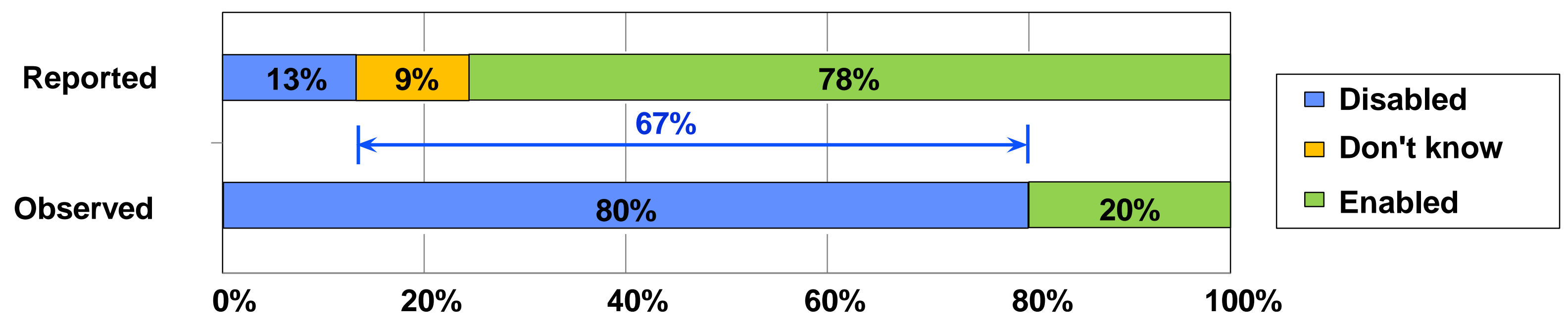

$>$ Approach: Develop a new user interface for sleep settings that is:

$>$ Easy to use and easy to access

$>$ Gives users engaging feedback about how often their computer is idle 


\section{User Feedback: Household Energy}

$>$ Problem: Energy displays at home are not effective.

$>$ Approach: Develop a new in-home Energy Display (Energy Channel) which:

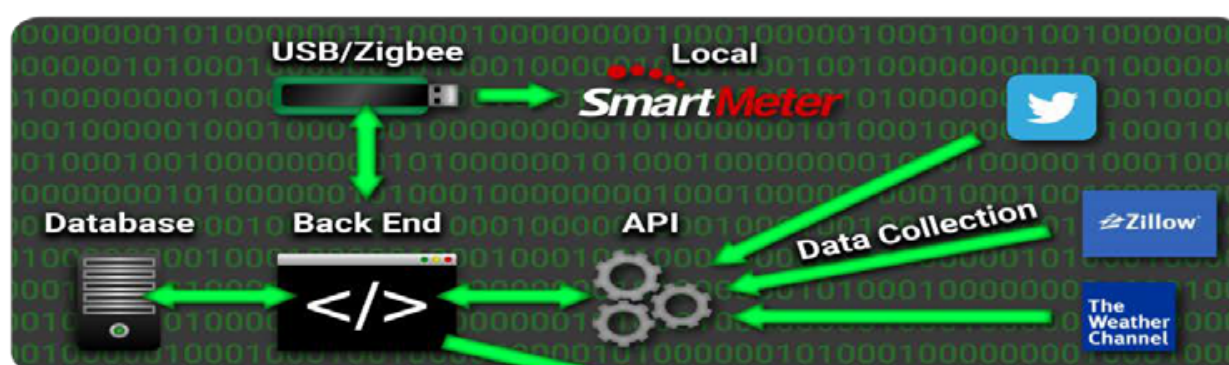

a. allows easy access to the information

b. provides feedback in real-time or as soon as possible

c. presents feedback in meaningful and motivating terms

d. provides comparisons with other references

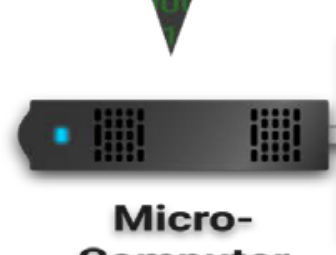

Computer

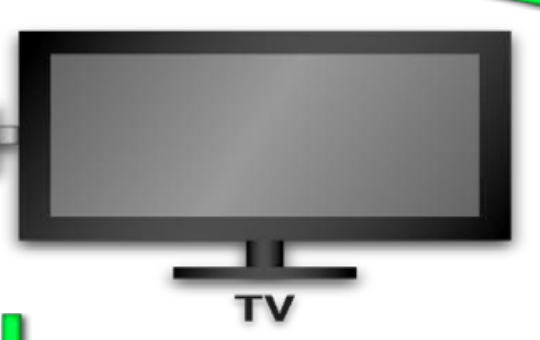

A) Initial Setup

B) Features Customization

C) Energy Display

D) Notifications
A) Remote Control

B) Additional Display

C) Notifications

D) Game Interface

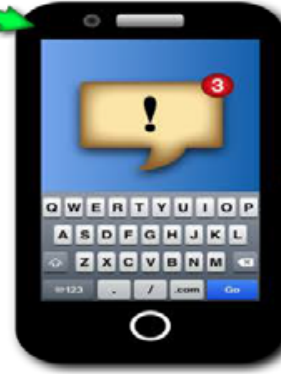

Mobile App 


\section{User Feedback: Household Energy}

$>$ Results: Energy Channel TV and mobile Apps
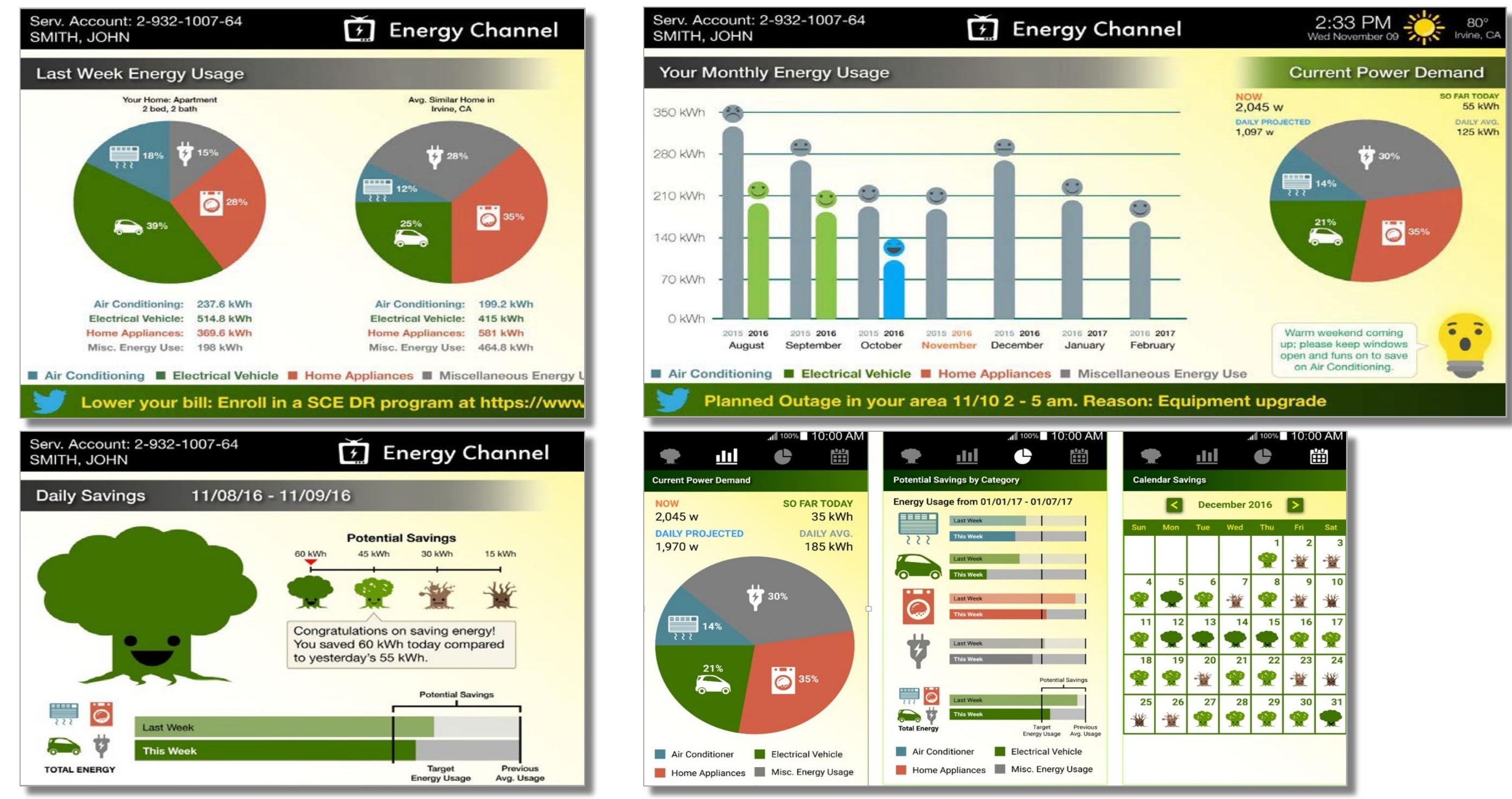


\section{Plug Load Analytics: SmartMon ${ }^{\mathrm{TM}}$ For Educational Purchases}

- Use Plug Load energy usage "signatures" to infer technology usage - Improve quality of feedback from pilot site installations

- Easy to use and portable
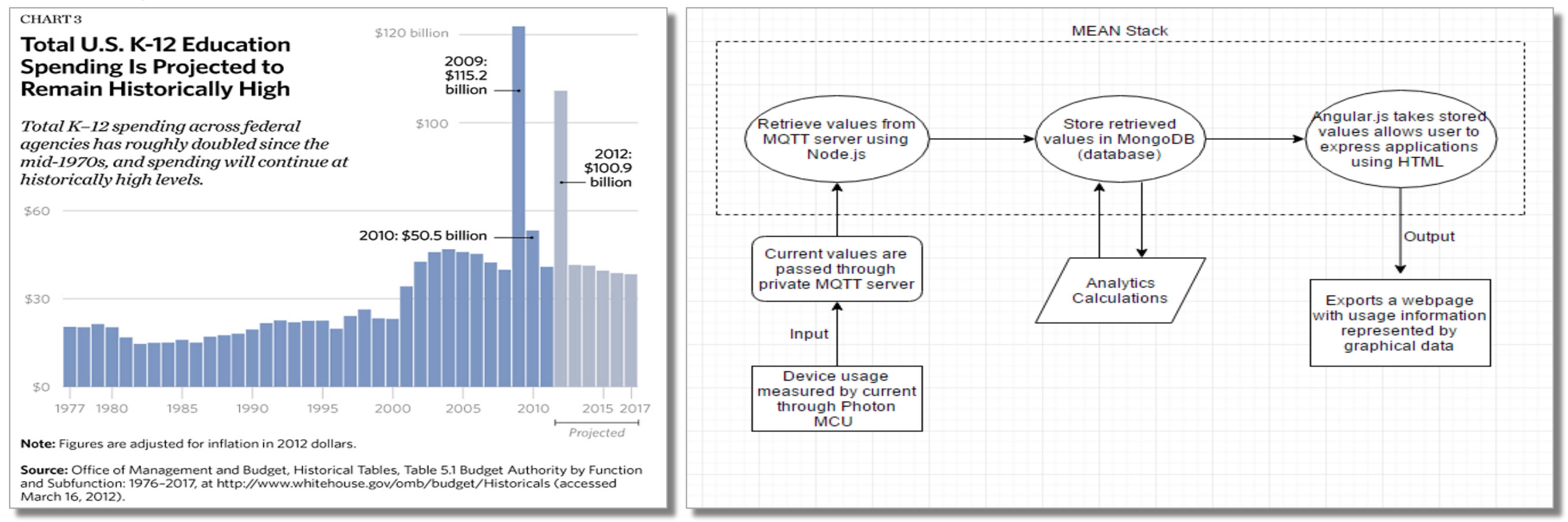


\section{Energy Channel - Industrial Application}

\section{- Integrated Sensing + Non-Intrusive Load Monitoring (NILM)}

- NILM presents an opportunity for Industry to monitor performance

- Inexpensive: data is collected from the current smart meter

- Easy to deploy: Minimum hardware and installation required

- Load monitoring can provide useful information in real-time and advantages

- Performance and distribution of discrete running times

- Identification of Energy/Labor Inefficient Behaviors

- Faulty detection: track nonstandard patterns

- Tailored preventive maintenance

- Integrated security resource management

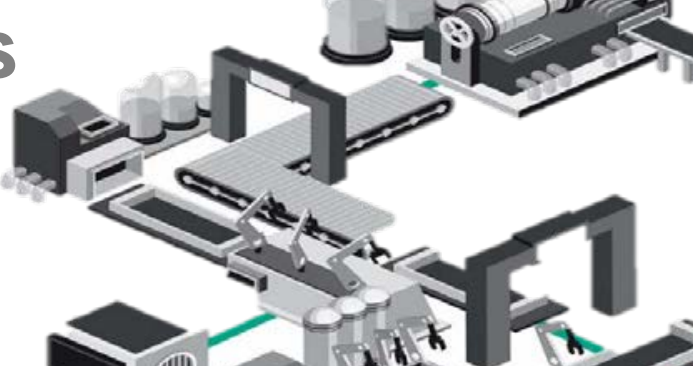
$+5$

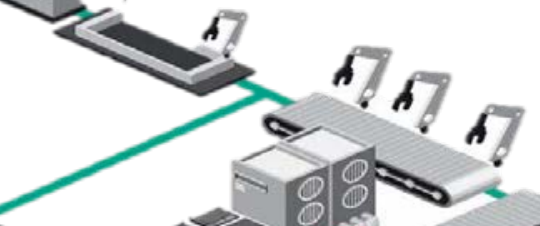




\section{We welcome \\ opportunities for collaboration.}




\section{CESMII}

\section{A National Network of Capability Headquartered in LA}

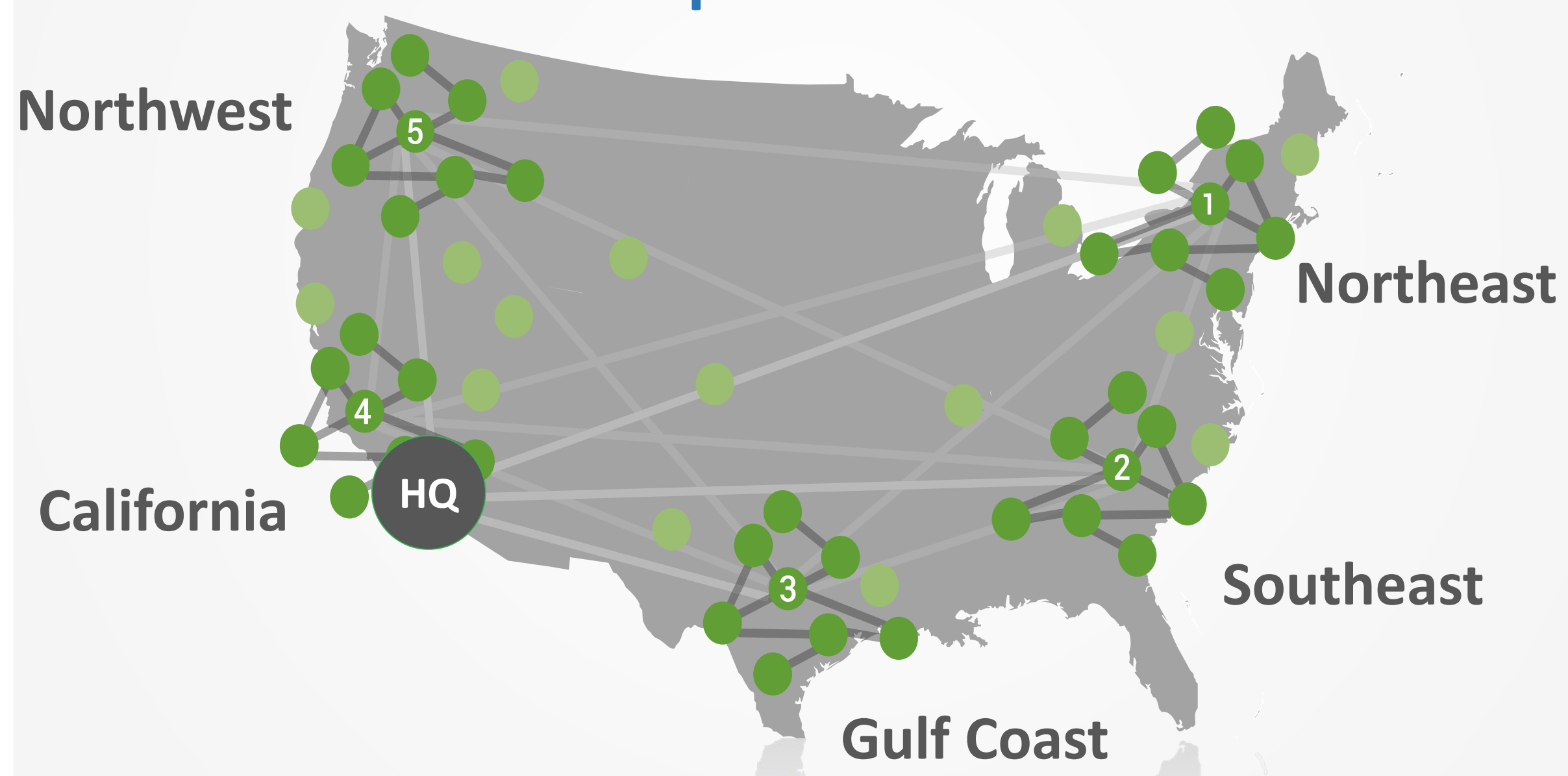




\section{CESMII}

\section{The Regional Manufacturing Centers}

- Test Bed Pipeline

- Drive Membership

- Develop Technology

- Implement SM Projects

- Participate in CESMII LRP

- Regional Workforce Development and Training

- Members of Advisory Committees

- Regional Budget Management

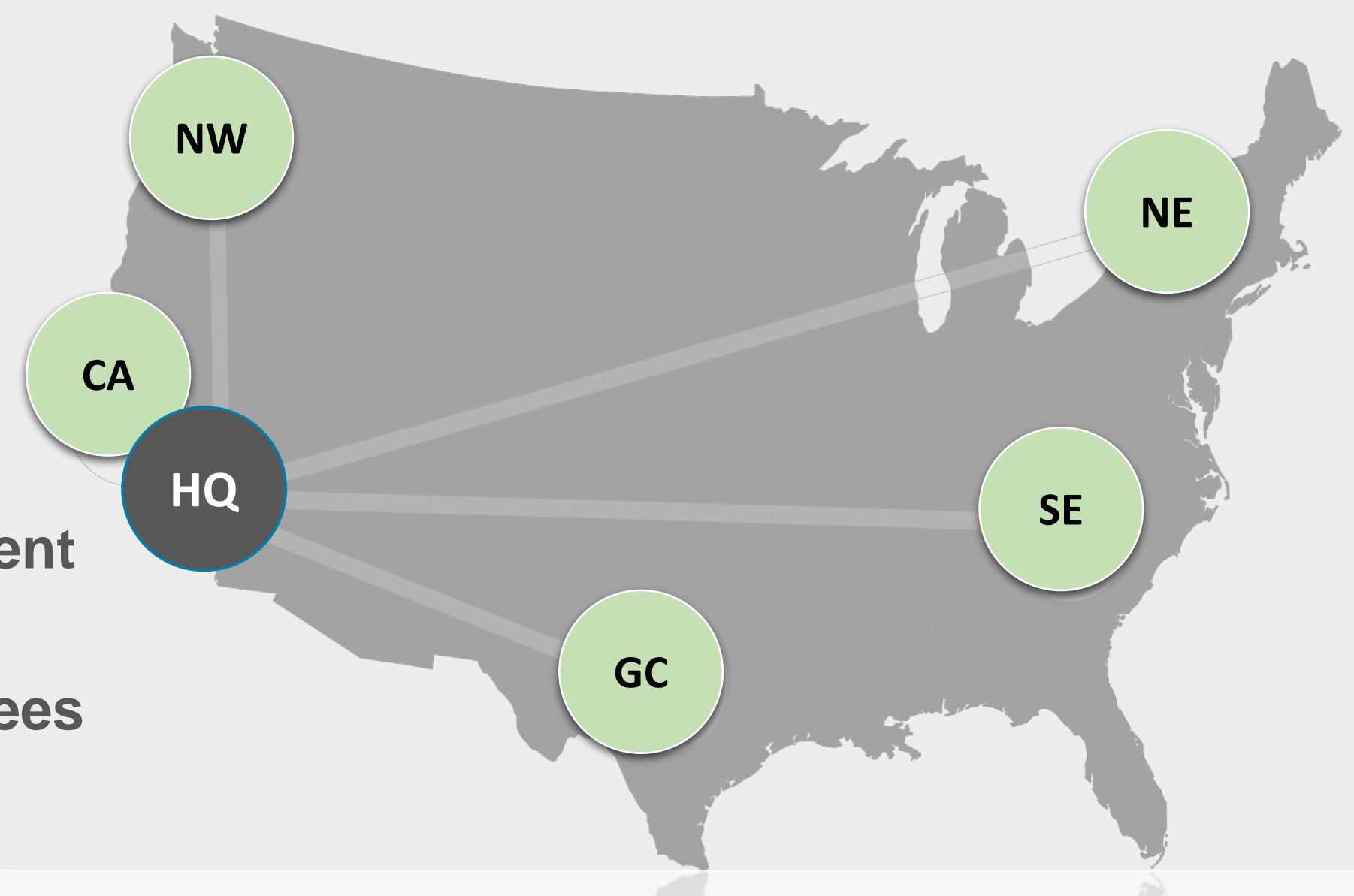




\section{Regional Centers}

\section{Each regional center is operated according to three key tenets:}

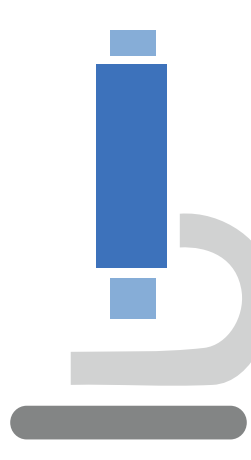

R\&D

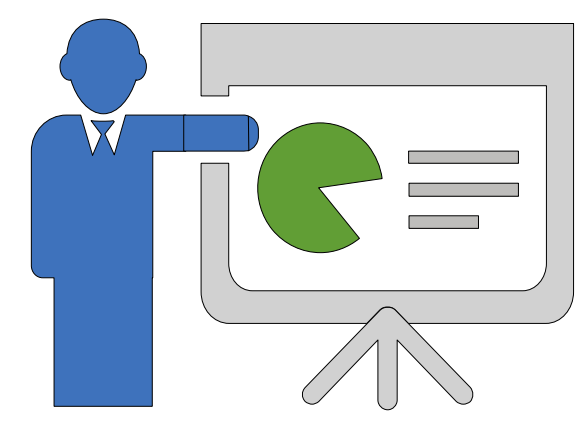

Workforce

Development

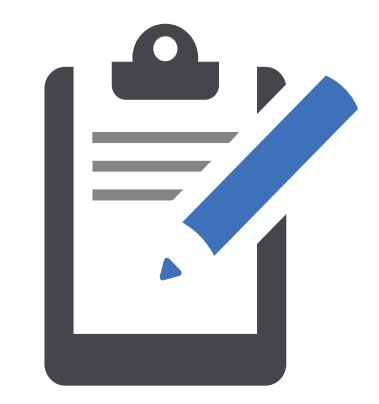

Testbed

Infrastructure 


\section{California RMC Capabilities Summary}

Sensors, Controls \& Algorithms, Platforms, HPC
Energy Sustainability, Economic

Development, Workforce Development, etc.
UCLA Berkeley

Now USCUniversity of

Southern California

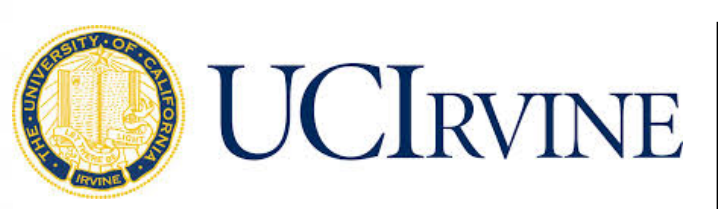
Calit2

UNIVERSITY of CALIFORNIA - IRVINE

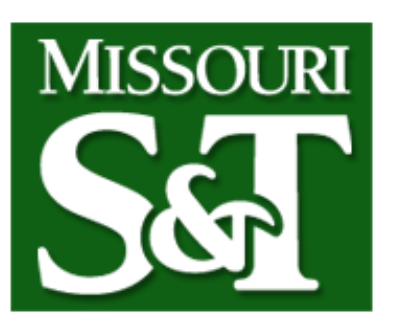

Jet Propulsion Laboratory

Lawrence Livermore National Laboratory
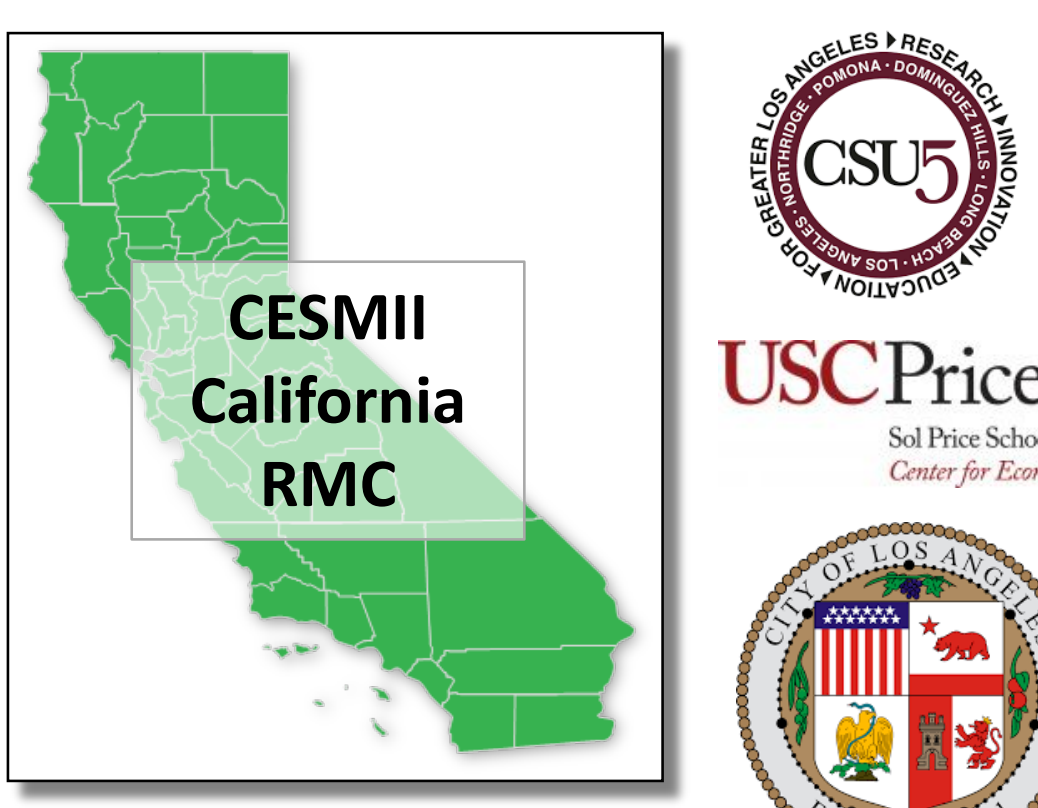

USCPrice Sol Price School of Public Policy
Center for Economic Development

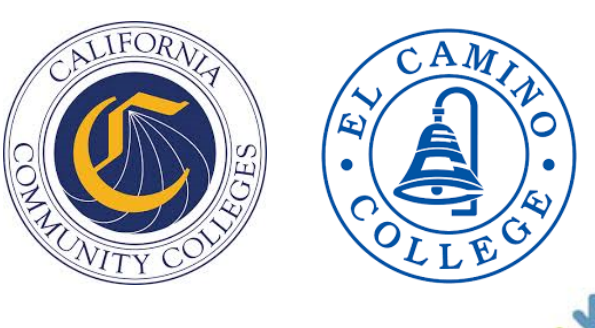

CSUN LAnSync

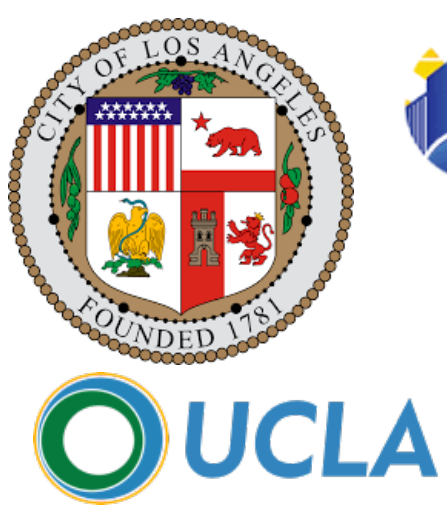

CALIFORNIA Governor's Office of Business and Economic Development

A Michigan Tech 


\section{CONTACTS}

Dale Turner

CA RMC Director, CESMII

https://twitter.com/SMCoalition

dale.turner@cesmii.org

1 Facebook.com/SMLeadershipCoalition

310.984.9180

\section{Professor G.P. Li}

in http://www.linkedin.com /groups /Smart-Manufacturing-LeadershipCoalition

\section{Director, California Plug Load Research Center} Calit2, UC Irvine gpli@calit2.uci.edu 949.824 .9073 


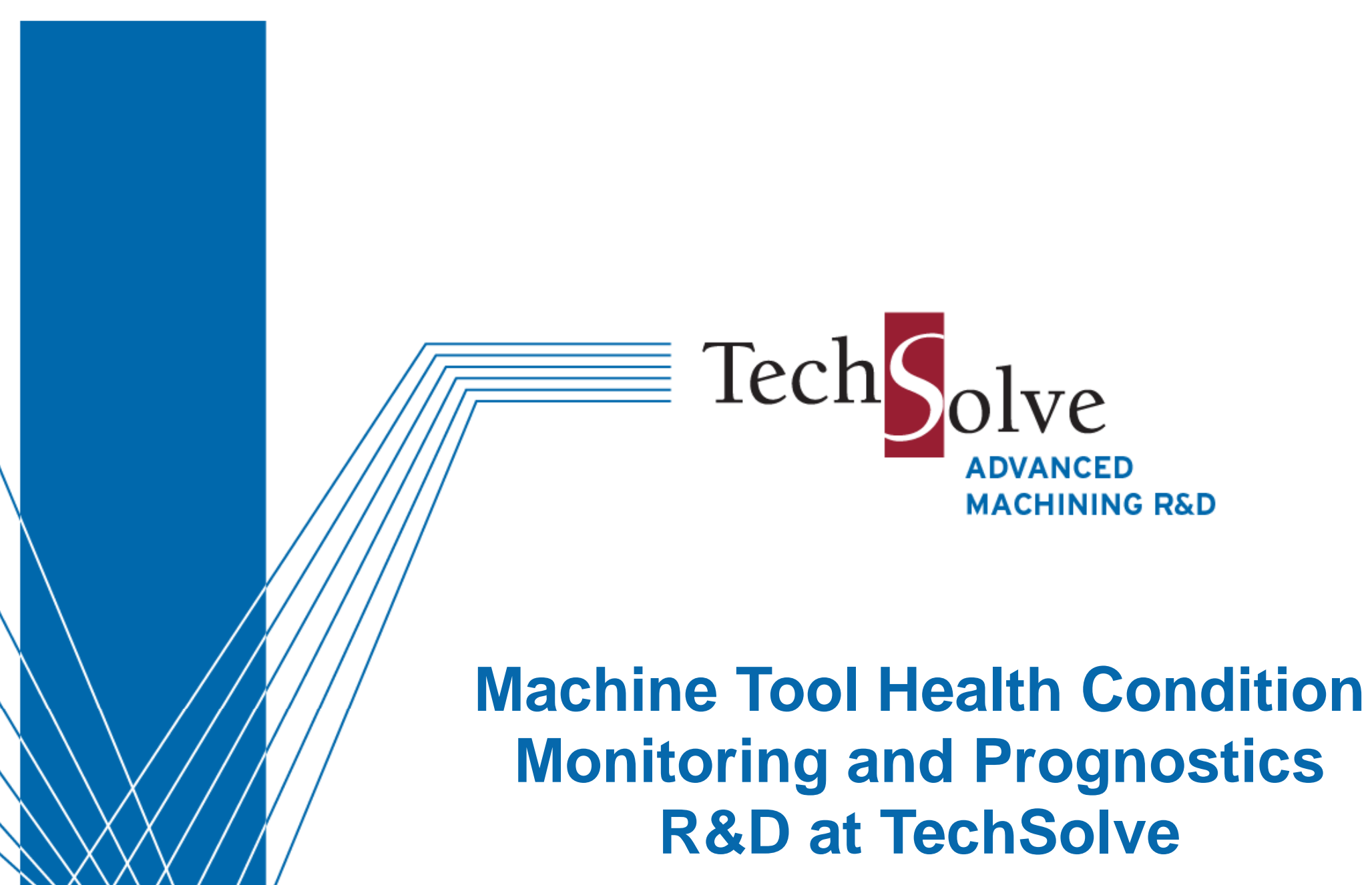

\title{
Machine Tool Health Condition Monitoring and Prognostics $R \& D$ at TechSolve
}

\author{
Radu Pavel, Ph.D. \\ Vice President of Engineering \\ Chief Technology Officer
}

ASME Workshop

June 2017 


\section{TechSolve, Inc. - Overview}
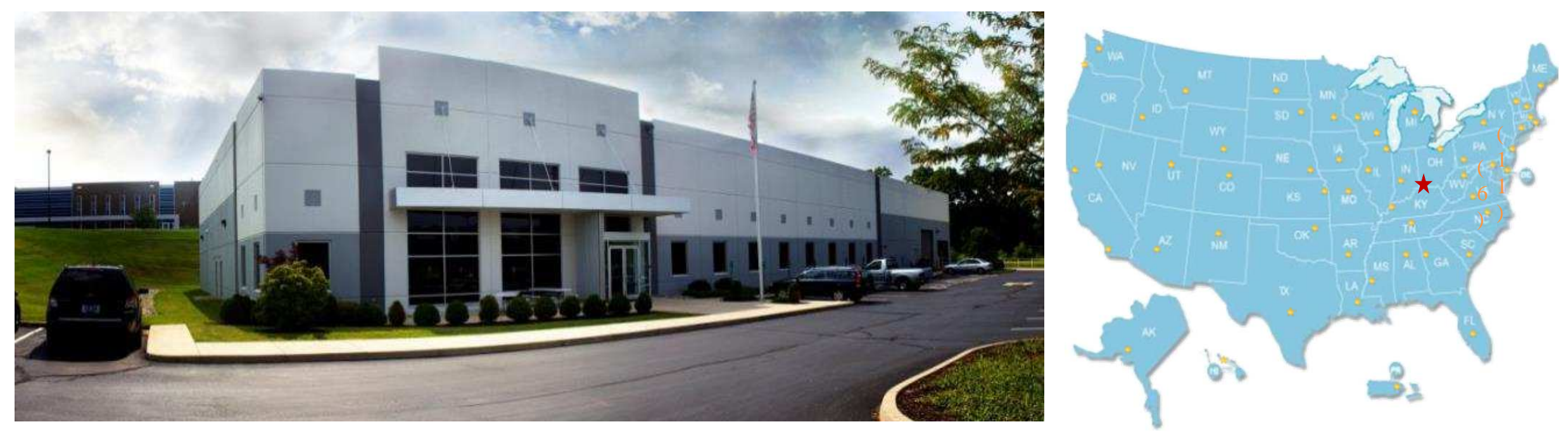

- A process improvement and machining services organization located in Cincinnati, OH, U.S.A.

- State and Federal Manufacturing Extension Partnership Center

- Founded as IAMS in 1982 ; rebranded as TechSolve, Inc. in 2000

- 45+ Member Team: Engineers, MBA's, PhD's, and former business owners 


\section{$\equiv$ Fully-Instrumented Machining Laboratory}

TechSolve's M. Eugene Merchant Technology Development Center (formerly MetCut Research Machining Laboratory, founded 1948)

\section{Equipment Highlights:}

- Mazak Integrex i200S Mill Turn

- Makino V55 - 3 Axis VMC w/20K spindle

- DMG DMU-50 - 3+2 Axis VMC w/Siemens 840D CNC \& through-spindle coolant

- DMG DMU-70 eVo Linear - 5 Axis VMC w/ Siemens 840D \& 580 psi through-spindle coolant

- Hardinge Cobra 65-2 Axis turning center w/Fanuc 21T \& Bar Feed

- Milltronics HMC35 - 4 Axis HMC w/Fanuc 0iMC

- Chevalier Smart B1224II CNC Surface Grinder

- Sheffield Cordax D-8 CMM

- Kistler Turning, Milling, and Drilling Dynamometers

- Keyence VHX Digital 3D Microscope

- Instrumented test-beds for PHM of equipment

- Fluids Lab

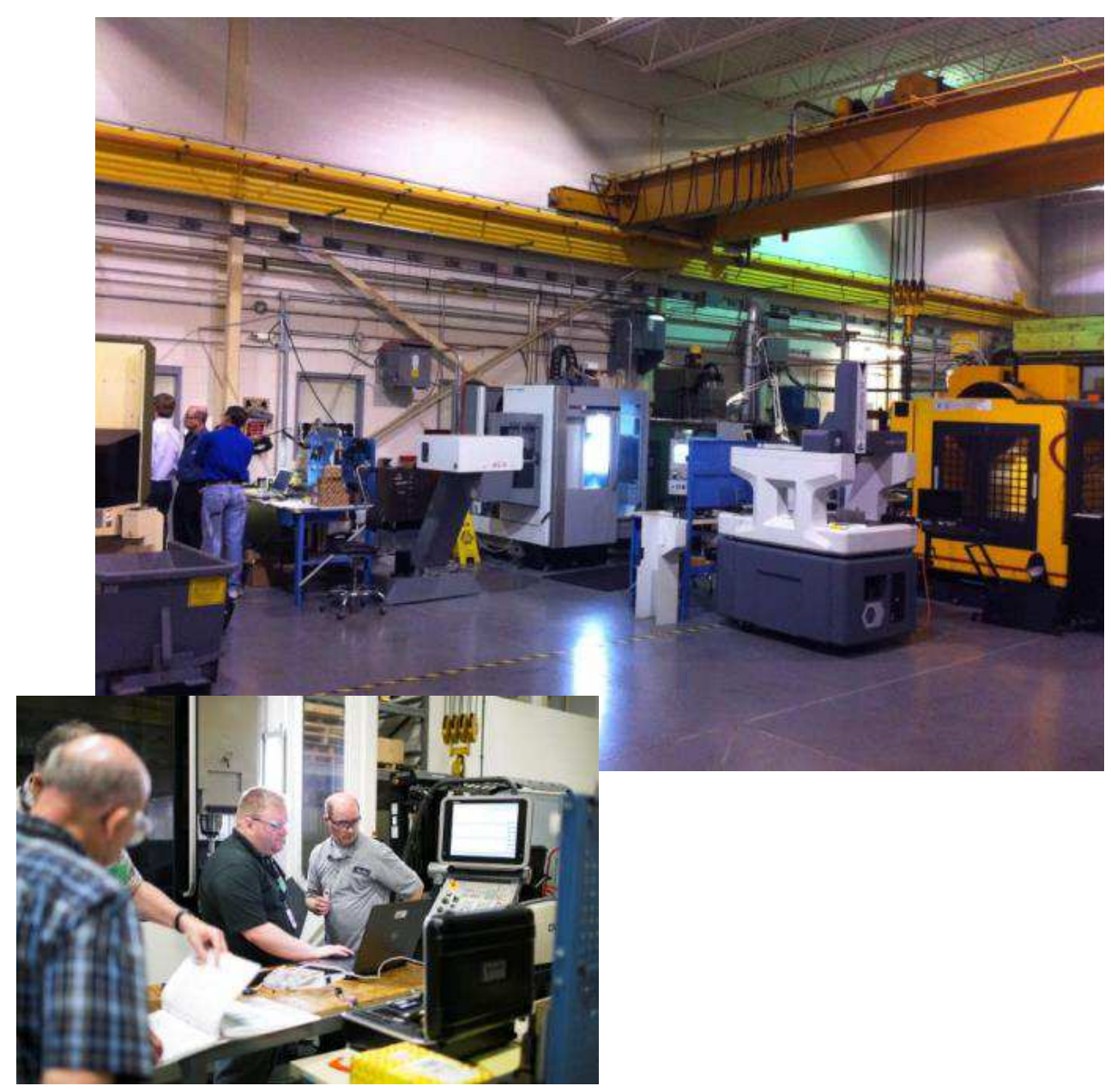




\section{$\equiv$ Services \& Products for Manufacturers}

TechSolve's consulting services available to manufacturing industry

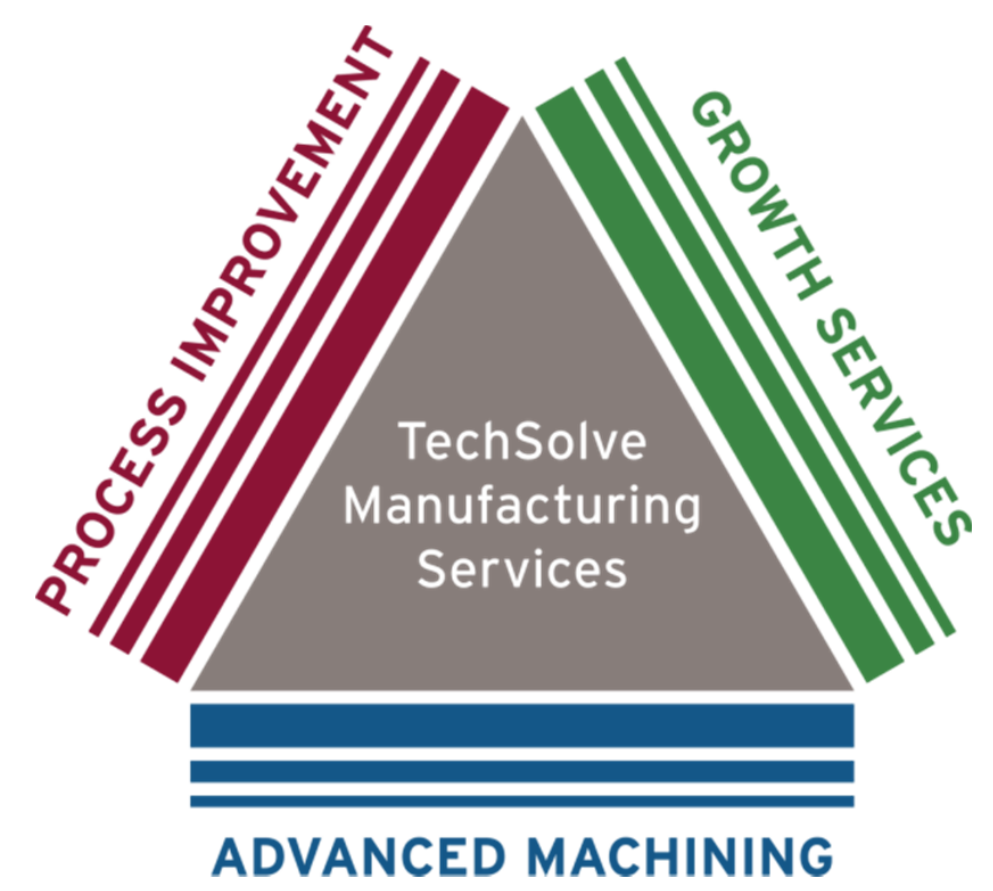

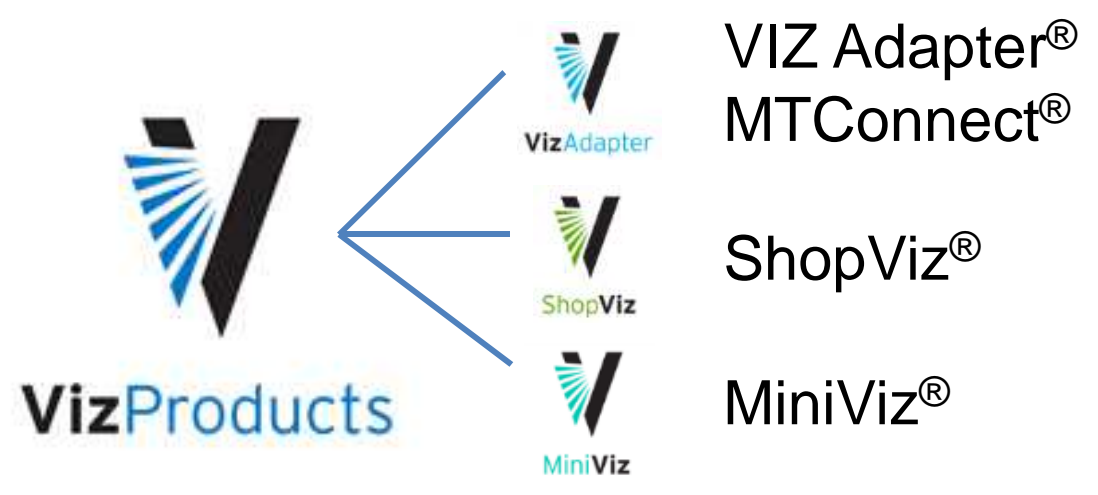
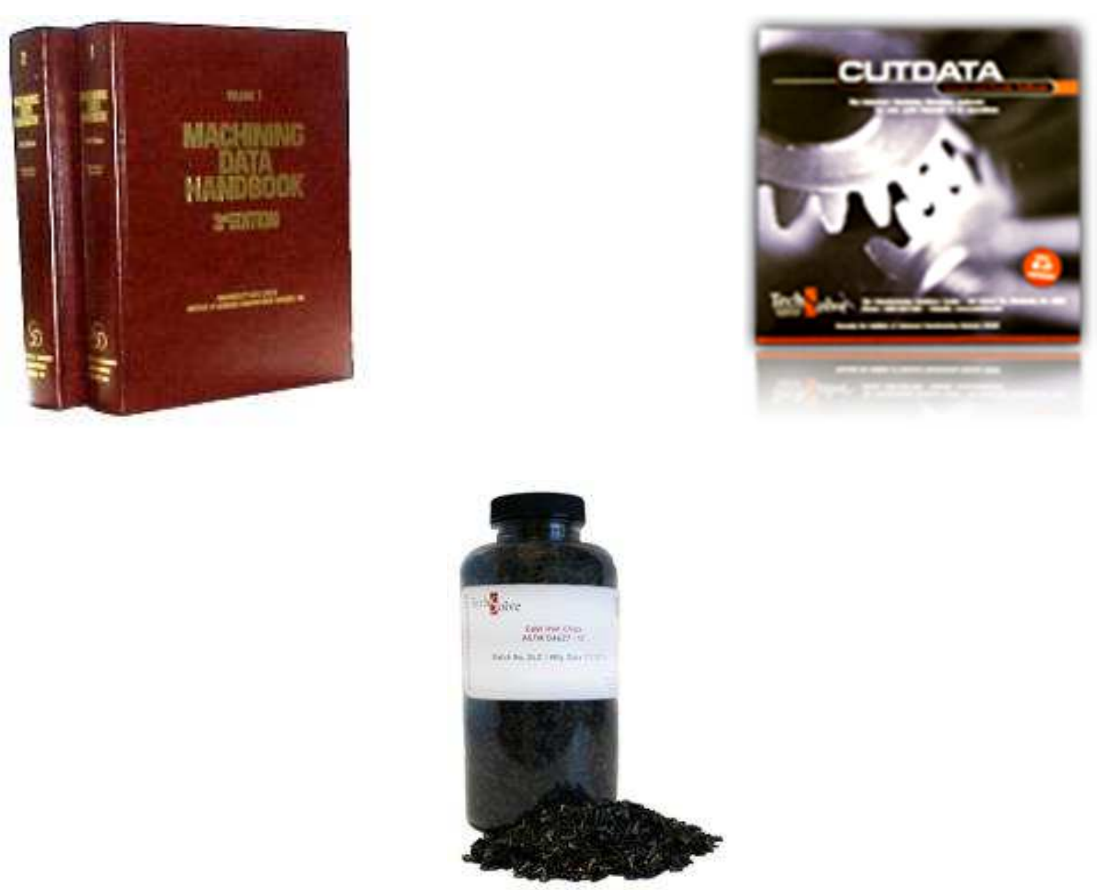


\section{三TechSolve History}

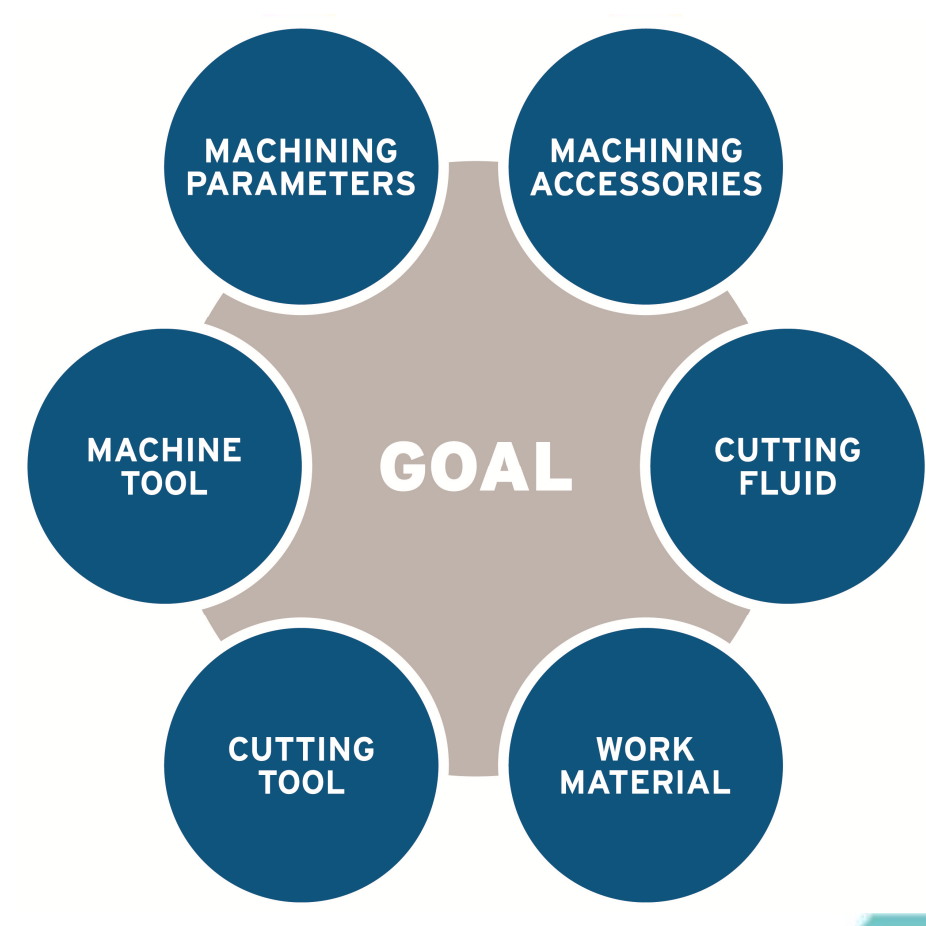

슬

2016: Industry 4.0 Program

2014: Intelligent Machining Program

2011: TechSolve awarded IMAP

2009: TechSolve launches machine monitoring application ShopViz ${ }^{\circledR}$

2008: $\quad$ MTConnect ${ }^{\circledR}$ Institute Founding Sponsor

2006: TechSolve awarded Smart Machine

Platform Initiative

2000: IAMS becomes TechSolve

1990: Acquired the Machinability Testing Equipment and Resources of Metcut Research's Machinability Data Center

1982: Institute of Advanced Manufacturing Sciences (IAMS) Founded 


\section{$\equiv$ Smart Machine Platform Initiative}

\section{Mission}

Be the framework for the identification, development, and transition of technologies that recognize the goal of "First Part Correct" manufacturing.

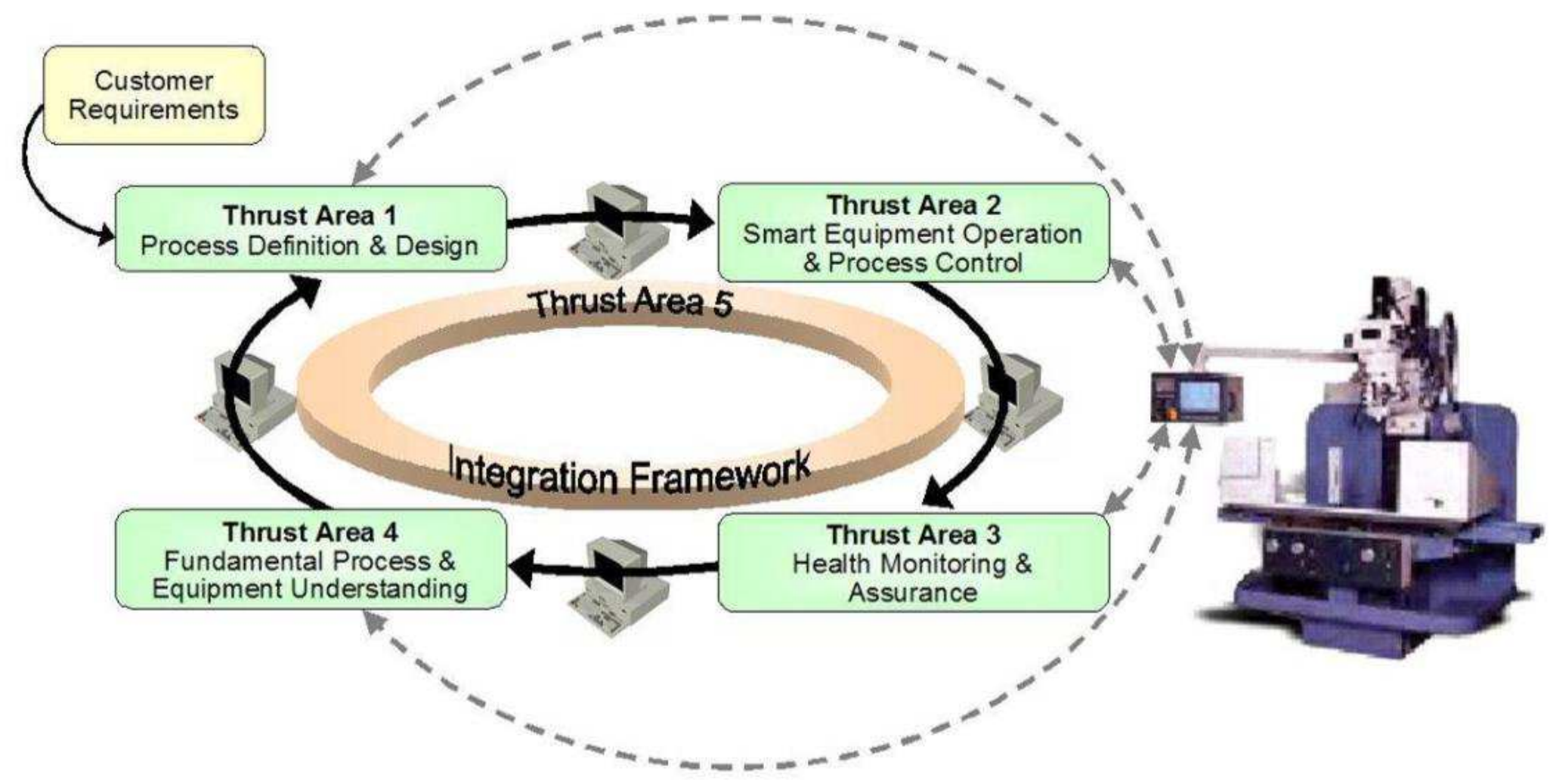




\section{$\equiv$ Machine Tool Health and Maintenance Area}

- Identify, evaluate, develop and demonstrate technologies and systems capable of monitoring and predicting the machine health for "Near-Zero Downtime" and "First Part Correct"

- Goals:

- reduce unscheduled machine downtime

- sustain machine performance at optimum condition

- minimize variability of parts produced 


\section{$\equiv$ Machine Tool Health Characterization}

\section{$15 \%-40 \%$ of manufacturing costs are typically attributable to maintenance activities*}

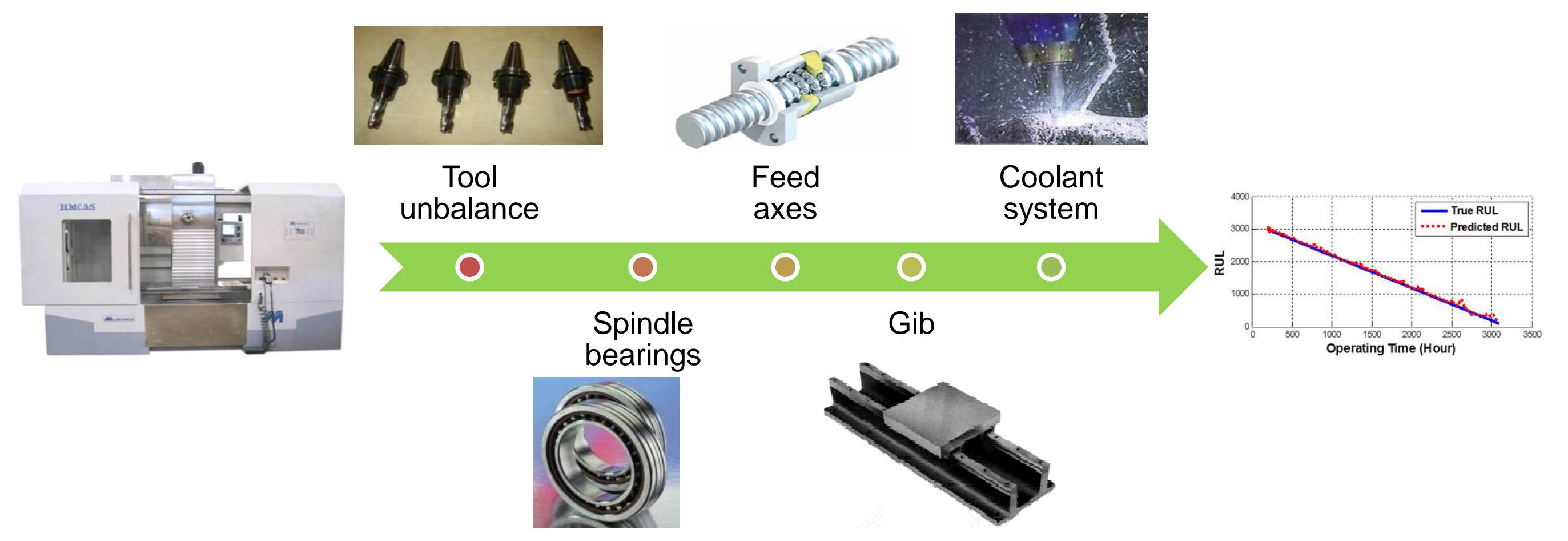

\footnotetext{
* Kothamasu, R., Huang, S. \& VerDuin, W., System health monitoring and prognostics - a review of current paradigms and practices, International Journal of Advanced Manufacturing Technology 28, 2006, pages 1012-1024. 


\section{严Collaborations}

TechSolve teamed up with a number of academic and industrial organizations in an effort to advance the machine tool's health and maintenance technology area.

- University of Cincinnati

- Intelligent Maintenance Systems (IMS)

- Computer Science

- Frontier Technology, Inc. (FTI)

- Siemens Corporation

- Palo Alto Research Center

- NIST - Intelligent Systems Division

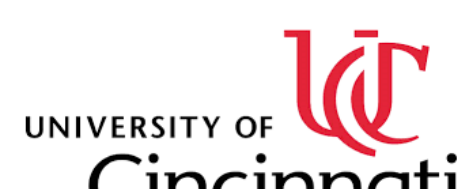

Cincinnati

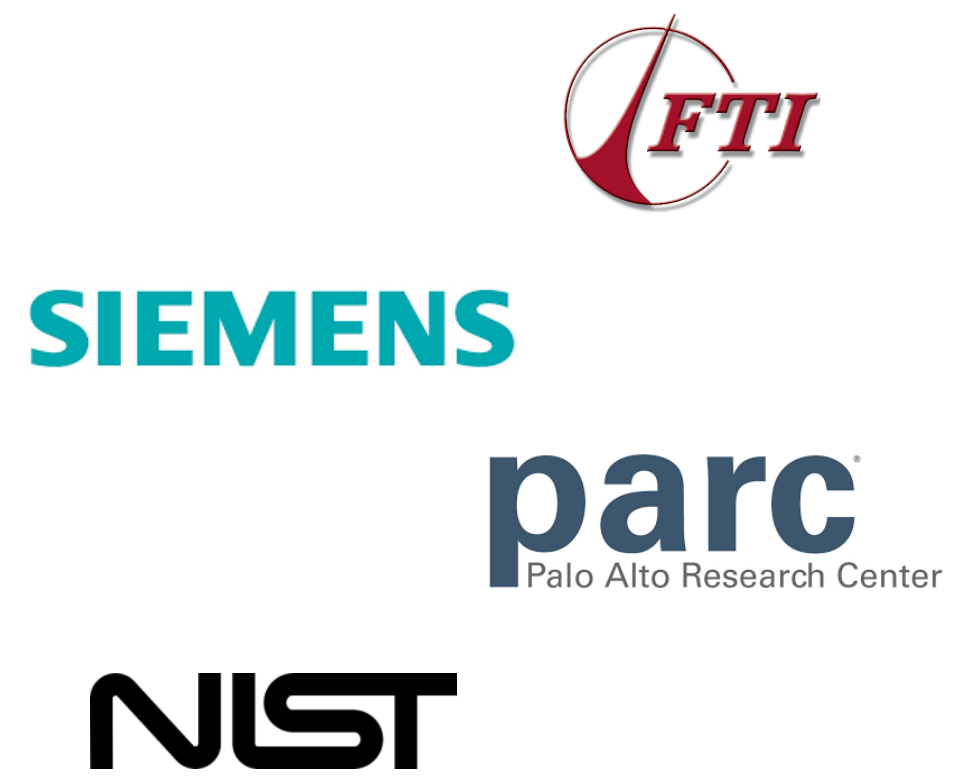

TechSolve 


\section{Test-beds at TechSolve}
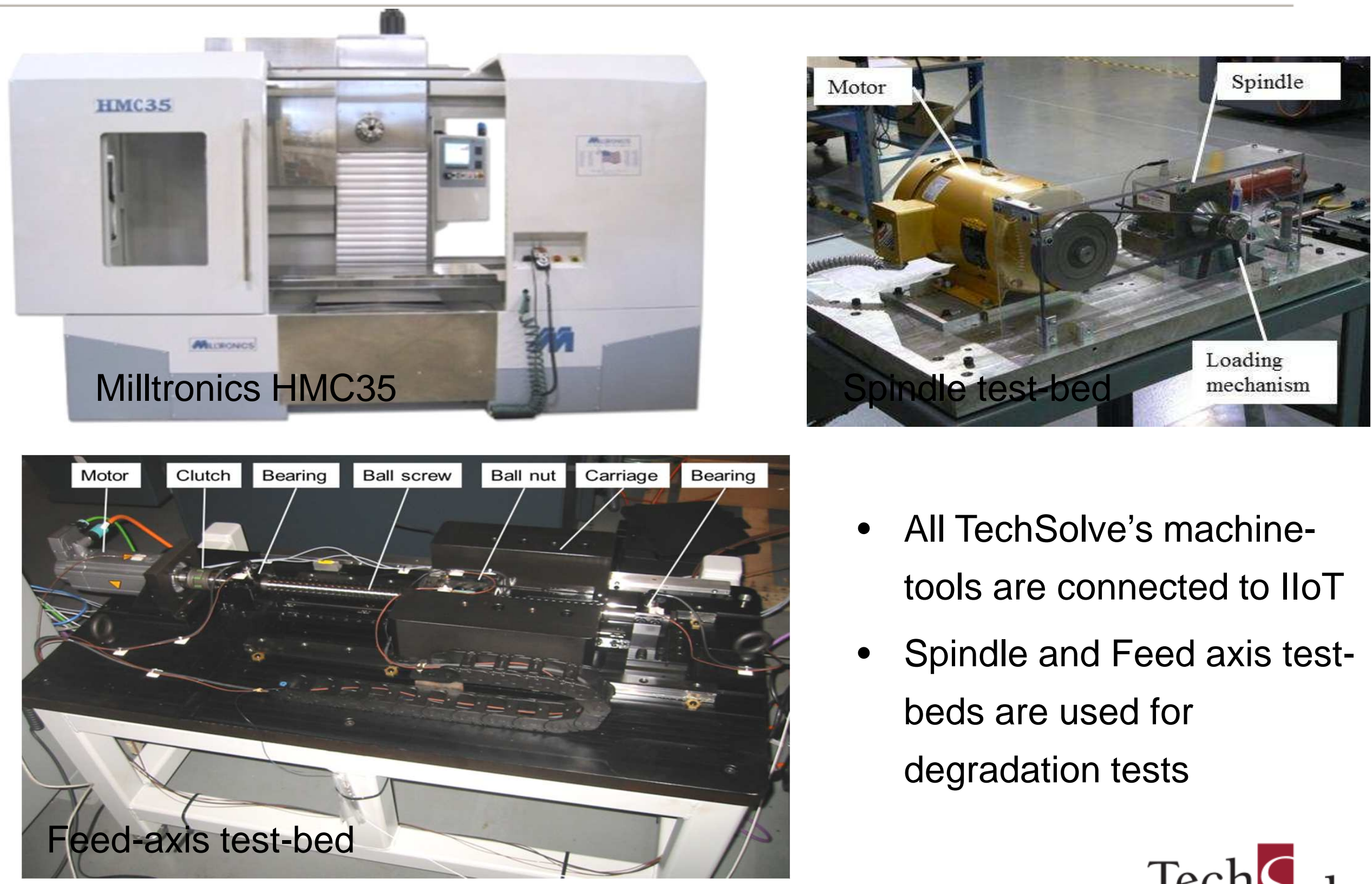

- All TechSolve's machinetools are connected to IIoT

- Spindle and Feed axis testbeds are used for degradation tests 


\section{Instrumented Machining Center Test-bed}
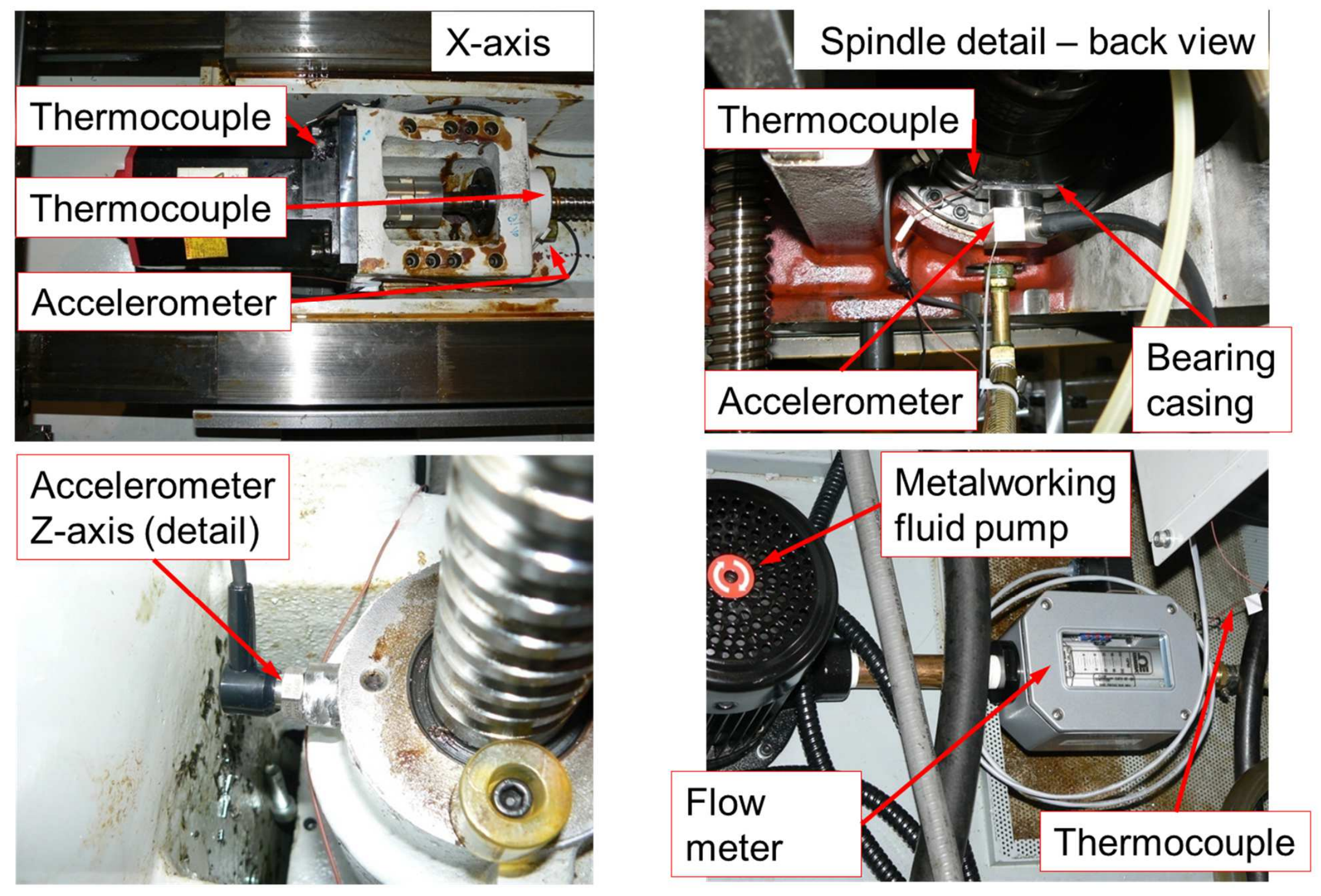


\section{E IMS - TechSolve Collaboration}

- Calculate the overall machine tool health index (MTHI) based on the health of different components of a machine tool

- A number of critical components had to be identified

\section{Critical Components IMS Algorithms}

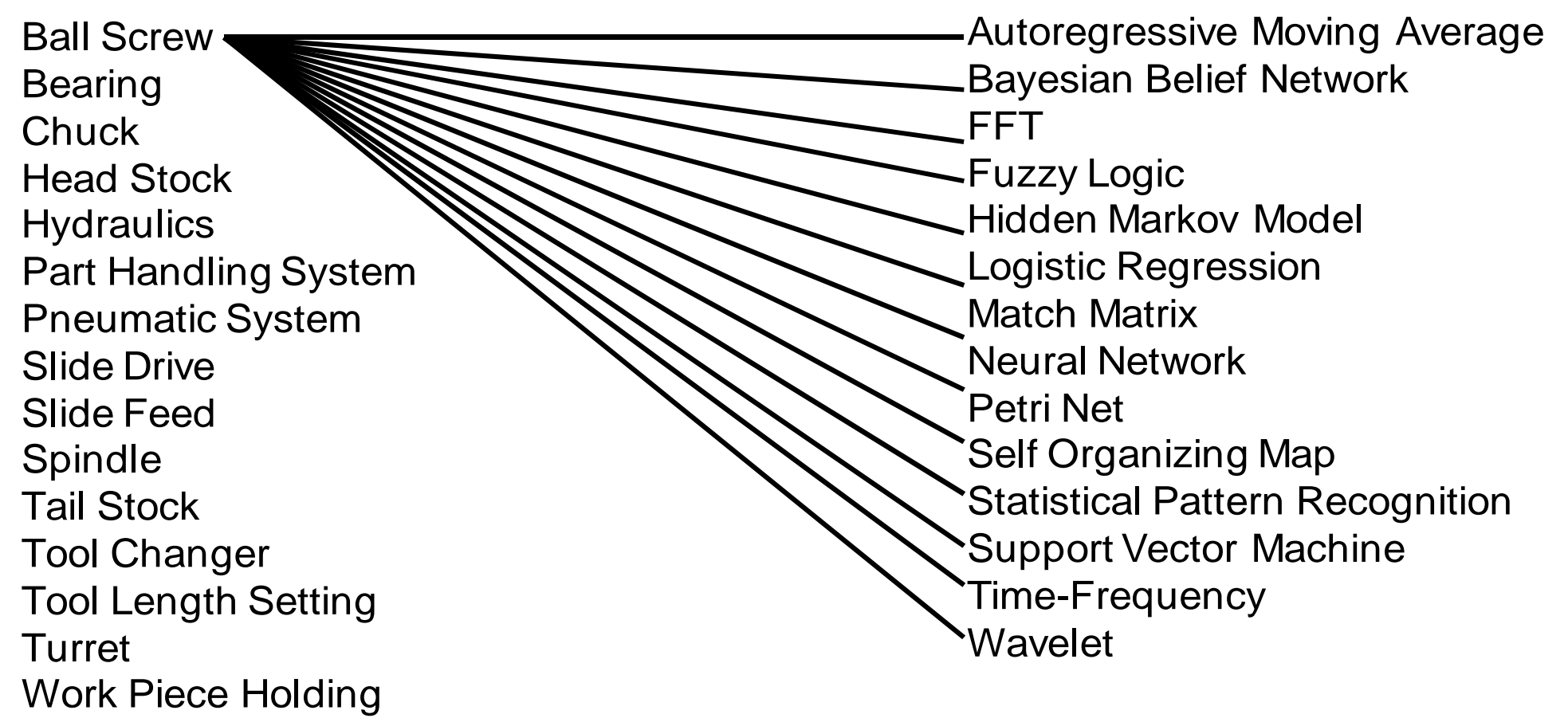




\section{Machine Tool Health Dashboard (MTHD)}

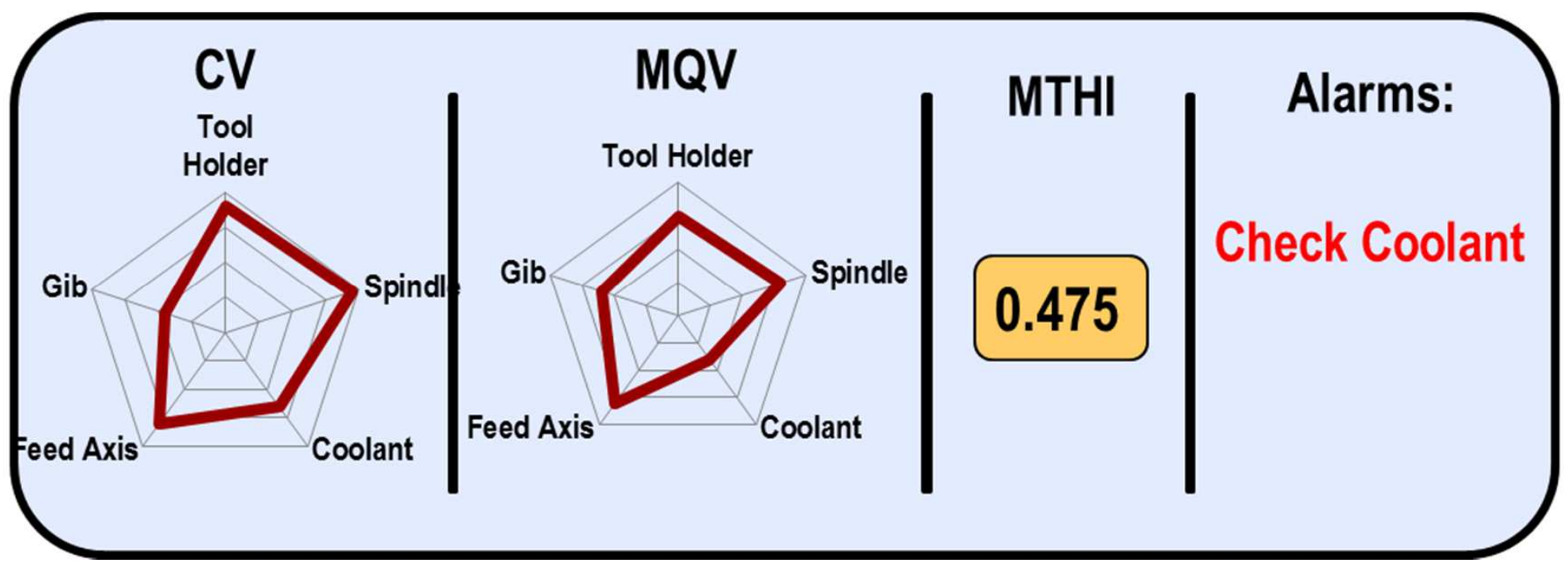

Step 1: Relate the Health of different components to the Machining Quality Indexes (MQI)

Step 2: Aggregate the Machining Quality Indexes (MQI) for each component to a Machining Quality Value (MQV)

Step 3: Aggregate the Machining Quality Values (MQI) of different components into a Machine Tool Health Index (MTHI) and generate alarms 


\section{Data Analysis Flow for Health Assessment}
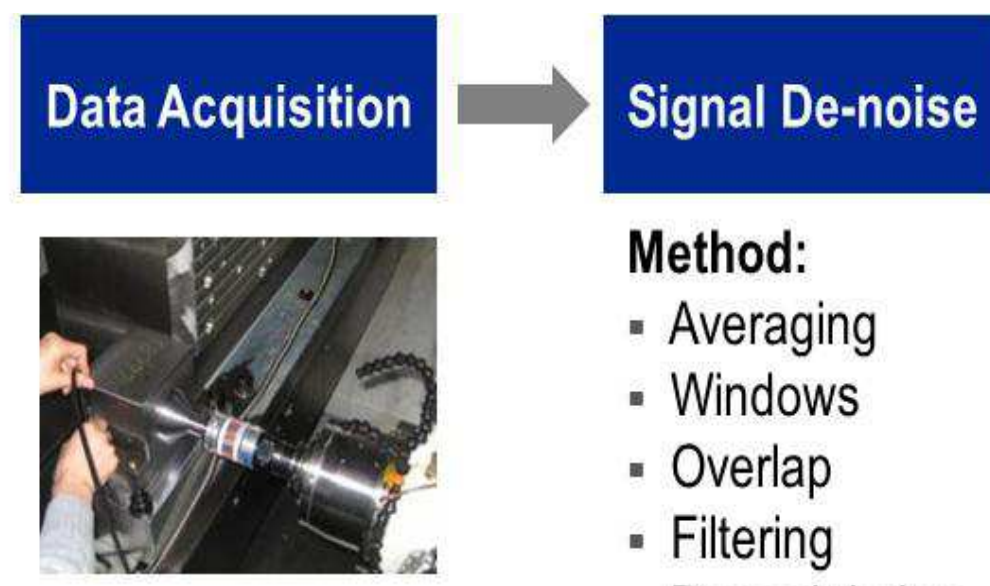

Method:

- Averaging

- Windows

- Overlap

- Filtering

- Demodulation
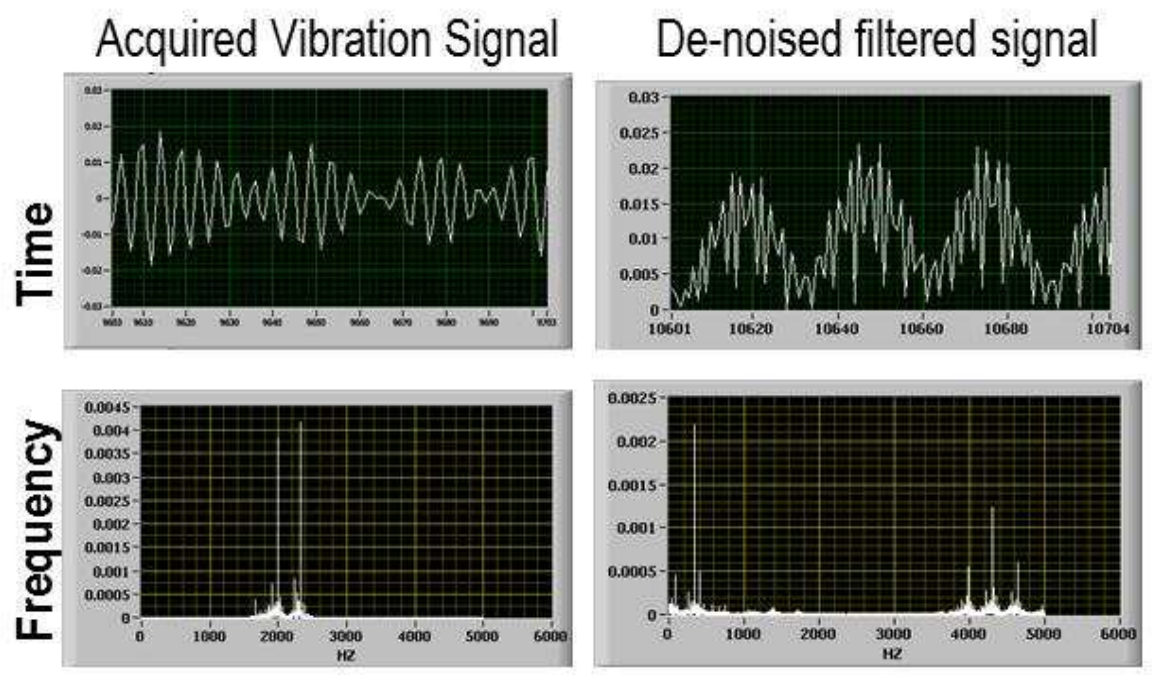

Bearing Health

Assessment

\section{Method:}

- Self Organizing

Map (SOM)

\section{- Kurtosis}

- Signature Frequency

(BPFO, BPFI, BSF, FTF)
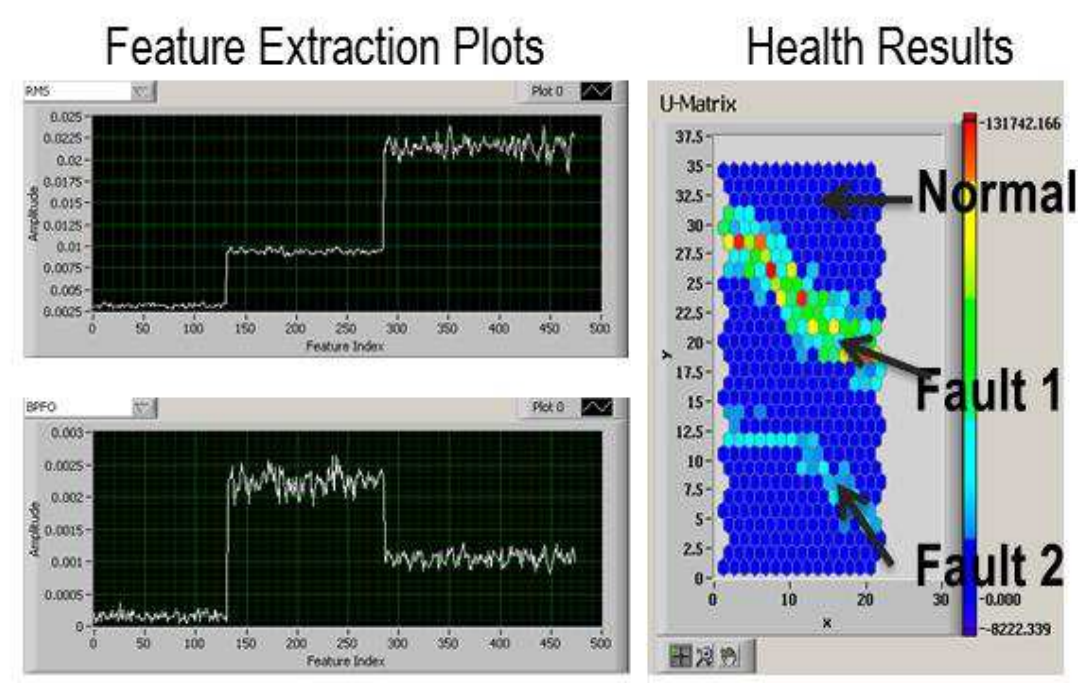


\section{NormNet ${ }^{\circledR}$ of Frontier Technologies Inc. (FTI)}

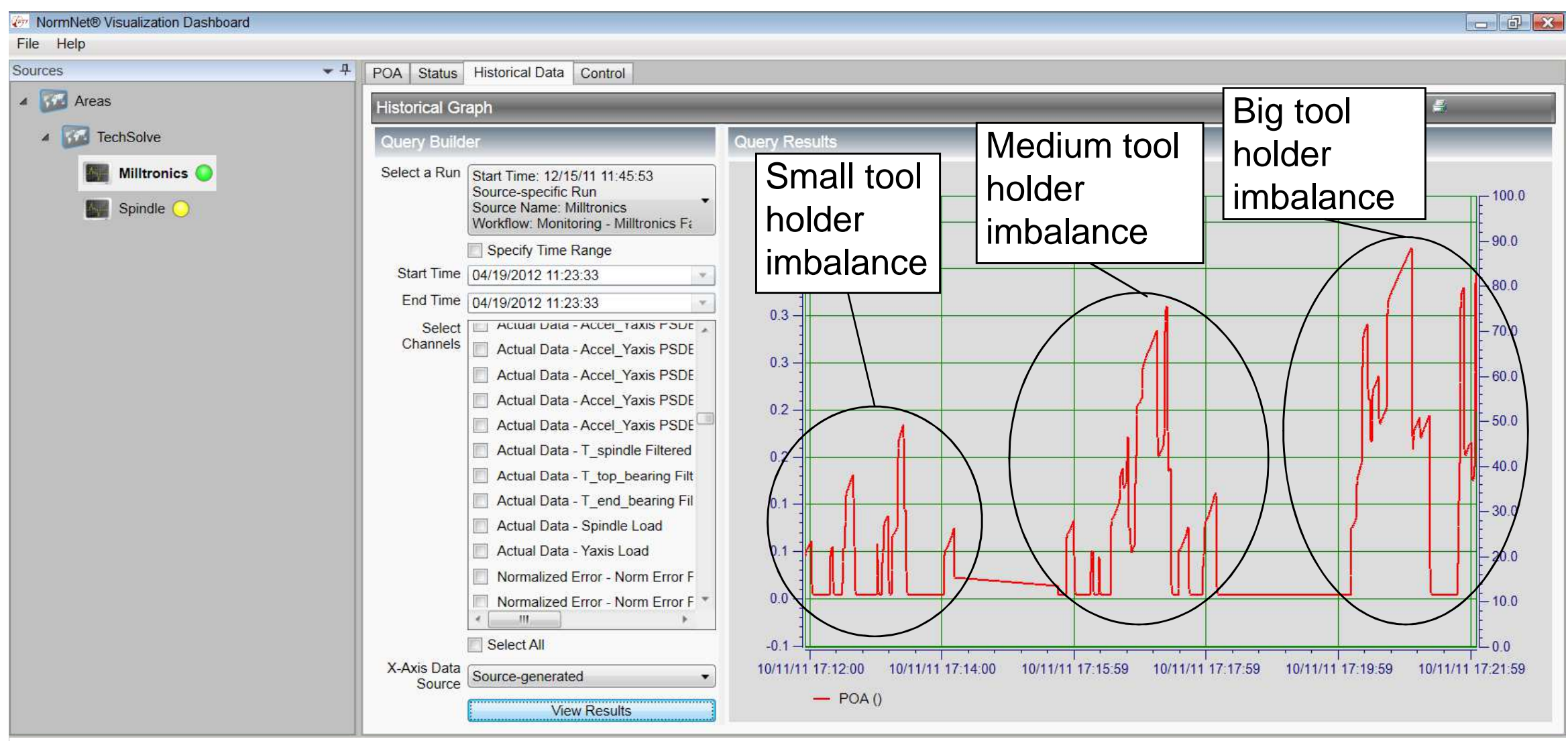

- The research approach was based on the Pattern Recognition of Health $\left(\mathrm{PRoH}^{\circledR}\right)$ paradigm of $\mathrm{FTI}$.

- Within this paradigm, system health is defined in terms of variance from an expected normal condition. 


\section{$\equiv$ Siemens Plug-And-Prognose (PnP)}

This collaboration was focused on the PnP technology. Two main capabilities of the software were evaluated:

- Performance Assessment - ability to quantitatively evaluate the deviation of the most recent behavior to the normal behavior or baseline

- Diagnosis - analyze patterns embedded in the data to determine what previously observed abnormality occurred
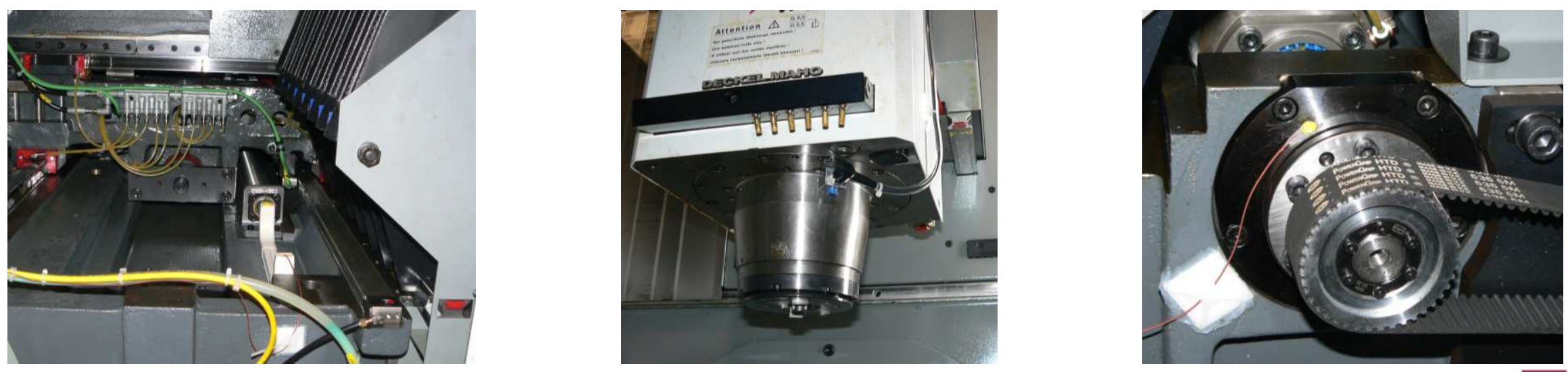


\section{Siemens Plug-And-Prognose}

The data analysis allows determining a so called minimum quantization error (MQE) which would be a direct representation of the condition of the feed axis.

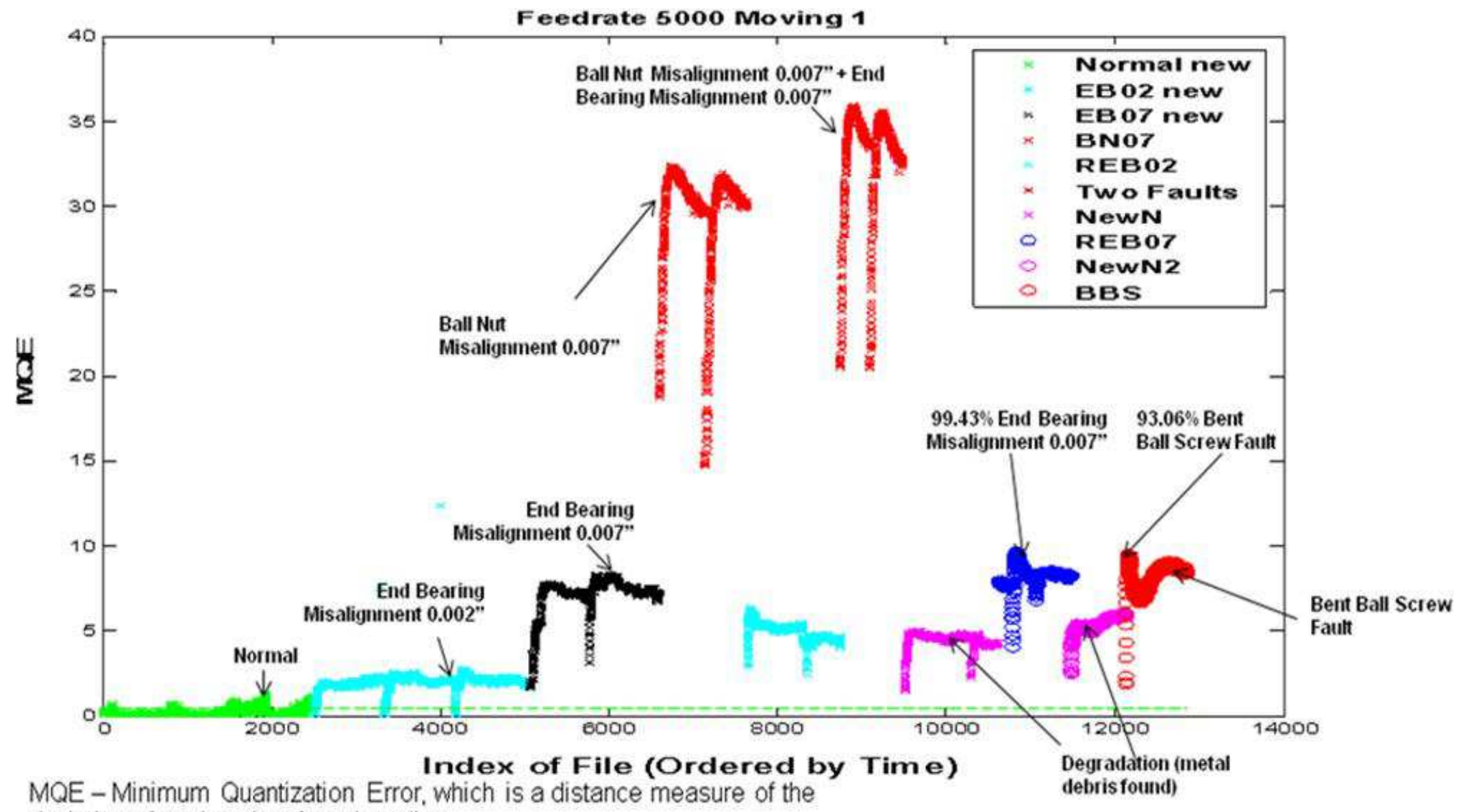

deviation of testing data from baseline. 


\section{Palo Alto Research Center}

Scope: Analysis of machine tool and spindle test-bed spindle data to evaluate prognostics algorithms.

- Combining control and sensor signals for machine health condition estimation, while utilizing a different set of sensor data such as temperature, power, flow, and lubricant/ coolant $\mathrm{pH}$ instead of vibration.

- A novel method of using Restricted Boltzmann Machine as a feature generation model and coupling with a random forest algorithm in remaining useful life prediction applications.
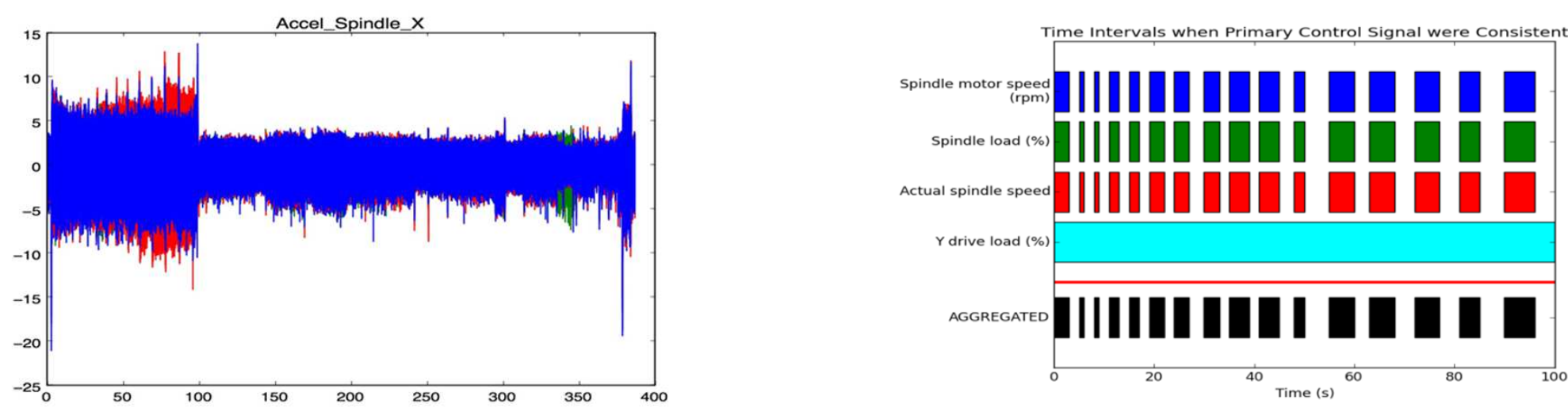


\section{三 Collaboration with NIST}

Evaluate NIST technology for machine health condition monitoring and characterization:

- Identification of machine tool geometric performance using on-machine inertial measurements

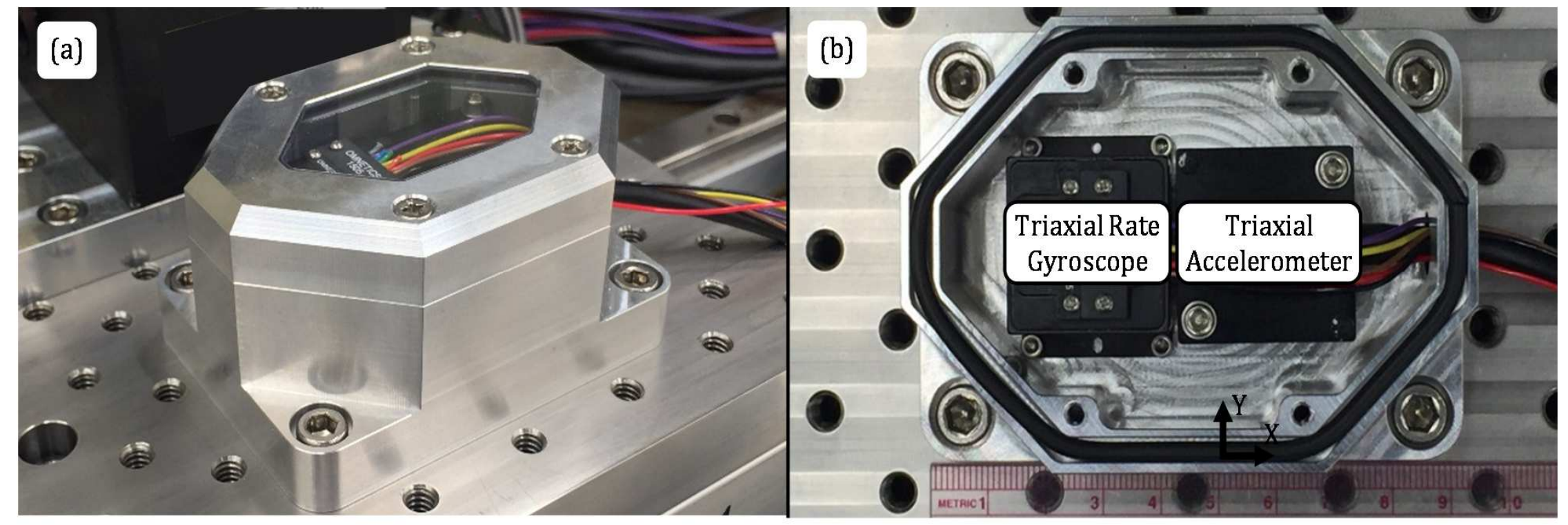

(a) Isometric view of industrial IMU and (b) top view of industrial IMU without its lid. 


\section{$\equiv$ Observations}

The machine tool health monitoring solutions are not offthe-shelf, universal solutions that can be implemented straight forward:

- some degree of customization is required

- highly-qualified developers

- finding the right algorithms and methodologies

- select what to monitor and how

- select sources of information (sensors, control, other)

- establishing efficient procedures for data collection

- lack of standardization 


\section{NIST Survey 2015 - Collaboration with TechSolve}

Support NIST's efforts to interact with small- \& mediumsized manufacturers:

- Understand performance measurement, condition monitoring, diagnostic, and prognostic activities in manufacturing facilities

- Identify best practices, capabilities, and opportunities for standards to simplify adoption and use of smart manufacturing technologies on the shop floor 


\section{Key Needs*}

- Heterogeneous system-of-systems approaches that can connect design, manufacturing, and inspection systems

- Advanced sensing and monitoring to understand best data strategies

- Reference datasets and verification and validation tools

- Standardization, especially for interoperability

- Demonstration and education

- New control paradigms to take advantage of knowledge

* Proceedings of the ASME MSEC2016, The Current State of Sensing, Health Management, and Control for Small-to- 


\section{三 MTConnect ${ }^{\circledR}$ Communication Standard}

VERSION 1.0 RELEASED DECEMBER, 2008

TechSolve partnered with AMT to establish the MTConnect Institute

The Institute developed MTConnect as open standard that addresses the needs for compatibility, interoperability, and plug-and-play capability for the machine tool industry

Standard vocabulary, syntax, and communication protocol for devices
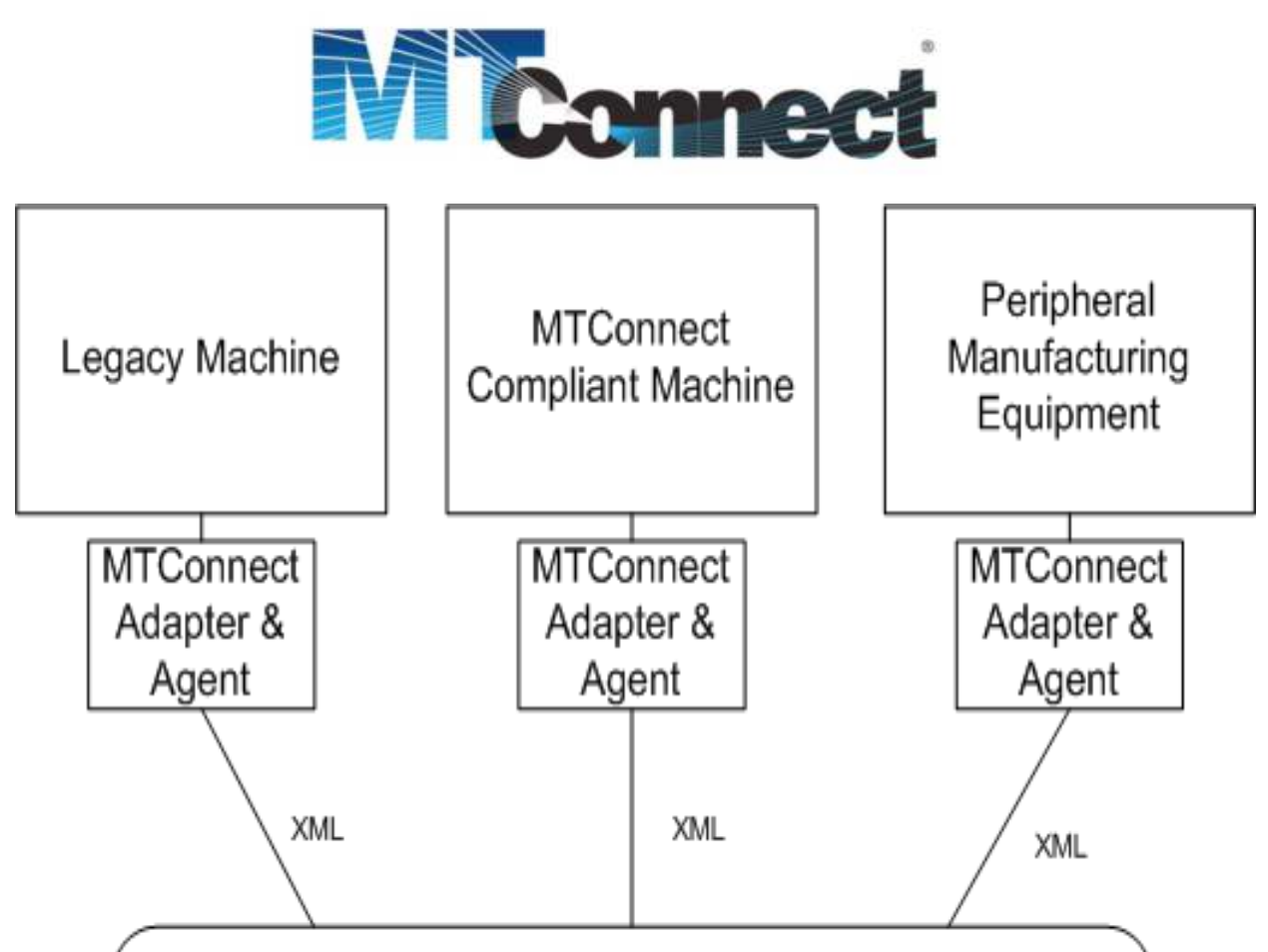

MTConnect

Adapter \&

Agent

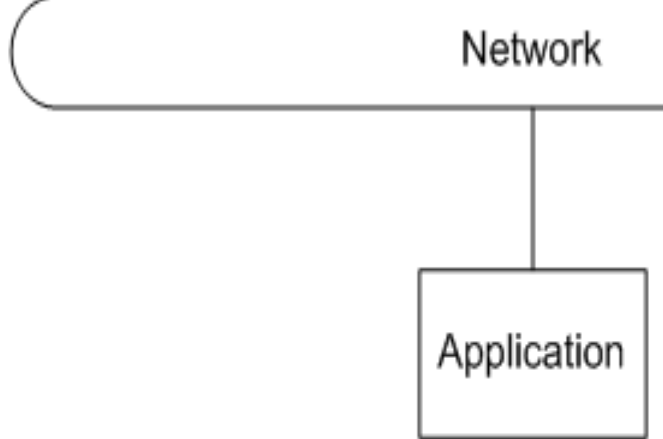




\section{TechSolve's Solution for Connectivity to IloT}

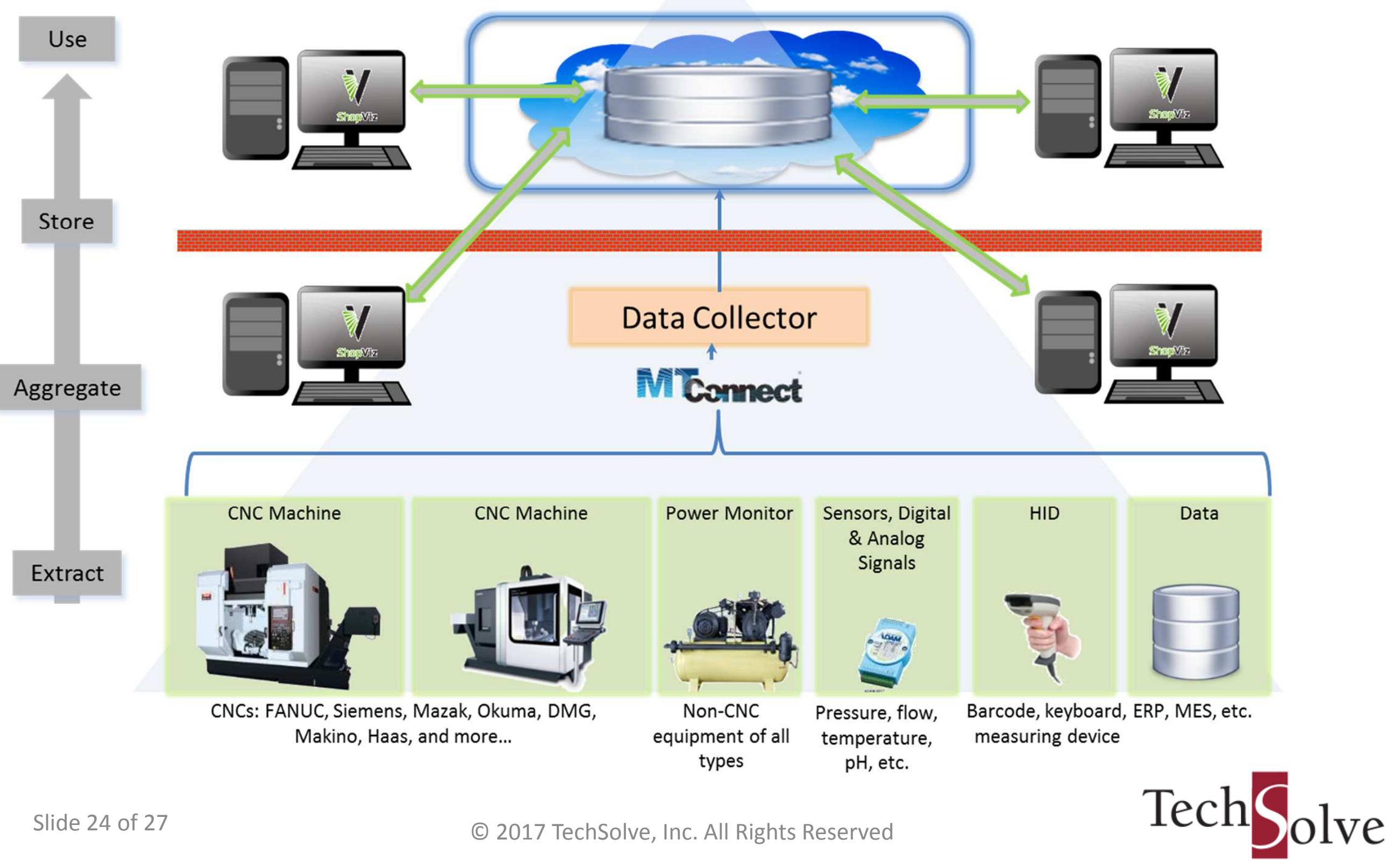




\section{VizProducts ${ }^{\circledR}$ - A Platform for PHM Dissemination}

Equipment and process monitoring \& reporting software

\section{ShopViz ${ }^{\circledR}$}
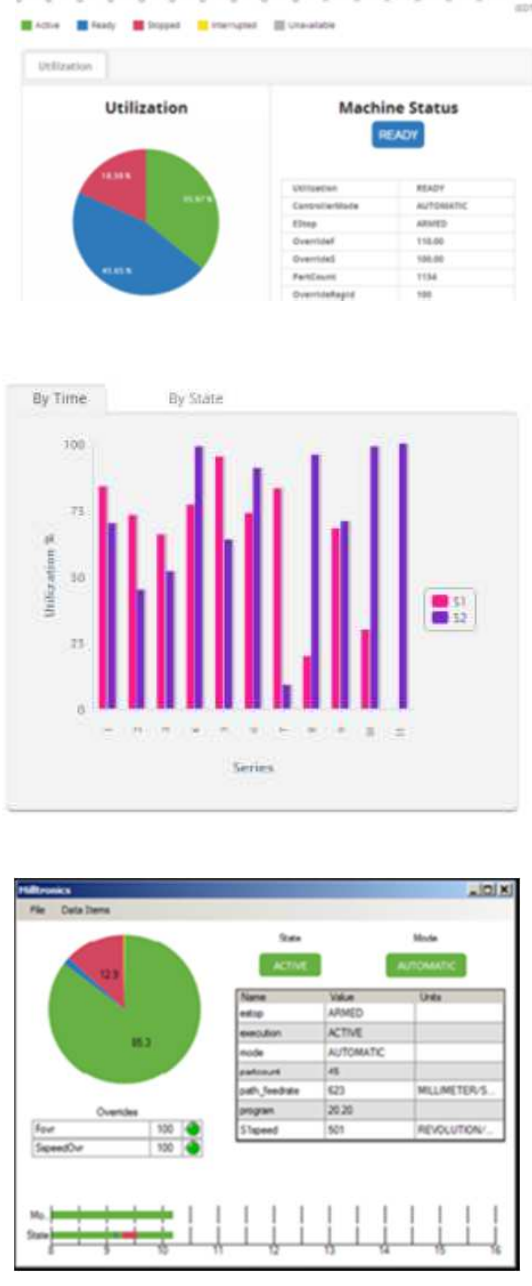

-Enterprise level monitoring

-Live dashboards, historical reporting, event notification

-Cloud or local deployment

\section{$\operatorname{MiniViz}^{\circledR}$}

-Introductory level monitoring

-Quick and simple - single .exe file

-Live dashboards and data logging

\section{VizAdapters $^{\circledR}$}

-MTConnect Adapters, data collection infrastructure, consulting services 


\section{$\equiv$ Moving Forward...}

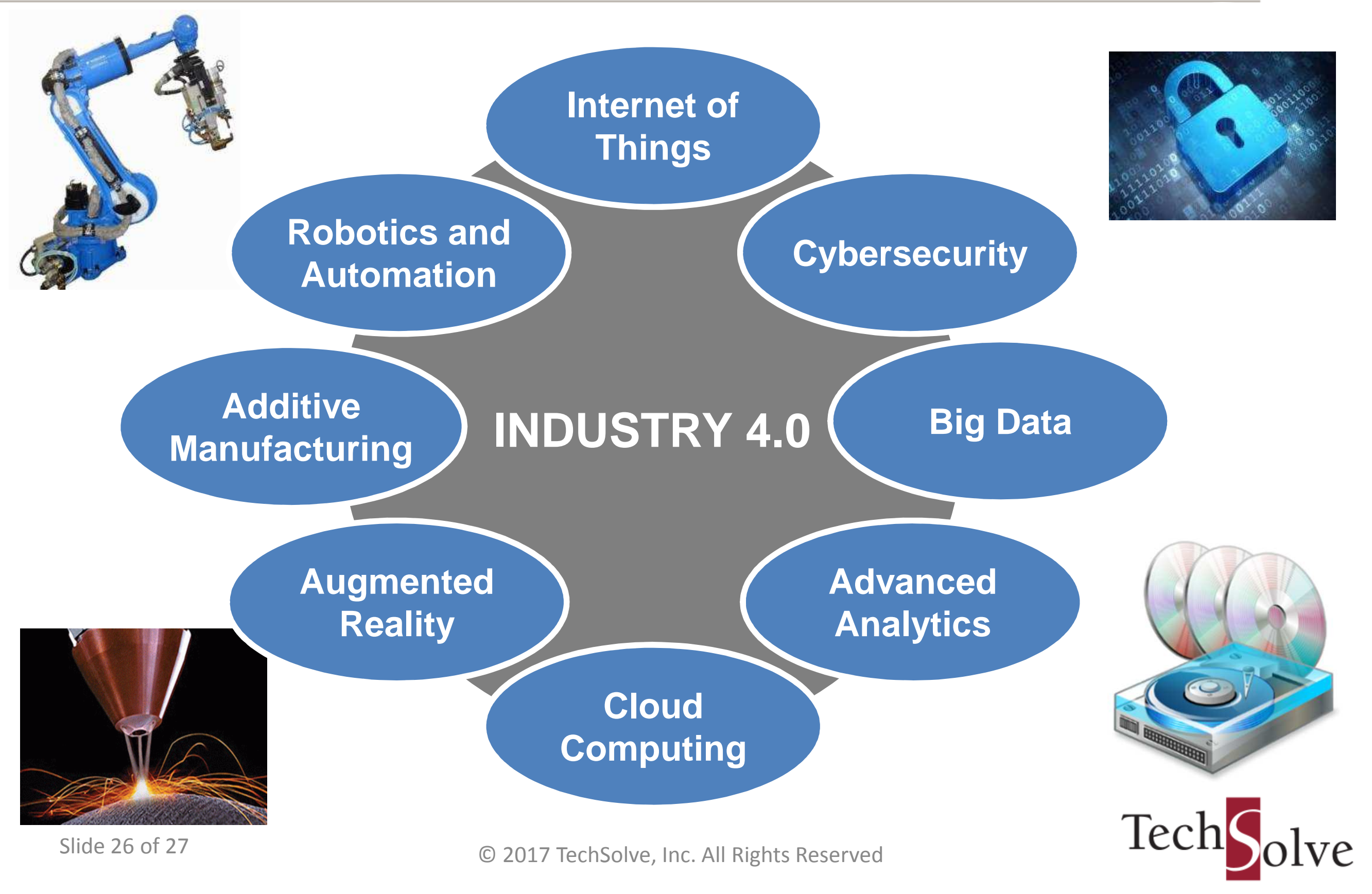


Radu Pavel, Ph.D.

VP of Engineering

Chief Technology Officer

TechSolve, Inc.

6705 Steger Drive,

Cincinnati, $\mathrm{OH} 45237$

Phone: (513) 9482062

pavel@techsolve.org

www.techsolve.org
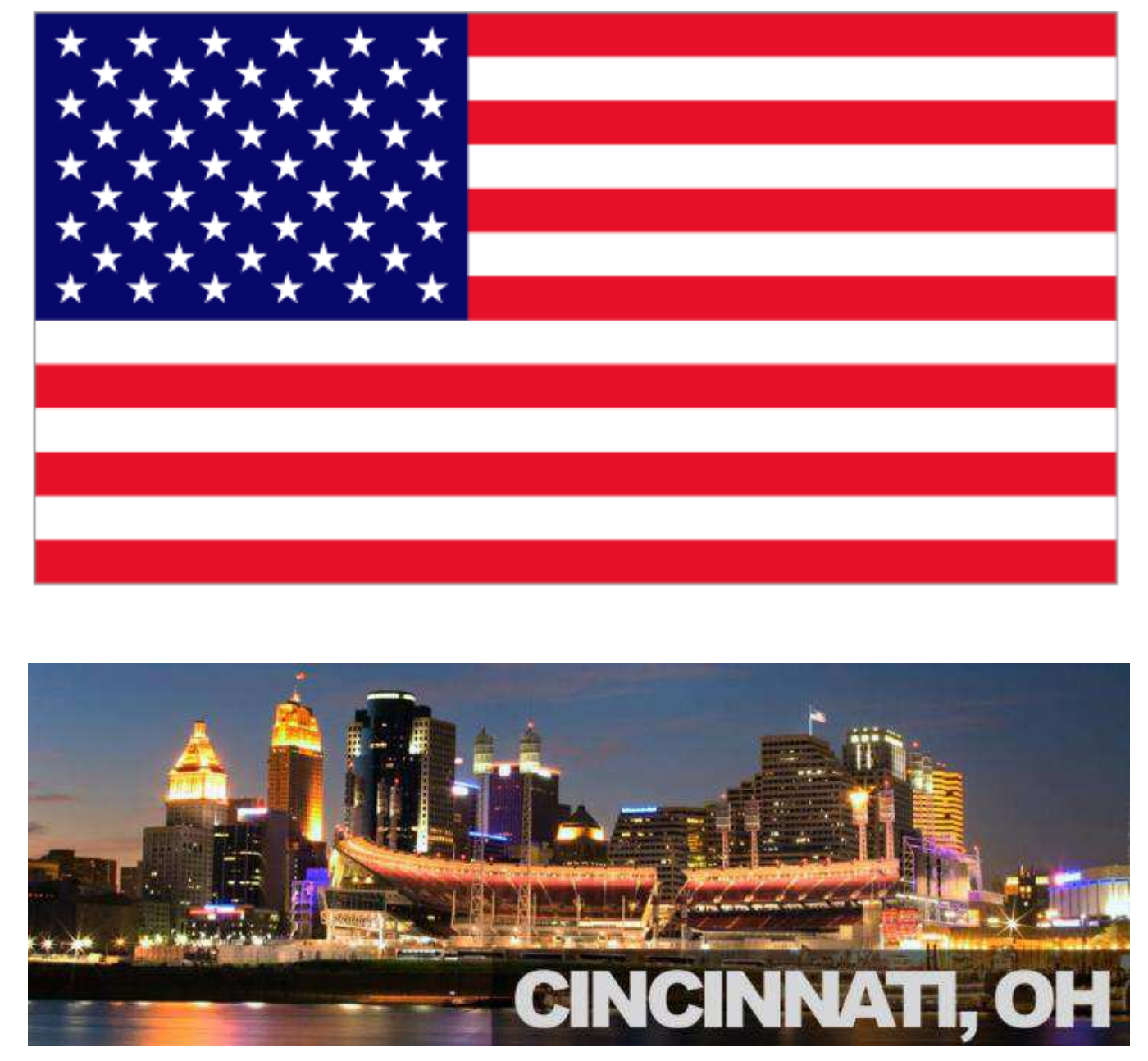

Tech $\boldsymbol{S}_{\text {olve }}$ 